
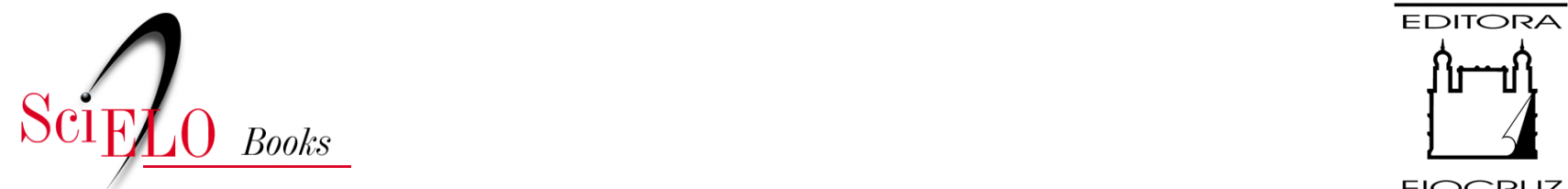

FIOCRUZ

\title{
Brasil Saúde Amanhã complexo econômico-industrial da saúde
}

\author{
Carlos Augusto Grabois Gadelha \\ Paulo Gadelha \\ José Carvalho de Noronha \\ Telma Ruth Pereira
}

(orgs.)

\section{SciELO Books / SciELO Livros / SciELO Libros}

GADELHA, C.A.G., GADELHA, P., NORONHA, J.C., and PEREIRA, T.R., eds. Brasil Saúde Amanhã: complexo econômico-industrial da saúde [online]. Rio de Janeiro: Editora FIOCRUZ, 2017, 227 p. ISBN: 978-65-5708-092-4. https://doi.org/10.7476/9786557080924.

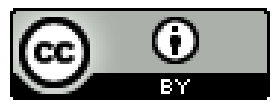

All the contents of this work, except where otherwise noted, is licensed under a Creative Commons Attribution 4.0 International license.

Todo o conteúdo deste trabalho, exceto quando houver ressalva, é publicado sob a licença Creative Commons Atribição 4.0.

Todo el contenido de esta obra, excepto donde se indique lo contrario, está bajo licencia de la licencia $\underline{\text { Creative }}$ Commons Reconocimento 4.0. 


\section{BRA S I L SA Ú DE A M A N H Ã complexo econômico-industrial da saúde}




\section{FUNDAÇÃO OSWALDO CRUZ}

Presidente

Nísia Trindade Lima

Vice-Presidente de Educação, Informação e Comunicação Manoel Barral Netto

\section{EDITORA FIOCRUZ}

\section{Diretor}

Manoel Barral Netto

Editor Executivo João Carlos Canossa Mendes

Editores Científicos

Carlos Machado de Freitas

Gilberto Hochman

Conselho Editorial

Denise Valle

José Roberto Lapa e Silva

Kenneth Rochel de Camargo Jr.

Ligia Maria Vieira da Silva

Marcos Cueto

Maria Cecília de Souza Minayo

Marilia Santini de Oliveira

Moisés Goldbaum

Rafael Linden

Ricardo Ventura Santos 
Carlos Augusto Grabois Gadelha Paulo Gadelha

José Carvalho de Noronha

Telma Ruth Pereira

organizadores

\section{B R A S I L \\ S A Ú DE \\ A M A N H Ã}

complexo econômico-industrial da saúde 
Copyright (C) 2017 dos autores

Todos os direitos desta edição reservados à

FUNDAÇÃO OSWALDO CRUZ / EDITORA

Revisão e copidesque

Irene Ernest Dias

Normalização de referências

Clarissa Bravo

Capa e projeto gráfico

Carlota Rios

Produção gráfico-editorial

Phelipe Gasiglia

Catalogação na fonte

Instituto de Comunicação e Informação Científica e Tecnológica em Saúde/Fiocruz

Biblioteca de Saúde Pública

B823b Brasil Saúde Amanhã: complexo econômico-industrial da saúde. / organizado por Carlos Augusto Grabois Gadelha, Paulo Gadelha, José Carvalho de Noronha, et al. - Rio de Janeiro: Editora FIOCRUZ, 2017.

227 p.: il.; tab.; graf.

ISBN: 978-85-7541-490-3

1. Inovação. 2. Serviços de Saúde. 3. Indústria Química.

4. Desenvolvimento Econômico. 5. Biotecnologia. 6. Segurança Industrial. 7. Política de Inovação e Desenvolvimento.

I. Gadelha, Carlos Augusto Grabois (Org.). II. Gadelha, Paulo

III. Noronha, José Carvalho de (Org.). (Org.). IV. Título.

CDD - 22.ed. -362.1

EDITORA FIOCRUZ

Av. Brasil, 4036, térreo, sala 112 - Manguinhos

21040-361 - Rio de Janeiro, RJ

Tels: (21) 3882-9039 / 3882-9041

Telefax: (21) 3882-9006

e-mail: editora@fiocruz.br

http://www.fiocruz.br

Editora filiada

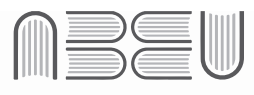

Associação Brasileira das Editoras Universitárias 


\section{AUTORES \& ORGANIZADORES}

\section{Carlos Augusto Grabois Gadelha (organizador)}

Economista, doutor em economia pelo Instituto de Economia da Universidade Federal do Rio de Janeiro; coordenador das ações de prospecção da Presidência e líder do Grupo de Pesquisa sobre Complexo Econômico-Industrial e Inovação em Saúde da Fundação Oswaldo Cruz.

\section{Eduardo Jorge Valadares Oliveira}

Engenheiro elétrico, doutor em engenharia biomédica pela Universidade Estadual de Campinas; professor do Departamento de Computação da Universidade Estadual da Paraíba.

\section{Gustavo Souto de Noronha}

Graduado em ciências econômicas, mestre em economia pelo Programa de Pós-Graduação em Economia da Universidade Federal Fluminense; economista do Instituto Nacional de Colonização e Reforma Agrária.

\section{José Carvalho de Noronha (organizador)}

Médico sanitarista, doutor em saúde coletiva pela Universidade do Estado do Rio de Janeiro; médico do Laboratório de Informações em Saúde do Instituto de Comunicação e Informação Científica e Tecnológica da Fundação Oswaldo Cruz (Fiocruz), coordenador executivo da iniciativa Brasil Saúde Amanhã, da Fiocruz.

\section{José Maldonado}

Economista, doutor em engenharia da produção pelo Instituto Alberto Luiz Coimbra de Pós-Graduação e Pesquisa de Engenharia, da Universidade Federal do Rio de Janeiro; coordenador adjunto do Mestrado Profissional em Política e Gestão da Ciência, Tecnologia e Inovação em Saúde da Escola Nacional de Saúde Pública Sergio Arouca, da Fundação Oswaldo Cruz.

\section{Laís Silveira Costa}

Administradora especializada em gestão de organizações de ciência e tecnologia em saúde e doutora em saúde pública pela Escola Nacional de Saúde Pública Sergio Arouca, da Fundação Oswaldo Cruz (Ensp/Fiocruz); pesquisadora do Grupo de Pesquisa de Inovação em Saúde/Fiocruz, integra os programas de pós-graduação em Saúde Pública da Ensp/Fiocruz e em Saúde Coletiva da Universidade Federal do Rio de Janeiro.

\section{Leonardo Batista Paiva}

Químico, pós-graduado em tecnologia em imunobiológicos pela Fundação Oswaldo Cruz; pesquisador tecnologista em tecnologia e inovação do Instituto Nacional de Metrologia, Qualidade e Tecnologia.

\section{Leonardo Costa Ribeiro}

Físico, pós-doutorado em economia pela Universidade Federal de Minas Gerais; pesquisador tecnologista em tecnologia e inovação do Instituto Nacional de Metrologia, Qualidade e Tecnologia. 


\section{Ligia Bahia}

Médica, doutora em saúde pública pela Escola Nacional de Saúde Pública Sergio Arouca, da Fundação Oswaldo Cruz; professora associada da Universidade Federal do Rio de Janeiro.

\section{Marco Antonio Vargas}

Economista, doutor em economia industrial e da tecnologia pela Universidade Federal do Rio de Janeiro; professor associado e chefe do Departamento de Economia da Universidade Federal Fluminense e pesquisador do Grupo de Pesquisa em Inovação em Saúde da Fundação Oswaldo Cruz.

\section{Paulo Gadelha (organizador)}

Médico, doutor em saúde pública pela Escola Nacional de Saúde Pública Sergio Arouca, da Fundação Oswaldo Cruz (Fiocruz); pesquisador titular da Fiocruz, onde é coordenador da iniciativa Brasil Saúde Amanhã.

\section{Raphael Padula}

Economista pela Universidade Federal do Rio de Janeiro (UFRJ), doutor em engenharia de produção pelo Instituto Alberto Luiz Coimbra de Pós-Graduação e Pesquisa de Engenharia/UFRJ; professor adjunto da UFRJ, onde é coordenador do Programa de Pós-Graduação em Economia Política Internacional do Instituto de Economia.

\section{Telma Ruth Pereira (organizadora)}

Médica; colaboradora da iniciativa Brasil Saúde Amanhã, da Fundação Oswaldo Cruz.

\section{Thiago Leone Mitidieri}

Economista, pós-graduado em finanças pelo Instituto Coppead de Administração da Universidade Federal do Rio de Janeiro; economista do Banco Nacional de Desenvolvimento Econômico e Social. 
1. Geração e Trajetórias de Inovação nos Serviços de Saúde

Laís Silveira Costa

Ligia Bahia

2. Indústria de Base Química no Brasil:

potencialidades, desafios e nichos estratégicos

Marco Antonio Vargas

3. Base Biotecnológica no Brasil: desafios e nichos estratégicos

Leonardo Batista Paiva

Leonardo Costa Ribeiro

4. Base Mecânica, Eletrônica e de Materiais

José Maldonado

Eduardo Jorge Valadares Oliveira

5. Complexo Econômico-Industrial da Saúde, Segurança e Autonomia Estratégica: a inserção do Brasil no mundo

Raphael Padula

Gustavo Souto de Noronha

Thiago Leone Mitidieri 



\section{PREFÁCIO}

Produto de um prolongado esforço de reflexão intelectual e de prática criativa no desenho e execução de políticas públicas para a saúde no Brasil, o presente livro sintetiza resultados da iniciativa Brasil Saúde Amanhã, conduzida pela Fundação Oswaldo Cruz.

A premissa de que as políticas públicas para a saúde devem articular o avanço do conhecimento tecnológico com o desenvolvimento produtivo nacional e com a promoção das condições de saúde da nossa população conduz as reflexões aqui empreendidas. A estreita articulação desses objetivos é indispensável não apenas para explorar os potenciais efeitos de realimentação virtuosa entre as três dimensões, mas principalmente para garantir a efetividade das próprias políticas, evitando que fragilidades em qualquer uma delas tornem inviável alcançar os propósitos almejados nas outras duas.

De acordo com os organizadores e colaboradores deste volume, as políticas devem ser idealizadas com uma visão sistêmica que contemple o fortalecimento do complexo econômico-industrial da saúde (CEIS) como um todo. A necessidade de uma abordagem sistêmica tornou-se evidente no início dos anos 2000, a partir da constatação de que as reformas de inspiração neoliberal da década de 1990 tinham, na prática, resultado em uma profunda desarticulação das competências tecnológicas e produtivas e na perda de oportunidades para avançar na estruturação de um sistema público de saúde acorde com requisitos estabelecidos na Constituição brasileira.

Nos estudos aqui apresentados ressalta-se que o mercado mundial de bens e serviços de saúde evolui em uma direção que torna os objetivos perseguidos pelo Brasil extremamente desafiadores. A concentração crescente dos mercados, o predomínio das finanças nos negócios da saúde, os obstáculos legais para o acesso ao conhecimento e os acordos internacionais que reduzem cada vez mais os graus de liberdade dos Estados nacionais configuram tendências de mercantilizarão e desigualdade em aumento.

A universalidade e a gratuidade da saúde que o Brasil almeja colocam grandes desafios para os formuladores de políticas públicas. É indispensável contar com recursos fiscais expressivos, com produção competitiva de medicamentos e de insumos para não comprometer a balança comercial, com competência tecnológica compatível com a autonomia nacional e com mecanismos institucionais ágeis e eficientes para coordenar os múltiplos atores. É necessário, portanto, construir uma trajetória 
de desenvolvimento tecnológico, produtivo e institucional capaz de vencer os obstáculos externos e de superar as limitações atuais do país. Os capítulos que compõem o presente volume se debruçam sobre as oportunidades e as dificuldades para avançar nesse caminho.

É preciso advertir aos leitores que a relevância das constatações e reflexões apresentadas na obra extrapola o âmbito das políticas públicas na saúde. Na atual fase globalizada da evolução do capitalismo, os desafios aqui analisados estão também presentes, em maior ou menor grau, em todos os âmbitos de atuação das políticas públicas. A atual relação de forças entre as corporações globais, os Estados nacionais e a sociedade civil dificulta a execução de políticas públicas em todos os países. Na periferia, com Estados nacionais submetidos a severas restrições por acordos internacionais assimétricos, além das pressões de instituições multilaterais, de agências de avaliação de crédito e de entidades privadas produtoras de rankings internacionais de competitividade e de ambiente de negócios, as dificuldades são ainda maiores.

No capitalismo contemporâneo, com as assimetrias entre o centro e a periferia e desigualdade social em aumento, os desafios a vencer para promover o desenvolvimento econômico e social são enormes. É necessário construir alianças internas e externas sólidas que sustentem as estratégias de desenvolvimento. As tensões a enfrentar na formulação de políticas públicas efetivas são imensas. É preciso identificar oportunidades e construir alternativas que compatibilizem interesse público e privado, competitividade com qualidade de vida da população, rentabilidade com redução da desigualdade, produção de bens e serviços em escala com sustentabilidade ambiental e integração na economia global com autonomia e segurança nacional.

A tarefa pode parecer inexequível, mas nos últimos anos o Brasil tem levado adiante com razoável sucesso um valioso processo de aprendizado na formulação de novas políticas de desenvolvimento. No âmbito da política industrial, a partir de 2004 o país foi se afastando progressivamente do falso dilema de ter que optar entre o laissez-faire e a reedição das políticas de substituição de importações do pós-guerra. A Política Industrial, Tecnológica e de Comércio Exterior (PITCE) executada de 2004 a 2008, a Política de Desenvolvimento Produtivo (PDP) do período 2008-2010 e o Plano Brasil Maior (PBM) de 2011 a 2014 representam uma sequência importante de iniciativas nessa direção.

Foi realizado um processo intenso de aprendizado envolvendo atores públicos e privados, dirigentes e técnicos do governo, representantes de entidades empresariais e de trabalhadores, especialistas e representantes da sociedade civil, para identificar oportunidades e desenhar ações para promover o desenvolvimento tecnológico e produtivo nacional. Abandonou-se a rígida dicotomia entre políticas horizontais e verticais. As iniciativas tiveram foco cada vez maior na promoção da inovação e paralelamente os alvos tornaram-se cada vez mais seletivos, evoluindo de grandes setores na PITCE para aspectos diferentes da competitividade na PDP e no PBM. Foram desenhados programas para enfrentar desafios específicos, na saúde, nos biocombustíveis, na microeletrônica e nos equipamentos da defesa, entre outros. Foram idealizados novos arranjos institucionais cooperativos, como a Empresa Brasileira de Pesquisa e Inovação Industrial (Emprapii) e o programa Inova Empresa, visando a agilizar a coordenação entre as agências estatais e o setor privado. 
É cedo ainda para avaliar plenamente os resultados de todas as iniciativas. É evidente, entretanto, que a política industrial executada a partir de 2004 deixa um legado importante para os atores públicos e privados que ensaiaram novas formas de atuação conjunta para promover o desenvolvimento da capacidade inovadora e produtiva na indústria brasileira. As iniciativas não tiveram nem a escala nem o tempo suficientes para produzir mudanças estruturais na indústria, mas mostraram que é possível induzir novas formas de comportamento das empresas e das instituições governamentais e articular a política industrial com outras políticas. Mostraram, assim, que é possível alinhar a estratégia de desenvolvimento industrial com a redução de desigualdades e com o aumento da autonomia nacional.

Este livro é leitura obrigatória para aqueles que procuram um caminho para a continuidade do desenvolvimento industrial do Brasil num mundo globalizado. Os leitores encontrarão nas suas páginas prova da rica experiência acumulada nos últimos anos no campo das políticas para o CEIS. As análises aqui apresentadas mostram que existem oportunidades que não devem ser desperdiçadas. O mesmo ocorre em outros segmentos do tecido industrial brasileiro. É importante que as dificuldades econômicas internas e externas do momento não sejam pretexto para o abandono dos esforços para aproveitar as oportunidades que se abrem para a indústria e para a sociedade brasileira.

Mariano Francisco Laplane

Presidente do Centro de Gestão e Estudos Estratégicos (CGEE) 



\section{APRESENTAÇÃO}

\section{A saúde como vetor de um padrão social-desenvolvimentista: o enfoque do complexo econômico-industrial da saúde}

A apresentação e sistematização acadêmica, desde o início dos anos 2000, do conceito de complexo econômico-industrial da saúde (CEIS) ${ }^{1}$ coincide com o início da retomada de uma agenda e de um debate político sobre uma perspectiva desenvolvimentista no século XXI, após a crise dos anos 1980 e o predomínio do ideário neoliberal na década de 1990. As ideias-chave que permearam o conceito e, posteriormente, um conjunto de ações políticas concretas iniciadas em 2003-2004 e intensificadas a partir de 2008, no âmbito do Ministério da Saúde e de uma rede integrada de instâncias de governo, podem ser sistematizadas nos seguintes tópicos:

1) A construção de um sistema de saúde que permita concretizar os preceitos constitucionais de universalidade, integralidade e equidade (Brasil, 1988) precisa estar associada à consolidação de uma base produtiva e de inovação em saúde para que o sistema nacional de saúde se sustente estruturalmente. Em um país continental como o Brasil, com mais de 200 milhões de pessoas, a existência de um sistema produtivo em saúde, envolvendo a indústria e os serviços de saúde de modo articulado, apresenta-se como uma condição sem a qual o acesso à saúde não pode ser garantido estruturalmente.

2) É crucial entender como as forças capitalistas se reproduzem dentro da saúde, para, dialeticamente, direcionar o processo de acumulação de capital e de inovação - sendo o papel do Estado decisivo - para a superação da dependência tecnológica e para o enfrentamento da questão global da constituição de um padrão tecnológico dissociado, e mesmo incompatível com estes princípios, da universalidade, da integralidade e da equidade (Viana \& Elias, 2007; Viana, Nunes \& Silva, 2011).

\footnotetext{
${ }^{1}$ Gadelha (2002, 2003) e colaboradores (Gadelha \& Costa, 2012; Gadelha et al., 2012) são algumas das principais referências conceituais e integram, no presente, uma linha de pesquisa enriquecida por contribuições de muitos autores. No estudo de 2002 o autor adotava simplesmente a denominação complexo da saúde; posteriormente, empregou-se o termo complexo industrial da saúde, como marca principal nas políticas públicas, e recentemente a designação evoluiu para complexo econômico-industrial da saúde; tal modificação não significa qualquer distinção analítica, e sim um esforço para ressaltar um sistema produtivo que segue a lógica industrial do capital no interior da saúde, envolvendo tanto a indústria quanto os serviços, cuja dinâmica é interdependente.
} 
A dependência tecnológica, evidenciada pela quadruplicação do déficit comercial de 2003 a 2013 em termos reais, que atingiu o patamar de US\$ 12 bilhões, ${ }^{2}$ coincide, não casualmente, com o momento em que se expandem o acesso e a percepção, pela sociedade, da saúde como um direito, pressionando o Sistema Único de Saúde (SUS) a ofertar os bens e serviços requeridos para a promoção da saúde, a prevenção e a atenção em saúde.

Ao mesmo tempo, constitui-se um padrão tecnológico que conforma um modelo de organização do sistema e um padrão de consumo nos quais a direção da pesquisa, das inovações e da incorporação tecnológica reproduz, em escala global, um sistema que, ao invés de gerar tecnologias que favoreçam a equidade, enseja um padrão que ameaça cindir os sistemas entre "os que podem e os que não podem pagar" por um acesso integral à saúde. Essa questão global - que gera um forte debate com diversos segmentos da sociedade civil, inclusive nos países desenvolvidos, nos novos blocos de poder como o Brics (Brasil, Rússia, Índia, China e África do Sul) e em instância internacionais, como a Organização Mundial da Saúde - é ainda mais agravada pelas condições de dependência, nas quais se materializa a dinâmica analisada com o enfoque furtadiano, segundo o qual um padrão tecnológico e um sistema produtivo geram modernização e marginalização ao mesmo tempo (basta ver o custo e a dificuldade para o tratamento de câncer ou doenças raras com produtos biotecnológicos de acesso bloqueado aos indivíduos nos sistemas privados de proteção mediante as despesas simplesmente impagáveis dos tratamentos oferecidos).

3) O fato de a saúde constituir um dos principais blocos de inovação e de desenvolvimento no século XXI, como ressaltado nos mencionados trabalhos sobre o CEIS, torna essas questões ainda mais cruciais e relevantes. A saúde será, inquestionavelmente, um dos grandes blocos de investimento, inovação e expansão do capital no século XXI que, junto com outros poucos e seletivos blocos como energia, defesa, alimentos e cadeias produtivas de recursos naturais e tecnologia da informação, determinarão os padrões de desenvolvimento, os graus de liberdade para o exercício das políticas nacionais e a nova divisão internacional do trabalho.

4) As estratégias nos setores ditos portadores de futuro - leia-se portadores de poder em uma nova geopolítica internacional - têm claramente grande expressão na área da saúde como um sistema produtivo gerador de inovações que são cruciais para toda a estrutura produtiva. A moderna biotecnologia e as ciências da vida (genética aplicada em uma escala impensável e terapia celular, por exemplo), a química avançada, a nanotecnologia, os novos materiais, a microeletrônica e a tecnologia da informação são não apenas utilizadas, mas alavancadas endogenamente pela dinâmica produtiva e de inovação no âmbito do CEIS.

5) O CEIS constitui, assim, um sistema (que por definição é interdependente), caracterizando uma rede imbricada de conhecimentos para a qual convergem as indústrias farmacêutica, de equipamentos e materiais e de diagnóstico e os serviços de saúde. Nele, a utilização coletiva e pelos indivíduos (a exemplo da pesquisa clínica) ocorre como elemento decisivo para a transformação do conhecimento em produtos apropriados, seja pela economia, em um processo de mercantilização, seja pelo seu uso social no âmbito dos sistemas nacionais de saúde. O CEIS, como sistema produtivo e de inovação em saúde, passa por um típico processo de convergência tecnológica, semelhante ao verificado nas tecnologias de informação no século

\footnotetext{
2 Dados do Grupo de Pesquisa em Inovação em Saúde da Fundação Oswaldo Cruz, baseados em estatísticas de comércio exterior do Ministério do Desenvolvimento, Indústria e Comércio Exterior (GIS/Fiocruz, 2014).
} 
passado (convergência dos segmentos de computadores, rádio e telecomunicações, telefonia e comunicações em suas diferentes formas contemporâneas, como a internet, softwares etc.), que lhe confere uma característica sistêmica e constitui um bloco dinâmico interligado de investimento e de inovação decisivo para o padrão de desenvolvimento global, regional e nacional.

6) Os grandes desafios para a saúde pública do futuro - envelhecimento, peso das doenças crônicas que exigem tratamento permanente, medicina personalizada, redes de atenção, envolvendo o nível local e domiciliar articulado com níveis produtivo-tecnológicos sub-regionais, regionais e nacionais, entre outros -, aliados à dimensão política de garantia de direitos, representam uma demanda econômica e de inovações forte e em crescimento acelerado, previsível e a longo prazo, para a qual os capitais privados estão em pleno processo estratégico de expansão. Tal movimento requer, por sua vez, o fortalecimento também da dimensão estratégica do Estado quando se trata de promover, induzir e regular esse sistema produtivo, articulando a dinâmica econômica com a social, sem o que a lógica dialética do capital levará a uma nova divisão seja no interior da sociedade, seja entre os países no jogo do poder global.

É sob esta ótica que, desde a formulação do conceito original do CEIS, se enfatizou a necessidade de superar a vulnerabilidade sanitária do SUS, expressa no crescimento explosivo do déficit comercial e também em outras dimensões, como o hiato entre o potencial de pesquisa e inovação dos países desenvolvidos e aquele dos países de baixa e média renda. A questão da vulnerabilidade e da dependência estrutural para assegurar os direitos à saúde, associada ao contexto econômico e tecnológico, talvez tenha sido o grande elemento da apropriação da perspectiva do CEIS pelo campo da saúde pública ou coletiva e, em um movimento quase simultâneo, pela política nacional de saúde.

A dimensão social da saúde, como elemento-chave de um padrão de desenvolvimento associado à conformação de um Estado de bem-estar, tardio e periférico, requeria conceber e articular elementos cruciais de uma economia política, envolvendo: capacitação econômica, produtiva e tecnológica em saúde; soberania para constituir sistemas universais; capacidade e graus de liberdade para estabelecer políticas nacionais; construção de capacidade estratégica no Estado para o enfrentamento de desafios intersetoriais de grande envergadura.

7) Com esta visão, a concepção do CEIS remete necessariamente a um enfoque sistêmico da saúde, o que implica também um esforço analítico para que a dinâmica interdependente dos distintos subsistemas produtivos seja captada. O esforço exige, ao mesmo tempo, que se olhe para o sistema com um enfoque totalizante - sob o risco de os setores olhados isoladamente serem "varridos", assim como suas análises, pelas forças do processo de destruição criativa (Schumpeter, 1985) - e que se estudem os subsistemas de modo a não desconsiderar suas especificidades, dinâmicas, lógicas, oportunidades e desafios próprios. E sempre com um olhar para a dimensão sistêmica, que neste livro remete à consideração da saúde e do sistema brasileiro em um horizonte estratégico a longo prazo.

Nos capítulos deste livro, seus autores avançam justamente nessa concepção que articula a visão sistêmica e de economia política com a dinâmica dos subsistemas produtivos e de inovação e dos setores de atividade envolvidos.

No primeiro capítulo, "Geração e trajetórias de inovação nos serviços de saúde", Laís Silveira Costa e Ligia Bahia refletem sobre as transformações em curso no sistema brasileiro de saúde, em 
um permanente tensionamento entre a desmercantilização do acesso à saúde e a dinâmica de mercado na oferta de produtos e serviços em saúde. As autoras se detêm também nos novos dilemas trazidos pelas mudanças demográficas, ocupacionais e no perfil epidemiológico, problematizando e articulando os desafios tanto para a conformação de um sistema universal quanto para a inovação. Com isso, avançam no estudo das inovações nos serviços de saúde com suas trajetórias de difusão, destacando particularmente os hospitais como parte central da dinâmica do subsistema de serviços de saúde. Encerram seu texto apresentando uma agenda importante de recomendações de linhas de pesquisa e de ação política voltadas para o estabelecimento de articulações virtuosas que reforcem os compromissos com um sistema de saúde universal e inovador.

No segundo capítulo, "Indústria de base química no Brasil: potencialidades, desafios e nichos estratégicos", Marco Antonio Vargas procura analisar o impacto das novas plataformas tecnológicas, em particular daquelas ligadas à nanotecnologia e à biotecnologia, sobre a dinâmica produtiva e de inovação dos principais segmentos da indústria farmacêutica no Brasil. Incorpora a análise das macrotendências tecnológicas, socioeconômicas e políticas no processo de capacitação produtiva e tecnológica na produção de fármacos e medicamentos no país.

Como nos demais capítulos, o enfoque sistêmico predomina: o autor sempre busca estabelecer pontes com as especificidades do sistema de inovação em saúde no Brasil e com a lógica sanitária requerida para pensar a dinâmica global e local da indústria farmacêutica no contexto do acesso universal. Para tanto, aborda a dinâmica recente de desenvolvimento da indústria farmacêutica global e suas principais tendências, a interface com as políticas de atenção à saúde e demais fatores de cunho social, demográfico, econômico, tecnológico e político. Por fim, analisa os obstáculos e potencialidades do setor farmacêutico no país e o impacto das novas plataformas e de nichos tecnológicos, com destaque para a biotecnologia, a nanotecnologia, as vacinas e os antibióticos como áreas-chave deste subsistema. Em sintonia com o fio condutor de todo este livro, Vargas articula, de modo arrojado, as dimensões específicas, tecnológicas e setoriais com questões abrangentes de economia política que remetem para a questão da soberania em saúde, aprofundada no último capítulo.

No terceiro capítulo, "Base biotecnológica no Brasil: desafios e nichos estratégicos", Leonardo Batista Paiva e Leonardo Costa Ribeiro desenvolvem uma análise prospectiva para a biotecnologia em saúde, elaborando um panorama geral do sistema nacional de inovação em biotecnologia no qual tomam como contexto o cenário internacional. Além da dinâmica de inovação e produtiva geral, enfatizam as principais políticas públicas desenvolvidas no período recente no Brasil. Com base nas patentes depositadas no Instituto Nacional de Propriedade Industrial (INPI) e no United States Patent and Trademark Office (USPTO) e nos artigos científicos indexados no ISI Web of Knowledge, efetuam uma rica análise para marcar as interações entre os âmbitos da ciência e da inovação, procurando caracterizar redes globais, mas sem perder o foco nos desafios para os sistemas nacionais. Identificam os estágios atuais de desenvolvimento de algumas das principais tecnologias abarcadas pela biotecnologia em saúde e suas possibilidades de evolução. Por fim, apresentam recomendações, articulando, como todos os autores, a lógica econômica com a da saúde. Suas recomendações abrangem desafios demográficos associados às doenças crônicas e ao envelhecimento, a dependência e 
vulnerabilidade tecnológica dos "residentes no Brasil" em um campo estratégico revelado por uma base empírica sólida que indica a reduzida inserção do setor empresarial nacional nas inovações mais radicais e a vulnerabilidade do país em relação aos países desenvolvidos que continuam a exercer sua liderança na fronteira tecnológica.

Adicionalmente, o estudo de Paiva e Ribeiro permite delimitar algumas das áreas científicas prioritárias para o processo de inovação em biotecnologia e a organização de redes globais científicas, mas que reforçam - ao invés de mitigar - as assimetrias de conhecimento científico e tecnológico que constituem um risco de aumento do hiato na divisão internacional do trabalho em biotecnologia. De modo implícito, seu texto revela, como aliás todo este livro, que o desenvolvimento em biotecnologia é assimétrico e concentrado, colocando riscos para um sistema de saúde universal em que as doenças crônicas ganham um peso decisivo, e que a inserção nas redes globais requer, mais do que nunca, o fortalecimento nacional das capacidades científicas, tecnológicas e produtivas, sem o que a articulação global se torna mais um mito do que uma possibilidade concreta. Isso demanda ações sistêmicas que vão muito além do fornecimento de infraestruturas científicas e tecnológicas, devendo abarcar a seleção de áreas, uma política estratégica de recursos humanos, o financiamento e o mercado para um efetivo envolvimento do setor empresarial na inovação.

No quarto capítulo, "Base mecânica, eletrônica e de materiais", José Maldonado e Eduardo Jorge Valadares Oliveira "fecham o ciclo" dos distintos subsistemas que fazem parte do CEIS. Enfatizam a grande variedade e diversidade de segmentos produtivos abarcados nesse subsistema, congregando um conjunto bastante díspar de atividades.

O caráter sistêmico do CEIS é particularmente revelado na área de equipamentos e materiais, quando esta se associa a mudanças intensas nas práticas assistenciais e, portanto, nos serviços de saúde. Maldonado e Oliveira evidenciam a relação serviço-indústria, reforçando o entendimento de que as lógicas setoriais não podem ser tratadas independentemente. Indo além, mostram também que o sistema produtivo da saúde transborda para fora de suas fronteiras, tendo potencial de promover o adensamento do sistema nacional de inovação como um todo, por exemplo, ao incorporar fortemente o paradigma microeletrônico.

De um lado, os autores demonstram que a grande variedade e diversidade desse subsistema apresenta a possibilidade de desenvolvimento de diversos nichos competitivos para empresas de diversas especialidades e porte, o que favorece ações regionais, locais e de novos atores de pequeno e médio porte. De outro lado, apesar de apresentar dinamismo no período recente, observa-se nessa indústria, como em todos os segmentos do CEIS, um crescente déficit na balança comercial de equipamentos e materiais, o que reflete as fragilidades estruturais vigentes.

Tendo em vista construir uma agenda prospectiva de oportunidades estratégicas, Maldonado e Oliveira privilegiaram a análise dos equipamentos médico-hospitalares, implantes e odontologia, considerando sua importância para o SUS e a competitividade nacional. O dilema entre pressão sobre os gastos em saúde e o avanço tecnológico é ressaltado pelos autores, que veem como incontornável a busca por tecnologias que passem pelo crivo da avaliação tecnológica na decisão sobre sua incorporação. Nos sistemas universais, nos quais o Estado tem um papel decisivo, as sinalizações advindas 
da política de saúde orientam o ritmo e as trajetórias tecnológicas que o setor produtivo deve perseguir. Os autores revelam que há um claro trade-off entre a difusão acelerada de novas tecnologias e a necessidade de racionalizar seu uso abusivo e irracional.

Todavia, é justamente uma visão que articula a lógica econômica com a social que pode atuar no estabelecimento de "jogos virtuosos" nos quais o horizonte de mercado e os incentivos se articulem com a incorporação de inovações em bases econômicas. Tal articulação viabilizaria a universalidade do acesso, uma vez que contemplaria as novas demandas do sistema de saúde que requerem aumento da qualidade dos padrões de tratamento e de diagnóstico para que estes que sejam mais efetivos, rápidos, seguros e menos invasivos.

Permeia todo o capítulo a aposta de que o apoio ao fortalecimento e dinamização do subsistema de base mecânica, eletrônica e de materiais representa uma possibilidade ímpar de articular a política de saúde com a política industrial e tecnológica, em um modelo de desenvolvimento que privilegie o social ao mesmo tempo que incorpore os requerimentos da competitividade e da inovação tanto para o setor produtivo quanto, e principalmente, para os cidadãos.

No quinto e último capítulo, "Complexo econômico-industrial da saúde, segurança e autonomia estratégica: a inserção do Brasil no mundo", Raphael Padula, Gustavo Souto de Noronha e Thiago Leone Mitidieri dirigem um olhar transversal para a geopolítica da saúde, em seus aspectos sistêmicos, com destaque para uma questão que permeia toda esta matriz conceitual e foi crucial no processo de sua absorção cognitiva e política no âmbito da saúde: o impacto da dinâmica econômica, social e política do CEIS na vulnerabilidade em saúde.

Os autores partem da instigante ideia sobre o aparecimento, no futuro, do Homo ricus, como uma evolução do Homo sapiens, apresentada em um texto do cineasta Carlos Diegues. Com o uso da genética para o restrito grupo de pessoas que a ela teriam acesso, a divisão social e de classes se aprofundaria até uma divisão entre espécies. O aspecto substantivo do estudo de Padula, Noronha e Mitidieri, para além da analogia e do desdobramento da imagem ficcional para a realidade, são os riscos de que os paradigmas científicos e tecnológicos dominantes no CEIS possam se acentuar e cindir estruturalmente os sistemas nacionais de saúde entre os que podem pagar e a maior parte da população, que não pode pagar, e ficaria sem acesso universal e integral. Ou seja, o desdobramento da visão estrutural que permeia o conceito do CEIS imporia limites também estruturais aos sistemas universais.

Padula, Noronha e Mitidieri desenvolvem uma reflexão sobre o conceito de complexo econômicoindustrial da saúde (CEIS) baseada em trabalhos mais recentes sobre este sistema produtivo e de inovação, ${ }^{3}$ ampliando seu foco para a economia política internacional. Analisam particularmente as questões de autonomia estratégica e de segurança de saúde, debatendo problemas contemporâneos de alta relevância na relação entre saúde e geopolítica internacional. Avaliam tendências para os próximos 15 anos, analisando temas relevantes como acesso a mercados, compras governamentais,

\footnotetext{
${ }^{3} \mathrm{O}$ conceito foi originalmente desenvolvido em um estudo que fazia parte de um projeto geral sobre a inserção internacional do Brasil a partir das cadeias produtivas e o impacto das zonas livres de comércio, de onde veio o foco nas relações comerciais do complexo da saúde e dos subsistemas que dele fazem parte. Nos textos iniciais dessa linha de pesquisa (Gadelha, 2002), evidenciava-se a vulnerabilidade em saúde como aspecto crítico.
} 
investimentos e propriedade intelectual, e procuram problematizar as questões futuras com base nas tensões - sempre estabelecendo analogias entre o sistema de saúde e o de defesa, visto que, nos aspectos de interesse para sua análise, estes apresentam forte similaridade - entre inovação, acesso, autonomia estratégica e segurança sanitária.

Os autores concluem com proposições importantes, como a de que se explorem laços e pontos de conexão com os Brics, a América do Sul e a África, com vistas a articular o novo contexto geopolítico com políticas nacionais que requerem graus de liberdade para que o Homo ricus não surja e se desenvolva, contrapondo-se aos direitos sociais universais e à equidade, conquistados a duras penas ao longo do pós-guerra. E a de que se constitua uma ampla agenda para a atuação do Estado que envolva a política macroeconômica, o papel das compras governamentais e as parcerias com o setor privado, incluindo empresas nacionais e estrangeiras. Por fim, em sintonia com os demais autores que estudaram os subsistemas de base química e biotecnológica e de equipamentos e materiais, propõem que sejam tomados como nichos estratégicos a biotecnologia e a nanotecnologia, as vacinas, os antibióticos e as tecnologias da informação e comunicação.

Com essa seleção de aspectos dos cinco capítulos deste livro, pretendemos estimular sua leitura e apresentá-los como partes de uma visão integrada, sistêmica e de economia política, associada a uma análise das oportunidades e desafios associados à dinâmica produtiva e de inovação no âmbito do CEIS.

Constitui um enorme e arriscado esforço analítico trazer para o campo social a lógica do capital, não como subordinação a este, mas pela necessidade de reconhecer seu movimento dialético, que desenvolve as forças produtivas mas gera relações sociais excludentes e desvinculadas das necessidades sociais. Com isso, torna-se necessário reforçar a necessidade da intervenção do Estado e de uma base social de sustentação para que seja possível orientar e regular o movimento do capital e com ele interagir, buscando circuitos virtuosos e sustentação política.

Talvez a maior contribuição analítica da abordagem do CEIS tenha sido justamente o fato de contemplar a dinâmica de reprodução e expansão do capital no interior da saúde e dos sistemas nacionais de saúde, endogeneizando a dimensão social no padrão de desenvolvimento como algo intrínseco às decisões estratégicas, públicas e privadas, de investimento que conformam a evolução da estrutura produtiva no contexto capitalista. ${ }^{4}$ Ressaltamos, assim, a necessidade de que as políticas de fortalecimento do complexo da saúde dialoguem com as propostas atualmente em debate para o desenvolvimento nacional, posto que um esforço substantivo de prospecção supera o foco das previsões técnicas de tendências. O futuro não é dado, mas sim construído pelas forças da sociedade que podem (ou não) dar a base de sustentação a uma política de Estado representada não pelo Leviatã, mas por coalizões concretas de forças sociais em uma disputa por hegemonia. Assim, a perspectiva teórica e política do CEIS insere-se claramente em um projeto de desenvolvimento na vertente desenvolvimentista-social ao privilegiar, desde sua formulação original, a possibilidade de articular, política e economicamente, um círculo virtuoso envolvendo inclusão social, consumo

\footnotetext{
${ }^{4}$ Este ponto foi destacado por Leandro Safatle, atual coordenador da Câmara de Regulação do Mercado de Medicamentos (CMED). Um trabalho anterior, desenvolvido para o Centro Brasileiro de Estudos de Saúde, apresenta um esforço mais explícito de articular endogenamente a dinâmica do capital com a construção de um sistema de saúde universal no país (Gadelha, 2007).
} 
de massas, expansão do emprego e da renda, fortalecimento da estrutura produtiva, de processos de inovação e dos investimentos, e a redução da dependência nacional (Carneiro, 2012; Bielschowsky, 2012; Gadelha, 2007; Fagnani, 2014a, 2014b). Pensar a saúde sem essa compreensão seria mais uma vez insular o sistema de saúde em relação a um projeto nacional que conforma a base política da análise estratégica. Sistema universal de saúde, base econômica, produtiva e de inovação e Estado são vertentes indissociáveis na construção de um novo amanhã na saúde. Por outra vertente, pode-se dizer que com este livro, parte da iniciativa Brasil Saúde Amanhã, também se procura sedimentar bases que contribuem política e academicamente para dimensões essenciais de um projeto nacional assentado no avanço social e da estrutura produtiva.

A dialética do desenvolvimento capitalista (Marx, 1983) na saúde - um sistema produtivo líder no século XXI - exige tanto o reconhecimento do avanço nas forças produtivas quanto a percepção de que esta constitui uma área que pode gerar segmentação, exclusão e dependência no interior dos sistemas nacionais. A proposta política desta prospecção, alinhada com o desenvolvimentismo em bases sociais, é de uma atuação voltada para a constituição no Brasil de um Estado de bem-estar contemporâneo, enraizado na sociedade, incluindo o setor empresarial, para articular a lógica do capital com a lógica e as demandas sociais, estabelecendo círculos virtuosos que envolvem, ao mesmo tempo, tensão, conflito e direção estratégica.

O que pode parecer uma visão naïf ou utópica representa, de fato, o esforço para atualizar e trazer para o contexto do século XXI, em um país de desenvolvimento tardio, uma arquitetura semelhante à que foi montada na experiência europeia do pós-guerra, envolvendo uma articulação entre o Estado, o setor produtivo e a sociedade civil, para gestar uma trajetória de desenvolvimento e uma prospecção política - que integre inovação, base produtiva nacional, redução da dependência e garantia de direitos. Tarefa árdua, difícil de ser construída politicamente, mas necessária. Este é o horizonte estratégico do CEIS, subordinado a um modelo de desenvolvimento, sem o que a barbárie, a cisão social e a exclusão se tornarão dominantes. Desta perspectiva estratégica decorre que a agenda do CEIS, do conhecimento e da inovação em saúde constitui uma agenda essencial da saúde pública no século XXI, cujas bases serão definidas justamente no período deste estudo prospectivo e da iniciativa Brasil Saúde Amanhã.

Os organizadores*

\footnotetext{
* Com a colaboração do pesquisador do Grupo de Pesquisa em Inovação em Saúde/Fiocruz Bernardo Cesário Bahia, na sistematização e análise das correntes desenvolvimentistas e do debate acadêmico e político atual.
} 


\section{Referências}

BIELSCHOWSKY, R. Estratégia de desenvolvimento e as três frentes de expansão no Brasil: um desenho conceitual. Economia e Sociedade, 21(n. esp.): 729-747, 2012.

BRASIL. Senado Federal. Constituição da República Federativa do Brasil. Brasília: Senado, 1988.

CARNEIRO, R. M. Velhos e novos desenvolvimentismos. Economia e Sociedade, 21(n. esp.): 749-778, 2012.

FAGNANI, E. Fragmentação da luta política e agenda de desenvolvimento. Campinas: IE/Unicamp, jul. 2014a. (Texto para Discussão n. 241). Disponível em: < http://plataformapoliticasocial.com.br/fragmentacao-da-lutapolitica-e-agenda-de-desenvolvimento/>. Acesso em: 27 jan. 2014.

FAGNANI, E. Política social e desigualdade: projetos em disputa. Campinas: IE/Unicamp, jun. 2014b. (Texto para Discussão n. 238)

GADELHA, C. A. G. Estudo da competitividade de cadeias integradas no Brasil: impactos das zonas livres de comércio (Cadeia: Complexo da Saúde). Nota Técnica Final. Campinas: IE/Neit/Unicamp, MCT-Finep, MDIC, 2002.

GADELHA, C. A. G. O complexo industrial da saúde e a necessidade de um enfoque dinâmico na economia da saúde. Ciência \& Saúde Coletiva, 8(2): 521-535, 2003.

GADELHA, C. A. G. Desenvolvimento e saúde: em busca de uma nova utopia. Saúde em Debate, 30: 71, 2007.

GADELHA, C. A. G. \& COSTA, L. S. Saúde e desenvolvimento no Brasil: avanços e desafios. Revista de Saúde Pública, 46, supl. 1: 13-20, 2012.

GADELHA, C. A. G. et al. A Dinâmica do Sistema Produtivo da Saúde: inovação e complexo econômico-industrial. Rio de Janeiro: Editora Fiocruz, 2012.

GRUPO DE PESQUISA DE INOVAÇÃO EM SAÚDE (GIS). Escola Nacional de Saúde Pública Sergio Arouca. Fundação Oswaldo Cruz. Dados selecionados da Rede Alice/MDIC. Disponível em: <www.aliceweb.mdic.gov. br>. Acesso em: $1^{\circ}$ sem. 2014.

MARX, K. O Capital: crítica da economia política. São Paulo: Abril Cultural, 1983. (Os Economistas)

SCHUMPETER, J. Capitalismo, Socialismo e Democracia. Rio de Janeiro: Zahar, 1985.

VIANA, A. L. D. \& ELIAS, P. Saúde e desenvolvimento. Ciência \& Saúde Coletiva, 12, supl.: 1.765-1.777, 2007.

VIANA, A. L. D.; NUNES, A. A. \& SILVA, H. P. Complexo produtivo da saúde, desenvolvimento e incorporação de tecnologias. In: IBAÑEZ, N.; ELIAS, P. E. M. \& SEIXAS, P. H. d'A. (Orgs.). Política e Gestão Pública em Saúde. v. 1. São Paulo: Hucitec, Cealag, 2011. 



\title{
GERAÇÃO E TRAJETÓRIAS DE INOVAÇÃO NOS SERVIÇOS DE SAÚDE
}

\author{
Laís Silveira Costa \\ Ligia Bahia
}

No Brasil, os desafios na área da saúde estão relacionados com as transformações que, ao longo das últimas seis décadas, têm ocorrido no sistema nacional de saúde; universalizar o acesso, reduzir custos e equilibrar a balança comercial emergiram como integrantes de um processo que desmercantilizou o acesso à saúde, mercantilizou a sua oferta e estimulou o surgimento de um conjunto de indústrias interligadas ao setor. A mudança no paradigma do acesso aos serviços de saúde foi iniciada com a formação de seguros ocupacionais e nacionais no século XX, que deram origem aos grandes sistemas públicos nacionais de saúde e fundamentaram a acepção da saúde como um direito, o de ter garantias para riscos considerados sociais.

No lado da oferta de serviços, o assalariamento dos profissionais da saúde ocorreu no início do século XX, por meio dos dispositivos da previdência social e dos serviços públicos, culminando na formação de uma densa trama institucional com unidades interligadas que desempenham, em determinados casos, simultaneamente, funções de prestação de serviços e comercialização de planos e seguros privados de saúde. Estes, por sua vez, desempenham a função de gerenciar a prestação de serviços e estão integrados aos circuitos de financeirização da economia. No que concerne à formação de grandes indústrias como as de base química e biotecnologia, mecânica, eletrônica e de materiais, que constituíram o denominado complexo industrial da saúde, muito dependente de inovações tecnológicas no setor, os desafios se referem à incipiência de uma base produtiva nacional e à geração de déficits crescentes na balança comercial em função da defasagem da tecnologia do setor em relação aos países produtores. No que diz respeito à demanda, envelhecimento da população e mudanças epidemiológicas e na estrutura ocupacional representam obstáculos estruturais para a universalização da saúde de acordo com os princípios constitucionais do Sistema Único de Saúde (SUS). Por sua vez, as alterações nos padrões de morbidade e mortalidade estão associadas com mudanças no acesso e na utilização de serviços voltadas para o atendimento de necessidades que incluem desde ações e cuidados preventivos até o uso de unidades de tratamento intensivo.

Essas tendências se projetam sobre uma trajetória do desenvolvimento no Brasil baseada, de 1930 até 1980, na substituição de importações, mas sem capacitação tecnológica endógena e com aumento da desigualdade social e regional, gerando uma assimetria que deixa de ser entre agricultura e indústria e passa a se caracterizar como clivagem entre atividades densas em conhecimento e atividades sem grande valor agregado. A adoção do receituário neoliberal, no fim do século XX, resultou na falta de investimentos indutores de inovação tecnológica na rede pública de laboratórios 
oficiais, que passaram a realizar atividades de formulação de medicamentos acabados, sem integração de produção e síntese das matérias-primas. A retomada do processo de indução do desenvolvimento social nos anos 2000 se baseia nos conceitos de subdesenvolvimento e de país em desenvolvimento como processo histórico, e não como etapas do percurso dos países desenvolvidos, e nas reflexões a respeito das defasagens entre os movimentos de criação e acumulação de capital na saúde e as políticas de universalização do direito à saúde. Balizadas por esses marcos, as políticas de investimento na saúde destinadas a conferir sustentabilidade, legitimidade e qualidade ao SUS se pautaram pela necessidade de elevar o peso dos segmentos produtivos de bens e serviços de saúde que atendem a demandas sociais e incorporam um grande potencial de inovação e de transformação nos novos paradigmas tecnológicos. Para Gadelha, Quental e Fialho (2003) o setor Saúde é um lócus fundamental de desenvolvimento econômico, uma vez que nele a inovação e a acumulação de capital geram oportunidades de investimento, emprego e renda. Segundo esses autores, o complexo econômicoindustrial da saúde (CEIS) é composto por um conjunto interligado de produção de bens e serviços em saúde, um grupo de atividades produtivas selecionadas que mantém relações intersetoriais de compra e venda de serviços.

Tendo como pano de fundo o panorama aqui delineado, procuramos articular a reflexão sobre os referenciais teóricos, a difusão e a trajetórias das investigações sobre mudanças nos serviços de saúde, em particular dos hospitais, com a situação atual e as perspectivas de expansão do conhecimento sobre processos inovadores e dos serviços envolvidos com atividades sistemáticas e permanentes de inovação.

\section{Inovação: usos e abusos do conceito}

As dificuldades que envolvem o conceito de inovação são sobejamente conhecidas. De acordo com reportagem publicada no Wall Street Journal, os diretores executivos das maiores empresas mencionam cada vez mais o termo em suas apresentações e conferências (Berman, 2013). Um levantamento do The Boston Consulting Group realizado em 2014 com 1.500 executivos solicitando a classificação da inovação em sua empresa em um espectro de 1 a 10 evidenciou que mais de dois terços a situaram no terço superior. No entanto, como o termo inovação tem sido utilizado para se referir a misturas de aromas em perfume, à elevação do teor de álcool em cerveja, a relatórios de créditos e a tatuagens temporárias para animais de estimação, questiona-se o seu significado inclusive no âmbito dos fóruns que reúnem executivos de grandes empresas.

Em função do consenso sobre a dependência de inovação para a sobrevivência das empresas, o significado de inovar muitas vezes pode se situar aquém das raízes etimológicas de innovatio e novus, que significam nova criação, algo novo, novidade. Uma acepção mais modesta, a que relaciona inovação com competitividade - manter o ritmo de disputa com os rivais - passou a ser aceita e amplamente veiculada. Assim, o conceito de competitividade, carregado pelo pressuposto de que alguns ganham e outros perdem, teria sido substituído pelo termo inovação, alusivo aos negócios que envolvam adaptação. Outra recente ampliação de significado da palavra inovação foi seu uso no sentido de otimização, especialmente como referência para a interação entre mudanças no processo de um produto final. 
De acordo com a Sociedade Portuguesa de Inovação (2004), a difusão do uso da palavra inovação no cotidiano das atividades empresariais é análoga à do conceito de qualidade nos anos 1990. As críticas ao uso abusivo do termo inovação se concentram em torno da indistinção entre inovar e apenas "ficar competitivo". As diferenças entre inovação e extensão de produto ou atualização seriam cruciais para questionar onde termina a sobrevivência e começa uma inovação real. Os que argumentam a favor de interpretações menos rígidas consideram que na dimensão pragmática, aquela envolvida com a criação, sustentabilidade e ampliação dos resultados das empresas, se um produto tem um desempenho compatível com tais necessidades, trata-se de algo que realiza inovação.

Apesar das divergências sobre os limites e as possibilidades da utilização da palavra inovação, o registro ampliado do conceito que conecta inovação com as finalidades das empresas tem sido adotado e legitimado por instâncias acadêmicas, especialmente da área dos cursos de administração para executivos. Há consenso sobre a desvinculação de inovação de um produto físico e questionamentos sobre as possibilidades de denominar de inovação novas formas de competição. Segundo Chintagunta (2014), existem quatro áreas de aplicação para o uso ampliado do conceito de inovação. A primeira se refere à precificação de um produto - por exemplo, aumento ou redução de valores de ingressos baseados na dinâmica do dia a dia da demanda. O argumento favorável a categorizar esse tipo de processo como inovação é a afirmação de que a tática para capitalizar diferenciais na preferência dos consumidores seria inovativa. A segunda área de aplicação diz respeito à marca, especialmente no que concerne às expectativas e aos resultados de lançamento de produtos que poderiam não ser rigorosamente considerados inovações, nem representam per se um significativo aumento da oferta, mas promovem a marca e todos os seus demais produtos. A terceira alternativa para o uso de inovação como nova categoria descritiva está afeta à extensão do uso de um produto que não introduz benefícios específicos para os consumidores, nem preenche lacunas nas necessidades da demanda, no entanto é empregado em outras atividades além da inicialmente proposta. A quarta se volta para a designação de benefícios para a sociedade que não representam inovações para as empresas, mas são direcionados para a base da pirâmide de renda - por exemplo, a oferta de calçados por um euro pela Adidas em Bangladesh, o sistema de baixo custo de filtragem da água da Unilever na Índia.

Obviamente, a transposição dessas interrogações e sugestões da ampliação do conceito de inovação para a saúde não é automática, e o alargamento do significado do conceito de inovação em um campo complexo de conhecimentos, saberes e práticas tem conotações singulares. No entanto, embora as definições clássicas de inovação como novo produto, nova técnica ou novo mercado não tenham sido abandonadas, a busca de definições abrangentes de inovação na saúde e em particular nos serviços de saúde tem sido uma marca dos estudos sobre o tema (Kaluzny et al., 1970). O pressuposto adotado para estabelecer marcos referenciais para o exame do tema inovação nos serviços de saúde é o de que os arranjos institucionais que compõem os sistemas de saúde são sociais e as análises sobre os diferentes tipos de inovação são socialmente determinadas (Kaluzny \& Veney, 1973). Tal enquadramento permite compreender as velozes mudanças tecnológicas na saúde vis-à-vis as tensões constitutivas entre qualidade e viabilidade financeira, bem como seus desdobramentos em termos de gestão organizacional e contextos regulatórios. 
Uma abordagem complementar aos estudos sobre inovação na saúde, aquela da inovação nos serviços de saúde, é a crítica ao denominado viés pró-inovativo. Greenhalgh (2013) identifica cinco vieses que perpassam a reflexão sobre inovação e saúde. O primeiro teria sido descrito pela primeira vez em 1960 pelo guru da inovação, Everett Rogers, que lançou uma classificação hierarquizada de pessoas e comportamentos: inovadores (o melhor tipo), seguido de early adopters, early majority, late majority e retardatário (como polo negativo). O segundo viés é denominado subjetivista e subjaz a parcela importante da retórica política sobre novas tecnologias, aquela que ressalta não resultados práticos, mas suposições otimistas sobre a contribuição que estas podem dar caso haja um desenvolvimento contínuo de pesquisas, se as tecnologias forem implementadas como anunciado e na ausência de barreiras de regulação ou técnicas-operacionais. O exemplo utilizado para demonstrar o problema é o da "adivinhação de um futuro próximo", no qual predominaria a calm computing ${ }^{1}$ e todas as tecnologias plug and play estariam disponíveis e isentas de falhas. $\mathrm{O}$ terceiro e o quarto estariam relacionados com o pressuposto segundo o qual o aumento da oferta de funções de determinadas tecnologias e de conectividade as torna, necessariamente, mais úteis e confiáveis. O último viés, concernente à intensificação dos estudos sobre robótica, resulta na exaltação acrítica das virtudes de substituição do humano por tecnologias que realizam atividades tão bem quanto este ou ainda melhor, inclusive capazes de suprir lacunas de relacionamento social.

A problematização das relações do setor industrial com os serviços, em sentido diverso daquele da valorização positiva da inovação na saúde, tem exposto os problemas advindos das investigações patrocinadas pelas empresas produtoras de medicamentos e equipamentos. Para Goldacre (2012), as evidências acumuladas ao longo das três últimas décadas são mais do que suficientes para demonstrar a existência de um fenômeno real e generalizado, que vincula a prescrição de medicamentos com a remuneração direta e indireta de médicos. A batalha para regular a produção e comercialização de medicamentos está longe de terminar, mas atingiu uma fase na qual se procura compreender e divulgar problemas e eventuais soluções e existe uma infraestrutura de governança das inovações, bem como um contra-ataque bem organizado da indústria de medicamentos para assegurar a expansão de seus negócios. A literatura sobre a inovação de outras tecnologias registra, por um lado, polêmicas sobre o ritmo de introdução que supera as evidências de efetividade e eficácia, e, por outro, a existência de barreiras à entrada de novos produtos impostas pelas grandes empresas e interesses de prestadores de serviços de saúde (Grennhalg et al., 2010; Shortell et al., 1996).

Estudiosos brasileiros consideram que as inovações na saúde potencializam a expansão do acesso e podem contribuir para a adequação do sistema às necessidades da população. Entretanto, os processos pretéritos e contemporâneos de geração de inovação em saúde não têm se pautado exclusivamente por demandas e condicionantes sanitários; ao contrário, frequentemente refletem uma trajetória de desenvolvimento que pode ser cativa de interesses de grupos restritos da sociedade (Costa et al., 2012). Daí a necessidade de levar em consideração a complexidade das distintas dimensões do

\footnotetext{
1 Conforme o dicionário Whatis.com, tecnologia calma é aquela reduz a excitação ou entusiasmo exagerado pela "sobrecarga de informações, e permite ao usuário selecionar as informações que devem permanecer no centro da sua atenção e as que são periféricas" (tradução nossa). A expressão foi cunhada em 1995 por Mark Weiser, chefe de tecnologia, e pelo diretor John Seeley Brown, da Xerox Palo Alto Research (Weiser \& Brown, 1995).
} 
CEIS para responder aos desafios de formular e implementar uma dinâmica inovativa virtuosa para a reestruturação dos serviços em saúde.

Assim, as tensões registradas pela literatura sobre o tema e as limitações para adequar reflexões sobre inovações e serviços de saúde realizadas em contextos de sistemas de saúde de países desenvolvidos ao sistema de saúde brasileiro que demarcam a área de estudos sobre inovações em serviços de saúde balizam o presente trabalho. O suposto que serve como fio condutor para relacionar as resenhas e sistematização das contribuições de estudiosos da inovação em serviços de saúde com o delineamento das perspectivas condizentes com as especificidades do sistema de saúde brasileiro é a necessidade de elaborar alternativas de caráter estratégico que potencializem programas táticos em curso.

\section{Políticas de Saúde, Sistemas, Serviços de Saúde e Inovação: referenciais teóricos}

Para Kaluzny (2007), os principais vetores que impactam as políticas de saúde são: as novas tecnologias; o envelhecimento da população; o aumento da diversidade étnica e cultural da população; mudanças na oferta e educação dos profissionais da saúde e a internacionalização dos serviços. Como as organizações de saúde têm sido caracterizadas como muito complexas e submetidas a velozes mudanças, a gestão dos serviços de saúde se tornou um fator relevante para a análise e a formulação de políticas públicas. Ratten (2012) considera a compreensão dos estilos gerenciais e iniciativas empreendedoras como uma chave interpretativa indispensável para os estudos sobre inovação na saúde. Assim, o conceito de inovação na saúde, especialmente a inovação nos serviços de saúde, inclui seus significados estruturados em termos de processos, organizações e produtos e desdobramentos conectados com a disrupção ou o incrementalismo das tecnologias, mas os remete à necessidade de ampliar a efetividade dos serviços de saúde.

Em seu trabalho sobre referencial teórico para inovação nos serviços de saúde, Kaluzny (1974) pressupõe que as dificuldades em eliminar as barreiras financeiras para o acesso desafiam os atuais sistemas de saúde a responder efetivamente às necessidades de saúde. Daí o crescente interesse pela inovação na saúde, uma vez que o ritmo acelerado das mudanças tecnológicas, a crescente especialização dos médicos e o rápido desenvolvimento de outras profissões da saúde, bem como o incremento na diferenciação e especialização dos serviços, impõem obstáculos à coordenação, e os sistemas de saúde tendem a aumentar despesas e produzem resultados com padrões de qualidade muito aquém dos desejados.

Ainda segundo Kaluzny (1974), o enquadramento para a análise das inovações nos serviços de saúde deve considerar três tipos de arranjo e formato institucional - público; filantrópico/comunitário e privado -, permeados por três características-chave, especialmente pertinentes à reflexão sobre inovação - autonomia da profissão médica e suas diversas especialidades; a ascendência de organizações formais; e a tendência da tecnologia de ponta e os valores a ela associados a influenciar o conjunto dos sistemas de saúde. Os tipos de arranjo institucional podem ser definidos pelo foco coletivo ou individual e pelo grau de unidade administrativa. As instituições públicas tendem 
a se direcionar mais ao coletivo do que aos indivíduos e têm alto grau de unidade administrativa; suas atividades estão sujeitas a controles administrativos relativamente rígidos. As organizações filantrópicas/comunitárias têm como foco principal de atenção os indivíduos e suas organizações, mantêm pouca relação entre si e não dispõem de um sistema integrado de controle administrativo; a estrutura interna desses órgãos se caracteriza pela dupla linha de autoridade, uma se concentrando na organização para o trabalho e outra se atendo ao desempenho do trabalho. O terceiro setor é constituído por profissionais e serviços de saúde que ofertam ações e cuidados de saúde em base individual. O indivíduo é o objeto exclusivo desse tipo de arranjo institucional, que tem como marca a limitada ingerência administrativa - ou até mesmo sua ausência - para o exercício da prática profissional. Portanto, a compreensão sobre a inovação nos sistemas de saúde necessariamente requer a análise sobre o potencial dos serviços de saúde (ou, mais especificamente, das organizações e dos profissionais da saúde) de se adaptar às mudanças e às alterações nas demandas. Portanto, o papel da inovação diz respeito à capacidade de adaptação dos diferentes elementos do sistema de saúde à emergência de novos problemas de saúde e às mudanças nas expectativas, nos valores e normas culturais e na esfera econômica e política.

No Quadro 1 estão sintetizados os elementos-chave do referencial teórico para a análise de inovação nos serviços de saúde elaborado por Kaluzny.

Quadro 1 - Referencial teórico de Kaluzny para a análise de inovações nos serviços de saúde: dimensões principais

\begin{tabular}{ll}
\hline Autonomia & A organização da prática médica é um elemento-chave das análises sobre inovação. \\
médica & Três aspectos da inserção e exercício da prática médica são particularmente relevantes: \\
& 1) a profissão é autônoma e a questão central não se reduz ao desempenho técnico \\
autônomo, mas contempla também a capacidade dos médicos para exigir autonomia & em âmbitos não técnicos envolvendo a organização dos serviços de saúde; 2) a \\
profissão pode ser vista como um amálgama de diversas especialidades médicas, com \\
diferentes objetivos e abordagens, mantidos sob um nome comum em determinado \\
ponto no tempo; esta conceituação contrasta com a visão tradicional da profissão \\
médica como uma comunidade estática e relativamente homogênea, cujos membros \\
compartilham valores, funções e interesses; 3) no nível da prática dos médicos, a \\
natureza da tarefa e o tipo de orientação psicológica necessária afetam a abordagem do \\
profissional na disseminação da inovação.
\end{tabular}


Quadro 1 - Referencial teórico de Kaluzny para a análise de inovações nos serviços de saúde: dimensões principais (cont.)

\begin{tabular}{|l|l|}
\hline 1) a maioria dos administradores não são médicos especialistas e as decisões \\
dentro dessas organizações exigem alto grau de participação (variável importante \\
na vinculação entre a decisão de implementar e a de adotar inovações); 2) os \\
administradores, embora tradicionalmente sejam médicos ou reverentes em relação \\
à profissão médica, estão sob crescente pressão para cumprir objetivos de alcançar \\
eficiência e responder a demandas sociais que conflitam com objetivos orientados \\
tecnicamente da comunidade médica. \\
O desenvolvimento de uma tecnologia extremamente sofisticada tem sido fundamental \\
para a ascensão de organizações formais nos sistemas de saúde. A diferenciação desta \\
tecnologia vis-à-vis seus objetivos e recursos tem implicações para a capacidade de \\
adaptação às novas demandas e necessidades, e sua receptividade a vários tipos de \\
pecnologia de \\
inovação pode ser identificada em duas dimensões: 1) à medida que a tecnologia se \\
torna mais sofisticada e baseada em corpus esotérico de conhecimento, as organizações \\
tendem a se proteger mediante o estabelecimento de uma dinâmica que envolve seus \\
próprios requisitos e processos tecnológicos, e essa dinâmica predispõe o sistema para \\
aceitar ou rejeitar certos tipos de inovação de forma totalmente independente das \\
necessidades de saúde; 2 ) a propensão para a aceitação de determinadas tecnologias \\
parte de ambos - provedores e consumidores de serviços de saúde - e se associa com \\
a inclinação para a ação diante de situações de elevada incerteza; tal predisposição \\
para a intervenção ativa, juntamente com a dinâmica do sistema que envolve os seus \\
próprios requisitos tecnológicos, favorece certos tipos de inovação.
\end{tabular}

Fonte: elaboração própria com base em Kaluzny, 1974.

A proposta de Kaluzny enfatiza a importância da compreensão da autonomia da prática médica e suas expressões objetivas como determinantes para o sucesso de qualquer mudança no sistema de saúde. A autora recupera a necessidade de encarar a profissão médica não como simplesmente um receptáculo que recebe ou se opõe à inovação. Sugere o exame da dinâmica das lutas de poder entre as várias disciplinas tradicionais e emergentes na medicina, afirmando que o fato de certas inovações serem mais bem aceitas do que outras evidencia utilidades adicionais àquelas da mera prestação de cuidados de saúde.

Uma tendência que tensiona a autonomia da prática médica é a crescente ascensão das instâncias administrativas e suas consequências tanto para a definição sobre qual seria a variável dependente adequada aos estudos sobre inovação na saúde quanto para a necessidade de observar a inclinação das organizações a desenvolver seus próprios requisitos tecnológicos. As organizações e os sistemas de saúde, por sua vez, têm mais receptividade a determinadas tecnologias que permitam fazer algo, isto é, que representem uma intervenção ativa em situações críticas - por exemplo, transplante de órgãos.

O quadro referencial que articula matricialmente os tipos de arranjo institucional com dimensões de níveis decisórios e tipos de tecnologia permite examinar inovações nos serviços de saúde, considerando os atributos de uma inovação em si. Serviços ou programas ou tecnologias implementados em hospitais são caracterizados principalmente por alto retorno em termos de qualidade dos serviços já ofertados pela organização, baixa taxa inicial de retorno de investimentos e reduzida atenção ou aprovação social. Nos demais estabelecimentos de saúde, as inovações se caracterizam por serem 
altamente divisíveis e terem custos relativamente baixos. A análise da sequência de adoção das inovações parece confirmar a existência de um padrão dependente do tipo de organização, e não apenas do tipo de inovação. Verificou-se que o padrão de inovação em hospitais pode ser compreendido como uma sequência unitária e não aleatória; constitui, portanto, uma escala de Guttman, ao passo que o padrão de adoção nos demais estabelecimentos de saúde segue um padrão diferente, não exibe escalabilidade (Kaluzny \& Veney, 1973).

Quadro 2 - Referencial teórico de Kaluzny para análise de inovações nos serviços de saúde: mensuração de inovação

MÉDICos
Variáveis
sociodemográficas
e de
personalidade,
situação
profissional e
características da
prática médica

ORGANIZAÇÕES DE SAÚDE

Variáveis relacionadas com características dos administradores

Variáveis relacionadas com características do pessoal da organização
As inovações são mais facilmente aceitas por aqueles que estão envolvidos em atividades especializadas, têm uma orientação racional e científica e são menos dogmáticos.

O nível de formação profissional e o grau de especialização estão associados com a propensão a aceitar inovações.

Estudos relacionam várias noções de orientação psicológica para a adoção da inovação.

Médicos mais diretamente interessados na medicina como ciência tendem a ser mais inovativos.

Outras variáveis sociodemográficas e de personalidade relativas à adoção de inovações são: idade mais jovem; a capacidade de nomear uma instituição de referência para a busca de informações e atualização de conhecimento; a proximidade da prática médica de uma escola médica.

Laços institucionais, contatos profissionais informais e relações de amizade contribuem para a difusão de inovações.

A inserção do médico individual no sistema de saúde, ou seja, o grau de integração com colegas e com a situação social dos pacientes, afeta o comportamento inovador em relação ao tipo de inovação.

O nível de formação profissional refletido na consciência de programas alternativos, grau de cosmopolitismo e situação social dos administradores ou gestores estão associados positivamente com a inovação organizacional. Contudo, há estudos que sugerem que quando o tamanho e a estrutura organizacional são controlados a importância das características do administrador tende a ser minimizada.

As variáveis contextuais e organizacionais são as principais responsáveis pela inovação organizacional. O tamanho da organização é a variável crítica que diferencia as organizações quanto ao investimento em ações e programas de alto risco versus programas de baixo risco. As organizações classificadas como inovadoras são caracterizadas pela baixa especificidade dos procedimentos ofertados, pela descentralização dos processos de tomada de decisão e pela alta complexidade. As organizações mais complexas e diversificadas são provavelmente mais inovadoras.

A complexidade (mensurada pelo número de tarefas especializadas dentro da organização) é o indicador estrutural mais importante da inovação organizacional.

Quatro fatores associados a processos internos de controle organizacional têm sido considerados nos estudos de inovação: visibilidade de consequências; padrões de comunicação; coordenação e estilos de liderança.

A dependência interorganizacional é uma variável importante para a inovação. As relações de poder entre organizações com recursos escassos podem ser inovativas porque a tomada de decisão no âmbito interorganizacional aumenta o poder de barganha de cada organização isoladamente. As organizações com mais programas conjuntos com outras instituições tendem a ser mais inovadoras. 
A tentativa de superar as lacunas para a compreensão e mensuração com base em modelos multiníveis é imprescindível para aprimorar as possibilidades de sucesso de políticas a serem implementadas. O modelo de Kaluzny busca articular diferentes abordagens explicativas em diferentes planos de análise.

Outra abordagem teórica para a análise da inovação nos serviços de saúde é o mapeamento dos diferentes agentes e interesses (stakeholders) envolvidos com os programas e projetos de desenvolvimento tecnológico que têm como pressuposto a necessidade de transpor duas barreiras à compreensão sobre sucessos e fracassos de políticas voltadas para o desenvolvimento e implementação de inovações: a falta de consenso sobre os construtos hipotéticos e a falta de consenso sobre a identificação e mensuração dos processos de inovação (Chaudoir, Dugan \& Barr, 2013; Velho, 2011, 2004).

Segundo Greenhalg (2012) podem ser identificados quatro discursos conflitantes, ao mesmo tempo que pervasivos, sobre inovações tecnológicas nos serviços de saúde. Os quatro discursos são referidos a uma concepção sobre inovações tecnológicas na saúde inscrita em uma comunidade de atores com valores e anseios, incluindo a indústria, o governo, organizações não governamentais, profissionais da saúde, pacientes e prestadores de serviços, pesquisadores e outros financiadores de serviços de saúde. A moldura para a apreensão e análise de feixes discursivos de agentes engajados nos processos inovativos é a acepção de que o lançamento de novas tecnologias requer: 1) interpretação - uma noção compartilhada daquilo que a tecnologia é e de como pode ser usada); 2) legitimação - uma lógica compartilhada sobre o que é a tecnologia e como deve ser adotada; 3) mobilização - estímulo e coordenação das partes interessadas para promover sua adoção e difusão.

O primeiro discurso é o denominado modernista, que considera os sistemas de saúde sobrecarregados, operando com capacidade máxima e em face de riscos de colapso, em consequência do aumento da longevidade da população e de demandas por novos bens e serviços, para expandir o acesso. A longevidade é encarada como um marcador positivo. As tecnologias são apresentadas como soluções racionais e de baixo custo para reduzir custos e gerar oportunidades de negócios. As tecnologias móveis e portáteis que assegurarão mais autonomia (reduzindo o contato entre pacientes e profissionais da saúde) são julgadas eticamente benignas. Alocações substanciais de recursos para construir as ligações intersetoriais e facilitar a pesquisa e o desenvolvimento foram justificados por meio de um discurso apoiado nas noções de aplicação de recursos e seu retorno e economias de escala. Os potenciais conflitos de interesses entre os agentes envolvidos com as inovações são reconhecidos e analisados. A mudança social prevista pelo discurso modernista é radical, de longo alcance e extensa alteração na base tecnológica: as novas tecnologias não serão utilizadas apenas para aprimorar as abordagens atuais dos problemas de saúde, mas sim para alterá-las (Greenhalg, 2012).

Um exemplo do discurso modernista pode ser encontrado no texto intitulado "Will disruptive innovations cure health care?", no qual se atribuem à corporação médica e aos hospitais vetos a inovações tecnológicas custo-efetivas (poderosas forças institucionais se opõem a alternativas que ameaçam sua subsistência). Segundo seus autores, tal como o telefone permitiu que as pessoas se comunicassem sem a necessidade de operadores de telégrafo, os avanços diagnósticos e terapêuticos requerem mudanças nos locais de intervenção, como ocorreu com os testes de glicose para pacientes de diabetes (Christensen, Bohmer \& Kenagy, 2000). 
O segundo tipo de discurso é o humanista; concebe tecnologias não necessariamente de forma negativa, desde que subsumidas à atuação de cidadãos em igualdade de condições na definição de suas necessidades e preferências. O discurso humanista difere do modernista nos seguintes aspectos: 1) não é centrado em tecnologias, mas nas experiências do processo saúde-doença e envelhecimento; 2) não se concentra em um futuro de alta tecnologia imaginado, mas na realidade do uso limitado de tecnologias; 3) enfatiza o significado simbólico de determinadas tecnologias como alarmes e tags que podem conotar intrusão, estigmatizacão e exposição à vigilância (ou seja, a medicalização do mundo da vida contribuiria para afirmar uma acepção de certas tecnologias como intrusas); 4) projeta as inovações tecnológicas como atividades participativas e interativas.

O terceiro feixe discursivo é o da economia política, cuja característica principal é a identificação e compreensão dos padrões tecnoeconômicos criados e perpetuados por interesses políticos e econômicos em torno das inovações. Um dos argumentos centrais do discurso da economia política é que os significados simbólicos conferidos às tecnologias estão subordinados a forças institucionais e à consciência (ou falta de consciência) de alternativas. Os discursos pertencentes à matriz da economia política questionam a narrativa da eficiência, isto é, a suposição de que as tecnologias aumentam necessariamente a eficiência e, consequentemente, representam alternativas de aumento de retornos e tendem a reduzir progressivamente os custos.

Adicionalmente, a reflexão sobre as inovações vinculada à matriz da economia política propõe que as tecnologias espelhem mudanças de valores sociais, que a saúde é um bem público e dever do Estado e que os valores neoliberais, segundo os quais a saúde das populações vulneráveis é um dever da sociedade, estimulam a adoção de alternativas meramente instrumentais (como, por exemplo, programas de inclusão digital) que não alteram a complexa determinação social do processo saúde-doença. Assim, uma solução tecnológica aparentemente simples, longe de ser uma força transformadora em direção a uma sociedade mais saudável, pode revelar formas injustas de controle social e aumento das desigualdades por meio da transferência de responsabilidade e carga de trabalho das instituições de saúde para as famílias.

A quarta matriz discursiva é a da mudança na gestão, e seus adeptos tendem a considerar as inovações tecnológicas como potencialmente benéficas, transformadoras e condutoras de redução de custos. Mas questionam o determinismo tecnológico do discurso modernista, ao enfatizar que as transformações exigem um grande volume de esforços adicionais e que as inovações tecnológicas são uma oportunidade para a mudança organizacional, e não o motor das transformações. Consequentemente, as crises e os problemas de saúde não podem ser atribuídos a lacunas tecnológicas, e sim à incompatibilidade entre as funcionalidades do sistema e práticas profissionais, ou à resistência, ou mesmo rejeição, por usuários finais de ações de saúde por razões que incluem preocupações com a relação paciente-profissional e a necessidade de redefinir as estruturas, os papéis e as hierarquias.

No Quadro 3 se expõem sinteticamente as relações entre agentes e as matrizes discursivas. De acordo com Greenhalgh (2012), a maioria dos discursos sobre inovação tecnológica se fundamenta na matriz modernista, seus elementos centrais são discerníveis e distintos uns dos outros, os pontos de contato são raros e não têm sido observadas mudanças nas narrativas no sentido não de informar, mas de propor diálogos interdisciplinares eficazes. 
Quadro 3 - Referencial teórico de Greenhalgh para a análise de inovações nos serviços de saúde: atores (agentes) sociais

Matrizes discursivas

$$
\text { e agentes }
$$

\section{MODERNISTA}

Executivos, empresários, políticos, instituições de pesquisa e pesquisadores das áreas biomédica, informática e business

\section{HUMANISTA}

Instituições acadêmicas da área de ciências sociais e determinadas organizações de pacientes

\section{ECONOMIA POLÍTICA}

Articulada (principal, mas não exclusivamente) por instituições e pesquisadores heterodoxos

\section{Posicionamentos, projetos, previsões}

A intervenção ocorrerá em fases cada mais precoces dos ciclos de vida e as tecnologias inclusive poderão estimular a escolha racional de estilos de vida mais saudáveis.

A infraestrutura de profissionais da saúde e de recursos físicos é encarada como tecnologias e estas são ubíquas, livres de erros e de fácil manejo.

Os cidadãos alfabetizados, incluídos digitalmente, qualificados tecnicamente e engajados socialmente terão pleno acesso a tecnologias que lhes permitirão acessar autonomamente de casas inteligentes (espaçosas, limpas, conectadas, seguras) soluções para problemas emocionais e monitoramento de doenças crônicas (Barlow et al., 2007).

Exemplos de inovações que representarão mudanças disruptivas nos sistemas de saúde: sensores ou outros equipamentos de monitoramento de sinais vitais a distância, a leitura dessas informações e a tomada de decisões, que poderá ser realizada em tempo real sem que o paciente precise recorrer a um prestador de serviços.

Cidadãos, pacientes, em particular idosos ou portadores de deficiência física ou cognitiva, são descritos como agentes ativos, engenhosos, que lutam para viver e dar sentido a suas vidas mediante cumprimento de obrigações sociais. As pessoas são os sujeitos, e não objetos de design e tecnologias, e por isso devem ser estimulados projetos de inovação participativos e qualitativos.

Equipes de saúde são propensas a falhas, a interoperabilidade do sistema de saúde é limitada e comportamentos de pacientes que se recusam a instalar, ligar ou utilizar as tecnologias (por exemplo, de telessaúde ou teleassistência) são entendidos como preservação das fronteiras entre o local de moradia e os serviços de saúde.

Determinadas tecnologias podem contribuir para aumentar o isolamento social porque afastam os pacientes de prestadores de serviços e familiares (permitiriam um afastamento de cheiros, necessidades emocionais, sofrimentos, conflitos interpessoais, fluidos corporais) e, portanto, dos contatos face a face entre pacientes e profissionais (Royal College of Nursing, 2013).

A inovação científica e tecnológica não é um exercício politicamente neutro na construção das atuais bases de conhecimento.

As atividades de pesquisa e marketing se conjugam e se cristalizam como cânones (narrativas que legitimam a necessidade de determinadas tecnologias) que integram simultaneamente postulados de verdade científica e inserção comercial; assim, o conhecimento gerado tem uma funcionalidade comercial implícita.

O atual impulso para controlar os custos crescentes dos sistemas de saúde pode estimular o incentivo a soluções tecnológicas apoiadas por poderosos interesses econômicos e comerciais de produtores e fornecedores de equipamentos, medicamentos, e a incerteza sobre a efetividade dessas inovações pode resultar em programas caros e inapropriados. 
Quadro 3 - Referencial teórico de Greenhalgh para a análise de inovações nos serviços de saúde: atores (agentes) sociais (cont.)

\begin{tabular}{|c|c|}
\hline $\begin{array}{c}\text { Matrizes discursivas } \\
\text { e agentes }\end{array}$ & Posicionamentos, projetos, previsões \\
\hline \multirow{5}{*}{$\begin{array}{l}\text { MUDANÇA NA GESTÃO } \\
\text { Consultorias de gestão }\end{array}$} & $\begin{array}{l}\text { Os formuladores de políticas de saúde, seduzidos pelo apelo racionalista da } \\
\text { tecnologia, podem confundir gestão das condições de saúde (isto é, o que é } \\
\text { necessário para viver bem, ainda que sendo portador de doença ou agravo } \\
\text { crônico) com o conjunto restrito de tarefas de gestão da doença (coleta } \\
\text { de dados biométricos, tais como pressão arterial, peso ou pico de fluxo } \\
\text { expiratório). } \\
\text { As previsões sobre a introdução de novas tecnologias consideram que as } \\
\text { inovações ocorrem em um ritmo lento, mediante negociações e competição de } \\
\text { interesses, e são limitadas por constrangimentos orçamentários, legislações, } \\
\text { culturas organizacionais e regulamentos profissionais. }\end{array}$ \\
\hline & $\begin{array}{l}\text { Uso intensivo de termos tais como complexidade e de metáforas orgânicas que } \\
\text { expressam uma perspectiva de sistema complexo adaptativo. Os sistemas de } \\
\text { saúde são descritos como um conjunto de partes e componentes para os quais } \\
\text { o principal desafio é essencialmente operacional: planejamento, gerenciamento } \\
\text { de projetos, clareza de papéis e responsabilidades integram abordagens } \\
\text { gerencialistas. }\end{array}$ \\
\hline & As inovações tecnológicas são constitutivas dos desafios gerenciais. \\
\hline & $\begin{array}{l}\text { Os passos para o desenvolvimento de serviços de saúde incluem: } \\
\text { 1) identificação de necessidades; 2) considerações sobre necessidades e } \\
\text { alternativas tecnológicas; } 3 \text { ) levantamento sobre os requisitos da força } \\
\text { de trabalho tais como formação de profissionais e gestão da inovação; } \\
\text { 4) avaliação do projeto; 5) implementação; 6) divulgação, difusão e } \\
\text { compartilhamento de boas práticas. }\end{array}$ \\
\hline & $\begin{array}{l}\text { Uma diferença fundamental entre o discurso da mudança na gestão e o } \\
\text { da economia política é que os conflitos são encarados como desafios de } \\
\text { gerenciamento; se forem seguidos os passos corretos, os efeitos em cadeia dos } \\
\text { problemas de relações desconectadas ou desalinhadas serão mitigados. }\end{array}$ \\
\hline
\end{tabular}

Fonte: elaboração própria com base em adaptação de Greenhalgh et al., 2012.

\section{As Trajetórias das Inovações nos Serviços de Saúde}

A trajetória da busca por inovação nos serviços de saúde é influenciada por quatro determinantes: o modo de busca por inovação; aspirações estratégicas; abundância de recursos; retorno do desempenho. O teste desse modelo em hospitais demonstrou a importância da persistência das atividades científicas em relação à busca de práticas inovativas (Greenhalgh et al., 2004; Chaudoir, Dugan \& Barr, 2013). As evidências revelam ainda a necessidade de um fluxo contínuo de novos produtos, processos e serviços em hospitais especializados que lhes assegurem participação na tomada de decisões estratégicas e a sustentação das atividades inovadoras. Há uma associação positiva entre maior folga financeira e a possibilidade de os hospitais efetuarem uma pesquisa inovadora contínua, baseada em uma infraestrutura científica sólida. 
Para Salge (2012), a adaptação organizacional depende fundamentalmente da busca contínua pela inovação, permitindo a reconfiguração das rotinas internas e ofertas externas, e valorizando seus recursos, novos produtos, serviços e processos. Em tempos de crescente dinamismo ambiental, a inovação e as pesquisas voltadas para a inovação são fundamentais tanto para gestores quanto para formuladores de políticas e pesquisadores. A persistência na busca por inovação tem importância tanto em termos teóricos quanto práticos, pois elucida a natureza dos processos de busca inovadores e também produz informações relevantes para os tomadores de decisão de programas e políticas voltados para a inovação. Ela gera, como proposto por Schumpeter $(1928,1984)$, um processo aleatório de destruição criativa, no qual empresários inovadores dilapidam a posição dos operadores históricos e se tornam eles próprios vítimas desse processo quando a geração seguinte de empresários de sucesso assume o comando. A pesquisa inovadora pode ser melhor entendida como um processo dependente da trajetória de acumulação criativa conduzida por agentes que obtêm vantagens mediante a acumulação sistemática de conhecimentos e de competências para gerar esforços inovadores. Os estudos sobre inovação na saúde focalizam quase exclusivamente os ambientes de produção. Por essa razão, a compreensão sobre a inovação nos serviços do setor público e privado ainda é muito limitada. No entanto, a inovação não pode ser encarada apenas como uma religião industrial, mas sim como atividade integrante de organizações de serviços, tanto do setor privado quanto do público (Damanpour \& Schneider, 2009).

Inovação é definida como "a geração, desenvolvimento e adaptação de novas ideias ou comportamentos. Uma inovação pode ser um novo produto ou serviço, um novo (...) processo (...), uma nova estrutura ou sistema administrativo, ou um novo plano ou programa pertencente a membros da organização" (Salge, 2012: 721, tradução nossa). Tal definição é suficientemente ampla para abarcar a atividade de inovação em suas múltiplas formas e manter seu significado específico. Uma vez que "o desenvolvimento de inovações é uma forma de pesquisa organizacional", usa-se o termo pesquisa inovadora para designar os atores envolvidos dentro das organizações no desenvolvimento de novos produtos, serviços e processos (Salge, 2012: 722).

Para Chen e Miller (2007), os investimentos financeiros e não financeiros em busca de inovação frequentemente são discricionários. Desse modo, os agentes decisórios têm considerável margem de manobra para moldar as atividades de busca inovadora em sua organização. Essa tendência influencia especialmente a intensidade e a direção das atividades da pesquisa inovadora. Consequentemente, os agentes decisórios se inclinam a adequar as atividades de busca inovadora às necessidades estratégicas e à dotação de recursos da respectiva organização. Entretanto, este é um processo inerentemente complexo, na medida em que os benefícios precisos e os custos da pesquisa inovadora costumam ter alto grau de incerteza e pressupõem horizontes de longo prazo. Além disso, os agentes tomadores de decisão têm restrições devido ao seu foco limitado e, portanto, não podem considerar todas as informações potencialmente relevantes para determinar o padrão de pesquisa inovadora mais adequado (Ocasio, 1997). Desse modo, aqueles que decidem tendem a usar métodos heurísticos simplificadores para orientar a busca de inovações em suas organizações.

A racionalidade dos processos de decisão é uma das chaves para explicar a variação interorganizacional nos esforços inovadores de novos produtos e mudanças organizacionais nos serviços de 
saúde (Salge, 2011). Portanto, tem-se recorrido à teoria comportamental da empresa para aprimorar a compreensão sobre as circunstâncias precisas em que os tomadores de decisão mantêm a motivação e a capacidade necessárias para sustentar as atividades de busca inovadora ao longo do tempo. E com base nesses pressupostos, da teoria comportamental, observa-se que os financiamentos a longo prazo para a pesquisa inovadora ajudam a reduzir a necessidade de os tomadores de decisão reavaliarem continuamente a intensidade e a direção de cada projeto. Uma vez que os compromissos de recursos permanentes para pesquisa inovadora receberam legitimidade interna, as negociações internas e os conflitos sobre a alocação de recursos têm menor probabilidade de acontecer (Chen \& Miller, 2007).

O processo de institucionalização da pesquisa costuma ser acompanhado pelo surgimento de rotinas de pesquisas específicas. As rotinas são padrões estáveis e repetidos de comportamento influenciados pelas regras e costumes específicos vigentes na organização (Edmondson, Bohmer \& Pisano, 2001). As rotinas, embora conotem estabilidade, são cada vez mais valorizadas por seu potencial transformador (Rerup \& Feldman, 2011). Isso é especialmente válido para rotinas que alimentam as atividades de adaptação organizacionais vitais, tais como inovação e aprendizagem organizacional. Assim, espera-se o desenvolvimento de rotinas para geração, assimilação e utilização de novos conhecimentos em serviços de saúde voltados para pesquisa inovadora. O desenvolvimento de rotinas e mecanismos de apoio que sustentam esforços de busca inovadores nas organizações fornece incentivos para a busca contínua e oportunidades de aprendizado cumulativo. Em particular, rotinas de pesquisa inovadoras tendem a se tornar mais eficazes quanto mais frequentemente são utilizadas. Em função do learning-by-doing e da "aprendizagem de aprender" (Stiglitz, 1987), a experiência de pesquisa aprimora as capacidades das organizações, facilitando, assim, as atividades de busca inovadora subsequentes (Malerba, Orsenigo \& Peretto, 1997). Da mesma forma, a pesquisa inovadora pode desencadear retornos financeiros positivos, gerando recursos adicionais para sustentar atividades inovadoras de busca das organizações. Portanto, institucionalização, rotinização, aprendizado cumulativo e retornos positivos promovem a estabilidade temporal das atividades voltadas para a inovação. De forma consistente com esses argumentos teóricos, a pesquisa empírica tem detectado altos níveis de persistência nos esforços de busca inovadores das organizações que se refletem nos gastos em pesquisa e desenvolvimento (P\&D).

Apesar de se esperar que, em geral, as buscas inovativas das organizações devam exibir forte estabilidade temporal, níveis de persistência podem diferir entre modos distintos de pesquisa para a inovação. Especificamente, esses níveis de persistência variam conforme a extensão em que as organizações são influenciadas e os seus graus de institucionalização, rotinização e aprendizado cumulativo. As atividades de pesquisa inovadora nos serviços de saúde podem ser classificadas em dois grandes grupamentos: 1) pesquisas baseadas em uma relativamente maior aproximação com a ciência e 2) inovações voltadas para a produção de serviços. Ou seja, em uma distinção entre ciência e pesquisas inovadoras baseadas na prática, ou, ainda, entre os modelos "ciência, tecnologia e inovação" e "fazer, usar e interagir". Esses modelos estariam localizados nos extremos opostos do espectro do gradiente das atividades de pesquisa inovadora no qual "inovar e aprender na prática diária se encontram no fim de um continuum de práticas inovadoras que se expandem até uma inovação radical cultivada em laboratórios de pesquisa no seu extremo oposto" (Brown \& Dugid, 1991: 53, tradução nossa). 
Pesquisas inovadoras fundamentadas na ciência normalmente requerem investimentos substanciais em recursos humanos e físicos. Estes incluem o recrutamento e treinamento de funcionários altamente qualificados, assim como o estabelecimento de laboratórios de P\&D com uma infraestrutura de suporte apropriada. Esses investimentos incorrem em custos altos irrecuperáveis a curto prazo e geram incentivos para manter pesquisas inovadoras ao longo do tempo (Sutton, 1991). O fato de as iniciativas de pesquisa inovadora fundamentadas na ciência serem costumeiramente organizadas como projetos formais de P\&D lhes confere visibilidade nos serviços de saúde e, consequentemente, maior probabilidade de atrair a atenção dos agentes tomadores de decisões, o que por sua vez leva a tentativas de rotinização e institucionalização. Similarmente, as rotinas que sustentam a pesquisa inovadora com base científica têm suas raízes na educação e no treinamento profissional dos funcionários. Além disso, a pesquisa inovadora fundamentada na ciência busca contribuir com o conhecimento técnico codificado, o que torna mais fácil o conhecimento cumulativo pela experiência, especialmente quando combinado com resultados de pesquisas anteriores.

Em contraste, a pesquisa inovadora fundamentada na prática ocorre como parte integral das atividades diárias de trabalho, e normalmente é abastecida pelos recursos já existentes. Portanto, requer menos investimentos em uma infraestrutura especializada e mecanismos de suporte, e não requer investimentos irrecuperáveis significativos. Dado que, na prática, está profundamente vinculada com as atividades de trabalho diárias, a pesquisa inovadora fundamentada muitas vezes não recebe a devida atenção dos agentes formadores de política, gerentes seniores e cotrabalhadores. Apesar de poder ser encontrada em qualquer lugar e de ocorrer em qualquer parte dos serviços de saúde, a pesquisa fundamentada na prática frequentemente se encontra invisível até mesmo para aqueles que fazem parte dela (Salge \& Vera, 2009). Isso cria um enorme desafio não apenas para os esforços empresariais de rotinização e institucionalização, mas também para o aprendizado cumulativo. Este se torna ainda mais difícil pelo fato de que a pesquisa inovadora fundamentada na prática depende fortemente do conhecimento pessoal, difícil de transmitir, e é menos passível de codificação e compartilhamento, tal como observado por Polanyi (Soares, 2012).

As pesquisas baseadas na ciência, dada a sua suscetibilidade à institucionalização, à rotinização e ao conhecimento cumulativo, tendem a se tornar mais estáveis ao longo do tempo do que as pesquisas baseadas na prática. Assim, as organizações de saúde tendem a reforçar suas atividades de pesquisa inovadora fundamentadas na ciência e não na prática, e a nelas persistir.

Embora os hospitais sejam uma fonte de importantes avanços no tratamento de doenças, o esforço de inovação em hospitais é subestimado, ou mesmo, em alguns casos, não reconhecido. Em particular, novos produtos, serviços e processos são desenvolvidos, não só no domínio da prática, mas também em uma série de outras funções hospitalares importantes, incluindo enfermagem, hotelaria, restauração, limpeza e administração. No Quadro 4, sobre a dinâmica da inovação em hospitais, procuramos sistematizar as alternativas de atividades inovadoras que ocorrem dentro dos hospitais e a gama de métodos ou hipóteses para estudá-las. Esta tipologia acentua a importância das atividades de busca inovadora com base na prática pertinentes à clínica e também de produtos não clínicos, serviços e processos (Djellal \& Gallouj, 2005). 
Quadro 4 - Métodos ou hipóteses para estudar as atividades inovadoras de pesquisa nos hospitais

\begin{tabular}{|c|c|c|c|c|}
\hline & Produtos & $\begin{array}{l}\text { Resultados/ } \\
\text { Otimização }\end{array}$ & $\begin{array}{l}\text { Processamento das } \\
\text { informações }\end{array}$ & $\begin{array}{l}\text { Provisão de } \\
\text { serviços }\end{array}$ \\
\hline $\begin{array}{l}\text { Abordagem } \\
\text { central }\end{array}$ & Políticas de saúde & $\begin{array}{l}\text { Profissionais da } \\
\text { saúde }\end{array}$ & $\begin{array}{l}\text { Administrador/ } \\
\text { Gestor }\end{array}$ & $\begin{array}{l}\text { Internações } \\
\text { hospitalares }\end{array}$ \\
\hline $\begin{array}{l}\text { Inspiração } \\
\text { disciplinar }\end{array}$ & Economia & Medicina & Administração & Sociologia \\
\hline $\begin{array}{l}\text { Objetivo principal } \\
\text { da pesquisa }\end{array}$ & $\begin{array}{l}\text { Maior eficiência } \\
\text { na produção de } \\
\text { cuidados à saúde }\end{array}$ & $\begin{array}{l}\text { Maior qualidade } \\
\text { dos resultados dos } \\
\text { serviços de saúde }\end{array}$ & $\begin{array}{l}\text { Melhor gestão da } \\
\text { informação clínica e } \\
\text { administrativa }\end{array}$ & $\begin{array}{l}\text { Melhor experiência } \\
\text { do paciente com os } \\
\text { cuidados como um } \\
\text { todo }\end{array}$ \\
\hline $\begin{array}{l}\text { Foco principal da } \\
\text { pesquisa }\end{array}$ & $\begin{array}{l}\text { Produtos clínicos e } \\
\text { processos inovativos }\end{array}$ & $\begin{array}{l}\text { Produtos clínicos } \\
\text { e inovações nos } \\
\text { serviços e processos }\end{array}$ & $\begin{array}{l}\text { Inovações } \\
\text { nos processos } \\
\text { administrativos } \\
\text { e estruturais e } \\
\text { inovações nos } \\
\text { produtos clínicos }\end{array}$ & $\begin{array}{l}\text { Serviços clínicos } \\
\text { e administrativos, } \\
\text { inovações de } \\
\text { processo e estrutura }\end{array}$ \\
\hline $\begin{array}{l}\text { Exemplos de } \\
\text { resultados de } \\
\text { pesquisas }\end{array}$ & $\begin{array}{l}\text { Novos } \\
\text { medicamentos, } \\
\text { tecnologias médicas } \\
\text { e processos de } \\
\text { tratamento }\end{array}$ & $\begin{array}{l}\text { Novos } \\
\text { medicamentos, } \\
\text { procedimentos } \\
\text { médicos, } \\
\text { tecnológicos e } \\
\text { processos de } \\
\text { tratamento }\end{array}$ & $\begin{array}{l}\text { Novos sistemas } \\
\text { de informação, } \\
\text { tecnologias médicas } \\
\text { e estruturas } \\
\text { organizacionais }\end{array}$ & $\begin{array}{l}\text { Novos processos } \\
\text { de tratamento, } \\
\text { procedimentos } \\
\text { clínicos, serviços } \\
\text { não médicos } \\
\text { e estruturas } \\
\text { organizacionais }\end{array}$ \\
\hline
\end{tabular}

Fonte: elaboração própria com base em Salge, 2011, 2012.

\section{A Inovação nos Serviços de Saúde: difusão das inovações}

As pesquisas sobre a difusão das inovações nos serviços de saúde evidenciam a importância dos contextos políticos, tecnológicos e ideológicos que envolvem a inovação e qualquer programa de disseminação, e em especial o valor social atribuído às inovações em diferentes sociedades. Há elevado grau de consenso sobre a importância da difusão das inovações à adequação de determinadas tecnologias e ideias para situações específicas em determinadas fases do desenvolvimento. Duas importantes conclusões derivadas dos estudos sobre a difusão de inovações são: 1) o significado de uma inovação para a agência que o apresenta pode ser muito diferente daquele assumido por aqueles que se pretende que a adotem, e 2) o sistema de inovação fit (relacionado à interação entre a inovação e o seu contexto potencial) pode se tornar uma construção válida e útil tanto ou quanto os atributos de inovação (Bourdenave, 1976).

De acordo com Greenhalgh e colaboradores (2004), das tradições relevantes para a difusão das inovações, quatro se referem às primeiras investigações significativas sobre a sua disseminação: 
1) Sociologia rural. Everett Rogers, em 1995, elaborou pioneiramente o conceito de difusão de inovações. Inovações foram definidas como ideias ou práticas percebidas como novas por profissionais (neste caso, agricultores). Difusão foi concebida como a disseminação de ideias entre os indivíduos, em grande parte, por imitação. As intervenções destinadas à difusão da inovação são atreladas à influência interpessoal dos líderes de opinião e agentes de mudança.

2) Sociologia médica. Conceitos e explicações teóricas similares aos da sociologia rural foram aplicados ao comportamento clínico dos médicos (principalmente no estudo realizado em 1966 por Coleman, Katz e Menzel sobre a propagação da prescrição de antibióticos recémintroduzidos); os primeiros estudos em sociologia médica definiram as bases para a rede de análise e estudo sistemático de "quem conhece quem" e "quem copia quem" e levaram à constatação de que indivíduos mais conectados a redes sociais têm grau de escolaridade mais elevado, status social superior e são adotantes precoces de inovações.

3) Estudos de comunicação. Inovações foram conceituadas como novas informações (muitas vezes como notícia) e disseminação foi concebida como a transmissão dessas informações por quaisquer meios de comunicação, inclusive a interpessoal; os estudos sobre difusão enfocaram medidas de velocidade e direção da transmissão da mensagem e estudaram possíveis impactos na alteração de variáveis, tais como o modelo de mensagem, o canal de comunicação (falada, escrita etc.) e a natureza da exposição.

4) Marketing. Inovações foram conceituadas como produtos ou serviços e a decisão de adoção encarada como uma análise racional (dos custos e benefícios); as pesquisas sobre difusão mensuraram o sucesso dos esforços para aumentar os benefícios ou reduzir os custos percebidos de uma inovação aos olhos de potenciais adotantes; importantes investigações nesta área desenvolveram modelos matemáticos para prever o comportamento da adoção de inovações.

As críticas às insuficiências e inconsistências dos primeiros estudos sobre difusão da inovação suscitaram o surgimento de outras áreas de reflexão sobre o tema, tais como:

1) Estudos sobre desenvolvimento. A difusão das inovações é explicitamente atribuída e ampliada ao contexto político, tecnológico e ideológico; qualquer programa de disseminação tem significado diferenciado, como inovações e valor social em diferentes sociedades; a difusão das inovações é tida como elemento central para a adequação de determinadas tecnologias e ideias para situações específicas em determinadas fases do desenvolvimento. Dois importantes princípios desta vertente são: a) o significado de uma inovação para a instituição/agência que a apresenta pode ser muito diferente daquela realizada pelos adotantes e b) o sistema de inovação fit é geralmente uma construção tão válida e útil quanto os atributos de inovação (muitas vezes, erroneamente assumidos como propriedades imutáveis da inovação em qualquer contexto) (Bourdenave, 1976).

2) Promoção da saúde. As inovações são definidas como boas ideias para estimular comportamentos saudáveis e estilos de vida, e a disseminação dessas inovações se expressa como o alcance e a absorção de programas de promoção da saúde em grupos-alvo definidos; as pesquisas sobre a promoção da saúde utilizam o marketing social, tomando a teoria de marketing como base conceitual. Mais recentemente, uma agenda mais radical baseada no enfoque de desenvolvimento surgiu na promoção da saúde, mantendo conexões com estudos de desenvolvimento, nos quais a transmissão unidirecional para o grupo-alvo foi 
substituída por vários modelos de parceria e de desenvolvimento comunitário (Potvin, Haddad \& Frohlich, 2001).

3) Medicina baseada em evidências. As inovações foram definidas como tecnologias e práticas de saúde sustentadas por evidências de pesquisa; a difusão da inovação, nesta vertente, é considerada um processo linear e técnico que ocorre no nível do indivíduo e, portanto, tem sido descrita com base na observação de mudanças no comportamento dos médicos, de acordo com diretrizes baseadas em evidências. Posteriormente, muitos pesquisadores da medicina baseada em evidências (talvez um pouco tardiamente) reconheceram que a implementação da maioria das diretrizes clínicas exige mudanças no sistema e, portanto, no nível organizacional (Grimshaw et al., 2004). Um desenvolvimento conceitual mais recente é a noção de que a base de evidências para determinadas tecnologias e práticas muitas vezes é ambígua e contestável e deve ser continuamente interpretada e reformulada de acordo com o contexto e as prioridades locais, um processo que muitas vezes envolve lutas de poder entre vários grupos profissionais (Ferlie et al., 2001).

\section{A Inovação nos Serviços de Saúde no Brasil}

A saúde revela-se um campo de alta intensidade de conhecimento e inovação, o qual incorpora e, principalmente, desenvolve tecnologias estratégicas que têm um impacto interdependente tanto no próprio Sistema Produtivo da Saúde quanto na dinamização do tecido econômico-produtivo. Apenas para citar alguns exemplos que estão longe de englobar as frentes sistêmicas existentes nas áreas de fronteira, podem-se destacar os seguintes que provocam alto impacto nos processos de transformação em curso e que articulam diversas áreas do Sistema de Inovação em Saúde: novas tecnologias médicas de alta complexidade que mobilizam todo o sistema de inovação (transplante, por exemplo); novas biotecnologias de fronteira; terapia celular na qual se desenha a fronteira entre os serviços assistenciais e a biotecnologia industrial; química orgânica avançada (química fina); tecnologia diagnóstica envolvendo plataformas tecnológicas para testes de diagnóstico de grande escala, com alta facilidade e precisão. Observa-se intenso aumento do esforço de P\&D em saúde no mundo, que cresce bem acima do gasto global com essas atividades e que talvez possa ser comparado apenas ao complexo de defesa. (Cassiolato et al., 2010: 4)

Por sua vez, o complexo industrial da saúde está inserido em determinado complexo político e institucional, condicionando e sendo condicionado pela dinâmica evolutiva do setor (Gadelha, Quental \& Fialho, 2003). Este último conta com quatro "forças" que influenciam o complexo industrial da saúde: instituições de ciência e tecnologia (C\&T); sociedade civil; população; Estado. Ao Estado compete atuar na mediação entre a oferta e a demanda de bens e serviços de saúde e responder aos desafios de conjugar a melhoria das condições de saúde com o desenvolvimento industrial e tecnológico na área (Gadelha, Quental \& Fialho, 2003). O Estado cumpre, portanto, papel fundamental na dinâmica do setor Saúde, mediante a realização de um conjunto amplo de atividades regulatórias que delimitam as estratégias dos agentes econômicos. Nesse contexto, o setor emerge como lócus fundamental para a geração e difusão da inovação no país e a saúde é concebida como integrante do sistema nacional de inovação e voltada para criar e estimular um padrão de desenvolvimento que aproxima a inovação do bem-estar. 
O aumento da expectativa de vida e a mudança nos padrões demográficos e epidemiológicos, a alteração no perfil de demanda em decorrência do aumento da prevalência das doenças crônicodegenerativas, a persistência e reemergência de determinadas doenças infecciosas e parasitárias e os altos índices de violência projetados ao longo de um vasto e heterogêneo território são desafios a que ainda não se respondeu adequadamente. Verifica-se clara inconsistência entre o gasto público em saúde, sua distribuição no Brasil e a conformação de um sistema universal, o que implica a necessidade simultânea tanto de aumento do financiamento público para os serviços quanto de fortalecimento da base produtiva nacional.

Em termos do CEIS [complexo econômico-industrial da saúde], como um todo, os elementos mais importantes que merecem ser destacados referem-se à crescente interação sistêmica no processo de inovação entre os segmentos produtivos. O esforço de tratamento e prevenção para um grupo de doença específico que tenha alta relevância - como câncer, por exemplo - mobiliza, a um só tempo, a busca de novos medicamentos, de prevenção com vacinas quando se evidencia sua relação com agentes infecciosos, a utilização de novos equipamentos eletrônicos para o tratamento e diagnóstico e a introdução de novas práticas assistenciais, em um processo de inovação que envolve, de forma interativa, os serviços médicos, diversos segmentos industriais e academia. (Cassiolato et al., 2010: 16)

As atividades que têm alto impacto nos processos de transformação, e articulam as diversas áreas do sistema de inovação e do CEIS são: 1) novas tecnologias médicas de alta complexidade, que mobilizam todo sistema de inovação (transplante, por exemplo); 2) novas biotecnologias de fronteira; 3) terapia celular, em que se desenha a fronteira entre serviços assistenciais e biotecnologia industrial; 4) química orgânica avançada; 5) tecnologia diagnóstica envolvendo plataformas tecnológicas para testes de diagnóstico de grande escala, com alta facilidade e precisão; 6) utilização intensiva de tecnologia da informação (TI) tanto nos serviços quanto nos equipamentos para diagnóstico e tratamento; 7) nanotecnologia (Cassiolato et al., 2010).

A despeito de seus segmentos produtivos serem relativamente estáveis, uma vez que a mudança tecnológica tende a ocorrer sem alteração profunda nos padrões competitivos vigentes, em termos internacionais o CEIS está passando por um processo de profundas transformações, entre as quais cabe destacar a busca por novas fontes de inovação diante do esgotamento das trajetórias em algumas áreas fundamentais (como ade medicamentos), a organização global das cadeias produtivas e das bases de P\&D, o enfrentamento e a arbitragem diante das condições políticas e sistêmicas de competitividade nacionais e locais, entre outros movimentos (Gadelha et al., 2012). O sistema produtivo da saúde torna-se um espaço competitivo mais orgânico, revelando a interdependência entre os distintos segmentos produtivos que convergem para o mesmo ambiente institucional e regulatório.

O Brasil, apesar de constituir um mercado mundial importante em todos os segmentos do CEIS, está em face do risco de ampliar o hiato em relação à fronteira tecnológica mundial, uma vez que a estrutura produtiva brasileira ainda se mostra bastante frágil, inclusive em termos de gestão corporativa, para enfrentar uma concorrência global mais acirrada e com atores de grande peso, atualmente também voltados para os mercados emergentes. Adicionalmente, os compromissos empresariais com atividades de P\&D envolvem baixa intensidade de conhecimento. A incorporação de inovações tecno- 
lógicas na saúde ocorre nas fases finais de lançamento de novos produtos e serviços, confundindo-se muitas vezes com as atividades de marketing, ou visando à superação das barreiras de regulação sanitária, ou adequação a estas (Cassiolato et al., 2010).

Os serviços são uma importante força motriz para a interação e a existência de uma dinâmica interdependente, constituindo-se simultaneamente como a atividade econômica que confere o caráter sistêmico à base produtiva e como a face mais visível do sistema de saúde. Os serviços de saúde constituem segmento de maior peso econômico do sistema e, portanto, com capacidade intrínseca tanto de gerar renda e emprego quanto de constituir o mercado final dos outros segmentos do complexo produtivo da saúde, além de ter uma participação decisiva - se bem que ainda pouco trabalhada - na dinâmica sistêmica de inovação (Costa et al., 2012).

A análise dos serviços de saúde no âmbito internacional evidencia a existência de um mercado com condicionantes específicos. A integração dos serviços e a competição em termos globais são distintas daquela que caracteriza a indústria de fármacos e medicamentos e de equipamentos médico-hospitalares, apesar das tendências recentes de ampliação dos investimentos internacionais nos hospitais e nas unidades de diagnóstico e terapia no país (Bahia, 2013).

As importantes mudanças nas características dos serviços de saúde que acompanham as transformações no conhecimento, nos saberes, não deslocaram por completo a centralidade dos hospitais nem no que se refere à concentração de profissionais e tecnologias mais especializados nem em sua importância financeira. As tabelas 1 e 2 sugerem uma estabilidade dos gastos com hospitais nos sistemas de saúde de países afluentes entre 2003 e 2013.

Tabela 1 - Gastos correntes com hospitais e gastos totais com saúde. Países selecionados - 2003 e 2013 (em US\$ milhões)

\begin{tabular}{lcccccc}
\hline \multirow{2}{*}{ Países } & \multicolumn{2}{c}{ Gastos com hospitais } & \multicolumn{2}{c}{ Gastos totais } & \multicolumn{2}{c}{$\%$} \\
& \multicolumn{1}{c}{2003} & 2013 & 2003 & 2013 & 2003 & 2013 \\
\cline { 2 - 7 } Canadá & $27.495,2$ & $48.682,9$ & $92.194,2$ & $158.296,2$ & 29,8 & 30,8 \\
França & $63.360,9$ & $112.007,9$ & $175.586,4$ & $282.188,0$ & 36,1 & 39,7 \\
Alemanha & $72.816,3$ & $117.191,0$ & $250.334,0$ & $396.922,7$ & 29,1 & 29,5 \\
Japão & $135.787,0$ & $218.334,6$ & $280.614,1$ & $528.508,7$ & 48,4 & 41,3 \\
EUA & $525.906,0$ & $933.916,0$ & $1.664 .482,9$ & $2.727 .394,9$ & 31,6 & 34,2 \\
\hline
\end{tabular}

Fonte: OECD. Stat, 2015, elaboração própria. Disponível em: <https://stats.oecd.org/Index. aspx? DataSetCode $=$ SHA $>$.

No Brasil, dados de aproximação das despesas com internações podem ser apreendidos em duas fontes: as internações remuneradas pelo SUS e aquelas remuneradas pelos planos de saúde. As informações contidas na Tabela 2, que representam apenas uma parte dos gastos com internação (os valores repassados pelo SUS, especialmente para o custeio corrente), mostram uma tendência de queda nas taxas de internação realizadas na rede SUS e pequena variação na proporção dos gastos com internações em relação às despesas públicas totais com saúde. 
Tabela 2 - Número de internações SUS, população, valor pago e despesas totais com saúde. Brasil - 2000-2011

\begin{tabular}{|l|c|c|c|c|c|c|}
\hline Ano & $\begin{array}{c}\text { n. de } \\
\text { nternações } \\
\text { SUS (a) }\end{array}$ & $\begin{array}{c}\text { População } \\
\text { brasileira (b) }\end{array}$ & $\begin{array}{c}\text { Taxa de } \\
\text { internação } \\
\text { em \% (a/b) }\end{array}$ & $\begin{array}{c}\text { Valor total das } \\
\text { internações } \\
\text { SUS (c) }\end{array}$ & $\begin{array}{c}\text { Despesas totais } \\
\text { com saúde* (d) }\end{array}$ & $\begin{array}{c}\text { Despesas com } \\
\text { internação em } \\
\text { \% (c/d) }\end{array}$ \\
\hline 2000 & 11.937 .323 & 171.279 .882 & 6,97 & 4.886 .848 .236 & 69.090 .000 .000 & 7,07 \\
\hline 2001 & 11.756 .354 & 173.808 .010 & 6,76 & 5.096 .155 .505 & 76.070 .000 .000 & 6,7 \\
\hline 2002 & 11.713 .749 & 176.303 .919 & 6,64 & 5.406 .391 .841 & 82.070 .000 .000 & 6,59 \\
\hline 2003 & 11.638 .194 & 178.741 .412 & 6,51 & 5.861 .712 .487 & 81.200 .000 .000 & 7,22 \\
\hline 2004 & 11.492 .883 & 181.105 .601 & 6,35 & 6.581 .213 .334 & 93.330 .000 .000 & 7,05 \\
\hline 2005 & 11.429 .133 & 183.383 .216 & 6,23 & 6.956 .764 .584 & 100.100 .000 .000 & 6,95 \\
\hline 2006 & 11.338 .039 & 185.564 .212 & 6,11 & 6.998 .043 .548 & 108.280 .000 .000 & 6,46 \\
\hline 2007 & 11.330 .096 & 187.641 .714 & 6,04 & 7.617 .769 .442 & 115.840 .000 .000 & 6,58 \\
\hline 2009 & 10.743 .603 & 189.612 .814 & 5,67 & 8.286 .055 .941 & 129.230 .000 .000 & 6,41 \\
\hline 2011 & 11.128 .809 & 191.480 .630 & 5,81 & 10.124 .918 .629 & 142.380 .000 .000 & 7,11 \\
\hline & 11.357 .965 & 193.252 .604 & 5,88 & 10.740 .754 .368 & 149.900 .000 .000 & 7,17 \\
\hline
\end{tabular}

* Valores deflacionados pelo Índice Nacional de Preços ao Consumidor Amplo (IPCA).

Fonte: elaboração própria com base em Datasus, 2014a, 2014b; IBGE, 2014; Subsecretaria de Planejamento e Orçamento/Ministério da Saúde (esfera federal) e Sistema de Informações sobre Orçamento Público em Saúde (Siops), 2014.

No que se refere aos planos e seguros de saúde, observa-se uma taxa de internação muito mais elevada do que a registrada para o SUS, ainda que se descontem do denominador do cálculo das internações na rede os clientes de planos privados e uma participação muito expressiva dos hospitais nas despesas totais das empresas de planos e seguros (Tabela 3). Em 2012 as despesas com hospitais representaram 42\% do total dos gastos assistenciais das empresas de planos e seguros no Brasil (ANS, 2014).

Tabela 3 - Taxa de internação de planos e seguros de saúde. Brasil - 2007-2011

\begin{tabular}{|c|c|}
\hline Ano & Taxa de internação \\
\hline 2007 & 13,3 \\
\hline 2008 & 13,4 \\
\hline 2008 & 13,0 \\
\hline 2009 & 13,7 \\
\hline 2010 & 14,1 \\
\hline 2011 & 13,9 \\
\hline
\end{tabular}

Fonte: ANS, 2014. 
Na Tabela 4, os dados sobre a oferta de serviços para planos privados de saúde referentes a dois períodos, 2010 e 2013, evidenciam o aumento do uso dos estabelecimentos de saúde e do número de leitos por clientelas privadas.

Tabela 4 - Vinculação de recursos físicos selecionados a planos privados de saúde. Brasil - 2010 e 2013

\begin{tabular}{lrrrrrr} 
& \multicolumn{3}{c}{2010} & & \multicolumn{2}{c}{2013} \\
& \multicolumn{1}{c}{ Total } & Não SUS & \% não SUS & Total & Não SUS & \% não SUS \\
\cline { 2 - 7 } Leitos & 462.760 & 125.979 & 27,22 & 452.454 & 131.029 & 28,96 \\
Hospitais gerais & 5.198 & 1.358 & 26,13 & 5.188 & 1.651 & 31,82 \\
Hospitais especializados & 1.200 & 401 & 33,42 & 1.094 & 433 & 39,58 \\
Unidades de diagnóstico & 16.305 & 6.095 & 37,38 & 20.017 & 8.757 & 43,75 \\
e terapia & & & & & &
\end{tabular}

Fonte: elaboração própria com base em ANS, 2007, 2013.

Esses dados sugerem a tendência à redução do número de leitos em função dos avanços científicos e tecnológicos que permitem que parte dos procedimentos, atualmente realizados exclusivamente no interior do hospital, passem a sê-lo em regime ambulatorial, conjugados a uma redivisão dos recursos assistenciais destinados às clientelas dos planos privados de saúde que possivelmente acentua a racionalização da assistência hospitalar no SUS.

Segundo Cassiolato e colaboradores (2010), na maioria dos países desenvolvidos os sistemas de saúde ainda são fortemente centrados no hospital e no médico. Serviços nucleados por pessoal de enfermagem são destinados a idosos ou focados em situações crônicas de saúde, em que o cuidado não dependa da prática médica, sugerindo que não há uma ruptura com o paradigma assistencial dominante, mas sim um processo intenso de transformação das trajetórias tecnológicas e a diferenciação do rumo e dos ritmos de progresso.

A racionalização das internações no SUS e o estímulo a determinados procedimentos hospitalares de maior complexidade e custo geram e reproduzem demandas por tecnologias diferenciadas agregadas ao leito de determinadas especialidades/áreas do conhecimento. Esse processo contribui para estimular nichos assistencial-comerciais em hospitais privados/filantrópicos e para segmentar a rede hospitalar do SUS, instituindo uma polarização entre um conjunto mais dinâmico de hospitais, que incorporam tecnologias, alcançam outras novas ou estabilizam escalas de produção economicamente mais sustentáveis, e os demais estabelecimentos. Em 2006, segundo dados do Cadastro Nacional de Estabelecimentos de Saúde (CNES), 293 hospitais no país vinculados à rede SUS tinham 201 leitos ou mais, representando apenas $4 \%$ da rede pública (incluindo os privados e particulares conveniados) e 39\% do total, ou seja, 2.659 hospitais tinham até 30 leitos, com menor dinamismo e limitada incorporação tecnológica.

Os dados individualizados do CNES referente ao ano de 2013 e a recursos físicos (hospitais gerais) evidenciam que dos 5.206 hospitais gerais, apenas 253 (4,8\%) contam com 201 ou mais leitos. Além disso, 13 desses hospitais de maior porte são instituições penitenciárias, psiquiátricas ou filantrópicas 
que não têm nenhum leito de terapia intensiva (Tabela 5). Esses hospitais estão majoritariamente vinculados ao SUS, como mostra a Tabela 4, embora se observe ligeira redução dos recursos físicos para o SUS em relação aos leitos de terapia intensiva.

Tabela 5 - Hospitais gerais com mais de 200 leitos. Brasil - 2013

\begin{tabular}{lcc} 
& Mais de 200 leitos & \% SUS \\
\cline { 2 - 3 } Número de leitos & 82.020 & 76,84 \\
Número de leitos SUS & 63.026 & \\
Número de leitos terapia intensiva & 10.511 & 70,09 \\
Número de leitos terapia intensiva SUS & 7.367 & \\
Relação leito terapia intensiva/leito & $12,8 \%$ & \\
\hline
\end{tabular}

Fonte: elaboração própria com base em Datasus \& CNES, 2013.

A distribuição geográfica dos hospitais gerais de maior porte é relativamente homogênea, embora se observe uma pequena concentração do número de hospitais de maior porte em São Paulo e no Rio de Janeiro e em alguns outros estados da federação, assim como a falta de unidade hospitalar no estado do Amapá (Tabela 6). O mesmo não ocorre em relação aos leitos disponíveis para o SUS. As diferenças entre as taxas de leitos disponíveis para o SUS por 1.000 habitantes variam desde aproximadamente 2 no Rio Grande do Sul e Rondônia até 1,2 e 1,3 em Sergipe e no Amazonas, sendo que São Paulo, que concentra o maior número de hospitais de maior porte, apresenta uma taxa menor do que a de várias unidades da federação, 1,4 (Tabela 7).

Tabela 6 - Distribuição dos hospitais gerais com mais de 200 leitos por unidade da federação. Brasil - 2013

\begin{tabular}{|l|c|c|c|c|}
\hline \multicolumn{1}{|c|}{ UF } & População* & & \multicolumn{2}{|c|}{$\begin{array}{c}\text { Hospitais } \\
\text { com mais de } \\
200 \text { leitos }\end{array}$} \\
\hline Rondônia & 1.590 .011 & 0,82 & 1 & 0,40 \\
\hline Acre & 758.786 & 0,39 & 1 & 0,40 \\
\hline Amazonas & 3.590 .985 & 1,85 & 1 & 0,40 \\
\hline Roraima & 469.524 & 0,24 & 1 & 0,40 \\
\hline Pará & 7.822 .205 & 4,03 & 5 & 1,98 \\
\hline Amapá & 698.602 & 0,36 & - & 0,00 \\
\hline Tocantins & 1.417 .694 & 0,73 & 2 & 0,79 \\
\hline Maranhão & 6.714 .314 & 3,46 & 5 & 1,98 \\
\hline Piauí & 3.160 .748 & 1,63 & 2 & 0,79 \\
\hline Ceará & 8.606 .005 & 4,44 & 10 & 3,95 \\
\hline Rio Grande do Norte & 3.228 .198 & 1,66 & 2 & 0,79 \\
\hline
\end{tabular}


Tabela 6 - Distribuição dos hospitais gerais com mais de 200 leitos por unidade da federação. Brasil - 2013 (cont.)

\begin{tabular}{|c|c|c|c|c|}
\hline UF & População* & $\%$ & $\begin{array}{l}\text { Hospitais } \\
\text { com mais de } \\
200 \text { leitos }\end{array}$ & $\%$ \\
\hline Paraíba & 3.815 .171 & 1,97 & 3 & 1,19 \\
\hline Pernambuco & 8.931 .028 & 4,60 & 9 & 3,56 \\
\hline Alagoas & 3.165 .472 & 1,63 & 4 & 1,58 \\
\hline Sergipe & 2.110 .867 & 1,09 & 2 & 0,79 \\
\hline Bahia & 14.175 .341 & 7,31 & 13 & 5,14 \\
\hline Minas Gerais & 19.855 .332 & 10,24 & 24 & 9,49 \\
\hline Espírito Santo & 3.578 .067 & 1,84 & 3 & 1,19 \\
\hline Rio de Janeiro & 1.6231 .365 & 8,37 & 30 & 11,86 \\
\hline São Paulo & 41.901 .219 & 21,60 & 76 & 30,04 \\
\hline Paraná & 10.577 .755 & 5,45 & 11 & 4,35 \\
\hline Santa Catarina & 6.383 .286 & 3,29 & 7 & 2,77 \\
\hline Rio Grande do Sul & 10.770 .603 & 5,55 & 25 & 9,88 \\
\hline Mato Grosso do Sul & 2.505 .088 & 1,29 & 1 & 0,40 \\
\hline Mato Grosso & 3.115 .336 & 1,61 & 4 & 1,58 \\
\hline Goiás & 6.154 .996 & 3,17 & 3 & 1,19 \\
\hline Distrito Federal & 2.648 .532 & 1,37 & 8 & 3,16 \\
\hline Total & 193.976 .530 & 100,00 & 253 & 100,00 \\
\hline
\end{tabular}

* População em 2012.

Fonte: elaboração própria com base em Datasus \& CNES, 2013 e Datasus, 2014a, 2014b. 
Tabela 7 - Número de leitos disponíveis para o SUS por UF. Brasil - 2014

\begin{tabular}{|c|c|c|c|}
\hline UF & Leitos SUS & População* & Leitos/1.000 hab. \\
\hline Rondônia & 3.257 & 1.590 .011 & 2,05 \\
\hline Acre & 1.198 & 758.786 & 1,58 \\
\hline Amazonas & 4.700 & 3.590 .985 & 1,31 \\
\hline Roraima & 777 & 469.524 & 1,65 \\
\hline Pará & 11.102 & 7.822 .205 & 1,42 \\
\hline Amapá & 979 & 698.602 & 1,40 \\
\hline Tocantins & 2.137 & 1.417 .694 & 1,51 \\
\hline Maranhão & 12.265 & 6.714 .314 & 1,83 \\
\hline Piauí & 6.957 & 3.160 .748 & 2,20 \\
\hline Ceará & 14.607 & 8.606 .005 & 1,70 \\
\hline Rio Grande do Norte & 6.344 & 3.228 .198 & 1,97 \\
\hline Paraíba & 7.733 & 3.815 .171 & 2,03 \\
\hline Pernambuco & 17.435 & 8.931 .028 & 1,95 \\
\hline Alagoas & 5.179 & 3.165 .472 & 1,64 \\
\hline Sergipe & 2.529 & 2.110 .867 & 1,20 \\
\hline Bahia & 24.940 & 14.175.341 & 1,76 \\
\hline Minas Gerais & 29.950 & 19.855 .332 & 1,51 \\
\hline Espírito Santo & 6.009 & 3.578 .067 & 1,68 \\
\hline Rio de Janeiro & 26.643 & 16.231 .365 & 1,64 \\
\hline São Paulo & 59.272 & 41.901 .219 & 1,41 \\
\hline Paraná & 20.058 & 10.577 .755 & 1,90 \\
\hline Santa Catarina & 11.120 & 6.383 .286 & 1,74 \\
\hline Rio Grande do Sul & 21.811 & 10.770 .603 & 2,03 \\
\hline Mato Grosso do Sul & 3.772 & 2.505 .088 & 1,51 \\
\hline Mato Grosso & 5.093 & 3.115 .336 & 1,63 \\
\hline Goiás & 11.378 & 6.154 .996 & 1,85 \\
\hline Distrito Federal & 4.478 & 2.648 .532 & 1,69 \\
\hline Total & 321.723 & 193.976 .530 & 1,66 \\
\hline
\end{tabular}

* População em 2012.

Fonte: elaboração própria com base em Datasus \& CNES, 2013 e Datasus, 2014a. 
Essa polarização - especializações e tecnologias em um número pequeno de estabelecimentos e disponibilidade de recursos físicos (leitos e leitos de terapia intensiva) para o SUS (plausivelmente um traçador da importância do SUS para o financiamento de hospitais de maior porte) - ocorre em um contexto de crescimento do uso da maior parte da oferta de recursos hospitalares existentes pelos planos privados de saúde, como pode ser observado no Gráfico 1, e sugere uma divisão complexa da rede física de recursos para internação. Observa-se a concentração de recursos assistenciais de uso comum e a expansão, sem incremento da base física (por disponibilidade de recursos antes usados pela rede SUS), da oferta de leitos menos especializados para a clientela dos planos e seguros de saúde.

Gráfico 1 - Estabelecimentos de internação segundo tipo de pagador das internações. Brasil - 2006 a 2014 (março)

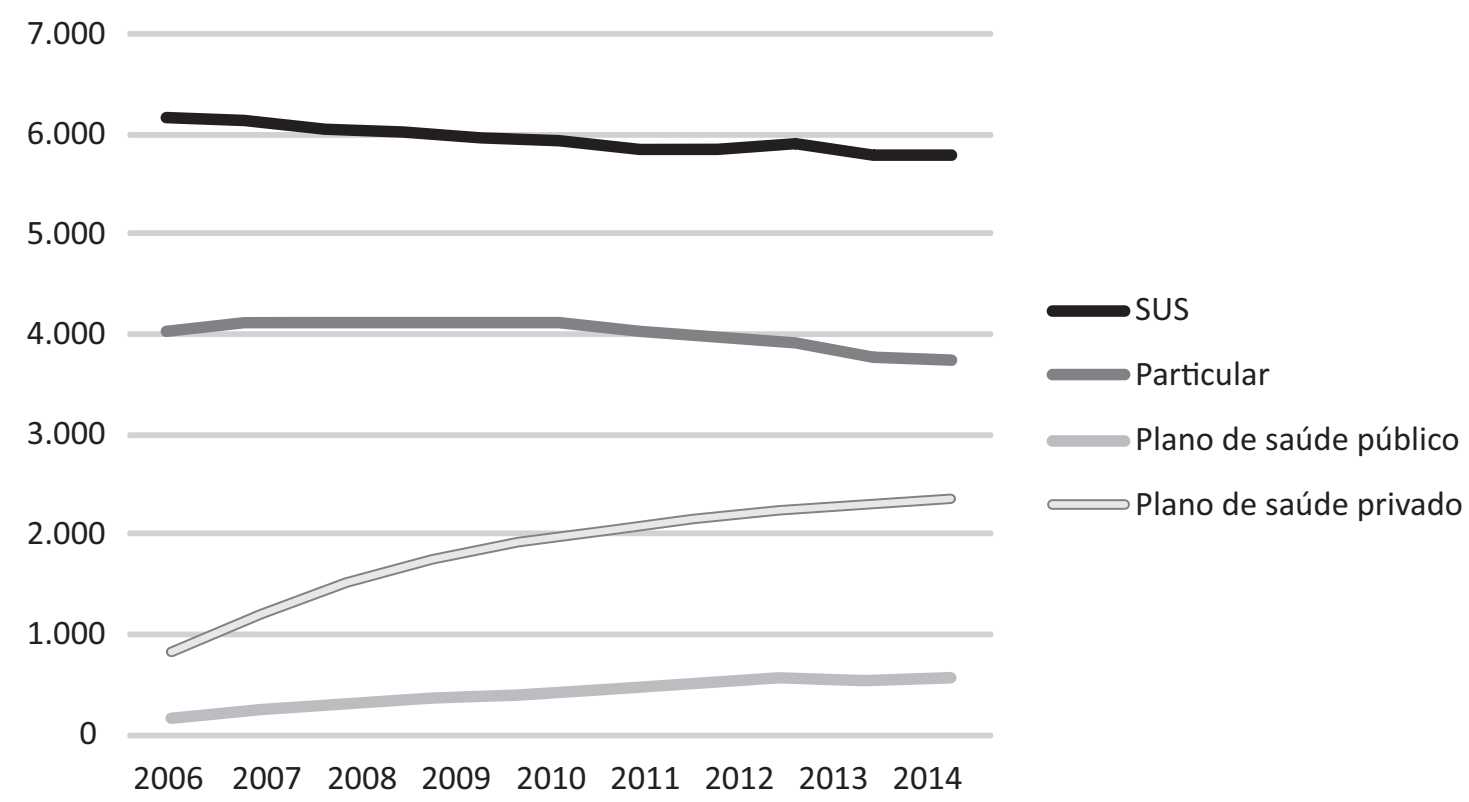

Fonte: ANS, 2014.

A tendência à concentração e especialização de recursos assistenciais também parece ocorrer no âmbito dos hospitais autoqualificados como de excelência vinculados à Associação Nacional de Hospitais Privados (Anaph). Dos 46 hospitais registrados em dezembro de 2013, apenas 26 tinham mais de 200 leitos, embora todos contassem com leitos de terapia intensiva. As tabelas 8 e 9 sugerem a existência no Brasil do fenômeno denominado nos EUA de "hospitais de alto e baixo preço", ainda que no interior de um estrato pretensamente homogêneo. Os dados confirmam os estudos internacionais sobre o porte dos hospitais e a capacidade de atrair recursos inclusive para inovação (White, Reschovsky \& Bond, 2014), e no caso brasileiro são fortemente sugestivos sobre a associação positiva entre a natureza filantrópica do estabelecimento e as receitas arrecadadas. 
Tabela 8 - Características dos hospitais vinculados à Associação Nacional de Hospitais Privados. Brasil - 2013

\begin{tabular}{lr}
\hline Número de hospitais & 46 \\
Número de leitos & 10.703 \\
Número de leitos de terapia intensiva & 2.433 \\
Relação leito terapia intensiva/leito & $23 \%$ \\
Faturamento em R\$ bilhões* & 8,5 \\
\hline * Referente a 34 hospitais que informaram o valor
\end{tabular}

* Referente a 34 hospitais que informaram o valor.

Fonte: elaboração própria com base em Anaph, 2013.

Tabela 9 - Faturamento por porte e natureza jurídico-institucional dos hospitais vinculados à Associação Nacional dos Hospitais Privados. Brasil - 2013

\begin{tabular}{|l|c|c|c|}
\hline & Número de hospitais & Número médio de leitos & $\begin{array}{c}\text { Faturamento } \\
\text { (em R\$ bilhões) }\end{array}$ \\
\hline Filantrópicos & 24 & 275 & 7,4 \\
\hline Com fins lucrativos & 11 & 144 & 1,1 \\
\hline
\end{tabular}

Fonte: elaboração própria com base em Anaph, 2013.

Esse padrão de polarização nas áreas pública e privada representa um desafio para o estudo e formulação de políticas sobre inovação e difusão de tecnologias nos serviços de saúde, uma vez que os circuitos dos processos de decisão relacionados com a inovação encontram-se, possivelmente, confinados a espaços e lógicas assistenciais não necessariamente voltados para mudanças na base produtiva e para a ampliação do acesso a serviços de saúde e do seu uso. Esse quadro torna-se ainda mais complexo em função dos processos de aquisição, fusões e financeirização e verticalização em empresas de planos e seguros de saúde em curso, ainda pouco estudados (Lima, 2014; Bahia, 2013).

Os estudos sobre inovação em serviços de saúde no Brasil ainda são escassos e não existem investigações ou esforços de mapeamento dos processos de criação ou incorporação de tecnologias no âmbito da rede assistencial. Dois elementos comuns à observação de analistas brasileiros são o protagonismo dos hospitais e as perspectivas do envolvimento dos setores baseados fortemente na ciência, o que pode ser exemplificado pela grande interação entre hospitais, indústria, universidade e Estado. O protagonismo dos hospitais na geração de inovação na saúde permite alterar a realidade da atenção hospitalar e do sistema assistencial como um todo em razão de seu impacto nas mudanças tanto nos próprios hospitais, tais como redução de leitos instalados, quanto nas práticas de atenção ambulatorial e disciplinar.

A inovação nos serviços hospitalares pode ser sistematizada em quatro grupos. No primeiro o hospital é considerado como uma empresa e, por conseguinte, visto com base na lógica de otimização do processo produtivo com uma expectativa de maior homogeneização vis-à-vis uma apropriada definição de tarifas. No segundo o hospital é visto como uma plataforma técnica e biofarmacológica, de forma que a evolução do sistema de saúde depende da biotecnologia e outras tecnologias. No terceiro os processos de inovação que ocorrem no hospital são vistos como causados pela introdução 
de novas tecnologias de informação e comunicação no seu interior. No quarto, a análise da inovação parte da consideração dos serviços e de suas relações no tratamento, separando as inovações tecnológicas (biotecnologia) das que ocorrem nos serviços (novos modelos e formatos de prestação de serviços) e das organizacionais (reorganizações administrativas, avaliação de qualidade do cuidado, desenvolvimento de protocolos), sociais e culturais. Para este, portanto, um modelo de análise dinâmica deve considerar essa complexidade de fatores (Barbosa \& Gadelha, 2012).

Para responder a desafios específicos do SUS é necessária a articulação sistêmica, e para isso as inovações são essenciais. Como observam Costa e colaboradores (2012), o uso de tecnologias como os diagnósticos remotos e a assistência domiciliar tem potencial para promover a diminuição relativa dos custos de prestação dos serviços, facilitar a integração dos diferentes níveis de atenção de um sistema de saúde e permitir o acompanhamento por meio de prontuários clínicos e atividades de atenção à saúde, mesmo que o profissional não se encontre na mesma localidade que o seu paciente. A incorporação de novas tecnologias também exerce impacto sobre a intensidade do uso dos leitos hospitalares, pois novos equipamentos, medicamentos e procedimentos qualificam e tornam mais resolutiva a atenção básica, o que reduz o tempo de internação e os riscos decorrentes. A integração da rede de atenção pode vir a se dar com o suporte da introdução de novas tecnologias, o que permitirá novas variações no formato da prestação de cuidados. O atendimento em casa e a incorporação de tecnologias que reduzem o tempo de internação hospitalar permitiriam que surgissem novos pontos de acesso e de interação qualificada entre o sistema e o paciente, especialmente nas regiões mais remotas.

Vecina e Malik (2007) ponderam sobre o potencial do estabelecimento de relações entre todos os agentes envolvidos na produção de bens e serviços de saúde, tal como tem ocorrido com a indústria farmacêutica para o desenvolvimento de protocolos assistenciais voltados para diagnósticos prioritários e em relação à indústria de equipamentos para desenvolver softwares adequados a seus utilizadores potenciais. Para os autores, ainda "faz falta, a percepção de que todos os envolvidos têm interesses comuns, integram a mesma cadeia de valor" (Vecina \& Malik, 2007: 835). Os comportamentos de comprador/fornecedor em que a vantagem de um é a perda do outro devem ser compreendidos e transformados em relações pautadas pelas necessidades de saúde e sustentabilidade do sistema de saúde. O fato de os hospitais do setor privado comercializarem medicamentos e materiais médicohospitalares, tornando-os mais um ponto de venda entre a produção e o uso pelo paciente, é um desafio incontornável.

\section{Inovação em Hospitais Brasileiros: a percepção de diretores de instituições selecionadas}

Responsáveis pelos processos decisórios de hospitais brasileiros envolvidos com atividades de pesquisa e ensino, os diretores consultados para fins de subsidiar uma reflexão sobre lacunas, desafios e perspectivas sobre inovação nos serviços de saúde traçaram um panorama bastante realista da situação atual dos esforços inovativos em suas instituições. As três instituições procuradas - dois hospitais especializados públicos (Hospital de Cardiologia de Laranjeiras, localizado no Rio de 
Janeiro, e Instituto Estadual do Câncer, em São Paulo) e um hospital geral filantrópico (Sírio Libanês, localizado em São Paulo) - desenvolvem atividades de ensino e pesquisa e mantêm projetos permanentes de pesquisa.

Os diretores desses estabelecimentos têm plena consciência da relevância dos processos inovativos e comungam a percepção de que suas instituições estão na fronteira do conhecimento de suas respectivas áreas de atuação. Os que atuam nas instituições públicas declararam conhecer de modo extenso e aprofundado as relações estabelecidas entre os distribuidores de material médico-hospitalar e o corpo clínico das instituições, bem como revelaram que o modus operandi para a incorporação de tecnologias é ainda dinamizado por demandas individuais de médicos que frequentam congressos e feiras hospitalares. O preconceito contra o produto nacional e as críticas à sua qualidade foram mencionados pelos três dirigentes. O diretor do hospital filantrópico, talvez por seu perfil profissional específico, mostrou maior conhecimento e formulou críticas, especialmente à Comissão Nacional de Ética em Pesquisa (Conep), sobre a dinâmica de aprovação de pesquisas clínicas. As três instituições estão planejando ou concluindo etapas de expansão de capacidade física instalada e de suas atividades de ensino e pesquisa no Brasil e na expectativa de atuação internacional. Como principal lacuna, a instituição pública não vinculada à universidade indicou a dificuldade de fixação de pesquisadores (sem carreira específica) e o hospital vinculado à Universidade de São Paulo as dificuldades burocráticas para conciliar a pesquisa com as regras da administração direta da Secretaria Estadual de Saúde (ver Apêndice).

Esse diálogo inicial e incipiente sinaliza que os estudos internacionais sobre inovação em serviços de saúde podem inspirar iniciativas para um mapeamento sistemático das inovações no Brasil considerando que as instituições abordadas de modo exploratório têm lideranças com aspirações estratégicas e dispõem de relativa abundância de recursos. Estas são características análogas às dos casos mencionados do Instituto do Câncer de São Paulo - no que se refere à necessária suplementação de valores da tabela SUS - e do Hospital Sírio Libanês - no tocante ao retorno em desempenho, seja financeiro, seja em termos de prestígio profissional. O diálogo com lideranças de instituições de serviços de saúde que desenvolvem atividades de ensino e pesquisa sugere que os hospitais públicos especializados que dependem de um fluxo contínuo de novos produtos, serviços e processos para atender às suas aspirações estratégicas estão mais bem posicionados para sustentar as atividades de busca baseadas em ciência do que os hospitais gerais. Mas essa afirmação não pode ser estendida aos hospitais privados.

\section{Lacunas no Conhecimento e na Formulação e Implementação de Políticas sobre Inovação nos Serviços de Saúde}

O Estado promoveu iniciativas para lidar com os empecilhos à inovação por meio de marco regulatório (Lei do Bem, Lei da Inovação, lei 12.349/2010, lei 12.401/2011, entre outras), do crescente apoio à inovação por parte dos produtores públicos e rede de laboratórios oficiais, do aumento substancial do orçamento e do estabelecimento de parcerias público-privadas para a transferência de tecnologia, entre outras. Essa agenda é essencial para a superação do descompasso 
entre a política de inovação e os interesses coletivos da saúde, e para desenvolvê-la é preciso estabelecer pautas de trabalho conjunto no qual se procure auscultar os agentes envolvidos na geração e incorporação de inovação, com o objetivo de diminuir as assimetrias de poder político e econômico dos atores do setor.

No que se refere à inovação de serviços de saúde, identificam-se seis tipos de lacuna: 1) número de serviços com atividades rotinizadas de pesquisa, ensino, C\&T e inovação reduzido, concentrado na região Sudeste e em hospitais especializados públicos e em alguns filantrópicos; 2) produção incipiente de conhecimentos sobre padrões e singularidades das inovações de serviços no Brasil; 3) processos decisórios sobre incorporação tecnológica fragmentados e desconectados dos esforços nacionais de aumento de fortalecimento da base produtiva nacional e do poder de compra do Estado; 4) inexistência de canais de conexão sistemática entre os serviços de saúde, os produtores e distribuidores de medicamentos, médicos e os órgãos governamentais responsáveis pelo registro, pela permissão e pela avaliação de tecnologias; 5) baixos padrões de remuneração dos serviços realizados especialmente nos hospitais privados induzindo à venda de medicamentos e materiais médico-hospitalares pelos hospitais; 6) informações incipientes de agentes decisórios de serviços de saúde sobre as políticas de saúde de C\&T. Além das inovações relacionadas com produtos, é essencial mapear as inovações decorrentes das práticas e aquelas diretamente conectadas com mudanças organizacionais. Daí a necessidade de identificar práticas inovadoras no âmbito da atenção primária à saúde e estimular e monitorar as tendências de automação, tanto em equipamentos biomédicos quanto em serviços, e destacar possibilidades reais e já regulamentadas legalmente para todo o manuseio de documentações médicas.

\section{Recomendações}

A reflexão e a formulação de políticas sobre inovações em serviços de saúde necessariamente terão que manter uma articulação permanente em função das tensões ideológicas e políticas que envolvem o tema e do alto grau de fragmentação e polarização tecnológica dos serviços de saúde no Brasil. Um caminho virtuoso em direção a tal articulação implica a busca de mobilização; a participação dos envolvidos; a atuação dos órgãos governamentais na criação, adequação e difusão das tecnologias, inclusive nos fóruns e no estabelecimento conjunto de regras para os mercados de distribuição e revenda de produtos que promovam a participação de todos agentes nos debates sobre as políticas de saúde. É também importante avançar na elaboração de estudos de mapeamento de inovações em serviços de saúde, conforme proposta a seguir:

1) Realizar um estudo linha de base (multinível, considerando as organizações e os profissionais da saúde e ainda as tecnologias baseadas na ciência e aquelas baseadas nas práticas) sobre inovação de serviços hospitalares, de diagnóstico e terapia e de atenção primária no Brasil, com a participação, em todas as etapas, dos agentes do setor.

2) Mapear indústrias e atividades de bem-estar, tais como academias da cidade e inovações arquitetônicas domésticas e telehealth.

3) Mapear a incorporação de tecnologias de registro eletrônico de informações assistenciais. 
4) Realizar reuniões das instituições que integram a rede de pesquisas clínicas para estabelecer uma agenda de apoio ao trabalho desenvolvido mediante identificação de nós críticos (carreiras para pesquisadores, relações com instituições financiadoras, convênios internacionais), bem como estimular por meio de editais a realização de pesquisas que envolvam redes regionais/locais de serviços coordenadas por instituições que já tenham rotinizado suas atividades de inovação.

5) Participar ativa e abertamente da organização e realização de eventos, tais como feiras hospitalares e exposições de produtores e distribuidores de medicamentos e equipamentos em congressos médicos, buscando por meio do conhecimento sobre a efetividade das tecnologias contribuir para o debate e a decisão sobre a sua incorporação.

6) Elaborar alternativas para a transição do modelo fee-for-service de pagamento vigente, especialmente nos hospitais privados, que estimula a revenda de materiais e medicamentos.

7) Orientar investimentos e esforços inovativos para a redução das desigualdades regionais considerando a difusão massiva (para o público especializado) das capacitações tecnológica e científica nos serviços de saúde.

8) Articular fóruns de debate de serviços de saúde, produtores e distribuidores de medicamentos e materiais médico-hospitalares com instituições e pesquisadores envolvidos com acreditação e qualidade e suas inter-relações com inovações.

Quadro 5 - Diretrizes para a elaboração de uma agenda sobre inovação nos serviços de saúde no Brasil

\begin{tabular}{|c|c|c|}
\hline Lacunas & Recomendações & Participantes/Perspectivas \\
\hline \multirow[t]{2}{*}{$\begin{array}{l}\text { Produção incipiente de } \\
\text { conhecimentos sobre padrões e } \\
\text { singularidades das inovações de } \\
\text { serviços no Brasil. }\end{array}$} & $\begin{array}{l}\text { Realizar um estudo linha de base } \\
\text { (multinível). } \\
\text { Mapear indústrias e atividades } \\
\text { de bem-estar. }\end{array}$ & $\begin{array}{l}\text { Pesquisadores da área de saúde } \\
\text { coletiva, diretores de serviços de } \\
\text { saúde, pesquisadores clínicos, } \\
\text { produtores e distribuidores, Ministério } \\
\text { da Saúde. }\end{array}$ \\
\hline & $\begin{array}{l}\text { Mapear a incorporação de } \\
\text { tecnologias de registro eletrônico } \\
\text { de informações assistenciais. }\end{array}$ & $\begin{array}{l}\text { Estudo linha de base sobre inovação } \\
\text { nos serviços de saúde. } \\
\text { Mapeamento de tecnologias de "bem- } \\
\text { estar" e de registro eletrônico de } \\
\text { informações assistenciais. }\end{array}$ \\
\hline $\begin{array}{l}\text { Número de serviços com } \\
\text { atividades de pesquisa, ensino, } \\
\text { C\&T e inovação reduzido e } \\
\text { concentrado. }\end{array}$ & $\begin{array}{l}\text { Reuniões da rede de pesquisas } \\
\text { clínicas e expansão de } \\
\text { articulações entre serviços } \\
\text { regionais/locais. }\end{array}$ & $\begin{array}{l}\text { Pesquisadores da área da saúde } \\
\text { pública, diretores e pesquisadores } \\
\text { clínicos, Ministério da Saúde, } \\
\text { secretarias de Saúde. }\end{array}$ \\
\hline Desigualdades regionais. & & $\begin{array}{l}\text { Expansão do número e tipo de serviços } \\
\text { de saúde com atividades de ensino, } \\
\text { pesquisa e inovação. }\end{array}$ \\
\hline
\end{tabular}


Quadro 5 - Diretrizes para a elaboração de uma agenda sobre inovação nos serviços de saúde no Brasil (cont.)

\section{Lacunas}

Processos decisórios sobre incorporação tecnológica fragmentados e desconectados.

Inexistência de canais de conexão sistemática entre os serviços de saúde e os produtores e distribuidores de medicamentos, médicos e órgãos governamentais.

Informações incipientes de decisores de serviços de saúde sobre as políticas de saúde de C\&T.

Padrões de remuneração dos serviços realizados especialmente nos hospitais privados induzem "revenda" de produtos.

\section{Recomendações}

Participar ativa e abertamente da organização e realização de eventos sobre difusão de tecnologias/debate sobre decisões estratégicas de incorporação de tecnologias.

Articular fóruns de debate de serviços de saúde, produtores e distribuidores de medicamentos e materiais médico-hospitalares.
Alternativas para a transição do modelo fee-for-service.
Participantes/Perspectivas

Ministério da Saúde, pesquisadores clínicos, pesquisadores de saúde pública, produtores distribuidores.

Política de difusão de tecnologias e inovação.

Processos de decisão sobre incorporação de tecnologias estratégicas compatíveis com a ampliação do acesso, uso e controle de custos.

Ministério da Saúde, ANS, empresas de planos e seguros, associações de hospitais, entidades médicas, produtores e distribuidores.

Pagamento prospectivo.

\section{Referências}

AGÊNCIA NACIONAL DE SAÚDE (ANS). Caderno de Informações de Saúde Suplementar, dez. 2007. Disponível em: <www.ans.gov.br/images/stories/Materiais_para_pesquisa/Perfil_setor/Caderno_informacao_saude suplementar/2007_mes12_caderno_informacao.pdf >. Acesso em: 8 nov. 2016.

AGÊNCIA NACIONAL DE SAÚDE (ANS). Caderno de Informações de Saúde Suplementar, dez. 2013. Disponível em: <www.ans.gov.br/images/stories/Materiais_para_pesquisa/Perfil_setor/Caderno_informacao_saude_ suplementar/2013_mes12_caderno_informacao.pdf >. Acesso em: 8 nov. 2016.

AGÊNCIA NACIONAL DE SAÚDE (ANS). Perfil do setor, dados e indicadores do setor, 2014. Disponível em: < www. ans.gov.br/materiais-para-pesquisas/perfil-do-setor/dados-e-indicadores-do-setor>. Acesso em: 1 maio 2014.

ASSOCIAÇÃO NACIONAL DE HOSPITAIS PRIVADOS (ANAPH). Panorama, out.-nov. 2013. Disponível em: <http://anahp.com.br/?gclid=CPT83YDFhdACFckIkQodYYwEpw>. Acesso em: 1 maio 2014.

BAHIA, L. Financeirização e restrição de coberturas: estratégias recentes de expansão das empresas de planos e seguros de saúde no Brasil. In: COHN, A. (Org.). Saúde, Cidadania e Desenvolvimento. Rio de Janeiro: Centro Internacional Celso Furtado, 2013.

BARBOSA, P. R. \& GADELHA, C. A. G. O papel dos hospitais na dinâmica de inovação em saúde. Revista de Saúde Pública, 46, supl.: 68-75, 2012.

BARLOW, J. et al. A systematic review of the benefits of home telecare for frail elderly people and those with long-term conditions. Journal of Telemedicine and Telecare, 13(4): 172-179, 2007. 
BERMAN, D. K. Is a peanut butter pop-tart an innovation? The Wall Street Journal. New York, Dec. 3, 2013. Disponível em: < http://online.wsj.com/news/articles/SB1000142405270230485480457923660141131050 2>. Acesso em: 1 maio 2014.

BOURDENAVE, J. D. Communication of agricultural innovations in Latin America: the need for new models. Communication Research, 3(2): 135-154, 1976.

BROWN, J. S. \& DUGID, P. Organizational learning and communities-of-practice: toward a unified view of working, learning, and innovation. Organization Science, 2(1): 40-57, 1991.

CASSIOLATO, J. E. et al. (Org.). Perspectivas do Investimento na Economia do Conhecimento. Rio de Janeiro, Campinas: Synergia, Unicamp, Instituto de Economia, 2010.

CHAUDOIR, S. R.; DUGAN, A. G. \& BARR, C. H. Measuring factors affecting implementation of health innovations: a systematic review of structural organizational provider patient and innovation level measures. Implementation Science, 8(22): 2-20, 2013.

CHEN, W. R. \& MILLER, K. D. Situational and institutional determinants of firms' R\&D search intensity. Strategic Management Journal, 28(4): 369-381, 2007.

CHINTAGUNTA, P. K. Don't knock “innovation”, create a framework for it. Chicago Booth. Chicago, 15 abr. 2014. Capital Ideas. Disponível em: <www.chicagobooth.edu/capideas/search?GSAq=innovation\&site=\%3C\%25 $\% 3 \mathrm{dBoothCollection}+\% 25 \% 3 \mathrm{E} \& \mathrm{client}=$ default_frontend\&output $=x m l \_$no_dtd\&proxystylesheet $=$defaul $>$. Acesso em: 1 maio 2014.

CHRISTENSEN, C. M.; BOHMER, R. \& KENAGY, J. Will disruptive innovations cure health care? Harvard Business Review, 78(5): 102-112, 2000.

COSTA, L. S. et al. A dinâmica inovativa para a reestruturação dos serviços de saúde. Revista de Saúde Pública, 46(1): 76-82, 2012.

DAMANPOUR, F. \& SCHNEIDER, M. Characteristics of innovation and innovation adoption in public organizations: assessing the role of managers. Journal of Public Administration Research and Theory, 19(3): 495-522, 2009.

DEPARTAMENTO DE INFORMÁTICA DO SUS (DATASUS). Assistência à Saúde. Internações Hospitalares, 2014a. Disponível em: <www2.datasus.gov.br/DATASUS/index.php?area=0202> . Acesso em: 1 maio 2014.

DEPARTAMENTO DE INFORMÁTICA DO SUS (DATASUS). Siops. Despesas, 2014b. Disponível em: <http:// portalsaude.saude.gov.br/images/pdf/2013/outubro/02/despesa-total-saude-021013.pdf $>$. Acesso em: 1 maio 2014.

DEPARTAMENTO DE INFORMÁTICA DO SUS (DATASUS) \& CADASTRO NACIONAL DE ESTABELECIMENTOS DE SAÚDE (CNES). CNES Estabelecimentos, 2013. Disponível em: <www2.datasus.gov.br/DATASUS/index. php?area $=0204>$. Acesso em: 1 maio 2014.

DJELLAL, F. \& GALLOUJ, F. Mapping innovation dynamics in hospitals. Research Policy, 34(6): 817-835, 2005.

EDMONDSON, A. C.; BOHMER, R. M. \& PISANO, G. Disrupted routines: team learning and new technology implementation in hospitals. Administrative Science Quarterly, 46(4): 685-716, 2001.

FERLIE, E. et al. Evidence-based medicine and organisational change: an overview of some recent qualitative research. In: ASHBURNER, L. (Ed.). Organisational Behaviour and Organisational Studies in Health Care: reflections on the future. Basingstoke: Palgrave, 2001.

GADELHA, C. A. G.; QUENTAL, C. \& FIALHO, B. C. Saúde e inovação: uma abordagem sistêmica das indústrias da saúde. Cadernos de Saúde Pública, 19(1): 47-59, 2003.

GADELHA, C. A. G. et al. A Dinâmica do Sistema Produtivo da Saúde: inovação e complexo econômico-industrial. Rio de Janeiro: Editora Fiocruz, 2012. 
GOLDACRE, B. Bad Pharma: how drug companies mislead doctors and harm patients. London: Fourth Estate, 2012.

GREENHALGH, T. Five biases of new technologies. British Journal of General Practice, 63(613): 425, 2013.

GREENHALGH, T. et al. Diffusion of innovations in service organizations: systematic review and considerations. Milbank Q, 82(4): 581-629, 2004.

GREENHALGH, T. et al. Adoption, non-adoption, and abandonment of a personal electronic health record: case study of Health Space. British Medical Journey, 341, 2010.

GREENHALGH, T. et al. The organization vision for telehealth and telecare: discourse analysis. BMJ Open, 2: 1-14, 2012.

GRIMSHAW, J. M. et al. Effectiveness and Efficiency of Guideline Dissemination and Implementation Strategies. Health Technology Assessment Report, 8(6): 1-72, 2004.

INSTITUTO BRASILEIRO DE GEOGRAFIA E ESTATÍSTICA (IBGE). População, projeção da população do Brasil por sexo e idade: 2000-2060, 2014. Disponível em: <www.ibge.gov.br/home/estatistica/populacao/ projecao_da_populacao/2013/default_tab.shtm>. Acesso em: 1 maio 2014.

KALUZNY, A. D. Innovation in health services: theoretical framework and review of research. Health Services Research, 9(2): 101-120, 1974.

KALUZNY, A. D. Vision and strategy for ubiquitous health care: the end of business as we know it. World Hospitals Health Service Journal, 43(4): 16-19, 2007.

KALUZNY, A. D. \& VENEY, J. E. Attributes of health services as factors in program implementation. Journal of Health and Social Behavior, 14(2): 124-133, 1973.

KALUZNY, A. D. et al. Diffusion of innovative health care services in the United States: a study in hospitals. Medical Care, 8(6):274, 1970.

LIMA, E. F. O caso do grupo D’Or. Projeto Grupos Econômicos no Sistema Brasileiro de Saúde. Relatório de pesquisa. Rio de Janeiro, 2014. (Mimeo.)

MALERBA, F.; ORSENIGO, L. \& PERETTO, P. Persistence of innovative activities, sectoral patterns of innovation and international technological specialization. International Journal of Industrial Organization, 15(6): 801-826, 1997.

OCASIO, W. Towards an attention-based view of the firm. Strategic Management Journal, 18, supl. 1: 187-206, 1997.

ORGANISATION FOR ECONOMIC CO-OPERATION AND DEVELOPMENT (OECD). Statistics. Health status. Disponível em: <http://stats.oecd.org/index.aspx?DataSetCode=HEALTH_STAT> . Acesso em: 1 abr. 2014.

POTVIN, L.; HADDAD, S. \& FROHLICH, K. L. Beyond process and outcome evaluation: a comprehensive approach for evaluating health promotion programmers. WHO Regional Publications, 92: 45-62, 2001.

RATTEN, V. A theoretical framework of entrepreneurship and innovation in healthcare organizations. International Journal of Social Entrepreneurship and Innovation, 1(3): 223-238, 2012.

RERUP, C. \& FELDMAN, M. S. Routines as a source of change in organizational schemata: the role of trial-anderror learning. Academy of Management Journal, 54(3): 577-610, 2011.

ROYAL COLLEGE OF NURSING. Telehealth and telecare. London, 2013. Disponível em: <www.rcn.org.uk/ development/practice/e-health/telehealth_and_telecare>. Acesso em: 1 maio 2014.

SALGE, T. O. A behavioral model of innovative search: evidence from public hospital services. Journal of Public Administration Research and Theory, 21(1): 181-210, 2011. 
SALGE, T. O. The temporal trajectories of innovative search: Insights from public hospital services: insights from public hospital services. Research Policy, 41(4): 720-733, 2012.

SALGE, T. O. \& VERA, A. Hospital innovativeness and organizational performance: evidence from English public acute care. Health Care Management Review, 34(1): 54-67, 2009.

SCHUMPETER, J. A. The instability of capitalism. Economic Journal, 38: 361-386, Sept. 1928.

SCHUMPETER, J. A. A Teoria do Desenvolvimento Econômico. 2. ed. São Paulo: Nova Cultura, 1984.

SHORTELL, S. M. et al. Remaking Health Care in America: building organized delivery systems. Michigan: JosseyBass, 1996.

SOARES, M. L. C. A Estrutura do Conhecimento Tácito em Polanyi: um paradigma pós-crítico para a epistemologia. Lisboa: Universidade Nova de Lisboa, 2012. Disponível em: <www.google.com/\#q=polanyi+dimens\%C3\%A 3o+tática >. Acesso em: 1 maio 2014.

SOCIEDADE PORTUGUESA DE INOVAÇÃO. O conceito de inovação,2004. Disponível em: <www.spi.pt/ documents/books/inovint/ippo/experimentar.manual/1.1/cap_apresentacao.htm >. Acesso em: 1 maio 2014.

STIGLITZ, J. E. Learning to learn: localized learning and technogical progress. In: DASGUPTA, P. \& STONEMAN, P. (Eds.). Economic Policy and Technological Performance. New York: Cambridge University Press, 1987.

SUBSECRETARIA DE PLANEJAMENTO E ORÇAMENTO/MINISTÉRIO DA SAÚDE (ESFERA FEDERAL) E SISTEMA DE INFORMAÇÕES SOBRE ORÇAMENTO PÚBLICO EM SAÚDE (SIOPS), 2014. Disponível em: <http:// portalsaude.saude.gov.br/index.php/o-ministerio/principal/siops > . Acesso em: 8 nov. 16.

SUTTON, J. Sunk Costs and Market Structure: price competition, advertising, and the evolution of concentration. Cambridge: MIT Press, 1991.

THE BOSTON CONSULTING GROUP. The 2014 health-care-services value creators report, 2014. Disponível em: $<$ www.bcgperspectives.com/content/articles/health_care_payers_providers_value_creation_strategy_finding sustainable_value_turbulent_market/?chapter $=2 \#$ ch̆ $a p>$. Acesso em: 18 maio $20 \overline{1} 4$.

VECINA, G. \& MALIK, A. Tendências na assistência hospitalar. Ciência \& Saúde Coletiva, 12(4): 825-839, 2007.

VELHO, L. Research capacity building for development: from old to new assumptions. Science, Technology and Society, 9(2): 172-207, 2004.

VELHO, L. Conceitos de ciência e a política científica, tecnológica e de inovação. Sociologias, 13(26): 128-153, 2011.

WEISER, M. \& BROWN, J. S. In design calm technology, 21 dez. 1995. Disponível em: <www.ubiq.com/ hypertext/weiser/calmtech/calmtech.htm>. Acesso em: 1 maio 2014.

WHITE, C.; RESCHOVSKY, J. D. \& BOND, A. M. Understanding differences between high-and-low price hospitals: implications for efforts to rein in costs. Health Affairs, 33(2): 324-331, 2014. 


\section{APÊNDICE}

\section{Contexto de Capacitação Tecnológica e Processos Inovativos de Hospitais Selecionados segundo Critérios de Participação em Pesquisas e Porte: potenciais e desafios destacados}

Os hospitais dispõem de profissionais qualificados, lideranças nas suas áreas de atuação e são muito bem equipados.

Os hospitais concentram profissionais com pós-graduação stricto sensu, mas alguns relatam necessitar de expertise específica ou não dispor de carreiras para pesquisadores. Poucas são as empresas responsáveis pelo suprimento da tecnologia incorporada, e destas as principais mencionadas foram GE, Siemens, PP/GE e Medtronic. Alguns hospitais contam com Núcleo de Avaliação Tecnológica (Nats), no entanto realizam procedimentos em suas áreas de atuação e especialização que ainda não integram os protocolos e diretrizes deste núcleo.

Destacaram-se entre as inovações tecnológicas: diagnósticos molecular/sequenciamento de DNA; ciclotron para radiofármacos; biobanco de tumores; vetores virais.

Um dos hospitais tem uma comissão orçamentária para materiais e insumos e outro um sistema de acompanhamento de tecnologia incorporada.

A percepção dos dirigentes dos hospitais é a de que "existe tudo que é necessário". Um deles afirmou que seu hospital não dispõe de equipamento PET-RM (que realiza, de forma integrada e simultânea, imagens de tomografia por emissão de pósitrons e de ressonância magnética) por ser "ainda muito caro" e registrou que "alguns testes são enviados para o exterior".

Os profissionais do hospital e gestores intermediários (chefes de serviços) tomam conhecimento das últimas inovações pela internet (artigos científicos) e em congressos. Um dos hospitais envia seus profissionais para congressos internacionais "sem participação de empresas no custeio". Outro, além dos incentivos à participação em eventos científicos, mantém profissionais "sendo preparados para inovação, em cursos no exterior".

No que se refere à origem (nacionalidade) da tecnologia utilizada, gerada ou incorporada foram elencadas as seguintes ponderações: a tecnologia complexa e recente utilizada é de origem internacional; a participação da indústria nacional se restringe a equipamentos de baixa complexidade, 
como bombas infusoras e monitores; "existe forte preconceito contra o produto nacional"; "não há muitos adeptos da tecnologia nacional no setor". No entanto, o preconceito se fundamenta em algum substrato real, na medida em que "a indústria nacional tem dificuldades para manter um nível elevado de qualidade".

Os hospitais selecionados realizam projetos/pesquisas sobre tecnologias nacionais.

As tendências tecnológicas registradas pelos serviços para 2030 foram: cirurgias minimamente invasivas guiadas por imagem; nanopartículas ativadas por ultrassonografia, terapias-alvo dirigidas, sequenciamento genético, marcadores tumorais, imagem molecular, paperless; pesquisa e protocolos de qualidade e segurança do paciente.

As pesquisas realizadas em um dos hospitais geraram duas patentes.

Sobre tendências de crescimento na prestação de serviços ambulatoriais, home care, cuidados domiciliares e outros, foram apontadas: expansão de serviços ambulatoriais mediante a construção e reforma para a criação de "grandes ambulatórios"; investimentos em internações de alta complexidade ("alta tecnologia").

Em relação às tecnologias de imagem, as expectativas de expansão registradas foram: imagens somatórios de tomografia computadorizada, PET e RM.

As principais pesquisas em curso se concentram nas áreas de oncologia, cardiopatia e ortopedia. As principais fontes citadas para o financiamento das pesquisas foram: indústrias; Fundação de Amparo à Pesquisa do Estado de São Paulo; Coordenação de Aperfeiçoamento de Pessoal de Nível Superior; Ministério da Saúde. 



\title{
INDÚSTRIA DE BASE QUÍMICA NO BRASIL: POTENCIALIDADES, DESAFIOS E NICHOS ESTRATÉGICOS
}

\author{
Marco Antonio Vargas
}

Propõe-se aqui analisar o impacto das novas plataformas tecnológicas, em particular daquelas ligadas à nanotecnologia e biotecnologia, sobre a dinâmica produtiva e de inovação da indústria farmacêutica no Brasil. ${ }^{1}$ Adicionalmente, tendo em vista o arcabouço conceitual e analítico adotado no âmbito dos estudos sobre o complexo econômico-industrial da saúde (CEIS), nesta análise prospectiva da indústria farmacêutica leva-se em conta um conjunto amplo de condicionantes que abrangem não somente a caracterização da base produtiva, mas também as macrotendências tecnológicas, socioeconômicas e políticas que contribuem para o processo de capacitação produtiva e inovativa na produção de fármacos e medicamentos no país, ou o restringem. Assim, a análise sobre nichos estratégicos apresentada neste capítulo não se restringe à escolha de novas plataformas e produtos que integram as fronteiras tecnológicas da indústria farmacêutica mundial. Tal perspectiva é importante, mas deve necessariamente estar associada a uma estratégia de desenvolvimento do setor farmacêutico nacional que seja capaz de articular o esforço de inovação e de produção com a resolução de problemas sanitários locais. Em outras palavras, a identificação de nichos estratégicos para a indústria farmacêutica nacional deve refletir as especificidades do sistema de inovação em saúde no Brasil, no tocante seja às características da base produtiva e tecnológica em saúde, seja às particularidades do seu arcabouço institucional que incorpora, entre outros elementos, o modelo de atenção à saúde (universal, integral e equânime) e o marco regulatório da produção e inovação em saúde (Gadelha et al., 2012; Vargas et al., 2012).

O texto encontra-se organizado da seguinte forma. Na próxima seção apresenta-se um breve panorama sobre a dinâmica recente de desenvolvimento da indústria farmacêutica global e focalizamse, em particular, as principais tendências que deverão marcar a trajetória de desenvolvimento desta indústria nas próximas décadas. Na segunda seção relacionam-se as principais macrotendências associadas ao contexto atual das políticas de atenção à saúde e demais fatores de cunho social, demográfico, econômico, tecnológico e político, que condicionam a dinâmica do sistema produtivo da saúde e da indústria farmacêutica de forma geral. Com base nesse quadro de referência analisam-se os obstáculos e potencialidades do setor farmacêutico no país, tendo em vista aspectos relativos à

\footnotetext{
${ }^{1}$ O estudo sobre a indústria de base química e biotecnológica desenvolvido na etapa anterior do Projeto Prospecção Estratégica do Sistema de Saúde Brasileiro permitiu traçar um amplo panorama sobre as principais tendências que condicionam a dinâmica recente de transformação da indústria farmacêutica mundial e seus reflexos sobre o atual processo de reestruturação dessa indústria no Brasil. Neste capítulo parte-se do quadro geral de referência apresentado em Vargas e colaboradores (2013), para avançar na discussão sobre os impactos das novas plataformas tecnológicas no processo de reestruturação da cadeia farmacêutica mundial e brasileira.
} 
dinâmica de inovação, ao marco regulatório e à infraestrutura científica e tecnológica. Finalmente, na última seção analisa-se o impacto das novas plataformas tecnológicas ligadas à biotecnologia e à nanotecnologia sobre produtos e processos produtivos associados aos diversos segmentos da indústria farmacêutica no Brasil; adicionalmente, discute-se a importância estratégica da consolidação de novas competências produtivas e tecnológicas no país, no campo das vacinas e dos antibióticos.

\section{Panorama Global}

As características estruturais da indústria farmacêutica global, bem como a dinâmica recente de desenvolvimento desta indústria e sua articulação sistêmica com os demais subsistemas do CEIS, já foram amplamente analisadas em estudos anteriores (Gelijns \& Rosenberg, 1995; Gadelha, Maldonado \& Vargas, 2008; Gadelha et al., 2012; Vargas et al., 2012, 2013).

A importância crescente que assume a incorporação de medicamentos biológicos no mercado farmacêutico global reflete o esgotamento de uma estratégia adotada durante anos pelas grandes empresas farmacêuticas globais. Tal estratégia consistia na concentração de investimentos de pesquisa e desenvolvimento (P\&D) em um número restrito de moléculas com elevado potencial para o desenvolvimento e comercialização de blockbusters. A trajetória recente de desenvolvimento da indústria farmacêutica global mostra que os gastos crescentes empreendidos pelas empresas no desenvolvimento de novos medicamentos têm sido acompanhados por uma redução no ritmo de descobertas de novas moléculas e no desenvolvimento de medicamentos inovadores.

No Gráfico 1 apresenta-se a evolução, de 1998 a 2012, do número de novas entidades moleculares (NMEs) e novas entidades biológicas (NBEs) aprovadas anualmente pela Food and Drug Administration (FDA) norte-americana e a relação entre o montante total de NMEs e NBEs aprovadas anualmente e o montante dos investimentos em P\&D das empresas farmacêuticas norte-americanas. Em 1975, o investimento total em P\&D empreendido por empresas farmacêuticas norte-americanas associadas à Pharmaceutical Research and Manufacturers of America era de cerca de US\$ 1 bilhão (PhRMA, 2011); em 2012 esse investimento atingiu um montante de US $\$ 48,5$ bilhões. Destaca-se que embora os dispêndios em P\&D na indústria farmacêutica tenham aumentado cerca de cinquenta vezes em trinta anos, entre 1980 e 2010, os resultados em termos do surgimento de moléculas candidatas a novos medicamentos se mantiveram constantes nesse período. 
Gráfico 1 - Número de novas entidades moleculares (NMEs), de novas entidades biológicas (NBEs) e número total de NMEs e NBEs por montante de gastos em P\&D. Indústria farmacêutica norteamericana - 1998-2012

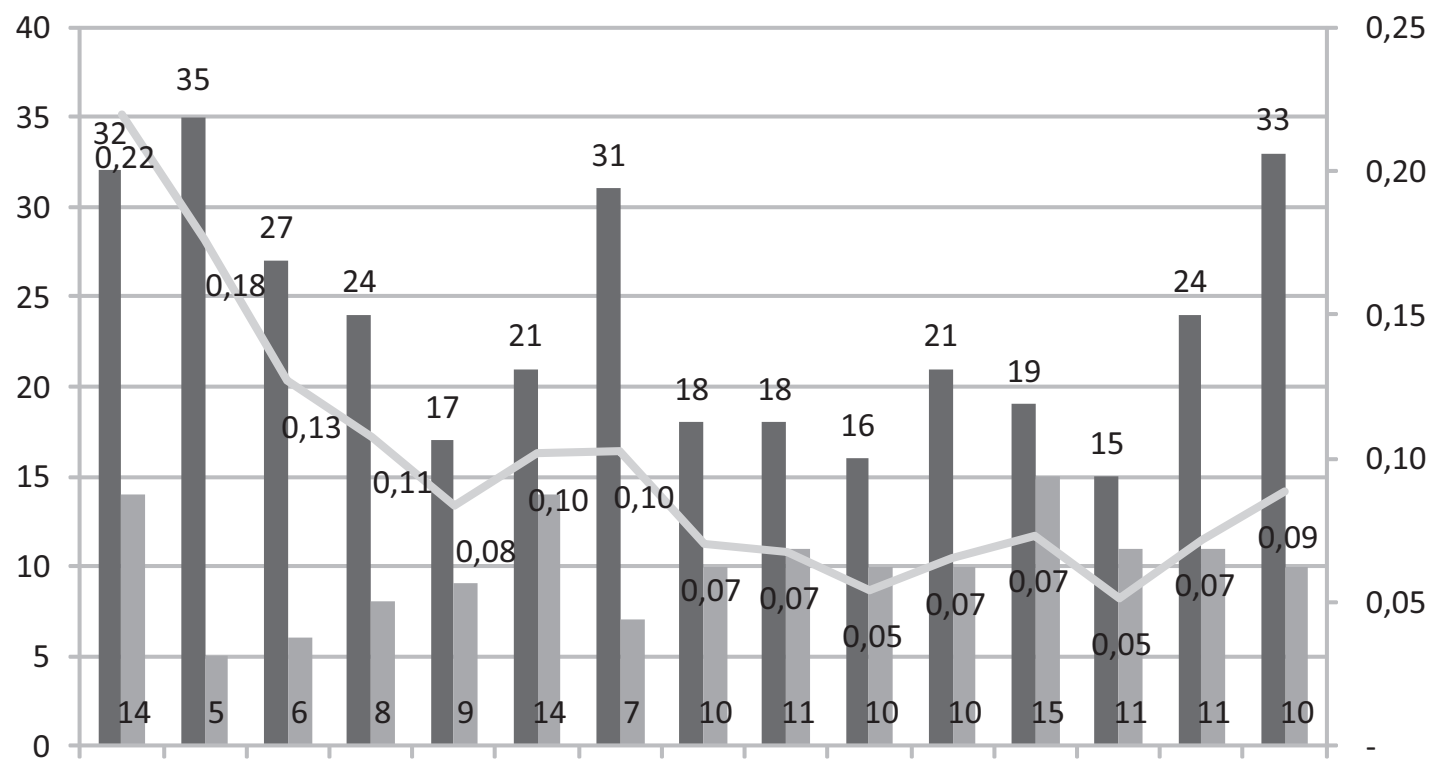

199819992000200120022003200420052006200720082009201020112012

Novas entidades químicas NMEs)
Novas entidades biológicas (NBEs)

\section{5}

0,20

Fonte: elaboração própria com base em dados da FDA e Evaluated Pharma, 2013.

O número de NMEs aprovadas em determinado ano é um importante indicador de desempenho inovativo da indústria farmacêutica. No decorrer das últimas duas décadas o número médio de novas drogas aprovadas anualmente pela FDA norte-americana foi de 28 novas entidades. Essa média anual de aprovações conheceu alguns ciclos de alta, como em 1996, quando foram aprovados 53 novos medicamentos, e ciclos de baixa, como em 2002, quando apenas 17 novos medicamentos foram aprovados pela agência. No decorrer da última década essa média esteve em torno de vinte novos medicamentos aprovados anualmente, o que mostra um padrão consistente com as evidências de declínio na produtividade de P\&D na indústria farmacêutica. A aprovação de 39 novos medicamentos pela FDA em 2012, um montante 63\% superior à média histórica da década, chegou a suscitar otimismo quanto à trajetória futura resultante dos esforços de P\&D da indústria farmacêutica e biofarmacêutica. Entretanto, persiste uma forte percepção de que o atual modelo de inovação das grandes empresas farmacêuticas ainda deve passar por mudanças profundas a fim de se adequar ao novo contexto de transformação da indústria farmacêutica mundial. 
A redução na produtividade das atividades de P\&D no setor farmacêutico é apenas uma das tendências que têm contribuído para o aumento das pressões competitivas na trajetória atual de transformação da indústria farmacêutica global, e deve ser analisada juntamente com elenco mais amplo de fatores, que incluem a intensificação do processo de consolidação patrimonial de empresas do setor farmacêutico, a mudança nos vetores de crescimento do mercado farmacêutico mundial que tem ampliado a importância dos chamados mercados emergentes (pharmerging markets) - e as mudanças no arcabouço institucional e no marco regulatório na área da saúde, entre outras.

No tocante ao processo de consolidação do setor farmacêutico, o elevado grau de internacionalização das empresas e a crescente concentração industrial no setor não se constituem em uma tendência recente. Da mesma forma, a busca de convergência entre a indústria farmacêutica e o segmento de biotecnologia aplicada à saúde é um movimento comum ao longo da década de 2000, na medida em que as big pharmas passaram a buscar novas estratégias para alimentar suas linhas de desenvolvimento de novos medicamentos (pipelines). Entretanto, no decorrer dos últimos anos, verifica-se uma intensificação nesse processo de convergência entre a indústria farmacêutica e a indústria de biotecnologia, em termos tanto do número de operações de fusões e aquisições como do volume médio de recursos envolvidos em cada operação. ${ }^{2}$

Entre 2000 e 2008, o valor médio das operações de fusão e aquisição (F\&A) entre empresas farmacêuticas e de biotecnologia aumentou de US\$ 80 milhões para US\$ 400 milhões, conforme pode ser observado no Gráfico 2. É interessante observar que as F\&As entre empresas de biotecnologia superam aquelas que envolvem empresas biotecnológicas e empresas farmacêuticas em termos do número de operações. De fato, em 2009, ocorreram 86 operações de F\&A envolvendo empresas de biotecnologia e vinte operações envolvendo F\&As entre empresas farmacêuticas e empresas de biotecnologia. Entretanto, o valor médio das operações é muito superior no caso das F\&As que envolvem empresas farmacêuticas e empresas de biotecnologia. Tal fenômeno reflete a nova estratégia das grandes empresas farmacêuticas, que recai fortemente sobre a captura de novas competências mediante a aquisição de empresas de biotecnologia e de suas plataformas de desenvolvimento de novos medicamentos.

\footnotetext{
${ }^{2}$ Um dos marcos recentes desse movimento de convergência entre a indústria farmacêutica e a indústria de biotecnologia aplicada à área da saúde foi, certamente, a operação de compra de $44 \%$ da maior empresa de biotecnologia do mundo - a Genentech - pela farmacêutica Roche, por um montante de US\$ 44 bilhões, em 2008.
} 
Gráfico 2 - Número de operações globais de fusão e aquisição e valor médio das operações, por ano (farma/bio e bio/bio) - 1999-2009

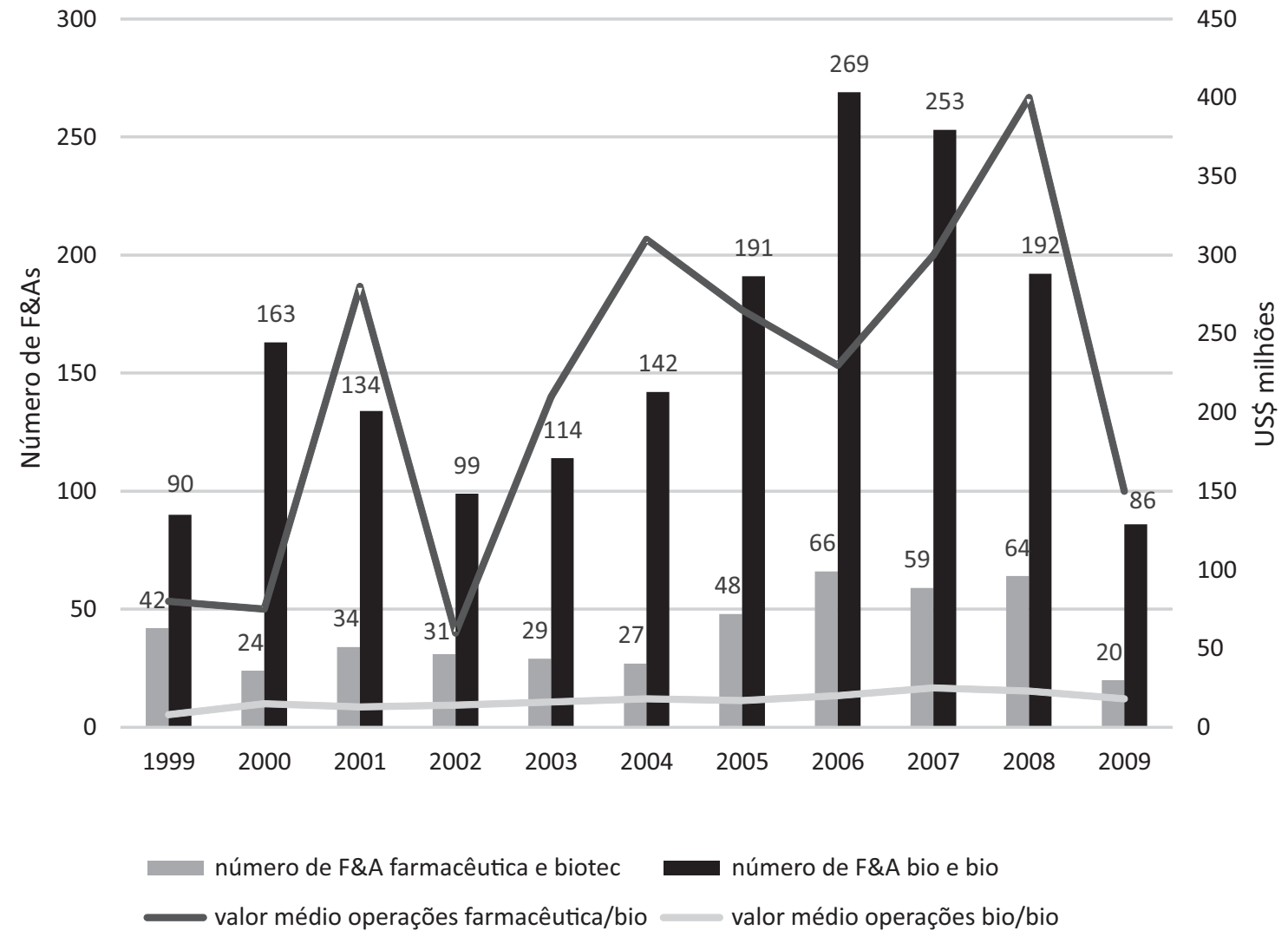

Fonte: Deloitte, 2009.

O aumento da participação dos mercados emergentes nas vendas globais de medicamentos, por sua vez, é uma tendência importante do mercado farmacêutico global, na medida em que vem impondo mudanças nas estratégias competitivas e de inovação das grandes empresas farmacêuticas globais.

De acordo com estimativas da IMS Health - consultoria internacional que fornece informações, serviços e tecnologia na área da saúde -, nos próximos anos cerca de dois terços do crescimento das vendas globais do mercado farmacêutico decorrerão do crescimento dos mercados emergentes. Em termos absolutos, os gastos globais com medicamentos devem chegar a US\$ 1,2 trilhão em 2017, o que significa um acréscimo de mais de US\$ 200 bilhões em relação ao volume atual de vendas. O Gráfico 3 mostra o aumento estimado no montante de gastos com medicamentos entre 2007 e 2017. 
Gráfico 3 - Gastos globais com medicamentos - 2007, 2012 e 2017 (em US\$ bilhões)

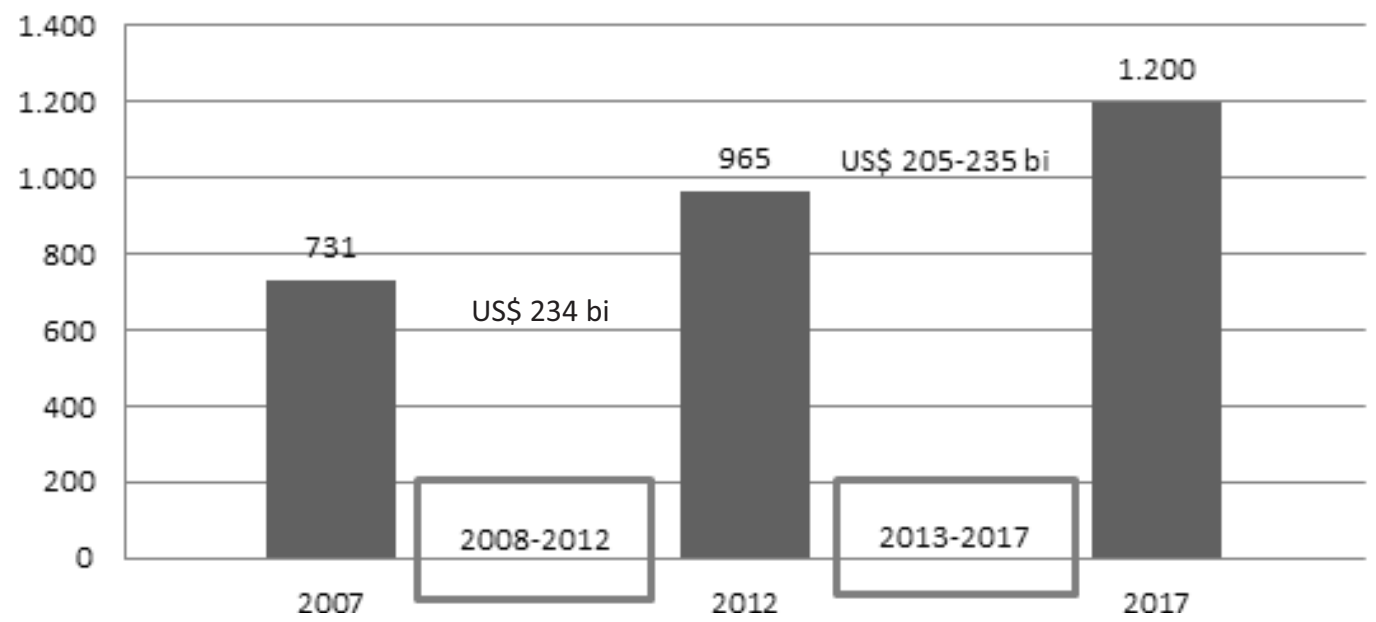

Fonte: IMS Health, 2013.

Estima-se que boa parte desse aumento nos gastos globais com medicamentos estará associada com o crescimento do consumo nos mercados emergentes, que constituem um grupo de 21 países com padrões bastante diferenciados em termos de modelo assistencial, taxa de crescimento e nível de renda per capita, mas são classificados em três grandes grupos conforme o dinamismo de seu mercado farmacêutico. No primeiro grupo está a China, com uma taxa de crescimento total nos gastos com medicamentos estimada de $15 \%$ a 18\% entre 2012 e 2017 . No segundo grupo estão o Brasil, a Rússia e a Índia, com uma taxa de crescimento nos gastos com medicamentos estimada entre 10\% e 13\% no mesmo período. No terceiro grupo encontra-se um conjunto de 17 países - Argélia, Argentina, Colômbia, Egito, Indonésia, México, Nigéria, Paquistão, Polônia, Romênia, Arábia Saudita, África do Sul, Tailândia, Turquia, Ucrânia, Venezuela e Vietnã - cuja taxa de crescimento nos gastos com medicamentos é estimada entre 7\% e 10\%, conforme a Tabela 1.

Tabela 1 - Estimativa da taxa média anual de crescimento, para o período 2012-2017, do consumo mundial de medicamentos, em países selecionados, para mercados maduros e grupos de mercados emergentes

\begin{tabular}{lrll}
\hline \multicolumn{2}{c}{ Mercados maduros } & & \multicolumn{2}{c}{ Pharmerging markets } \\
\hline EUA & $1-4 \%$ & Grupo 1 & \\
Japão & $2-5 \%$ & China & $15-18 \%$ \\
Alemanha & $1-4 \%$ & Grupo 2 & $10-13 \%$ \\
França & $-1-2 \%$ & Brasil & $11-14 \%$ \\
Itália & $0-3 \%$ & Rússia & $09-12 \%$ \\
Canadá & $1-4 \%$ & Índia & $11-14 \%$ \\
Espanha & $(-4)-(-1) \%$ & Grupo 3 & $7-10 \%$ \\
Reino Unido & $1-4 \%$ & & $11-14 \%$ \\
\hline Média desenvolvidos & $1-4 \%$ & Média emergentes & \\
\hline
\end{tabular}

Fonte: IMS Health, 2013. 
Dentre as demais tendências que deverão moldar a trajetória futura da indústria farmacêutica mundial, é possível destacar ainda: 1) o processo de mudanças no perfil epidemiológico mundial, que tem implicado o aumento da carga de doenças crônico-degenerativas e tende a ampliar as pressões nos gastos públicos com saúde, e 2) as mudanças significativas no marco regulatório e institucional na área da saúde, com maior influência das organizações públicas e privadas de saúde na avaliação de novas terapias baseada em critérios fármaco-econômicos com o objetivo de reduzir os custos de cobertura e preços dos medicamentos. Tal estratégia tem sido potencializada pelo uso crescente de informações provenientes de prontuários eletrônicos nos sistemas de saúde. No campo regulatório percebe-se maior precaução por parte dos órgãos reguladores na aprovação de medicamentos inovadores, particularmente no que se refere aos medicamentos biológicos e biossimilares.

Em síntese, essas grandes tendências que marcam a trajetória atual de desenvolvimento da indústria farmacêutica mundial devem contribuir para uma ampla transformação da cadeia de desenvolvimento de novos medicamentos e fármacos ao longo da próxima década, conforme ilustrado no Quadro 1.

Quadro 1 - Fatores que deverão condicionar o processo de transformação na cadeia farmacêutica até 2030

\begin{tabular}{|c|c|}
\hline Fator & Implicações \\
\hline Novos tipos de produtos & $\begin{array}{l}\text { Maior complexidade dos processos de produção e distribuição de novos } \\
\text { medicamentos. } \\
\text { Redução dos ciclos de vida dos produtos. } \\
\text { Cadeias de produção diferenciadas de acordo com o tipo de produto. }\end{array}$ \\
\hline Live licensing & $\begin{array}{l}\text { Lançamento incremental de novos medicamentos. } \\
\text { Maior agilidade na capacidade de escalonamento da produção. }\end{array}$ \\
\hline $\begin{array}{l}\text { Aumento na utilização } \\
\text { de fontes externas de } \\
\text { fornecimento }\end{array}$ & $\begin{array}{l}\text { Expansão da gestão de serviços na área da saúde. } \\
\text { Estruturas de custo adaptadas aos novos ciclos de produção com vista à } \\
\text { preservação das margens de lucros da big pharma. }\end{array}$ \\
\hline $\begin{array}{l}\text { Novas formas de prestação de } \\
\text { serviços de saúde }\end{array}$ & $\begin{array}{l}\text { Maior fluidez nas fronteiras entre prevenção e tratamento. } \\
\text { Redes mais amplas de atendimento e prestação de serviços. } \\
\text { Processos de produção e distribuição orientados pela demanda. }\end{array}$ \\
\hline $\begin{array}{l}\text { Importância crescente dos } \\
\text { mercados emergentes }\end{array}$ & $\begin{array}{l}\text { Foco no desenvolvimento de medicamentos para grupos de pacientes } \\
\text { nestes mercados. } \\
\text { Cadeias de fornecimento mais dispersas e robustas. }\end{array}$ \\
\hline $\begin{array}{l}\text { Maior nível de intervenção } \\
\text { pública }\end{array}$ & $\begin{array}{l}\text { Regulação mais restrita. } \\
\text { Maior controle sobre o levantamento e gestão de riscos. }\end{array}$ \\
\hline
\end{tabular}

Fonte: PwC, 2013. 


\section{Panorama Nacional}

Na medida em que se busca orientar a escolha de nichos estratégicos para a indústria farmacêutica brasileira, é necessário ter em conta não somente as principais tendências tecnológicas que marcam a evolução da indústria farmacêutica e biofarmacêutica mundial, mas também as especificidades associadas ao sistema nacional de inovação em saúde e sua articulação com a base produtiva. Nesta seção apresenta-se uma análise sucinta sobre as principais macrotendências associadas ao contexto atual das políticas de atenção à saúde e demais fatores de cunho social, demográfico, econômico, tecnológico e político, que condicionam a dinâmica do sistema produtivo da saúde e da indústria farmacêutica de forma geral.

De acordo com Gadelha e colaboradores (2012), o grande desafio para a análise da dinâmica econômica dos segmentos que integram o CEIS consiste precisamente em articular uma visão sistêmica da área da saúde que dê conta, simultaneamente, das dimensões econômica, sociossanitária, tecnológica e política, buscando captar as interfaces e tensões entre essas diferentes dimensões. A saúde é uma das áreas em que esse desafio se coloca de forma mais evidente, por constituir uma das mais importantes frentes de inovação no contexto atual, respondendo por cerca de um quinto do gasto mundial com atividades de $\mathrm{P} \& \mathrm{D}$, ao mesmo tempo que é uma área de alto interesse estratégico para a sociedade, ocupando um lócus privilegiado nas políticas públicas e nos debates políticos nacionais. ${ }^{3}$

No Quadro 2 apresentam-se as principais macrotendências que condicionam a dinâmica produtiva e de inovação da indústria de base química e biotecnológica no país e que serão discutidas, de forma breve, nesta seção a fim de explorar as implicações analíticas da articulação entre o CEIS e o sistema nacional de inovação em saúde sobre as perspectivas de desenvolvimento da indústria farmacêutica no Brasil.

De maneira geral, as macrotendências, associadas tanto à política de atenção à saúde como ao perfil sociodemográfico e epidemiológico, ressaltam a importância da incorporação das novas plataformas tecnológicas da biotecnologia e da nanotecnologia nas práticas assistenciais em saúde. Tais tendências representam um grande desafio para a base produtiva em saúde do país, seja no tocante ao atendimento das demandas do sistema nacional de saúde, que deve contemplar os princípios de universalidade, integralidade e equidade, seja pela intensificação das pressões competitivas de um sistema produtivo claramente intensivo em conhecimento. A análise da indústria farmacêutica e biofarmacêutica no Brasil revela importantes obstáculos associados tanto à configuração da base produtiva quanto ao arcabouço regulatório e à infraestrutura de ciência, tecnologia e inovação (CT\&I) ligada à área da saúde, que serão tratados a seguir.

\footnotetext{
${ }^{3}$ Conforme destacado por Gadelha e colaboradores (2012: 15), "o estudo da dinâmica industrial e competitiva na área da saúde constitui, ao mesmo tempo, um grande desafio acadêmico e político-normativo para uma perspectiva centrada no processo de inovação e de desenvolvimento. A própria tensão inerente à lógica capitalista, particularmente na contraposição entre o interesse privado e o interesse público, se expressa de modo incisivo na área da saúde, impondo aos analistas e gestores de política o risco de privilegiar ora a dimensão econômica, ora a social, sem estabelecer, entretanto, a necessária conexão entre ambas".
} 
Quadro 2 - Macrotendências na área da saúde, restrições e potencialidades da indústria farmacêutica e critérios para identificação de nichos estratégicos

\section{Macrotendências associadas a mudanças nos padrões de demanda, regulação e tecnologia}

Mudanças associadas à política de atenção à saúde: desospitalização, medicina personalizada, valorização da qualidade de vida, modelos de financiamento público-privado.

Mudanças associadas ao perfil socioeconômico e demográfico: envelhecimento populacional, novos padrões de vida, impacto de mudanças ambientais, urbanização.

Impacto das novas plataformas tecnológicas na biotecnologia e nanotecnologia - biologia molecular (genômica, proteômica etc.), bioinformática e bioimagem, nanobiotecnologia, ciências de materiais, sistemas de informação de alto desempenho e neurociência.

\section{Restrições e potencialidades da indústria de base química e biotecnológica brasileira}

Base produtiva e inovação

Crescimento expressivo do mercado farmacêutico nacional, papel destacado de laboratórios públicos nas vendas para o Sistema Único de Saúde, gargalos significativos na cadeia produtiva (insumos farmacêuticos ativos), investimentos reduzidos em atividades inovativas e $\mathrm{P} \& \mathrm{D}$, reduzida inserção na produção de medicamentos e fármacos por rota biotecnológica.

\section{Regulação}

Avanços recentes na regulamentação do poder de compra do Estado na área da saúde e ampliação dos gastos públicos em saúde, necessidade de adequação do marco regulatório para solução de problemas, no tocante ao registro de medicamentos e à pesquisa em biotecnologia.

\section{Infraestrutura de CT\&I}

Ampla gama de instituições e grupos consolidados de pesquisa na área da saúde, participação crescente na produção científica internacional na área da saúde, elevada capacitação em certos estágios de estudos clínicos, baixa interação universidade-empresa, carência de recursos humanos e de capacitações em áreas estratégicas, hiato-descolamento entre capacitação científica e desempenho tecnológico.

\section{Critérios para identificação de nichos estratégicos}

Papel das novas plataformas tecnológicas: ênfase na convergência de plataformas tecnológicas (biotecnologia, nanobiotecnologia e tecnologias de informação e comunicação), com reflexos nos procedimentos de atenção à saúde (medicina personalizada, telemedicina, prevenção de doenças degenerativas e novas rotas tecnológicas para vacinas ligadas tanto à prevenção como ao tratamento de doenças).

Identificação de áreas prioritárias para o Sistema Nacional de Inovação em Saúde.

Fonte: elaboração própria.

\section{Base produtiva, esforço inovativo e capacitação tecnológica}

Embora o padrão de investimento em P\&D no setor farmacêutico brasileiro esteja bastante distante do vigente no âmbito das grandes farmacêuticas mundiais, verifica-se, no decorrer dos últimos anos, um aumento expressivo tanto nas taxas de inovação como nos dispêndios em P\&D realizados pela indústria farmacêutica no país. ${ }^{4}$

Essa mudança gradativa no padrão de inovação do setor farmacêutico no Brasil pode ser observada, inicialmente, na evolução na taxa de inovação neste setor entre 1998 e 2011, apresentada

\footnotetext{
${ }^{4}$ O padrão global de dispêndio em P\&D por parte das grandes empresas farmacêuticas equivale, em média, a 15-20\% das vendas líquidas, consideravelmente inferior ao percentual de dispêndio em P\&D da indústria farmacêutica no Brasil. Para uma discussão mais ampla sobre este tema, ver Vargas et al., 2012.
} 
no Gráfico 4. O gráfico mostra, com base nos dados da Pesquisa de Inovação Tecnológica, realizada pelo Instituto Brasileiro de Geografia e Estatística (Pintec/IBGE), a evolução nas taxas de inovação do setor farmacêutico e farmoquímico em comparação com a taxa média de inovação na indústria de transformação para diferentes períodos cobertos pela pesquisa. Conforme pode ser observado, no período 1998-2000 a taxa de inovação na indústria farmacêutica foi de $46,8 \%$, ao passo que para o conjunto da indústria de transformação esta taxa foi de 31,5\%. Entre os períodos 1998-2000 e 20062008 verifica-se um aumento expressivo na taxa de inovação da indústria farmacêutica, que chega a $63,7 \%$ no período 2006-2008. Apesar de a indústria de transformação como um todo também ter ampliado sua taxa de inovação no período considerado, verifica-se que essa expansão foi mais forte no setor farmacêutico. Essa evolução expressiva nas taxas de inovação da indústria farmacêutica brasileira pode ser, em parte, atribuída a um processo de construção de capacitações que teve início com o mercado de genéricos e que, atualmente, se reflete no esforço para domínio da produção de medicamentos e fármacos a partir da rota biotecnológica.

Gráfico 4 - Taxa de inovação na indústria de transformação e na indústria farmacêutica. Brasil 1998-2011(em \%)

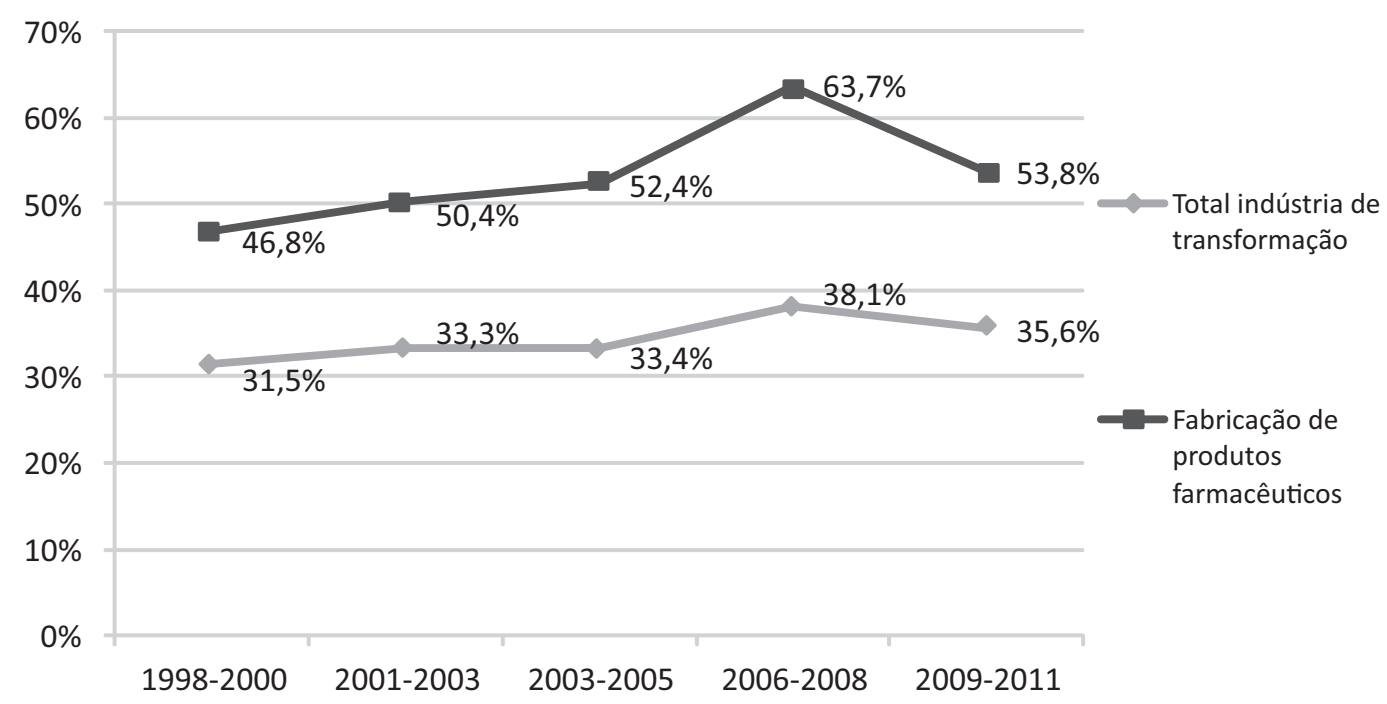

Fonte: elaboração própria com base em dados da Pintec/IBGE, 2002, 2005, 2007, 2010, 2013.

Outro elemento importante para a avaliação do esforço inovativo das empresas farmacêuticas no Brasil reside na análise da estrutura de dispêndio em atividades inovativas do setor farmacêutico a partir dos dados da Pintec/IBGE. O Gráfico 5 apresenta a evolução da estrutura para os diferentes períodos contemplados nessa pesquisa.

Em 2000, o dispêndio com atividades internas de P\&D, que constitui um elemento-chave no padrão de concorrência dessa indústria, representava apenas $0,83 \%$ do total da receita líquida de vendas, e em 2011 esse percentual aumentou para 2,39\%. Juntas, as atividades de P\&D internos e externos representaram cerca de $3 \%$ da receita de vendas em 2011, o equivalente a cerca de $\mathrm{R} \$ 1,14$ bilhão. 
Da mesma forma, percebe-se entre 2000 e 2011 um aumento na participação relativa dos gastos em P\&D internos, no total dos dispêndios em atividades inovativas. Em 2000, as atividades internas de P\&D representavam $14,6 \%$ do total do dispêndio em atividades inovativas. Essa participação aumentou para $15,3 \%$ em 2003, 17,4\% em 2005, 29,4\% em 2008 e chegou a 49,8\% em 2011. Ao mesmo tempo, verifica-se uma gradual redução na importância relativa dos dispêndios associados à compra de máquinas e equipamentos, que passam de 28,7\% em 2000 para 1,3\% em 2011, bem como dos gastos com a introdução de inovações tecnológicas no mercado, que passam de 20,9\% em 2000 para 3,2\% em 2011. Dessa forma, os dados da Pintec permitem evidenciar a consolidação de um novo padrão de dispêndio em atividades inovativas na indústria farmacêutica brasileira, que se reflete também no aumento da taxa de inovação deste setor.

Gráfico 5 - Estrutura do dispêndio em atividades inovativas no setor farmacêutico - Brasil, 2000, 2003, 2008 e 2011 (em \% da receita líquida de vendas)

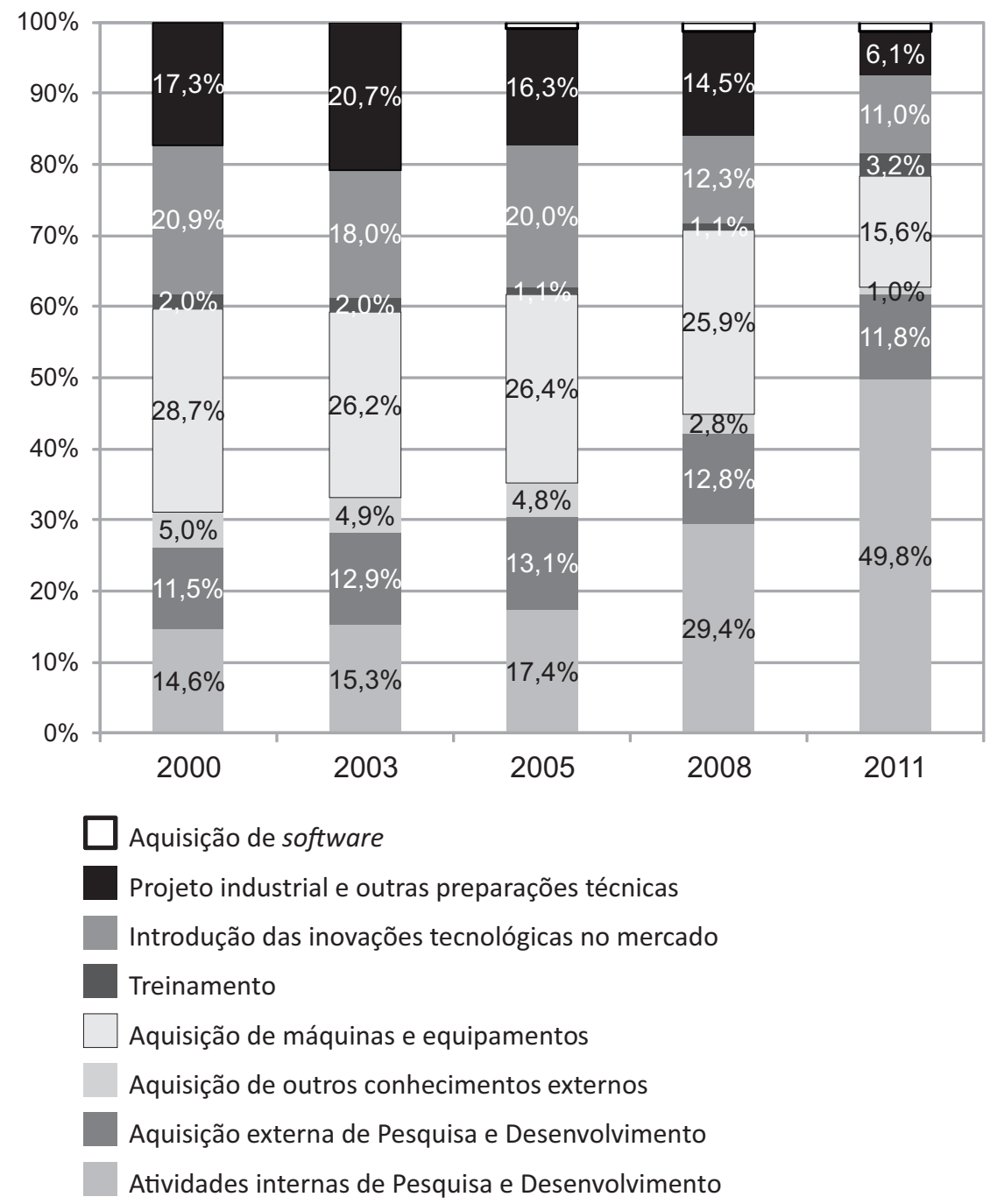

Fonte: elaboração própria com base em dados da Pintec/IBGE, 2002, 2005, 2007, 2010, 2013. 
O terceiro aspecto a ser destacado na análise do esforço inovativo da indústria farmacêutica no Brasil diz respeito às diferenças que podem ser observadas nos padrões de investimento das empresas farmacêuticas de capital nacional em relação às subsidiárias de empresas farmacêuticas de capital multinacional. O Gráfico 6, baseado em uma tabulação especial dos dados da Pintec/IBGE, mostra o dispêndio em atividades internas de $P \& D$ de empresas farmacêuticas com mais de quinhentos funcionários, em termos do percentual da receita líquida de vendas. O gráfico permite diferenciar esses gastos de acordo com a propriedade do capital das empresas (majoritariamente nacional ou estrangeiro). Conforme pode ser observado, os gastos com atividades internas de P\&D das grandes empresas farmacêuticas de capital nacional são consideravelmente mais altos do que os gastos das empresas de capital estrangeiro em todos os períodos considerados. Assim, em 2008, as grandes empresas farmacêuticas de capital nacional apresentaram um dispêndio de 3,6\% da sua receita líquida de vendas em atividades de P\&D, ao passo que no caso das grandes empresas de capital estrangeiro esse percentual foi de menos de 1\%. Esse tipo de evidência reforça a percepção de que as grandes empresas farmacêuticas de capital estrangeiro tendem a concentrar seus esforços de P\&D em seus países de origem. De fato, esse descompasso é ilustrado pelos dados da Associação da Indústria Farmacêutica Americana que mostram que, a despeito da presença marcante de empresas norteamericanas no mercado brasileiro, que representa $2 \%$ do mercado mundial, os gastos em pesquisa no Brasil por parte das empresas farmacêuticas norte-americanas correspondem a apenas 0,2\% dos seus gastos globais em pesquisa (Vargas et al., 2012).

Gráfico 6 - Evolução do dispêndio em atividades inovativas e P\&D internos em relação à receita líquida de vendas no setor de fabricação de produtos farmoquímicos e farmacêuticos. Brasil - 2000, 2003, 2005, 2008, 2011

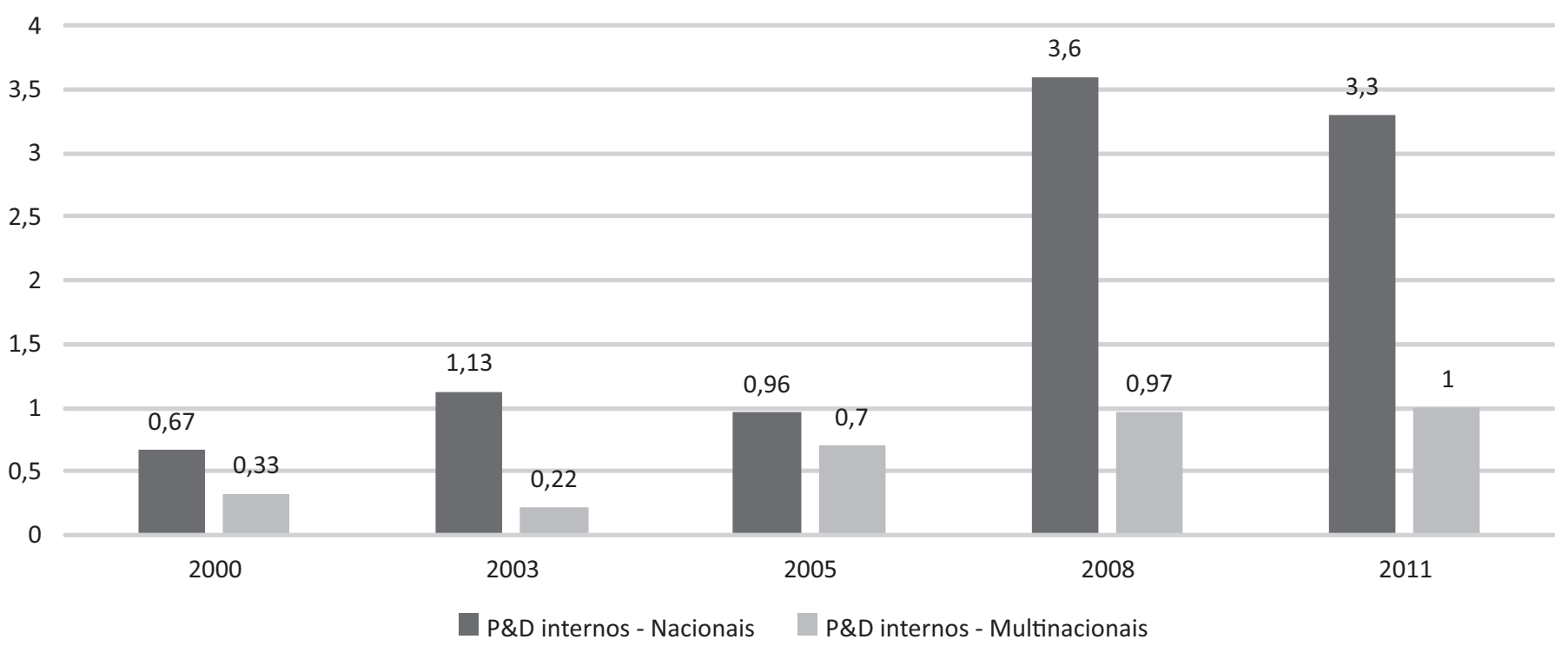

Fonte: elaboração própria com base em tabulação especial da Pintec/IBGE, 2002, 2005, 2007, $2010,2013$. 
Em síntese, as mudanças aqui evidenciadas no padrão de esforço inovativo e de taxa de inovação na indústria farmacêutica brasileira nos últimos anos podem ser atribuídas a um ciclo virtuoso de desenvolvimento deste setor no país, que resulta de uma forte convergência entre a política industrial e de inovação e a política de saúde (Vargas et al., 2012).

\section{Infraestrutura científica e tecnológica}

A infraestrutura científica e tecnológica constitui um elemento crucial do sistema nacional de inovação em saúde, e é o suporte fundamental para o desenvolvimento da indústria de base química e biotecnológica. No Brasil, entretanto, verifica-se que essa infraestrutura ainda é frágil e que os avanços em termos da construção de novas capacitações em pesquisa, desenvolvimento e inovação (PD\&I) ainda são limitados. Tal situação se reflete em um ciclo não virtuoso, no qual o investimento privado ainda fica aquém do necessário em PD\&I, aliado à incapacidade dos centros de P\&D na área da saúde para atender a demandas mais complexas do setor produtivo que convergem no sentido de limitar ainda mais a demanda pelos serviços desses centros. O rompimento desse ciclo requer mudanças que abrangem o marco regulatório e o aumento dos investimentos públicos e privados em ciência e tecnologia (C\&T) na área da saúde.

No Quadro 3 procurou-se sintetizar as restrições e potencialidades no concernente à capacitação científica e tecnológica e à infraestrutura de C\&T na área da saúde no Brasil, tendo em vista sua relação com as necessidades da indústria farmacêutica.

Quadro 3 - Restrições e potencialidades associadas à capacitação científico-tecnológica e à infraestrutura de CT\&I e desenvolvimento tecnológico na área da saúde. Brasil

\section{Capacitação científico-tecnológica na área da saúde}

\section{Restrições}

A participação relativa no número de pesquisadores e doutores é relativamente mais intensa em áreas como medicina e saúde coletiva do que em áreas como biofísica, bioquímica, genética e microbiologia, entre outras, que compõem bases de conhecimento importantes no domínio de novas plataformas tecnológicas.

Instituições de C\&T no país têm, em geral, cultura excessivamente acadêmica e dificuldades de interação com o mundo empresarial.

Apesar do amplo conhecimento disponível sobre o perfil de qualificação científica na área da saúde, falta clareza quanto à demanda de capacitações (qualitativa e quantitativa) no sentido de viabilizar o avanço do país em novas plataformas tecnológicas estratégicas, particularmente naquelas relacionadas à biotecnologia.

Há carência de centros de pesquisa especializados que apresentem certificação de acordo com exigências internacionais em estudos pré-clínicos.
O país conta com ampla gama de instituições e grupos consolidados de pesquisa na área da saúde.

A importância dessa infraestrutura científica se revela, em parte, na participação crescente e relevante do país na produção científica em termos de publicações internacionais.

O número de doutores formados e de grupos de pesquisa tem crescido, acompanhado pelo volume de publicações na área da saúde, apesar da grande concentração nos indicadores de formação de doutores e produção de artigos científicos nas universidades federais e na região Sudeste.

A interação de grupos de pesquisa na área da saúde com o setor produtivo tem aumentado nos últimos anos. 
Quadro 3 - Restrições e potencialidades associadas à capacitação científico-tecnológica e à infraestrutura de CT\&I e desenvolvimento tecnológico na área da saúde. Brasil (cont.)

\section{Capacitação científico-tecnológica na área da saúde}

\section{Restrições}

Diversos estudos pré-clínicos toxicológicos ainda não são realizados no país ou o são de forma incipiente (em farmacocinética, por exemplo).

Há carência de recursos humanos e de cursos de pós-graduação em diferentes áreas: toxicologia, metabolismo de fármacos, farmacocinética, transposição de escalas, patologia experimental etc.

Há baixa disponibilidade e qualidade de animais de laboratório para ensaios pré-clínicos.

Há poucas iniciativas para a construção de instalações dedicadas a atividades de escalonamento da produção (scaling-up), com boas práticas de fabricação, para o desenvolvimento e produção de lotes para estudos clínicos. Dentre os laboratórios que operam com prestação desse tipo de serviço destacam-se os produtores públicos Bio-Manguinhos e Butantan - e algumas pequenas empresas de base tecnológica, constituídas por profissionais experientes provenientes de determinados grupos universitários.

Fonte: elaboração própria.

Uma questão crucial para a inserção brasileira em novas plataformas tecnológicas estratégicas na área de saúde é o descompasso entre o grau de capacitação científica e a atualmente limitada capacidade de inovação na base produtiva da saúde. O principal empecilho na relação entre a produção de conhecimento nas universidades e a inovação no setor produtivo está no fato de que os resultados das pesquisas realizadas não se transformam em inovações. Adicionalmente, diante da baixa intensidade do esforço inovativo das empresas, as universidades e os centros tecnológicos acabam por reforçar o seu foco em atividades de pesquisa básica e deixam de avançar para etapas subsequentes do processo de P\&D voltadas para a viabilização da inovação em produtos e processos em escala industrial. A análise da infraestrutura de C\&T em saúde no Brasil demonstra que ainda há diversas lacunas nas etapas do processo de desenvolvimento tecnológico de medicamentos, apesar de sua maior capacitação na área de ensaios clínicos.

\section{Arcabouço institucional e marco regulatório}

No tocante às restrições e potencialidades associadas ao marco regulatório, é possível verificar uma ampla gama de questões que implicam a articulação deste com os requerimentos da inovação, envolvendo, entre outros, vigilância sanitária, propriedade intelectual, uso sustentável da biodiversidade, política de preços e carga tributária. No Quadro 4 apresenta-se uma relação parcial das questões regulatórias que têm impactado mais diretamente o segmento de fármacos e medicamentos. 
Quadro 4 - Restrições e potencialidades associadas ao marco regulatório

Marco regulatório

Restrições

A resolução da diretoria colegiada (RDC) 57/2009, que regulamenta o registro de insumos farmacêuticos ativos (IFAs) da Anvisa, ainda tem aplicação limitada a vinte produtos e favorece a entrada de IFAs importados sem exigência de controle sanitário.

Elevado tempo de tramitação no registro de medicamentos e na aprovação de testes pré-clínicos e clínicos.

Margem de preferência (de 25\% no máximo) é um instrumento importante, porém, segundo produtores, insuficiente para fazer frente à valorização cambial e aos preços chineses e indianos.
Potencialidades

Registro de produtos biológicos já conta com uma normativa da Anvisa (RDC 55/2010) que favorece a produção de produtos biológicos não novos.

Avanços significativos na regulamentação do poder de compra do Estado (lista de produtos estratégicos, margem de preferência etc.).

Modificação na Lei de Acesso ao Patrimônio Genético, sancionada pelo governo federal em maio de 2015, com que se pretende estimular a pesquisa sobre a biodiversidade no Brasil.

Novos instrumentos de apoio ao complexo industrial da saúde que têm sido adotados no âmbito do Grupo Executivo do Complexo Industrial da Saúde (Gecis), coordenado pelo Ministério da Saúde.

Fonte: elaboração própria.

Algumas das principais questões que servem de estímulo ou de barreira à atuação competitiva do segmento de fármacos e medicamentos vinculam-se ao ambiente regulatório. A elevada importância da regulação decorre do fato de que o ambiente produtivo da saúde está imerso em um campo da política social que a coloca como um direito a ser protegido e garantido. Tal questão manifesta-se de forma clara nas políticas regulatórias, sobretudo no campo sanitário (segurança e eficácia da produção em saúde); na propriedade intelectual (polarização entre o reforço da apropriação privada dos resultados da inovação e a garantia de acesso dos cidadãos aos bens em saúde); e na política de incorporação tecnológica dos novos produtos e procedimentos nos sistemas nacionais de saúde, uma vez que o peso público no mercado da inovação em saúde obriga o Estado a analisar o custoefetividade dos novos produtos para aceitar sua incorporação nas práticas e no sistema de saúde, mesmo nos sistemas universais mais avançados.

No decorrer da última década, observa-se um movimento importante em busca de maior articulação e conciliação entre a lógica sanitária - que implica padrões de segurança técnica e equilíbrio econômico no sistema - e as necessidades de fomentar a dinâmica de inovação e competitividade no segmento de biofármacos. Em outras palavras, percebe-se um claro avanço normativo da Agência Nacional de Vigilância Sanitária (Anvisa) no sentido de incorporar demandas do setor industrial que visam à adequação do marco regulatório. As iniciativas de implementação de ações para a solução de gargalos regulatórios envolveram a edição de diversas resoluções da diretoria colegiada da agência com vista a agilizar o processo de registro para produção de biológicos, como no caso da isenção de apresentação de dossiês completos para registro de produtos biológicos não inovadores. Em um âmbito regulatório mais amplo, destacam-se também as modificações recentes na Lei de Acesso ao Patrimônio Genético, sancionadas pelo governo federal em maio de 2015, que visa a estimular a pesquisa com a biodiversidade no país. Não obstante, persistem limitações regulatórias a serem 
superadas em um futuro próximo, particularmente no que se refere aos entraves burocráticos que resultam em aumento no tempo de tramitação, tanto no registro de medicamentos como no caso de ensaios clínicos e pré-clínicos.

\section{Inovação na Indústria Farmacêutica: análise preliminar das fronteiras tecnológicas e nichos tecnológicos na indústria farmacêutica brasileira}

As novas plataformas tecnológicas ligadas à área das ciências da vida têm recebido crescente atenção no escopo das políticas industriais, tecnológicas e de inovação adotadas no âmbito de diversos países. Ao passo que nas economias desenvolvidas tal prioridade reflete a preocupação com a manutenção da hegemonia e liderança no campo científico e tecnológico, no caso de economias emergentes tal escolha estratégica reflete um esforço de aproveitamento de janelas de oportunidades com vista à promoção de processos de catching $u p^{5}$ tecnológico e de inserção ativa e dinâmica na ordem internacional. ${ }^{6}$

Não obstante os impactos da recente crise financeira mundial em termos de pressões orçamentárias para cortes nos gastos públicos, o reconhecimento da importância que assume a contribuição econômica e social de plataformas tecnológicas ligadas à biofarmacêutica e à nanomedicina tem levado diversos países a implementar políticas e programas destinados a atrair para o território nacional as atividades de pesquisa e de produção relacionadas a este setor.

Em âmbito global, os setores ligados à área de ciências da vida abrangem um conjunto de atividades que integram a chamada indústria baseada em conhecimento e intensiva em pesquisa (knowledge-based industry). Além de responderem por um alto valor agregado nas economias nacionais e na geração de divisas, tais atividades apresentam elevado potencial de contribuir para o crescimento e a sustentabilidade de países e regiões e constituem um foco estratégico da política industrial e de CT\&I em diferentes países desenvolvidos e em desenvolvimento.

A existência de um modelo de atenção à saúde pautado pelo acesso universal, associada às mudanças nos padrões demográficos e epidemiológicos no país, tem ampliado consideravelmente a demanda por serviços de saúde e pressionado os gastos públicos com medicamentos, principalmente no que se refere à crescente incorporação de terapias baseadas nos avanços da biotecnologia e nanomedicina nas compras do Sistema Único de Saúde (SUS). A busca de competências nessas novas plataformas tecnológicas assume um caráter ainda mais estratégico para o país ao possibilitar o aumento da produção doméstica de medicamentos e fármacos que representam uma parcela

\footnotetext{
${ }^{5}$ Em perspectiva macroeconômica, o conceito de catching up parte da hipótese de que países tecnologicamente atrasados possam crescer a taxas maiores que os países que compartilham a fronteira da tecnologia mundial, mediante a utilização de conhecimentos já desenvolvidos por estes últimos (Abramovitz, 1986; UNCTAD, 2005).

${ }^{6}$ Cabe mencionar a percepção dos Estados Unidos sobre a importância associada ao domínio do paradigma da biotecnologia, inclusive na área da saúde, que está claramente definida no policy paper divulgado recentemente pelo governo norte-americano, intitulado "National bioeconomy blue print". Disponível em: <www.whitehouse.gov/ sites/default/files/microsites/ostp/national_bioeconomy_blueprint_april_2012.pdf>. Acesso em: 6 out. 16.
} 
significativa do déficit na balança comercial do CEIS. ${ }^{7}$ A incorporação dessas novas plataformas tecnológicas associadas à biotecnologia e à nanotecnologia exerce também elevado impacto econômico na base produtiva da saúde em função do potencial de mercado e do elevado valor agregado associado aos biofármacos e às aplicações da nanotecnologia nas áreas de diagnóstico, terapia e medicina regenerativa. No contexto atual, em que a expansão do mercado farmacêutico mediante a estratégia de produção de medicamentos genéricos já foi assimilada pelos grandes grupos farmacêuticos internacionais, o ingresso da indústria farmacêutica nacional em novas plataformas tecnológicas representa uma janela de oportunidade importante para o crescimento e consolidação desta indústria no país (Vargas et al., 2012).

Nesta seção conclusiva destacou-se, em um primeiro momento, o potencial de transformação associado às novas plataformas ligadas à biotecnologia e à nanotecnologia no campo da saúde e, particularmente, nos segmentos que integram a indústria farmacêutica (medicamentos, fármacos, vacinas, reagentes para diagnóstico, hemoderivados e soros). A seguir destacam-se alguns nichos que podem ser considerados estratégicos para o desenvolvimento da indústria farmacêutica nacional.

\section{As novas plataformas tecnológicas na área da saúde: nano e biotecnologia}

\section{Nanotecnologia}

A nanotecnologia envolve a manipulação de moléculas e estruturas em uma escala nanométrica (milionésima parte de um metro) ou atômica. A aplicação da nanotecnologia na área da saúde humana é denominada nanomedicina. Exemplos de aplicação da nanotecnologia na área da saúde residem no uso experimental de nanopartículas que atuam seletivamente na destruição de células neoplásicas em uma escala celular ou na administração de fármacos de forma mais eficaz.

As aplicações da nanotecnologia na saúde humana apresentam um impacto significativo nos diferentes segmentos da esfera da saúde, tanto nas áreas de diagnóstico e terapia como no campo da medicina regenerativa. No Quadro 5 estão exemplos de áreas de aplicação da nanotecnologia no campo da saúde nas quais esta já apresenta um impacto tangível e substancial no tratamento, diagnóstico e imageamento de diferentes tipos de doença.

\footnotetext{
${ }^{7}$ Cabe aqui, necessariamente, a ressalva de que o fortalecimento do sistema nacional de saúde e do atendimento das demandas em saúde não se limita à incorporação das novas plataformas tecnológicas na base produtiva da saúde. Tal questão envolve um amplo conjunto de dimensões, tais como as condições de acesso, desde a atenção primária até a atenção de alta complexidade, ou o foco necessário em doenças e medicamentos negligenciados, cuja análise transcende o escopo deste trabalho. Entretanto, registre-se que a diminuição do hiato tecnológico na indústria farmacêutica nacional constitui uma condição necessária, ainda que não suficiente, do processo de melhoria do sistema de saúde e fortalecimento da articulação entre a dimensão sociossanitária e a dimensão produtivo-tecnológica.
} 
Quadro 5 - Aplicações da nanotecnologia na área da saúde: terapia, diagnóstico e medicina regenerativa

\begin{tabular}{|c|c|c|c|}
\hline Desafios & Terapia & Diagnóstico/imagem & Medicina regenerativa \\
\hline $\begin{array}{l}\text { Doenças } \\
\text { cardiovasculares }\end{array}$ & $\begin{array}{l}\text { Modificação de superfícies de } \\
\text { implantes. }\end{array}$ & $\begin{array}{l}\text { Uso de nanopartículas em } \\
\text { theranostic (diagnóstico }+ \\
\text { terapia). }\end{array}$ & $\begin{array}{l}\text { Materiais bioativos inteligentes. } \\
\text { Mobilização de células-tronco } \\
\text { e homing at site injury (sistema } \\
\text { de implantação em lesões) }\end{array}$ \\
\hline $\begin{array}{l}\text { Doenças } \\
\text { neurodegenerativas }\end{array}$ & $\begin{array}{l}\text { Nanomecanismos semi- } \\
\text { invasivos para sistemas de } \\
\text { liberação (Parkinson). } \\
\text { Nanoformulações para } \\
\text { transposição de BBB (blood } \\
\text { brain barrier, barreira } \\
\text { hematoencefálica). }\end{array}$ & $\begin{array}{l}\text { Implantação de } \\
\text { neuroestimuladores } \\
\text { avançados guiados por } \\
\text { imagem. }\end{array}$ & $\begin{array}{l}\text { Sistemas de liberação para } \\
\text { moléculas neuroativas. } \\
\text { Biomateriais inteligentes para } \\
\text { controle da regeneração do } \\
\text { sistema nervoso central. }\end{array}$ \\
\hline Diabetes & $\begin{array}{l}\text { Medição e liberação de } \\
\text { insulina por nanomecanismos. }\end{array}$ & $\begin{array}{l}\text { Encapsulamento e } \\
\text { monitoramento de } \\
\text { transplantes de ilhotas. } \\
\text { Uso de nanopartículas para } \\
\text { imageamento da distribuição } \\
\text { de gordura no corpo inteiro. } \\
\text { Implante de sistemas não } \\
\text { invasivos de monitorização } \\
\text { contínua de glicose. }\end{array}$ & $\begin{array}{l}\text { Funcionalização de materiais } \\
\text { 2D e 3D para liberação de } \\
\text { fatores bioquímicos para } \\
\text { pâncreas artificial. }\end{array}$ \\
\hline Câncer & $\begin{array}{l}\text { Novas nanoformulações para } \\
\text { tratamento de tumores. } \\
\text { Nanopartículas aquecíveis por } \\
\text { radiofrequência para terapia. } \\
\text { Mecanismos implantáveis } \\
\text { para liberação controlada de } \\
\text { drogas. } \\
\text { Novas ferramentas } \\
\text { terapêuticas com modo de } \\
\text { ação físico. } \\
\text { Monitoramento de eficácia } \\
\text { terapêutica. }\end{array}$ & $\begin{array}{l}\text { Nanopartículas e agentes de } \\
\text { contraste para diagnóstico } \\
\text { (imageamento de partículas } \\
\text { magnéticas). } \\
\text { Compósitos de nanopartículas } \\
\text { para monitoramento de } \\
\text { terapias. } \\
\text { Endoscopia minimamente } \\
\text { invasiva/cateter para } \\
\text { diagnóstico e terapia. } \\
\text { Superfícies nanoestruturadas } \\
\text { para biossensores. }\end{array}$ & $\begin{array}{l}\text { Nanopartículas funcionalizadas } \\
\text { para ativação in vivo da } \\
\text { produção de células-tronco. }\end{array}$ \\
\hline
\end{tabular}

Fonte: Nanomedicine European Technology Plataform, 2013.

A elevada participação de aplicações ligadas a sistemas de liberação no âmbito da nanomedicina é ressaltada no levantamento recente realizado pela desenvolvido pela Bionest Partners para a associação da indústria farmacêutica francesa (Les Entreprises du Médicament), sobre o mercado da nanomedicina (LEEM, 2013). 
O desenvolvimento de novas plataformas tecnológicas no segmento da nanomedicina estendese usualmente a três áreas principais - terapia, diagnóstico e imagem, medicina regenerativa -, que envolvem diversos segmentos da indústria de base química e biotecnológica, tais como reagentes para diagnóstico (in vitro e in vivo), vacinas (profiláticas e terapêuticas), fármacos e medicamentos (Figura 1).

Figura 1 - Segmentação de produtos na área de nanomedicina

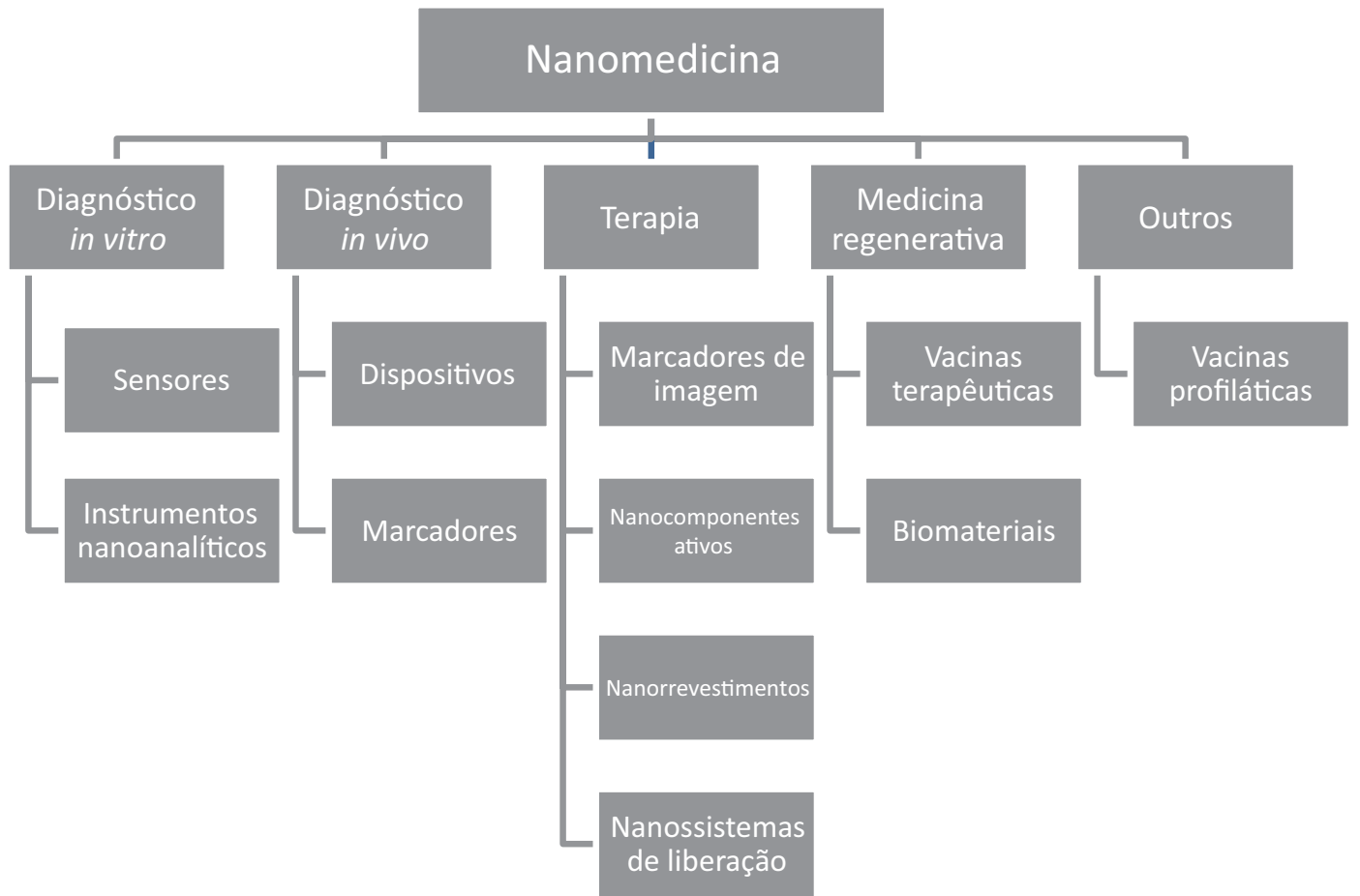

Fonte: elaboração própria com base em LEEM, 2013.

Em 2011, o mercado mundial da nanomedicina representava um montante estimado entre US\$ 50,1 e US\$ 68 bilhões, com estimativas de crescimento para um montante entre US\$ 97 e US\$ 129 bilhões até 2016. Desse total, os sistemas de liberação respondiam por 35\%, ou US\$ 17 bilhões, constituindo assim o segmento majoritário de vendas no mercado da nanomedicina. As aplicações ligadas aos sistemas de liberação de medicamentos e fármacos, por sua vez, deverão representar 46\% do mercado de nanomedicina, ou o equivalente a US\$ 44,6 bilhões (LEEM, 2013).

No caso do Brasil, é possível destacar algumas das aplicações da nanotecnologia na área da saúde que foram consideradas nichos estratégicos importantes para o país, em estudo prospectivo sobre as plataformas de nanotecnologia desenvolvido pelo Centro de Gestão e Estudos Estratégicos (Quadro 6). 
Quadro 6 - Aplicações da nanobiotecnologia na indústria farmacêutica no Brasil

\begin{tabular}{|l|l|}
\hline \multicolumn{1}{|c|}{ Aplicação } & \multicolumn{1}{c|}{ Uso } \\
\hline $\begin{array}{l}\text { Sistemas de entrega e liberação } \\
\text { controlada }\end{array}$ & $\begin{array}{l}\text { Uma das mais importantes aplicações da nanobiotecnologia, explora } \\
\text { nanobiomateriais com propriedades terapêuticas (fármacos). }\end{array}$ \\
$\begin{array}{l}\text { Materiais nanoestruturados } \\
\text { biocompatíveis }\end{array}$ & $\begin{array}{l}\text { Compreendem materiais (polímeros, cerâmicas, metais etc.) e seus } \\
\text { compósitos, estruturados em escala nanométrica e biocompatíveis. } \\
\text { Podem ter aplicações em reconstrução de órgãos para transplantes, } \\
\text { produção de insumos e próteses etc. }\end{array}$ \\
\hline Biossensores & $\begin{array}{l}\text { Compreendem uma classe de sensores biológicos e sondas } \\
\text { inteligentes in vivo e lab-on-a-chip (dispositivo que pode } \\
\text { integrar as funções de laboratório miniaturizado em um único } \\
\text { chip microprocessador usando volumes de líquidos na ordem } \\
\text { de nanolitros com aplicações na medicina diagnóstica). }\end{array}$ \\
Imageamento molecular & $\begin{array}{l}\text { Compreende uma nova classe de técnicas e métodos de diagnóstico } \\
\text { em nível molecular ou mediante o uso de sistemas moleculares para } \\
\text { geração de imagens. }\end{array}$ \\
\hline
\end{tabular}

Fonte: ABDI, 2010.

\section{Biotecnologia}

Ainda que os produtos farmacêuticos oriundos de síntese química respondam pela maior parte das receitas da indústria farmacêutica, os de origem biotecnológica estão entre os medicamentos mais vendidos no mundo e sua participação relativa no mercado farmacêutico global tem crescido expressivamente. Estima-se que até 2018 os produtos de origem biotecnológica deverão responder por aproximadamente $49 \%$ das vendas entre os cem principais produtos farmacêuticos no mercado global, ou o equivalente a US\$ 234 bilhões, ${ }^{8}$ conforme ilustra o Gráfico 7. Da mesma forma, sete dos dez produtos farmacêuticos mais vendidos no mundo serão medicamentos biotecnológicos, dentre os quais se destacam diferentes tipos de anticorpos monoclonais, outras proteínas terapêuticas e vacinas (Evaluate Pharma, 2013).

\footnotetext{
${ }^{8}$ Em 2011 essa participação era de 34\%, o que representou um montante de vendas de US\$142 bilhões e um crescimento de 51\% nas vendas de biofármacos entre 2011 e 2018 (Evaluate Pharma, 2012).
} 
Gráfico 7 - Mercado farmacêutico mundial por tecnologia de produção - 2002-2018* (em US\$ bilhões)

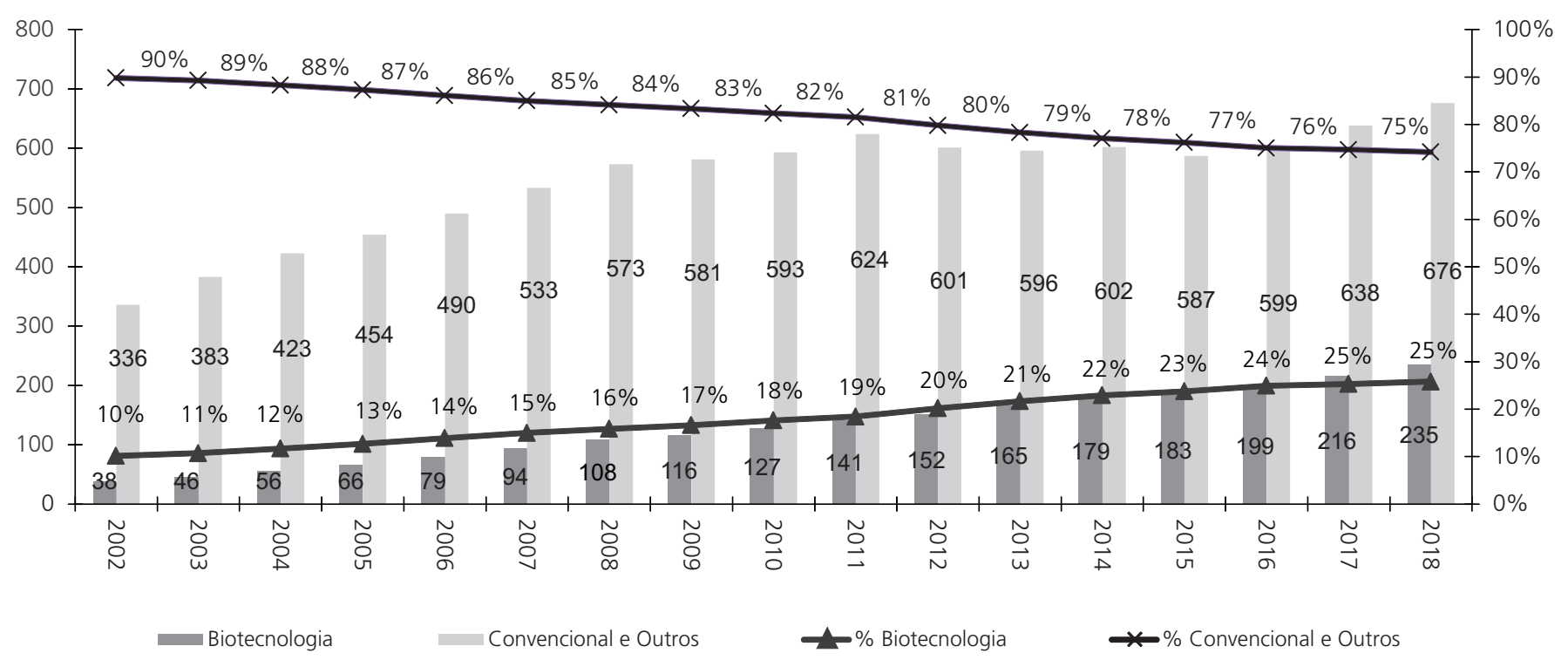

* Os dados para os anos de 2013 a 2018 são estimativas.

Fonte: Evaluate Pharma, 2013.

A trajetória futura de desenvolvimento da indústria farmacêutica, seja no mundo ou no Brasil, encontra-se necessariamente vinculada à incorporação da rota biotecnológica na produção de medicamentos e fármacos.

Os produtos biológicos para saúde podem ser classificados em três grupos principais: proteínas terapêuticas, anticorpos monoclonais e vacinas. A maior parte dos medicamentos biológicos comercializados atualmente no mercado mundial são proteínas recombinantes para fins terapêuticos usadas no tratamento de uma ampla gama de doenças crônicas tais como câncer, diabetes, doenças cardiovasculares, entre outras.

A produção de biofármacos pode envolver produtos de primeira ou de segunda geração. No primeiro grupo encontram-se medicamentos cujas patentes, em muitos casos, já expiraram e que apresentam menor complexidade tecnológica do que os de segunda geração, por se tratar de produtos com rotas de desenvolvimento conhecidas, tais como insulina, interferons, filgrastim e hormônios do crescimento. Os medicamentos biotecnológicos de segunda geração, por sua vez, encontram-se com patentes ainda vigentes e apresentam maior grau de complexidade tecnológica. Nesse grupo destacam-se tanto as versões melhoradas de produtos de primeira geração como os anticorpos monoclonais (Rituximabe, Adalimumabe, Dazatinibe etc.) que estão associados a terapias de primeira linha para uma ampla variedade de condições que incluem o câncer e doenças autoimunes (Reis, Landin \& Pieroni, 2011).

Em termos dos esforços de P\&D no segmento de medicamentos biotecnológicos, as áreas mais promissoras ainda estão associadas com o desenvolvimento de anticorpos monoclonais e proteínas 
de fusão, nos quais se verifica o maior número de moléculas com potencial aplicação no desenvolvimento de novos medicamentos em diferentes fases de estudos e plataformas tecnológicas novas em fase de exploração. No caso das proteínas terapêuticas, as frentes de desenvolvimento mais promissoras estão associadas aos fatores de coagulação recombinantes, plasmas e insulinas.

A produção de biossimilares constitui, atualmente, uma das principais janelas de oportunidade dos países em desenvolvimento para ingresso no mercado de biofármacos, tendo em vista que o marco regulatório desse mercado ainda está em processo de definição. A consolidação do mercado de biossimilares nos próximos anos deverá mudar consideravelmente o panorama do mercado de biofármacos no mundo.

No caso brasileiro, a incorporação da rota biotecnológica para a produção de medicamentos e outros produtos para a atenção à saúde humana tem suscitado um processo de mudança estrutural na indústria de base química e biotecnológica nacional. Tais mudanças decorrem de diversos fatores, que incluem a ação dos agentes privados, as transformações no cenário mundial e as políticas industriais e de inovação impulsionadas pelo Estado.

Nesse contexto verificam-se crescentes incentivos para que os produtores nacionais, públicos e privados, comecem a enxergar o segmento de produção de biológicos, especialmente aqueles que perdem a proteção patentária nestes anos. Esse movimento coincide com o interesse do Estado em impulsionar o barateamento da produção de medicamentos biológicos.

A produção de medicamentos por rota biotecnológica já conta com iniciativas importantes no Brasil, no âmbito tanto dos laboratórios públicos como dos laboratórios farmacêuticos privados de capital nacional. Ainda que muitas dessas iniciativas envolvam biofármacos de primeira geração, verifica-se o interesse crescente de agentes públicos e privados em consolidar o conjunto de competências necessárias para a produção de biofármacos de segunda geração.

A identificação da rota biotecnológica como um nicho estratégico para a produção de fármacos e medicamentos no país está contemplada tanto na política de desenvolvimento da base produtiva em saúde como no escopo das políticas de CT\&I. No primeiro caso destacam-se, entre outras, as políticas que têm sido implementadas com base no trabalho do Grupo Executivo do Complexo Industrial da Saúde (Gecis), coordenado pelo Ministério da Saúde, e que envolvem ampla gama de ações voltadas para a modernização de plantas de laboratórios públicos e estímulos à internalização da produção de biofármacos estratégicos para o sistema de saúde. No segundo, caberia mencionar a própria Política de Desenvolvimento em Biotecnologia aprovada em 2007, que define alvos estratégicos, áreas prioritárias e áreas de fronteira para inovações radicais em biotecnologia.

\section{Nichos estratégicos e soberania em saúde}

Por fim, além do impacto evidente das novas plataformas da nanotecnologia e da biotecnologia sobre os diversos segmentos que integram a indústria farmacêutica, caberia destacar pelo menos dois outros nichos que assumem importância estratégica no desenvolvimento da indústria farmacêutica nacional: o da produção de vacinas e o da produção de antibióticos. 


\section{Vacinas}

A escolha do segmento de vacinas como nicho prioritário está relacionada tanto à sua importância no âmbito da política nacional de saúde quanto às condições propícias para a consolidação da produção de vacinas no país. A indústria de vacinas é um segmento em que, no Brasil, o papel do Estado se revela fundamental, tanto no âmbito da produção por laboratórios públicos como no tocante ao poder de compra associado às políticas públicas de vacinação. ${ }^{9}$

Em 2010, as compras governamentais de vacinas para uso humano foram de cerca de 300 milhões de doses, com quatro laboratórios oficiais (Bio-Manguinhos, Butantan, Fundação Ataulpho de Paiva e Fundação Ezequiel Dias) tendo sido responsáveis por cerca de 93\% do número de doses produzidas, o que indica elevado grau de autossuficiência na produção nacional de vacinas.

Ao contrário do contexto que caracteriza o déficit estrutural na balança comercial dos segmentos de medicamentos, fármacos e hemoderivados, o segmento de vacinas no país já conta com relativa autossuficiência na produção para atender ao Programa Nacional de Imunização (PNI). Não obstante, verifica-se ainda clara necessidade de avanços no tocante ao aumento do conteúdo tecnológico da produção nacional, particularmente no desenvolvimento e produção de vacinas de terceira geração.

Assim, a ampliação da participação do Brasil não somente na produção, mas principalmente no conteúdo tecnológico das vacinas produzidas, deve constituir uma prioridade em termos de políticas públicas e está diretamente associada à ampliação dos investimentos em modernização de plantas de produção, formação de quadros e intensificação nos esforços de transferência tecnológica.

No âmbito de laboratórios públicos como Bio-Manguinhos e Butantan, verifica-se um esforço para a introdução de novas vacinas que atendam às demandas do Ministério da Saúde no tocante ao PNI e permitam ampliar as exportações principalmente para o mercado da América Latina. Verificase a progressiva inserção desses produtores públicos na produção de vacinas tecnologicamente mais complexas, de terceira geração, tais como a vacina contra hepatite $\mathrm{B}$, a vacina contra a gripe, a tríplice viral e aquela contra Haemophilus influenzae tipo B (Gadelha, Maldonado \& Vargas, 2008; Gadelha et al., 2012).

A escolha da produção de vacinas como segmento prioritário e tendo como ponto focal os produtores públicos implica também a solução de diferentes limitações que envolvem aspectos relativos à modernização das plantas produtivas e a própria redefinição de modelos jurídicos de gestão que sejam compatíveis com as atividades de produção industrial e sustentáveis do ponto de vista econômico e tecnológico.

Finalmente, a priorização do segmento de vacinas deve ainda ser orientada por estratégias de políticas públicas que estejam alinhadas com as principais tendências que marcarão o seu desenvolvimento nos próximos anos e que incluem, entre outras:

\footnotetext{
${ }^{9}$ Por um lado, o avanço na produção de vacinas no país foi possível em virtude de um programa de investimento em que se associou aumento da capacidade de oferta interna e melhoria da qualidade, tendo como marco o Programa de Autossuficiência Nacional em Imunobiológicos (Pasni), criado em 1985. Além disso, o Programa Nacional de Imunizações (PNI), lançado em 1971, constitui uma iniciativa internacionalmente reconhecida de vacinação em massa em um país com as dimensões populacional e territorial do Brasil.
} 
1) crescente introdução de vacinas vivas, vacinas DNA, de vetores ou de subunidade recombinante;

2) desenvolvimento de novos adjuvantes;

3) esforço na introdução de novas vias de administração (intranasais, orais, adesivos, sem agulha etc.) associado ao desenvolvimento de tecnologias que permitam a armazenagem em temperatura ambiente;

4) melhoria de vacinas e desenvolvimento de novas combinações com redução no número de doses como fator de orientação das estratégias de mercado;

5) desenvolvimento de antígenos de subunidades de proteínas, vacinas personalizadas para grupos populacionais específicos e vacinas terapêuticas;

6) aumento dos investimentos em farmacovigilância;

7) surgimento de novas vacinas com altas margens (blockbusters) voltadas para as necessidades de saúde não atendidas (Fiocruz, 2010).

\section{Antibióticos}

Outro nicho prioritário é o da produção doméstica de antibióticos (medicamentos e insumos farmacêuticos ativos), particularmente de produtos obtidos por biossíntese. A produção dessa classe de produto farmacêutico se reveste de caráter estratégico, particularmente em termos da soberania nacional em saúde.

Em âmbito internacional verifica-se que a produção, e particularmente a manutenção de programas robustos de pesquisa em antibióticos, envolve um número restrito de grandes laboratórios farmacêuticos multinacionais, dentre os quais se destacam o AstraZeneca e a GlaxoSmithKline (GSK). As vendas globais de antibióticos estavam estimadas em mais de US\$ 40 bilhões em 2010 e representavam $4 \%$ do mercado farmacêutico global. Por se tratar de um mercado maduro com taxas de crescimento declinantes na última década, e, portanto, de menor retorno comercial, a produção de antibióticos não costuma atrair a atenção das big pharma. Adicionalmente, o principal desafio da pesquisa nessa área reside no surgimento de espécies bacterianas resistentes aos diferentes antibióticos e nas dificuldades associadas aos ensaios clínicos, que exigem a identificação e o recrutamento de pacientes com características específicas de infecções bacterianas.

Entretanto, são precisamente a preocupação com a crescente resistência de doenças bacterianas aos antibióticos existentes e a consequente subalocação do investimento privado em PD\&I nesta área que têm recolocado a produção e pesquisa em antibióticos como foco prioritário na agenda recente da política industrial e tecnológica em países que lideram o mercado farmacêutico global. Nos Estados Unidos, entre 1983 e 1992 a FDA aprovou trinta novos antibióticos, ao passo que de 2003 a 2012 apenas sete novos antibióticos foram aprovados pela agência reguladora. Assim, com o objetivo de promover a ampliação da pesquisa com antibióticos, em maio de 2012 um subcomitê foi formado no Congresso norte-americano para iniciar um debate sobre o incentivo à pesquisa com antibióticos, que deve incluir medidas como a extensão do período de vigência de patentes. No âmbito da União Europeia, a Comissão Europeia, em conjunto com a Associação da Indústria Farmacêutica Europeia, 
iniciou o detalhamento de um pacote de instrumentos de apoio à pesquisa com antibióticos de US\$ 760 milhões (The Economist, 2012).

Em termos nacionais, a balança comercial brasileira de antibióticos é deficitária, tanto no segmento de medicamentos como no de insumos farmacêuticos. No segmento de fármacos, a importação de antibióticos - que correspondem ao código NCM (Nomenclatura Comum do Mercosul) 2941 - respondia em 2011 por aproximadamente 10\% do déficit na balança comercial do segmento. Dentre os antibióticos com maior participação nas importações de fármacos destacam-se a amoxilina e seus sais $(1,22 \%)$, a tetraciclina $(0,85 \%)$, outros macrolídeos $(0,81 \%)$, cefaclor e cefalexina $(0,64 \%)$, além de outros antibióticos diversos agrupados sob o NCM 29419099 (1,98\%). No segmento de medicamentos, a importação de antibióticos, sob o NCM 30042, foi de um montante de US\$ 218 milhões em 2011, o que equivale a 6\% do déficit do segmento de medicamentos no período. Nesse conjunto de produtos importados encontram-se tanto fármacos e medicamentos produzidos por rota sintética e semissintética como aqueles produzidos por rota biotecnológica.

No âmbito das compras do SUS, esse tipo de medicamento é objeto de compra descentralizada, o que dificulta o uso do poder de compra do Ministério da Saúde para induzir o aumento da produção local. Ainda assim, o país conta com diversos laboratórios farmoquímicos e farmacêuticos nacionais, que atuam na produção de antibióticos e têm demonstrado interesse em expandir sua produção mediante o investimento em novos produtos com maior valor agregado.

Em termos estratégicos, trata-se de buscar espaços para promover um alinhamento entre as políticas de apoio governamental ao desenvolvimento da base produtiva em saúde e as estratégias de laboratórios farmoquímicos e farmacêuticos nacionais para a produção de antibióticos, mediante a orientação dos instrumentos de apoio às atividades de PD\&I relacionadas a vias de biossíntese de antibióticos.

Em síntese, o apoio a pesquisas e à produção de novos antibióticos no país deve ser considerado prioritário por diferentes razões:

1) o aparecimento de novos patógenos e a seleção de resistentes;

2) a intensificação da aquisição de múltiplos níveis de resistência pelas bactérias;

3) a permanência de variados efeitos colaterais indesejáveis dos antibióticos existentes, que devem ser eliminados;

4) a inexistência ou escassez de tratamento efetivo para múltiplas doenças tropicais como malária, doença de Chagas, leishmaniose e diversos tipos de diarreias.

Finalmente, no caso do Brasil, além das medidas de incentivo à ampliação do esforço de PD\&I na área de antibióticos, a expansão da produção doméstica deste tipo de medicamento, com vista ao mercado local e às exportações, deve enfrentar também as limitações associadas à fragilidade da base produtiva farmoquímica, um elo central da cadeia de produção farmacêutica. 


\section{Referências}

ABRAMOVITZ, M. Catching up, forging ahead, and falling behind. Journal of Economic History, 46: 386-406, 1986.

AGÊNCIA BRASILEIRA DE DESENVOLVIMENTO INDUSTRIAL (ABDI). Panorama nanotecnologia. Cadernos da Indústria ABDI, XIX, 2010.

DELOITTE. Acquisition versus product development: an emerging trend in life science. s.l.: M\&A Industry Advantage Series, 2009. Disponível em: < https://pt.scribd.com/document/56792814/Acquisitions-VersusProduct-Development>. Acesso em: 10 ago. 2014.

EVALUATE PHARMA. World preview 2018: embracing the patent cliff. EUA: s.n., 2012. Disponível em: <www. evaluategroup.com/public/EvaluatePharma-World-Preview-2018-Embracing-the-Patent-Cliff.aspx > . Acesso em: 5 ago. 2014.

EVALUATE PHARMA. World preview 2018: returning to growth. EUA: s.n., 2013. Disponível em: < http://info. evaluategroup.com/rs/evaluatepharmaltd/images/World_Preview_2013_Outlook_to_2018_Infographic.pdf $>$. Acesso em: 5 ago. 2014.

FUNDAÇÃO OSWALDO CRUZ (FIOCRUZ). Instituto de Tecnologia em Imunobiológicos. Planejamento Estratégico 2010-2020, 2010 (Mimeo.)

GADELHA, C.; MALDONADO, J. \& VARGAS, M. A. Estudo setorial sobre a indústria farmacêutica. Nota técnica do Projeto Uma Agenda de Competitividade para a Indústria Paulista. São Paulo: Instituto de Pesquisas Tecnológicas do Estado de São Paulo, 2008.

GADELHA, C. et al. A Dinâmica do Sistema Produtivo da Saúde: inovação e complexo econômico-industrial. Rio de Janeiro: Editora Fiocruz, 2012.

GELIJNS, A.C. \& ROSENBERG, N. The changing nature of medical technology Development. In: ROSENBERG, N.; GELIJNS, A.C. \& DAWKINS, H. (Eds.). Sources of Medical Technology: universities and industry. Washington: National Academy Press, 1995.

INSTITUTE FOR HEALTHCARE INFORMATICS (IMS). The Global Use of Medicines: outlook through 2017. Parsippany: IMS, 2013.

INSTITUTO BRASILEIRO DE GEOGRAFIA E ESTATÍSTICA (IBGE). Pesquisa Industrial de Inovação Tecnológica 2000. Rio de Janeiro: IBGE, 2002.

INSTITUTO BRASILEIRO DE GEOGRAFIA E ESTATÍSTICA (IBGE). Pesquisa Industrial de Inovação Tecnológica 2003. Rio de Janeiro: IBGE, 2005.

INSTITUTO BRASILEIRO DE GEOGRAFIA E ESTATÍSTICA (IBGE). Pesquisa Industrial de Inovação Tecnológica 2005. Rio de Janeiro: IBGE, 2007.

INSTITUTO BRASILEIRO DE GEOGRAFIA E ESTATÍSTICA (IBGE). Pesquisa Industrial de Inovação Tecnológica 2008. Rio de Janeiro: IBGE, 2010.

INSTITUTO BRASILEIRO DE GEOGRAFIA E ESTATÍSTICA (IBGE). Pesquisa Industrial de Inovação Tecnológica 2011. Rio de Janeiro: IBGE, 2013.

LES ENTREPRISES DU MÉDICAMENT (LEEM). Applications des nanotechnologies à la médecine, 2013. Disponível em: <www.etp-nanomedicine.eu/public/press-documents/publications/public-documents/bionestpartners-2014-nanomedicine-study-leem/Rapport\%20final\%20version\%20definitive.pdf $>$. Acesso em: 5 ago. 2014.

NANOMEDICINE EUROPEAN TECHNOLOGY PLATAFORM. European technology platform for nanomedicine: nanotechnologies for breakthroughs in healthcare. Luxembourg: Office for Official Publications of the European Communities, 2013. Disponível em: <www.etp-nanomedicine.eu/public/press-documents/publications/etpdocuments/ETPN\%20flyer\%202013\%20long\%20version>. Acesso em: 5 ago. 2014. 
PHARMACEUTICAL RESEARCH AND MANUFACTURES OF AMERICA (PhRMA). Pharmaceutical Industry Profile 2011. Washington: PhRMA, 2011.

PRICE WATERHOUSE COOPERS (PWC). Pharma 2020: from vision to decision, 2013. Disponível em: <www. pwc.com/gx/en/pharma-life-sciences/pharma2020/index.jhtml>. Acesso em: 3 ago. 2014.

REIS, C.; LANDIN, A.\& PIERONI, J. P. Lições da Experiência Internacional e Proposta para Incorporação da Rota Biotecnológica na Indústria Farmacêutica Brasileira. Rio de Janeiro: BNDES, 2011.

THE ECONOMIST. The path of least resistance, May 12 2012. Disponível em: <www.economist.com/ node/21554542 >. Acesso em: 3 ago. 2014.

UNITED NATIONS CONFERENCE ON TRADE AND DEVELOPMENT (UNCTAD). Panel on bridging the technology gap between and within nations. Morocco, 2005. Disponível em: < http://unctad.org/en/Docs/ ecn162006crp1_en.pdf>. Acesso em: 3 ago. 2014.

VARGAS, M. A. et al. Inovação na indústria química e biotecnológica em saúde: em busca de uma agenda virtuosa. Revista de Saúde Pública, 46: 37-40, 2012.

VARGAS, M. A. et al. Indústrias de base química e biotecnologia voltadas para a saúde no brasil: panorama atual e perspectiva para 2030. In: GADELHA, P.; CARVALHO, J. N. \& PEREIRA, T. R. (Orgs.). A Saúde no Brasil em 2030: diretrizes para a prospecção estratégica do sistema de saúde brasileiro. Rio de Janeiro: Fiocruz, Secretaria de Assuntos Estratégicos da Presidência da República, Ipea, Ministério da Saúde, 2013. 



\title{
BASE BIOTECNOLÓGICA NO BRASIL: DESAFIOS E NICHOS ESTRATÉGICOS
}

\author{
Leonardo Batista Paiva \\ Leonardo Costa Ribeiro
}

Com o intuito de delinear um cenário do desenvolvimento tecnológico para o período de 2014 a 2030, desenvolvemos uma análise prospectiva para o setor da biotecnologia em saúde. Tal análise se pautou em dados empíricos, em algumas metodologias publicadas em artigos científicos e em entrevistas com especialistas da área. Para seu desenvolvimento, iniciamos com um panorama geral do sistema nacional de inovação em biotecnologia, abordando tanto o cenário mundial quanto o nacional, identificando suas peculiaridades, o que é apresentado na primeira seção do texto, "Panorama geral do Sistema Nacional de Inovação (SNI)".

Na segunda seção, "Políticas para biotecnologia”, listamos e caracterizamos as principais políticas públicas desenvolvidas nos últimos anos para incentivo e construção tecnológica da biotecnologia em saúde no Brasil.

Na terceira seção, "A dinâmica de inovação tecnológica em biotecnologia", identificamos tal dinâmica por meio da análise das patentes depositadas no Instituto Nacional de Propriedade Industrial (INPI), tendo em vista uma leitura do cenário nacional e da forma como as tecnologias internacionais nele estão se inserindo. Para uma leitura do cenário internacional e do modo como o Brasil nele se insere, fizemos duas análises: na primeira, tomando como base as patentes depositadas no United States Patent and Trademark Office (USPTO), visamos a construir as matrizes de interação entre ciência e tecnologia e seu recorte para a biotecnologia em saúde; na segunda, além das patentes depositadas no USPTO, identificamos os artigos científicos indexados no Institute for Scientific Information (ISI) e citados nessas patentes, tendo em vista a caracterização das redes globais de inovação.

Na quarta seção, “Tendências tecnológicas, lacunas, desafios e potencialidades", identificamos os estágios atuais de desenvolvimento das principais tecnologias para biotecnologia em saúde e traçamos a perspectiva de desenvolvimento dessas tecnologias ao longo do tempo.

Na última seção apresentamos nossas conclusões e recomendações.

\section{Panorama Geral do Sistema Nacional de Inovação (SNI)}

Diversos estudos teóricos e práticos têm indicado a crescente importância da inovação para a sobrevivência e o crescimento das firmas no cenário econômico atual, e, como decorrência, a grande influência que a inovação tem exercido na definição da distribuição da riqueza mundial e na hierarquia econômica entre os países. Nesse contexto, a biotecnologia ganha especial relevância devido à intensa 
necessidade de inovações tecnológicas para seu desenvolvimento e também ao grande potencial econômico dos produtos biológicos no mercado mundial.

\section{Inovação tecnológica em biotecnologia aplicada à saúde}

A base teórica econômica para a inovação foi estabelecida por Schumpeter em sua obra Teoria do Desenvolvimento Econômico, de 1911. Schumpeter (1985) rompeu com a tradicional forma de pensar sobre o sistema econômico, em que este era avaliado somente em seu estado de equilíbrio, e postulou que a inovação é o fator que constantemente o retira desse estado, imprimindo-lhe uma dinâmica temporal.

A inovação é importante para a definição do cenário econômico porque atribui à firma inovadora um poder temporário de monopólio: enquanto se diferencia dos concorrentes por apresentar um produto ou processo produtivo exclusivo ela pode cobrar um "preço prêmio" (acima do mercado) por seu produto. Esse processo leva ao aumento do lucro da firma e a maior remuneração do capital investido. Dessa forma, estudar a distribuição da riqueza mundial entre as nações pressupõe estudar sua capacidade de inovação, pois esta, conforme a teoria de Schumpeter, é uma importante forma de apropriação de riqueza.

Na tipologia proposta por Schumpeter para a inovação, esta é classificada como incremental ou radical. As inovações incrementais representam uma alteração sobre uma tecnologia ou produto já conhecido e as radicais implicam uma ruptura com o estado da arte tecnológica da sua época.

Dado seu caráter inovativo e a necessidade de desenvolvimento tecnológico que pressupõem, os produtos biológicos podem ser classificados como inovações radicais, de sorte que, em geral, toda a cadeia do processo inovativo será percorrida até a entrada do novo produto ou processo no mercado, geralmente tida como a culminância de um processo de inovação.

Nas áreas da bioquímica e biológica, a proteção intelectual por meio do registro de uma patente é um dos caminhos, com resultados efetivos, pelos quais as empresas optam por proteger o seu desenvolvimento tecnológico. E como essa proteção é um passo intermediário do processo inovativo, uma análise do depósito de patentes permite inferir, de forma probabilística devido às incertezas desse processo, perspectivas de futuro para o mercado em análise, tais como empresas potencialmente entrantes no mercado, países líderes em tecnologia etc., a curto ou médio prazo.

\section{Panorama global dos SNIs}

No cenário de alta importância do desenvolvimento tecnológico para a definição do desenvolvimento econômico das nações e da alta intensidade tecnológico envolvida no desenvolvimento dos produtos biológicos, uma análise da situação atual do mercado relacionado a esses produtos ganha relevância. É necessário também avaliar se haveria nesse mercado especificidades que o diferenciariam dos demais mercados e o tornariam mais dependente de inovações.

\section{Análise de mercado}

Alguns trabalhos recentes (Reis, Pieroni \& Souza, 2010; Reis, Landim \& Pieroni, 2011) indicam que a indústria farmacêutica mundial está passando por uma fase de redução de margens de lucro, 
devido à popularização dos medicamentos genéricos e à queda de produtividade observada nas atividades de pesquisa e desenvolvimento (P\&D). Mesmo com o crescimento dos investimentos em $\mathrm{P} \& \mathrm{D}$, o número de novos medicamentos registrados anualmente está em declínio. Outra característica desta fase é a expiração de patentes de medicamentos muito lucrativos, o que faz com que as empresas busquem outras fontes de receita.

Para a sustentabilidade a longo prazo da indústria farmacêutica nesse cenário, as empresas têm buscado produtos de maior valor agregado, como os de base biotecnológica. Esta fase, somada à demanda social, tem servido como um motivador de mercado para o crescente interesse das empresas farmacêuticas pelo desenvolvimento de produtos biotecnológicos.

Tal tendência de desenvolvimento interno em biotecnologia tem sido observada em diversos países. China, Índia e Israel, por exemplo, estão utilizando incentivos regulatórios, de financiamento e, mais amplamente, de política industrial, para se capacitarem na produção de medicamentos biológicos, em especial de biossimilares.

Segundo Reis, Pieroni e Souza (2010), com base em informações do Evaluate Pharma, o crescimento das vendas de biológicos foi de $17 \%$ entre 2002 e 2010, ao passo que o crescimento médio dos demais produtos farmacêuticos foi de 7\%. Fazendo-se uma projeção com essa taxa de crescimento, espera-se que em 2016 os produtos biotecnológicos representem cerca de $21 \%$ das vendas. O indicador desse crescimento é o aumento do número de registros de novos produtos biológicos: em 2010, o registro de novos produtos biológicos nos Estados Unidos da América (EUA) representou 44\% do total de registros novos, contra 35\% em 2002.

Segundo Campbell (2011), grande parte do crescimento do mercado farmacêutico previsto para os próximos anos se deve aos países emergentes, em que está havendo maior inclusão de contingentes populacionais na demanda por produtos de saúde.

Espera-se que os medicamentos biotecnológicos passem de cinco para sete entre os dez produtos farmacêuticos mais vendidos. Entre eles, destacam-se os anticorpos monoclonais (Humiraadalimumabe, Avastin-bevacizumabe, Rituxan-rituximabe, Herceptin-trastuzumabe, Remicadeinfliximabe), a proteína terapêutica Enbrel-etanercepte e a vacina antipneumocócica Prevnar13 (Evaluate Pharma, 2016; OECD, 2009).

\section{Biossimilares}

Outra peculiaridade do mercado de medicamentos biológicos é a questão dos biossimilares, que são os equivalentes aos genéricos dos produtos de origem sintética.

Apesar da equivalência entre os genéricos e os biossimilares, não é possível aplicar o mesmo arcabouço regulatório de registro e produção para ambos os tipos de medicamentos, devido à maior complexidade tecnológica do desenvolvimento dos produtos biológicos.

Embora tenham se esforçado, diversas agências regulatórias do mundo não conseguiram definir marcos regulatórios compatíveis entre si, o que gerou um tratamento heterogêneo para os biossimilares entre os países e, consequentemente, dificuldades em estabelecer intercambialidade entre os produtos. 
Além disso, as altas barreiras à entrada no mercado, tais como dificuldades tecnológicas e o custo de desenvolvimento e produção de biotecnológicos, tendem a levar à redução do número de empresas e também do número de empresas de maior porte no mercado. Somando-se a isso a falta de garantia de intercambialidade, vê-se que nesse mercado, assim como no mercado de genéricos, não há, a médio prazo, tendência à competição por preços. O que pode tornar marca e credibilidade características importantes na concorrência entre as empresas no mercado biotecnológico (Ferman, 2010).

\section{Marco regulatório para registro e produção de produtos biológicos}

Para regular a produção e registro de produtos biológicos, a Agência Nacional de Vigilância Sanitária (Anvisa) publicou as novas resoluções de sua diretoria colegiada, RDC 55/2010 e RDC $17 / 2010$, alterada pela RDC 33/2015. Com isso o Brasil entra no grupo dos poucos países que têm uma norma específica para produtos biológicos. A RDC 55/2010 da Anvisa possibilita duas vias para o registro de produtos biológicos: a via do desenvolvimento individual e a via de desenvolvimento por comparabilidade.

Nessas normas, a Anvisa não utiliza o termo biossimilar, mas sim produto biológico, em contraponto ao termo produto biológico novo. Conforme definido na norma, "produto biológico novo" é o "medicamento biológico que contém molécula com atividade biológica conhecida, ainda não registrado no Brasil, e que tenha passado por todas as etapas de fabricação". "Produto biológico", por sua vez, é definido como "medicamento biológico não novo ou conhecido que contém molécula com atividade biológica conhecida, já registrado no Brasil, e que tenha passado por todas as etapas de fabricação".

Pela via do desenvolvimento individual, deve ser apresentado à Anvisa um relatório completo do medicamento, incluindo dados de caracterização do produto, descrição detalhada do processo produtivo, comprovação de segurança e eficácia clínicas demonstradas por meio de estudos não clínicos e clínicos. Nessa via pode haver flexibilidade, após análise do caso, quanto aos ensaios não clínicos e aos testes clínicos das fases 1 e 2, que podem ser dispensados ou simplificados. Mas os testes da fase 3 são sempre obrigatórios - com exceção para os casos de hemoderivados, vacinas e produtos com indicação oncológica - e devem demonstrar a não inferioridade, a equivalência clínica ou a superioridade em relação ao produto biológico novo.

Para o registro pela via de comparabilidade, por sua vez, exige-se a apresentação de dados que demonstrem a qualidade e a comparabilidade do produto não novo em relação ao produto biológico comparador. São necessários também estudos não clínicos de farmacodinâmica e toxicidade, e estudos clínicos de farmacocinética, farmacodinâmica e estudo pivotal de segurança e eficácia.

Apesar dos avanços representados pela publicação da RDC 55/2010, não foi observada tendência de crescimento do número de registro de produtos biológicos, resguardada a hipótese de que tenha havido desistência de registrar determinados produtos.

Na RDC 17/2010, alterada pela RDC 33/2015, dispõe-se sobre os requisitos mínimos a serem seguidos quando da fabricação de medicamentos, a fim de padronizar a verificação do cumprimento das boas práticas de fabricação (BPF) de medicamentos de uso humano durante as inspeções sani- 
tárias. O título IV da norma reforça os pontos específicos sobre a fabricação de produtos biológicos no que se refere a pessoal, instalações, equipamentos e instalação para animais.

Ao contrário dos produtos farmacêuticos convencionais, que normalmente são fabricados e controlados com técnicas químicas e físicas reprodutíveis, a forma como os produtos biológicos são produzidos, controlados e administrados requer precauções especiais necessárias. Os produtos biológicos são fabricados com tecnologias que envolvem processos e materiais biológicos passíveis de variação. Os processos de produção de biológicos têm uma variabilidade intrínseca e, portanto, a natureza dos subprodutos não é constante. Por essa razão, na fabricação de produtos biológicos é ainda mais fundamental o cumprimento das recomendações estabelecidas pelas BPF, durante todas as fases de produção.

\section{Especificidades do panorama nacional do SNI}

Será avaliado agora o cenário nacional do mercado relacionado à biotecnologia, observando-se suas especificidades em relação ao cenário mundial apresentado anteriormente. Por se tratar da área da saúde, não se pode deixar de lado a demanda social e o poder de compra do governo para atender a essa demanda e possibilitar o acesso da população a produtos biológicos.

\section{Demanda social}

Recentemente, tem-se observado a tendência de crescimento dos gastos com produtos biológicos nas compras diretas do Ministério da Saúde (Campbell, 2011; Calixto, 2010). Conforme Reis, Pieroni e Souza (2010), os gastos totais desse ministério têm tendido a crescer a uma taxa média de 17\% ao ano, ao passo que a parcela de biológicos evoluiu $28 \%$ ao ano, em média.

Gráfico 1 - Gasto do Ministério da Saúde com medicamentos. Brasil - 2005-2014

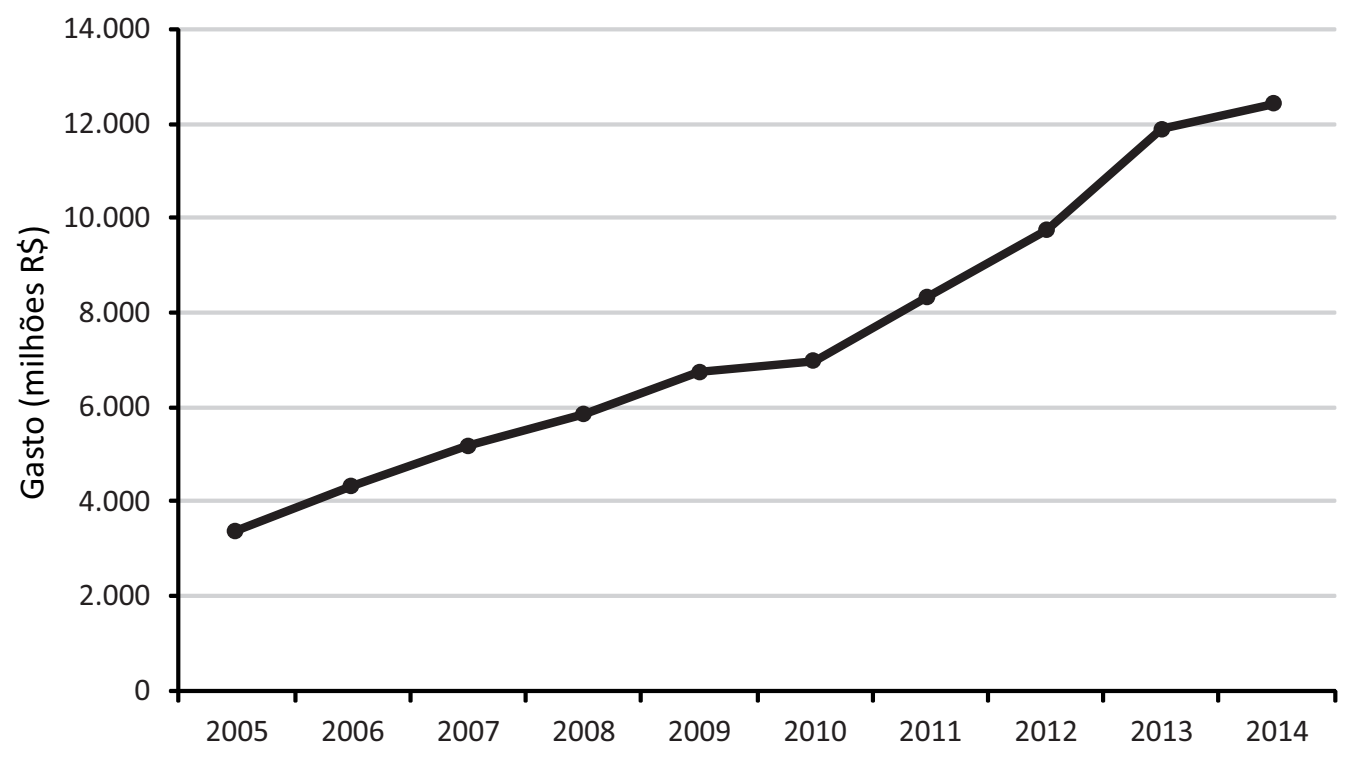

Fonte: elaboração própria com base em dados da Secretaria de Ciência, Tecnologia e Insumos Estratégicos (Brasil, 2014). 
Uma saída para a redução do preço desses medicamentos, que possibilitaria maior acesso da população, e também para aumento de sua oferta, seria sua produção local no Brasil.

Conforme Reis, Pieroni e Souza (2010), devido à baixa produção nacional de medicamentos biológicos, a crescente demanda por esses produtos está sendo suprida por importações. Os dados da balança comercial do complexo industrial da saúde brasileiro (Gadelha, 2009), apresentados no Gráfico 2, refletem numericamente essa tendência.

Gráfico 2 - Evolução da balança comercial da saúde. Brasil - 1996-2013 (em US\$ bilhões EUA)

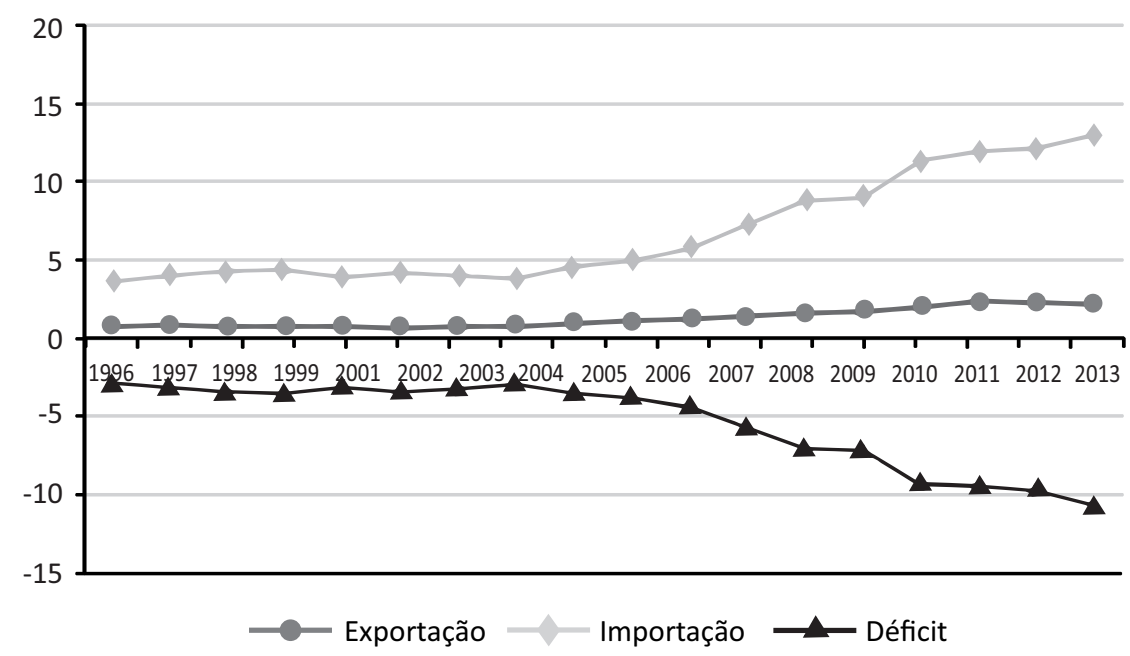

Fontes: Reis, Pieroni \& Souza, 2010 e Rede Alice/MDIC, 2014.

$\mathrm{Na}$ balança comercial de medicamentos (produtos acabados), destacam-se as importações de produtos de base biotecnológica, que cresceram a uma taxa média de 23\% entre 1998 e 2011, alcançando mais de US\$ 4 bilhões nesse último ano, ao passo que a tendência de crescimento das importações de medicamentos como um todo é bem menor (Gráfico 3).

Gráfico 3 - Evolução da balança comercial de medicamentos . Brasil - 1996-2013 (em US\$ bilhões EUA)

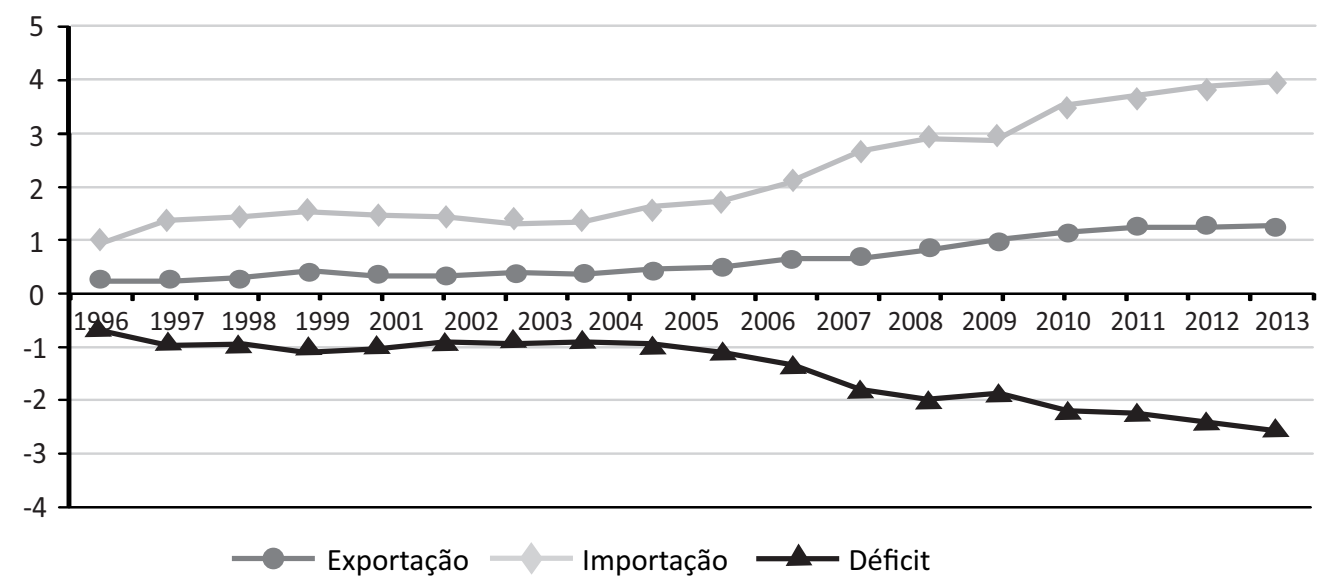

Fontes: Reis, Pieroni \& Souza, 2010 e Rede Alice/MDIC, 2014. 
No Gráfico 4 se apresenta o aumento das importações no período entre 1998 e 2010. As importações de produtos biológicos cresceram em média 37\% ao ano, contra o aumento médio anual da ordem de 19\% para os demais produtos farmacêuticos. Observa-se ainda que entre os dez principais produtos farmacêuticos com maior valor de importação, oito são produzidos por meio de rota biológica, processo produtivo que não se baseia somente em processos químicos convencionais, mas também envolve insumos biológicos.

Gráfico 4 - Importações de medicamentos. Brasil - 1998-2010

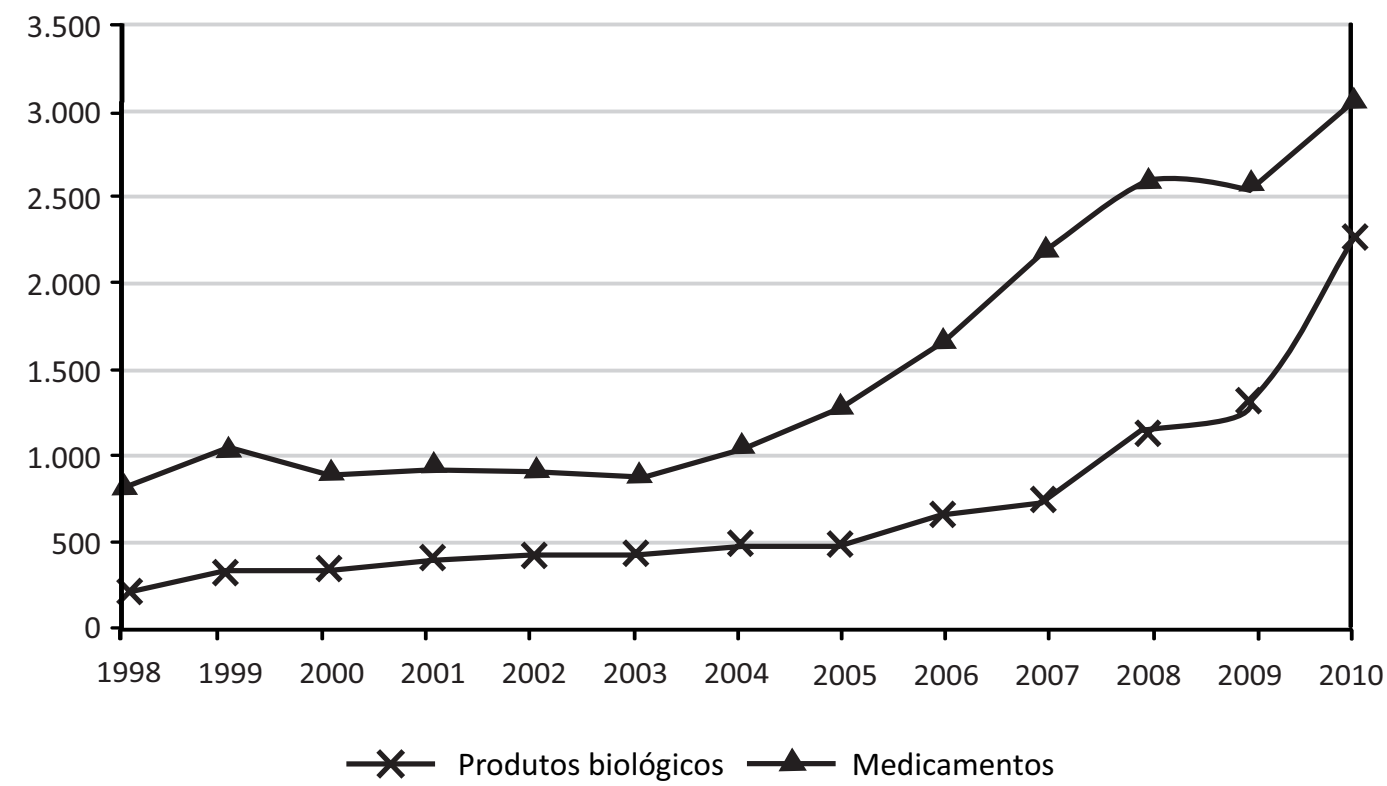

Fonte: Reis, Landim \& Pieroni, 2011.

\section{Compras governamentais}

Com o intuito de aumentar o acesso da população a produtos biológicos e reduzir o déficit comercial, o governo brasileiro tem tomado medidas para promover o desenvolvimento da biotecnologia no país, dentre as quais a lei de compras públicas; a lista de produtos estratégicos do Ministério da Saúde; e as parcerias público-privadas para o desenvolvimento produtivo (PDPs).

Desde 2008, o Brasil tem construído um amplo marco legal e normativo para dar sustentabilidade à política de desenvolvimento e aumentar a competitividade da indústria brasileira. Dentre os instrumentos legais aprovados nesse contexto, vale ressaltar:

1) Portaria n. 374, de 28 de fevereiro de 2008 - Institui, no âmbito do Sistema Único de Saúde - SUS, o Programa Nacional de Fomento à Produção Pública e Inovação no Complexo Industrial da Saúde.

- Objetivos específicos: destacam-se, no segmento farmacêutico, os de "estimular a internalização da produção de farmoquímicos e medicamentos de maior impacto para o Sistema Único de Saúde" e "modernizar os Laboratórios Farmacêuticos Oficiais em termos tecnológicos e organizacionais e capacitá-los para estabelecer parcerias com o setor produtivo privado". 
- Diretrizes do programa: destacam-se o fortalecimento dos produtores públicos de medicamentos; o incentivo a parcerias entre os produtores públicos e a indústria privada; importações de produtos e insumos de uso em saúde estratégicos para o SUS; uso estratégico do poder de compra do Estado em articulação com políticas de fomento ao desenvolvimento industrial.

2) Decreto presidencial de 12 de maio de 2008 - Cria, no âmbito do Ministério da Saúde, o Grupo Executivo do Complexo Industrial da Saúde - GECIS, e dá outras providências.

3) Portaria interministerial n. 128, de 29 de maio de 2008 - Estabelece diretrizes para a contratação pública de medicamentos e fármacos pelo Sistema Único de Saúde.

4) Portaria n. 1.942 de 17 de setembro de 2008 - Aprova o Regimento Interno do Grupo Executivo do Complexo Industrial da Saúde - Gecis e institui o Fórum Permanente de Articulação com a Sociedade Civil.

5) Lei n. 12.349, de 15 de dezembro de 2010 - Permite o uso de margens de preferências nas licitações públicas destinadas às aquisições de produtos manufaturados no Brasil.

6) Lei n. 12.715, de 17 de setembro de 2012 - Altera a lei n. 8.666, permitindo modelo de contratualização com empresas públicas via dispensa de licitação (contempla novas empresas criadas após a Lei n. 8.666). Marco legal favorável às transferências e parcerias tecnológicas com o setor produtivo privado (encomendas tecnológicas para a capacitação nacional).

7) Decreto n. 7.713, de 3 de abril de 2012 - Estabelece a aplicação de margem de preferência nas licitações realizadas no âmbito da Administração Pública Federal para aquisição de fármacos e medicamentos descritos no Anexo I, para fins do disposto no art. $3^{\circ}$ da lei n. 8.666, de 21 de junho de 1993.

8) Decreto n. 7.767, de 27 de junho de 2012 - Estabelece a aplicação de margem de preferência em licitações realizadas no âmbito da Administração Pública Federal para aquisição de produtos médicos para fins do disposto no art. $3^{\circ}$ da lei n. 8.666, de 21 de junho de 1993.

9) Portaria n. 837, de 18 de abril de 2012 - Define as diretrizes e os critérios para o estabelecimento das parcerias para o desenvolvimento produtivo (PDPs).

10) Resolução RDC n. 50, de 13 de setembro de 2012 - Dispõe sobre os procedimentos no âmbito da Anvisa para registro de produtos em processo de desenvolvimento ou de transferência de tecnologias, objetos de Parcerias de Desenvolvimento Produtivo público-público ou públicoprivado de interesse do Sistema Único de Saúde.

11) Portaria n. 3.089, de 11 de dezembro de 2013 - Redefine a lista de produtos estratégicos para o Sistema Único de Saúde (SUS) e as respectivas regras e critérios para sua definição. REVOGA as portarias n. 978/GM/MS, de 16 de maio de 2008, e n. 1.284/GM/MS, de 26 de maio de 2010.

Notadamente, há um amplo marco legal para o desenvolvimento de produtos em saúde no país, em particular o de medicamentos. A orientação para a continuidade da formulação de políticas em curso - de investimentos, formação de recursos humanos e infraestrutura para a indústria - foi recentemente atualizada com a nova Lista de Produtos Estratégicos para o SUS, publicada no âmbito da portaria Ministério da Saúde 3.089/2013, na qual são arrolados os produtos objeto de prioridade para o sistema de saúde. 


\section{Políticas para Biotecnologia}

Outro componente do Sistema Nacional de Inovação são as políticas de governo para financiamento e incentivo do desenvolvimento da biotecnologia no Brasil. Dentre essas políticas podemos destacar (Brasil, 2013):

1) Fundo Nacional de Desenvolvimento Científico e Tecnológico (FNDCT) - Instrumento criado para financiar a pesquisa e o desenvolvimento científico e tecnológico nacional, em diferentes áreas. Ficou conhecido como fundos setoriais. No período entre 1997 e 2011, o FNDCT apoiou, entre outros, 1.200 projetos ligados à biotecnologia, investindo, aproximadamente, R\$ 896 milhões. Somente o Fundo Setorial da Biotecnologia (CT-Biotec) apoiou 531 projetos, somando um montante de, aproximadamente, $\mathrm{R} \$ 160$ milhões. Os projetos contemplados com esse apoio concentraram-se nas áreas de ciências biológicas (57,5\%), ciências agrárias $(13,3 \%)$, ciências da saúde $(11,4 \%)$, ciências exatas e da terra $(9,3 \%)$ e demais áreas $(8,5 \%)$. A distribuição desses recursos encontra-se altamente concentrada em três estados (São Paulo, Rio de Janeiro e Paraná) e no Distrito Federal, que receberam 63,6\% do total investido.

2) Programa Genoprot - Lançado pelo Ministério da Ciência, Tecnologia e Inovação e executado pela Financiadora de Estudos e Projetos (Finep), visa a promover o avanço do conhecimento nas áreas de genômica e proteômica e permitir a produção de conhecimento científico para o desenvolvimento de produtos biotecnológicos de interesse econômico e social. No período de 2003 a 2011 foram destinados aproximadamente R\$ 61 milhões para projetos de pesquisa, compra e manutenção de equipamentos, formação de redes de pesquisa e fortalecimento na área de bioinformática.

3) Política de Desenvolvimento da Biotecnologia (PDB) - Criada em 2007 pelo decreto n. 6.041, tem como objetivo principal o estabelecimento de um ambiente favorável para o desenvolvimento de produtos, processos e serviços biotecnológicos com o estímulo à estruturação produtiva nacional, o aumento da competência inovativa das empresas brasileiras e a absorção de tecnologias já desenvolvidas.

4) Institutos Nacionais de Ciência e Tecnologia (INCTs) - Criados para a formação de grupos de pesquisa em âmbito nacional, com o objetivo de produzir, de forma integrada e colaborativa entre seus participantes, projetos de pesquisas de fronteira para gerar conhecimento e novos produtos destinados a atender às necessidades da sociedade. Desde 2008, a biotecnologia se insere em sessenta dos 125 INCTs atuais, estando presente em trinta INCTs da área da saúde, 11 de ciências agrárias e agronegócio, oito de ecologia e meio ambiente, cinco de nanotecnologia, três de energia, dois de engenharia e tecnologia da informação e um da área de ciências exatas.

5) Política de Desenvolvimento Produtivo - Tem o objetivo de promover a competitividade a longo prazo da economia brasileira, para fortalecer o crescimento e integrar diferentes instrumentos de política já em desenvolvimento. Uma das suas prioridades é a articulação entre o setor público e o setor privado. Dentre suas linhas de ação, várias estão relacionadas ao complexo econômico-industrial da saúde (CEIS). O Ministério da Saúde já desenvolveu noventa parcerias para o desenvolvimento produtivo (PDPs), com 77 produtos (64 medicamentos, seis vacinas, quatro produtos para a saúde e três de $\mathrm{P} \& \mathrm{D}$ ), que envolvem setenta parceiros (17 laboratórios públicos e 53 privados). A política se encontra hoje na 
segunda geração de PDPs voltadas para o CEIS, tendo como objetivos o desenvolvimento tecnológico, a inovação e a substituição de importação de medicamentos biológicos, além do estímulo à concorrência e à cooperação entre instituições públicas e privadas, visando ao desenvolvimento de inovações e à transferência de tecnologia para diminuir a dependência da tecnologia nacional e a vulnerabilidade do SUS. Na segunda etapa foram desenvolvidas 27 novas PDPs, que envolveram oito laboratórios públicos e 17 privados nacionais e internacionais, com 14 produtos biológicos de última geração (seis para câncer, quatro para artrite reumatoide, um para diabetes, um cicatrizante cirúrgico, um hormônio do crescimento e uma vacina alergênica).

6) Rede Nordeste de Biotecnologia (Renorbio), Rede de Biodiversidade e Biotecnologia da Amazônia Legal (Bionorte) e Rede Centro-Oeste de Pós-Graduação, Pesquisa e Inovação (PróCentro-Oeste) - Criadas para diminuir as diferenças intra e inter-regionais, reforçar a formação de recursos humanos nessas áreas e a produção científica, tecnológica e de inovações, com o intuito de contribuir para o desenvolvimento a longo prazo das regiões Centro-Oeste, Norte e Nordeste, respectivamente. Iniciada em 2004, a Renorbio é constituída de 36 instituições e 208 professores credenciados, tendo como o suporte o Programa de Pós-Graduação em Biotecnologia (PPGB-Renorbio). Os recursos nele investidos até o momento estão em torno de R $\$ 57$ milhões. A Bionorte foi iniciada em 2009 contemplando vinte projetos também com o intuito de formar de redes interestaduais, os quais envolviam cerca de R\$20,0 milhões. A Rede Pró-Centro-Oeste iniciou em 2010, abarcando 16 redes e contemplando 101 projetos de pesquisa, com financiamentos que somam um montante da ordem de $\mathrm{R} \$ 48$ milhões. $\mathrm{Na}$ interface com a ação transversal dos fundos setoriais (FNDCT) desenvolveu-se, a partir de 2013, uma linha específica para as redes regionais de pesquisa em biodiversidade e biotecnologia (edital n. 79/2013). Foram repassados recursos do FNDCT da ordem de R\$ 7 milhões para a Rede Pró-Centro-Oeste, $\mathrm{R} \$ 9$ milhões para a Bionorte e R $\$ 8$ milhões para a Renorbio.

7) Estratégia Nacional de Ciência, Tecnologia e Inovação (ENCTI) - No que diz respeito ao uso sustentável da biodiversidade brasileira e à integração de novas tecnologias, a biotecnologia tem importante papel como área de fronteira do conhecimento para o desenvolvimento de produtos, processos e serviços de alto valor agregado. A ENCTI visa a incrementar a capacidade de competição do setor produtivo nos âmbitos nacional e internacional, por meio de investimentos constantes e crescentes, tanto públicos quanto privados, para que as descobertas científicas se transformem em produtos, processos ou serviços úteis à população. Dentre as linhas previstas na ENCTI em biotecnologia, ressaltam-se o apoio ao aumento de empresas com base biotecnológica, a implantação de plataformas de semiescalonamento industrial de produtos biológicos, a implantação do Observatório de Inovação em Biotecnologia, a criação e consolidação de uma rede de centros de recursos biológicos, a consolidação do Centro Brasileiro de Materiais Biológicos e a criação da Rede Biosul, bem como o fortalecimento das já existentes (Rede Centro-Oeste, Rede Bionorte e Renorbio).

8) Plano Brasil Maior (PBM) - Quando da crise monetária internacional que teve início em 2008, uma das estratégias para a recuperação da economia nacional privilegiou o desenvolvimento tecnológico e a inovação. Esta política industrial propõe dar suporte ao crescimento econômico mesmo no cenário econômico mundial adverso observado na época da sua proposição, de modo a permitir que o Brasil saísse da crise internacional. Para atender 
a essa proposta, foram tomadas medidas de desoneração dos investimentos, melhoria do marco regulatório para a inovação, desenvolvimento de incentivos fiscais e facilitação de financiamentos para agregação de valor nacional e de competitividade das cadeias produtivas. Dentre os setores contemplados estão o CEIS e os sistemas agroindustriais, altamente dependentes das inovações biotecnológicas.

9) Empresa Brasileira de Pesquisa e Inovação Industrial (Embrapii) - Criada em 2013 para complementar a atuação das agências de fomento já existentes e outras ações de governo em curso, tem como objetivo fomentar a articulação institucional entre os setores públicos. Para atender a esse objetivo procurou-se ampliar a articulação entre universidades, centros de pesquisa e empresas no desenvolvimento de tecnologias inovadoras, com ênfase na fase final do desenvolvimento de produtos, em atividades como escalonamento, prova de conceito e planta demonstração. Com isso buscam-se soluções tecnológicas que permitam promover estratégias de inovação decorrentes das demandas empresariais, fortalecendo a produtividade e a competitividade da indústria. A Embrapii funcionará como uma grande rede de pesquisas para a etapa pré-competitiva, na qual os riscos inerentes à inovação industrial são muito elevados. Atuará integrando laboratórios e pesquisadores credenciados, direcionando esforços na resolução de problemas enfrentados pelo setor empresarial de forma ágil.

10) Programa Inova Empresa -Lançado em 2013, é um plano do governo federal para investimento em inovação, que prevê a articulação de diversos ministérios para disponibilização de apoio financeiro mediante crédito, subvenção econômica, investimento e financiamento de instituições de pesquisa. Em seu âmbito já foram lançados os editais do Inova Saúde, que contemplou sete projetos reembolsáveis que totalizam $\mathrm{R} \$ 573$ milhões de apoio e 23 projetos não reembolsáveis que totalizam $\mathrm{R} \$ 43$ milhões. Além desses projetos, foram aprovados $\mathrm{R} \$$ 1,65 bilhão de crédito e $\mathrm{R} \$ 43,2$ milhões de subvenção para a linha de biofármacos. Outro edital proveniente desse programa foi o Inova Agro, com R\$ 1 bilhão. Produtos inovadores provenientes da biotecnologia são contemplados nesses editais.

\section{A Dinâmica de Inovação Tecnológica em Biotecnologia}

Como já visto aqui, as inovações necessárias ao desenvolvimento da biotecnologia são classificadas como inovações radicais, ou disruptivas, porque nelas, em geral, para que se alcance seu objetivo (um novo processo ou produto no mercado, p. ex.) é preciso percorrer todas as etapas do processo de inovação. Especialmente nas áreas bioquímica e biológica, a proteção intelectual, uma das formas escolhidas pelas empresas para salvaguardar seu desenvolvimento tecnológico, é um passo intermediário do processo inovativo. Desenvolvemos nesta seção uma análise prospectiva do depósito de patentes, a qual permite inferir, guardadas as margens de incerteza inerentes ao processo inovativo, perspectivas de futuro tais como potenciais empresas entrantes no mercado, países líderes tecnológicos etc., a curto ou a médio prazo.

\section{Patenteamento no INPI}

Para analisar as patentes depositadas no Instituto Nacional da Propriedade Industrial (INPI) baseamo-nos no banco de dados Badepi v1.0, fornecido por esse instituto. A base contém as infor- 
mações dos pedidos de patentes protocolados no período de 2000 a 2011 e os despachos relativos a essas patentes.

Primeiramente recorremos à informação da Classificação Internacional da Patente (IPC) a ela atribuída durante o período de análise. Essa classificação é atribuída de acordo com a área do conhecimento com a qual a patente está associada (sendo possível classificar a mesma patente em mais de uma área).

Partindo das diversas classes IPC, o Observatoire des Sciences et des Techniques (OST) propôs um agrupamento de 27 subdomínios tecnológicos associados com diferentes aplicações tecnológicas da patente (OST, 2006). Um dos domínios tecnológicos propostos, a biotecnologia engloba as suas diferentes aplicações: saúde, veterinária, agricultura, energia. Para restringir nossa análise à sua aplicação na saúde, selecionamos dentre as classes IPC que compõem o subdomínio biotecnologia proposto pelo OST apenas aquelas que se referem explicitamente à saúde, quais sejam: C12N 1*, C12N 7*, C12N 15/07*, A61K 39/00*.

Na Tabela 1 se apresenta o número de depósitos de patentes no INPI dessas quatro classes para a biotecnologia em saúde, separando os depósitos de residentes (cuja nacionalidade do primeiro depositante é brasileira) e de não residentes (cuja nacionalidade do primeiro depositante não é brasileira).

Tabela 1 - Patenteamento no Instituto Nacional de Propriedade Industrial em biotecnologia em saúde. Brasil - 2000-2011

\begin{tabular}{|c|c|c|c|}
\hline Ano & Depósitos de residentes & Depósitos de não residentes & $\%$ de depósitos de residentes \\
\hline 2000 & 17 & 476 & $3,4 \%$ \\
\hline 2001 & 7 & 451 & $1,5 \%$ \\
\hline 2002 & 12 & 379 & $3,1 \%$ \\
\hline 2003 & 29 & 327 & $8,1 \%$ \\
\hline 2004 & 19 & 330 & $5,4 \%$ \\
\hline 2005 & 25 & 386 & $6,1 \%$ \\
\hline 2006 & 29 & 428 & $6,3 \%$ \\
\hline 2007 & 51 & 463 & $9,9 \%$ \\
\hline 2008 & 43 & 566 & $7,1 \%$ \\
\hline 2009 & 37 & 606 & $5,8 \%$ \\
\hline 2010 & 51 & 614 & $7,7 \%$ \\
\hline
\end{tabular}

Fonte: elaboração própria com base em dados do INPI, 2000-2011.

No Gráfico 5, em que se apresenta o número das patentes depositadas por residentes e por não residentes (informação extraída da Tabela 1), é possível visualizar a tendência de crescimento dos depósitos na área de biotecnologia em saúde no período de 2004 a 2011. Essa tendência corrobora a análise de mercado e de demanda social na qual a biotecnologia se faz como um caminho de continuidade de crescimento das farmacêuticas, o que, em parte, justificaria esse investimento em inovação. 
Gráfico 5 - Distribuição de patentes entre residentes e não residentes para a área de biotecnologia em saúde no INPI. Brasil - 2000-2011

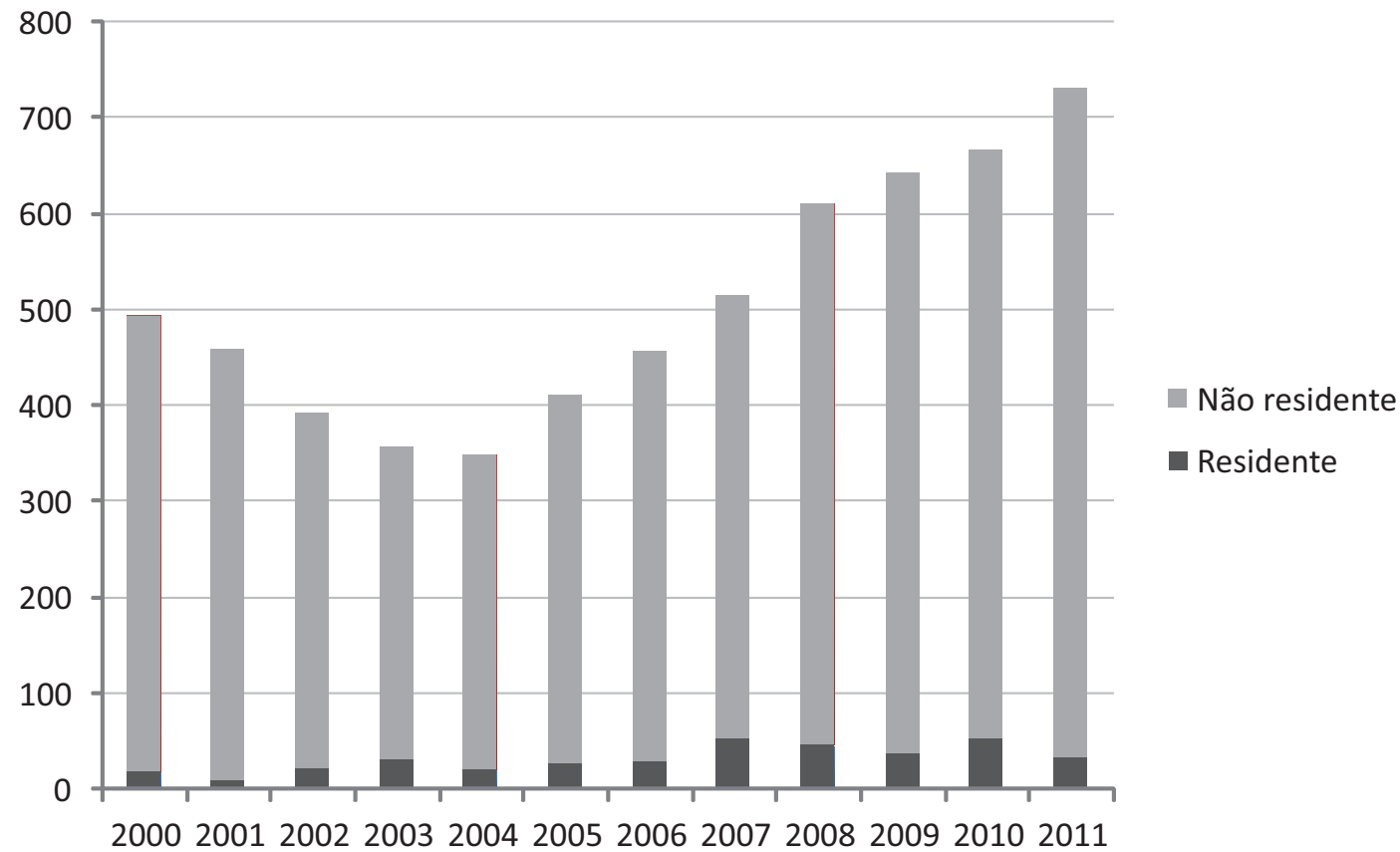

Fonte: elaboração própria com base em dados do INPI, 2000-2011.

No Gráfico 6 se apresenta o percentual de patentes de residentes na área de biotecnologia em saúde (também extraído da Tabela 1). A parcela de depósitos de residentes representa um baixo percentual em relação aos de não residentes, além de apresentar um contraponto ao crescimento do número de depósitos, devido à sua tendência de declínio no período de 2007 a 2011. Tal cenário é danoso para o mercado nacional de biotecnologia em saúde, pois mostra um domínio tecnológico, no período analisado, de empresas estrangeiras e, consequentemente, um possível futuro domínio de mercado, pois quando essas empresas finalizarem a cadeia da inovação relativa à tecnologia, ou seja, apresentarem um produto novo no mercado, terão seus produtos protegidos, inviabilizando, assim, a entrada de empresas nacionais sem o controle da tecnologia por parte das empresas estrangeiras ou o pagamento de royalties por parte das empresas nacionais entrantes, dificultando o desenvolvimento tecnológico e econômico nacional na referida área.

Na Tabela 2 se apresenta o ranking anual dos vinte titulares não residentes com maior número de patentes depositadas no período de 2009 a 2011. Mesmo com o recorte para as classes IPC relacionadas à biotecnologia em saúde, podem-se observar empresas de outras áreas na lista dos titulares; essa é uma limitação da metodologia do recorte e se deve, primordialmente: a tecnologias transversais, com aplicações em diversas áreas, o que faz com que haja múltipla atribuição de classes IPC na análise da patente (sendo uma delas a de biotecnologia aplicada à saúde); ao desenvolvimento conjunto de tecnologia entre empresas de diferentes áreas, mas apenas uma delas figurando como titular; ao desenvolvimento de reagentes com aplicações de diversos processos 
biológicos, ou mesmo falha na atribuição da classe IPC à patente. Entretanto, tal limitação não invalida a metodologia, mas demanda que se considere com ressalva a presença, na lista de titulares, das empresas de outras áreas.

Gráfico 6 - Percentual de patentes de residentes depositadas no INPI para a área de biotecnologia em saúde. Brasil - 2000-2011

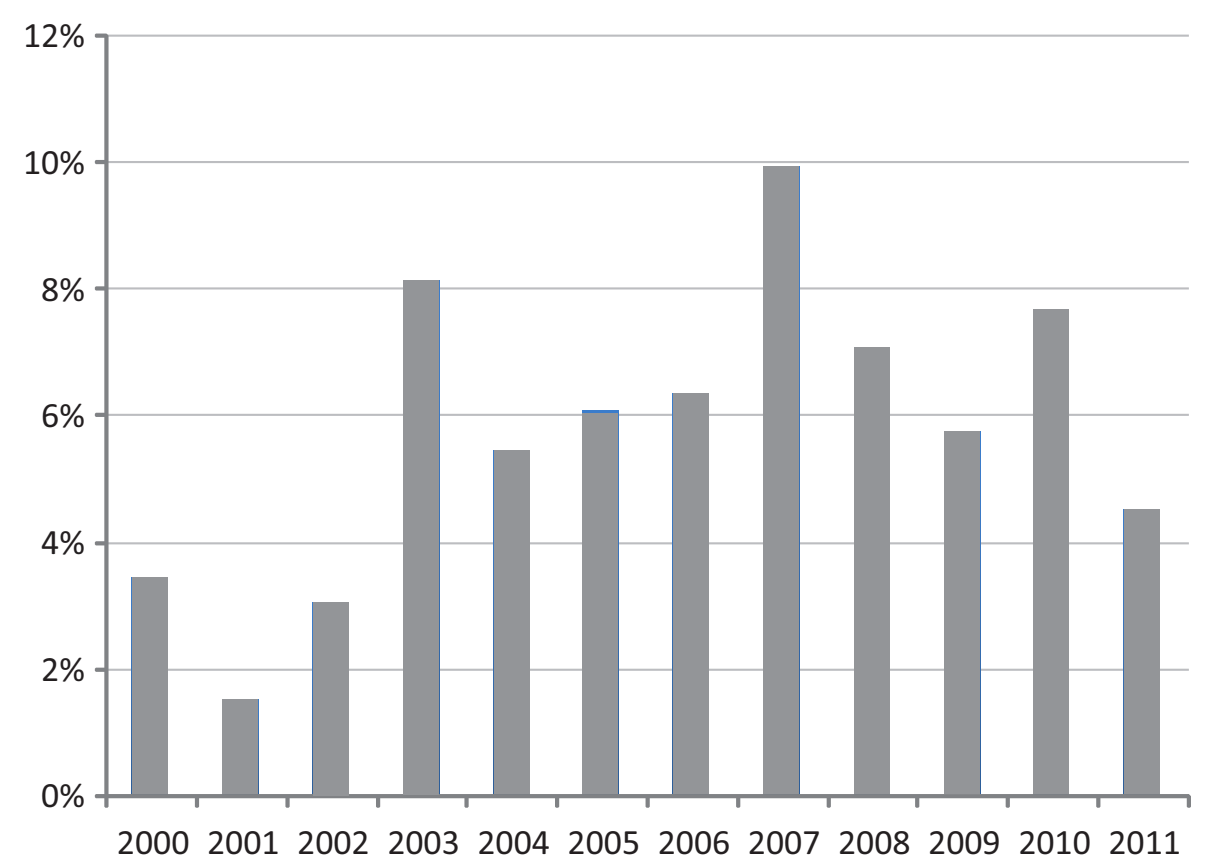

Fonte: elaboração própria com base em dados do INPI, 2000-2011.

Nota-se a baixa frequência de universidades ou instituições de pesquisa na lista; a maioria dos titulares é de empresas privadas. Observam-se também nomes de grandes farmacêuticas que estão entrando na área biotecnológica e novas empresas especializadas apenas em biotecnologia.

Na Tabela 3 apresenta-se o ranking anual dos vinte titulares residentes com maior número de patentes depositadas no período de 2009 a 2011. Em contraponto ao caso dos não residentes, é evidente o predomínio de universidades seguidas de instituições públicas de pesquisa como maiores patenteadores nacionais em biotecnologia em saúde. São poucas as empresas privadas encontradas na lista, e até mesmo titulares pessoa física são encontrados, o que evidencia o descolamento entre o desenvolvimento das pesquisas na área e o interesse do setor empresarial, e certamente dificulta a conclusão da cadeia da inovação com o produto final no mercado. 
Tabela 2 - Ranking de depósito de patentes de não residentes no Instituto Nacional de Propriedade Industrial. Brasil - 2009, 2010, 2011

\begin{tabular}{|c|c|c|c|c|c|}
\hline \multicolumn{2}{|l|}{2009} & \multicolumn{2}{|l|}{2010} & \multicolumn{2}{|l|}{2011} \\
\hline Basf Plant Science GMBH & 37 & Basf Plant Science GMBH & 32 & Bolder Biotechnology Inc. & 33 \\
\hline Corixa Corporation & 25 & Danisco US Inc. & 27 & Oncotherapy Science Inc. & 29 \\
\hline Monsanto Technology LLC & 18 & $\begin{array}{l}\text { Chugai Seiyaku Kabushiki } \\
\text { Kaisha }\end{array}$ & 24 & Basf Plant Science GMBH & 23 \\
\hline $\begin{array}{l}\text { Danisco US Inc. Genencor } \\
\text { Division }\end{array}$ & 18 & Novozymes A/S & 18 & $\begin{array}{l}\text { Basf Plant Science Company } \\
\text { GMBH }\end{array}$ & 17 \\
\hline Ajinomoto Co. Inc. & 14 & Oncotherapy Science Inc. & 17 & Iogen Energy Corporation & 15 \\
\hline CropDesign N.V. & 13 & $\begin{array}{l}\text { Pioneer hi-Bred International } \\
\text { Inc. }\end{array}$ & 17 & $\begin{array}{l}\text { Smithkline Beecham } \\
\text { Biologicals S.A. }\end{array}$ & 15 \\
\hline Medarex Inc. & 12 & Ajinomoto Co. Inc. & 17 & Medicago Inc. & 13 \\
\hline $\begin{array}{l}\text { Danisco US Inc. Genecor } \\
\text { Division }\end{array}$ & 11 & Suntory Holdings Limited & 16 & Suntory Holdings Limited & 11 \\
\hline Dow Agrosciences LLC & 10 & Monsanto Technology LLC & 11 & Baylor Research Institute & 11 \\
\hline Evonik Degussa GMBH & 10 & Medicago Inc. & 9 & Novartis AG & 11 \\
\hline $\begin{array}{l}\text { The Regents of the University } \\
\text { of California }\end{array}$ & 9 & DSM IP Assets B.V. & 9 & Avesthagen Limited & 10 \\
\hline Oncotherapy Science Inc. & 9 & Ceres Inc. & 9 & CJ Cheiljedang Corporation & 10 \\
\hline Plant Bioscience Limited & 9 & Syngenta Participations AG & 8 & Danisco US Inc. & 10 \\
\hline CJ Cheiljedang Corporation & 9 & $\begin{array}{l}\text { E. I. Du Pont de Nemours and } \\
\text { Company }\end{array}$ & 8 & $\begin{array}{l}\text { The Regents of the University } \\
\text { of California }\end{array}$ & 10 \\
\hline $\begin{array}{l}\text { Pioneer Hi-Bred International } \\
\text { Inc. }\end{array}$ & 9 & $\begin{array}{l}\text { E. I. Du Pont de Nemours and } \\
\text { Company }\end{array}$ & 8 & Syngenta Participations AG & . \\
\hline F. Hoffmann-La Roche AG & 9 & Genentech Inc. & 7 & Metabolic Explorer & \\
\hline Verenium Corporation & 8 & $\begin{array}{l}\text { Boehringer Ingelheim } \\
\text { International GMBH }\end{array}$ & 7 & Chr. Hansen A/S & 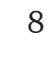 \\
\hline $\begin{array}{l}\text { E.I du Pont de Mours and } \\
\text { Company }\end{array}$ & 8 & $\begin{array}{l}\text { Shanghai Institutes for } \\
\text { Biological Sciences Chinese } \\
\text { Academy of Sciences }\end{array}$ & 6 & $\begin{array}{l}\text { Commonwealth Scientific } \\
\text { and Industrial Research } \\
\text { Organisation }\end{array}$ & \\
\hline Suntory Holdings Limited & 8 & $\begin{array}{l}\text { The Trustees of the University } \\
\text { of Pennsylvania }\end{array}$ & 6 & Dow Agrosciences LLC & 7 \\
\hline $\begin{array}{l}\text { GSF - Forschungszentrum Fuer } \\
\text { Umweltund Gesundheit GMBH }\end{array}$ & 8 & Gevo Inc. & 6 & Alexion Pharmaceuticals Inc. & 7 \\
\hline Asgrow Seed Company & 8 & Sanofi Pasteur Limited & 6 & $\begin{array}{l}\text { Pioneer hi-bred International } \\
\text { Inc. }\end{array}$ & 7 \\
\hline \multirow[t]{4}{*}{ Syngenta Participations AG } & 8 & Genomatica Inc. & 6 & $\begin{array}{l}\text { Butamax Advanced Biofuels } \\
\text { LLC }\end{array}$ & 7 \\
\hline & & Bayer Bioscience N.V. & 6 & Deinove & 7 \\
\hline & & $\begin{array}{l}\text { E.I. du Pont de Mours and } \\
\text { Company }\end{array}$ & 6 & $\begin{array}{l}\text { Daiichi Sankyo Company } \\
\text { Limited }\end{array}$ & 7 \\
\hline & & Novartis AG & 6 & $\begin{array}{l}\text { Pioneer Hi-Bred International } \\
\text { Inc. }\end{array}$ & \\
\hline
\end{tabular}

Fonte: elaboração própria com base em dados do INPI, 2000-2011. 
Tabela 3 - Ranking de depósito de patentes de residentes no Instituto Nacional de Propriedade Industrial. Brasil - 2009, 2010, 2011

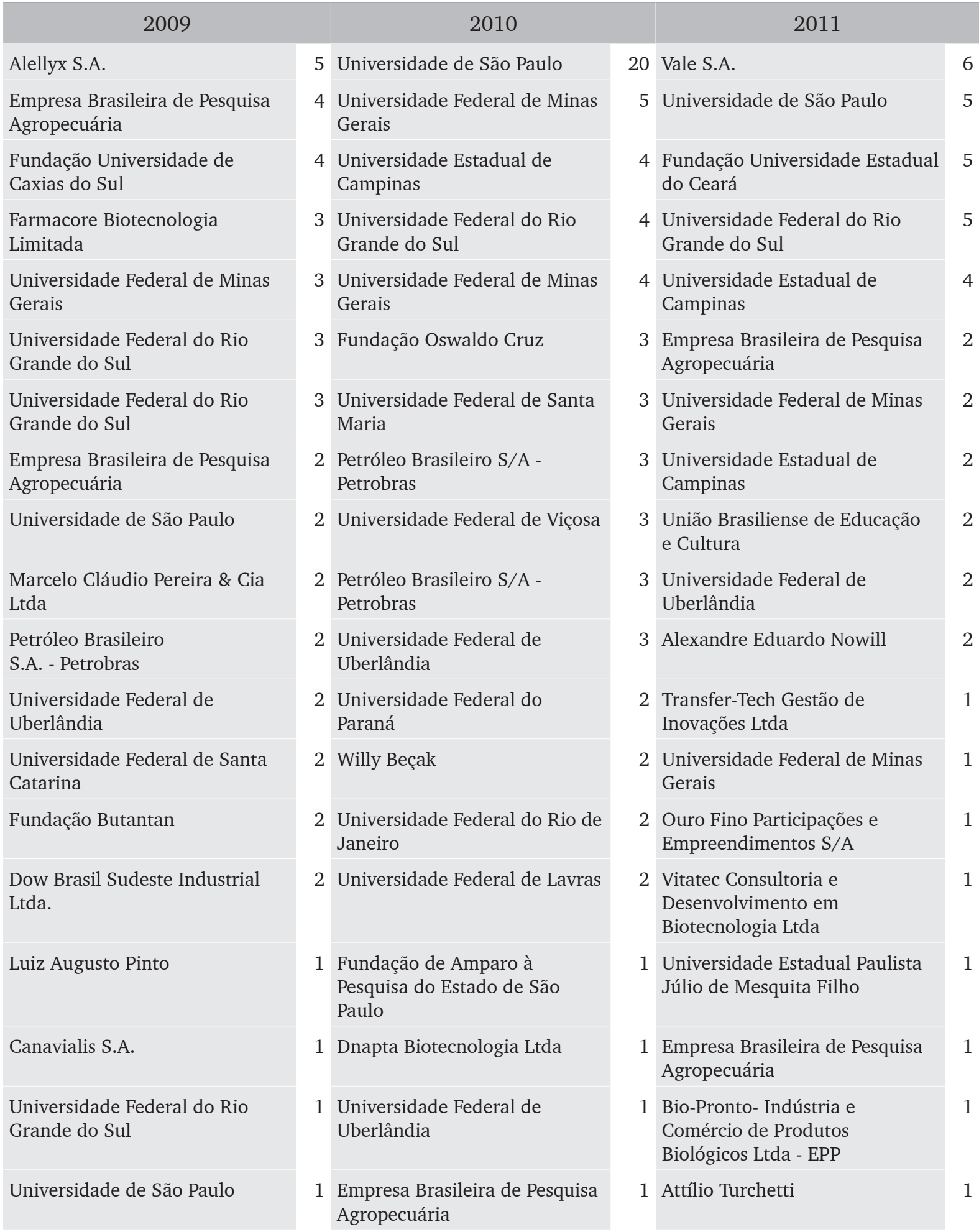


Tabela 3 - Ranking de depósito de patentes de residentes no Instituto Nacional de Propriedade Industrial. Brasil - 2009, 2010, 2011 (cont.)

\begin{tabular}{|c|c|c|c|c|c|}
\hline \multicolumn{2}{|l|}{2009} & \multicolumn{2}{|l|}{2010} & \multicolumn{2}{|l|}{2011} \\
\hline $\begin{array}{l}\text { Universidade Federal do Rio de } \\
\text { Janeiro }\end{array}$ & 1 & $\begin{array}{l}\text { Universidade Federal Rural de } \\
\text { Pernambuco }\end{array}$ & 1 & $\begin{array}{l}\text { Universidade Federal do Rio de } \\
\text { Janeiro }\end{array}$ & 1 \\
\hline $\begin{array}{l}\text { Universidade Estadual de } \\
\text { Campinas }\end{array}$ & 1 & Anderson Cácio Bernardi & 1 & Alellyx S.A. & 1 \\
\hline Universidade Federal de Goiás & 1 & $\begin{array}{l}\text { Alberto Basílio Moreira de } \\
\text { Barros }\end{array}$ & 1 & $\begin{array}{l}\text { Empresa Brasileira de Pesquisa } \\
\text { Agropecuária }\end{array}$ & 1 \\
\hline Fundação Ezequiel Dias & 1 & $\begin{array}{l}\text { Empresa Brasileira de Pesquisa } \\
\text { Agropecuária }\end{array}$ & 1 & Fernando Domingues Zucchi & 1 \\
\hline \multirow[t]{9}{*}{$\begin{array}{l}\text { Proteobras Desenvolvimento } \\
\text { Biotecnológico Ltda }\end{array}$} & 1 & $\begin{array}{l}\text { LCG Biotecnologia e } \\
\text { Monitoramento Ambiental Ltda }\end{array}$ & 1 & & \\
\hline & & $\begin{array}{l}\text { TMG - Tropical Melhoramento } \\
\text { e Genética Ltda }\end{array}$ & 1 & & \\
\hline & & $\begin{array}{l}\text { Fundação Universidade } \\
\text { Estadual de Maringá }\end{array}$ & 1 & & \\
\hline & & $\begin{array}{l}\text { Universidade Federal do Rio de } \\
\text { Janeiro }\end{array}$ & 1 & & \\
\hline & & $\begin{array}{l}\text { Ândrea Kely Campos Ribeiro } \\
\text { dos Santos }\end{array}$ & 1 & & \\
\hline & & $\begin{array}{l}\text { Fundação Universidade de } \\
\text { Brasília }\end{array}$ & 1 & & \\
\hline & & $\begin{array}{l}\text { Turfal Indústria e Comércio } \\
\text { de Produtos Biológicos e } \\
\text { Agronômicos Ltda. }\end{array}$ & 1 & & \\
\hline & & Alellyx Applied Genomics & 1 & & \\
\hline & & $\begin{array}{l}\text { Universidade Estadual do } \\
\text { Maranhão }\end{array}$ & 1 & & \\
\hline
\end{tabular}

Fonte: elaboração própria com base em dados do INPI, 2000-2011.

Na Tabela 4 se apresenta o ranking anual dos dez países de origem com maior número de depósitos dentre as patentes de não residentes no período de 2002 a 2011. Em todos os anos os EUA lideram, com mais que o dobro de patentes que o segundo lugar na lista. Nos segundo e terceiro lugares se alternam Japão e Alemanha (sigla DE), com exceção dos anos 2002 e 2003, em que a França aparece em terceiro lugar. Vale destacar a flutuação na posição da França, que em 2004 cai para o nono lugar e depois gradativamente recupera posição, mas sempre com grande variação. Suíça (CH) e Suécia (NL) apresentam, em geral, um bom posicionamento na classificação. E a China (CN) chega a figurar na lista nos anos de 2007 e 2009. 
Tabela 4 - Ranking do país de origem das patentes de não residentes - 2002 a 2011

\begin{tabular}{|l|r|r|r|r|r|r|r|r|r|r|r|r|r|r|r|r|r|r|r|r|}
\hline \multicolumn{2}{|c|}{2002} & \multicolumn{2}{|c|}{2003} & \multicolumn{2}{|c|}{2004} & \multicolumn{2}{|c|}{2005} & \multicolumn{2}{|c|}{2006} & \multicolumn{2}{|c|}{2007} & \multicolumn{2}{|c|}{2008} & 2009 & 2010 & 2011 \\
\hline US & 338 & US & 231 & US & 293 & US & 258 & US & 278 & US & 283 & US & 279 & US & 383 & US & 335 & US & 401 \\
\hline DE & 76 & JP & 68 & DE & 78 & JP & 55 & DE & 66 & DE & 102 & DE & 91 & JP & 97 & JP & 145 & JP & 131 \\
\hline FR & 47 & FR & 59 & JP & 53 & DE & 53 & JP & 48 & JP & 62 & JP & 73 & DE & 94 & DE & 80 & DE & 77 \\
\hline JP & 44 & DE & 52 & GB & 24 & CH & 30 & FR & 43 & BE & 37 & BE & 40 & CH & 41 & CA & 42 & CA & 60 \\
\hline GB & 35 & CA & 31 & NL & 24 & NL & 23 & CH & 41 & NL & 33 & CA & 36 & BE & 41 & FR & 37 & FR & 49 \\
\hline CA & 16 & CH & 27 & DK & 23 & FR & 21 & DK & 31 & CH & 33 & FR & 36 & FR & 37 & CH & 35 & NL & 39 \\
\hline NL & 16 & GB & 18 & CH & 22 & DK & 18 & BE & 21 & FR & 27 & CH & 32 & CN & 36 & NL & 34 & CH & 37 \\
\hline CH & 14 & AU & 15 & CA & 17 & GB & 18 & GB & 20 & DK & 21 & NL & 28 & CA & 31 & DK & 27 & BE & 34 \\
\hline BE & 13 & NL & 14 & FR & 16 & BE & 16 & CA & 20 & CA & 11 & IN & 27 & AU & 27 & ES & 23 & AU & 27 \\
\hline AU & 13 & BE & 11 & BE & 10 & AU & 10 & NL & 19 & CN & 10 & GB & 20 & NL & 25 & AU & 19 & KR & 26 \\
\hline
\end{tabular}

Fonte: elaboração própria com base em dados do INPI, 2000-2011.

\section{Patenteamentos no United States Patent and Trademark Office (USPTO)}

Apresentaremos aqui os dados da matriz de interações entre ciência e tecnologia (Ribeiro et al., 2010) e seu recorte para a área de biotecnologia em saúde, que permitem identificar as áreas científicas que têm sido base teórica para o desenvolvimento tecnológico para a biotecnologia em saúde, assim como a intensidade com que têm desempenhado esse papel.

O arcabouço teórico e empírico para essa matriz provém de uma ampla literatura sobre citações de artigos científicos e outras referências em patentes como ferramentas para a avaliação de interações entre ciência e tecnologia (Britto et al., 2013; Cohen, Nelson \& Walsh, 2002; Dutrénit, 2010; Ernst \& Kim, 2002; Ernst, 2006; Hagedoorn, 2002; Jaffe \& Trajtenberg, 2002; Klevorick, 1995; Kuemmerle, 1997; Lemley \& Sampat, 2012; Moed, Glanzenl \& Schmoch, 2004; Mowery \& Sampat, 2005; Narin \& Noma, 1985; Pavitt, 1988, 1991; Powell \& Grodal, 2005; Roach \& Cohen, 2013; OECD, 1998, 2008a, 2008b). A citação da literatura de ciência e engenharia (C\&E) em patentes é um indicativo do conteúdo científico presente na tecnologia. Um exemplo é a primeira patente de diagnóstico por imagem que utiliza ressonância magnética para identificação de tecidos cancerosos em humanos (USPTO, patente n. 3.789.832, concedida em 1974). Nessa patente cita-se um artigo de J. R. Singer, publicado no Journal of Applied Physics em 1960, em que o autor descreve aplicações de técnicas de ressonância nuclear em processos biológicos. Outro exemplo é a patente de Cohen e Boyer (USPTO, patente n. 4.237.224, concedida em 1980), que transformou a biotecnologia em uma nova área tecnológica. Esses dois exemplos, embora relacionados a patentes muito importantes, não são exceções na base de dados utilizada: o número de artigos de C\&E citados em patentes do USPTO aumentou de 7.115 em 1974 para 822.733 em 2006.

Narin, Hamilton e Olivastro (1997: 321), os idealizadores dessa matriz cujo trabalho pioneiro se dirigia a áreas tecnológicas selecionadas (patentes de drogas e de medicamentos), construíram uma 
pequena matriz com base na área científica do referido artigo. Em seguida, esse tipo de matriz foi expandido por Tijssen, Buter e Van Leeuwen (2000: 406), Verbeek e colaboradores (2002), Verbeek, Debackere \& Luwel (2003), Callaert e colaboradores (2006) e Callaert, Grouwels e Van Looy (2012), para certos domínios tecnológicos e áreas de C\&E.

Em uma revisão ampla da literatura, Tijssen, Buter e Van Leeuwen (2000: 398) afirmaram que,

no geral, esse novo conjunto de evidências confirma que citações da literatura de C\&E (non-patent references) representam conexões explícitas entre pesquisa científica e inovação tecnológica e, consequentemente, podem ser utilizadas como uma fonte, razoavelmente válida, de informação sobre a interação entre ciência e tecnologia. (tradução nossa)

Em outra vasta revisão da literatura, Tijssen ressaltou que "conexões derivadas de citações" são "apropriadas para estatísticas sobre interações entre ciência e tecnologia" (2004: 704, tradução nossa).

Para a construção das matrizes, foram coletados e processados dados de todas as patentes registradas no USPTO no ano de 2009. No processo de seu registro, são atribuídas à patente classes que identificam as suas áreas tecnológicas. Essas classes podem ser convertidas nos subdomínios tecnológicos propostos pelo Observatoire des Sciences et Techniques (OST, 2006). O texto da patente pode também citar artigos científicos publicados em revistas, jornais ou periódicos (indexados ou não) e referências técnicas, tais como manuais de equipamentos, revistas internas de grandes corporações, citações que permitem identificar a área de C\&E utilizada para a construção da inovação patenteada.

Uma análise léxica foi então implementada, na qual se constrói um dicionário em que cada verbete corresponde a uma área científica definida pelo ISI (Braun, Glanzel \& Grupp, 1996) e seu "significado" corresponde a palavras-chave ou expressões que caracterizam univocamente tal área. Em seguida, faz-se a conversão da citação da patente para uma área de C\&E quando uma das palavras-chave ou expressões é encontrada no corpo da referência.

Por meio dessas duas conversões, identificam-se os subdomínios tecnológicos aos quais a patente está relacionada e as áreas de C\&E que se relacionam a tal inovação. Identifica-se, assim, uma interação entre um subdomínio tecnológico e uma área de C\&E. Esse par constitui a célula da matriz que será apresentada a seguir. Essa interação ocorre da seguinte forma: se o subdomínio tecnológico $\alpha$ interage com a área $C \& E \beta$, isso significa que, para o desenvolvimento da tecnologia $\alpha$, necessitou-se de conhecimento(s) científico(s) desenvolvido(s) em $\beta$.

Esse processo resulta em matrizes com 810 células: trinta linhas (os trinta subdomínios do OST) e 27 colunas (as 27 disciplinas de C\&E do ISI). O Gráfico 7 representa a matriz mundial para o ano de 2009. 


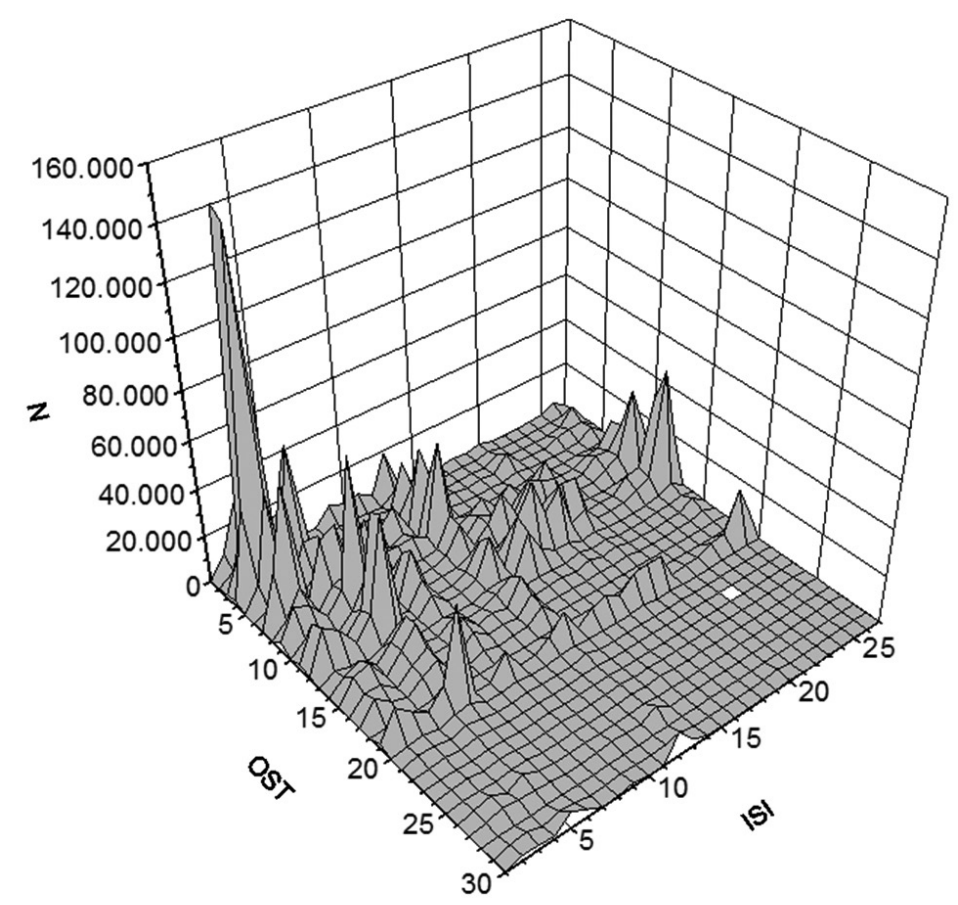

No eixo OST (Observatoire des Sciences et des Techniques) são apresentados os subdomínios tecnológicos nos quais as patentes foram classificadas, no eixo ISI (Institute for Scientific Information), as áreas científicas em que as referências às NPRs (non-patent references) foram classificadas, e no eixo $\mathrm{N}$ o número de patentes que foram classificadas no OST correspondente e citaram NPRs classificadas na área ISI correspondente.

Fonte: elaboração própria com base em dados do USPTO, 2009.

Na Tabela 5 apresenta-se o recorte da matriz para a área de biotecnologia em saúde, seguindo-se a mesma metodologia apresentada na seção anterior. Nela se pode observar, para as patentes dos EUA, Alemanha e França (grandes patenteadores na área), a frequência das citações de artigos de cada uma das áreas científicas definidas pelo ISI, o que permite levantar as áreas científicas mais utilizadas para embasar o desenvolvimento tecnológico em biotecnologia aplicada à saúde. Vale ressaltar que, proporcionalmente, não há, entre os três países, grandes variações na frequência de citações de textos das diferentes áreas científicas, o que confere robustez à análise e permite extrair um perfil de citação ou uso de conhecimento científico para o desenvolvimento tecnológico em biotecnologia em saúde. Ou seja, permite discernir as áreas científicas que é preciso desenvolver para se obter uma base de conhecimento para o desenvolvimento da biotecnologia em saúde. 
Tabela 5 - Áreas científicas das referências a literatura não patente nas patentes USPTO analisadas. EUA, Alemanha e França - 2009

\begin{tabular}{|c|c|c|c|c|}
\hline & Área científica ISI & EUA & Alemanha & França \\
\hline 1 & Matemática & 60 & 2 & 1 \\
\hline 2 & Ciência dos materiais & 2.467 & 129 & 128 \\
\hline 3 & Engenharia eletrônica & 906 & 24 & 21 \\
\hline 4 & Ciências nucleares & 508 & 8 & 15 \\
\hline 5 & Engenharia mecânica, civil e outras & 1.486 & 40 & 38 \\
\hline 6 & Química inorgânica e Engenharia química & 5.779 & 224 & 186 \\
\hline 7 & Química analítica & 21 & 0 & 0 \\
\hline 8 & Físico-química & 0 & 0 & 0 \\
\hline 9 & Química orgânica & 444 & 11 & 5 \\
\hline 10 & Física aplicada & 25 & 0 & 2 \\
\hline 11 & Física do estado sólido & 22 & 2 & 0 \\
\hline 12 & Geociências & 531 & 15 & 7 \\
\hline 13 & Outras físicas & 1.500 & 47 & 23 \\
\hline 14 & Ecologia & 371 & 9 & 6 \\
\hline 15 & Ciência dos alimentos e Agricultura & 1.458 & 66 & 35 \\
\hline 16 & Biotecnologia & 3.278 & 192 & 110 \\
\hline 17 & Microbiologia & 4.082 & 216 & 253 \\
\hline 18 & Biologia geral & 2.692 & 125 & 74 \\
\hline 19 & Farmacologia e Farmácia & 910 & 18 & 13 \\
\hline 20 & Saúde pública & 1.349 & 21 & 31 \\
\hline 21 & Patologia & 137 & 3 & 4 \\
\hline 22 & Neurociência & 74 & 0 & 0 \\
\hline 23 & Medicina da reprodução e Geriatria & 159 & 16 & 1 \\
\hline 24 & Medicina geral & 631 & 14 & 16 \\
\hline 25 & Medicina interna & 861 & 26 & 35 \\
\hline 26 & Pesquisa em medicina & 7.257 & 103 & 103 \\
\hline \multirow[t]{2}{*}{27} & Imunologia & 6.588 & 58 & 140 \\
\hline & Total & 43.596 & 1.369 & 1.247 \\
\hline
\end{tabular}

Fonte: elaboração própria com base em dados do USPTO, 2009. 


\section{Redes globais de inovação}

Nesta subseção apresentamos uma aplicação para a área de biotecnologia em saúde do trabalho na qual foi desenvolvida uma metodologia para identificar empiricamente as redes globais de inovação (Ribeiro et al., 2012), que são interações entre empresas e universidades, em nível global, para desenvolvimento tecnológico. Essa metodologia baseia-se em trabalhos anteriores dos autores sobre patentes e suas citações de artigos científicos (Ribeiro et al., 2010) e foi adaptada para identificar as redes globais de inovação.

A metodologia utiliza patentes concedidas pelo USPTO e suas citações de artigos indexados no ISI para rastrear os fluxos entre as empresas e universidades que fazem parte dessas redes globais de inovação.

Para a análise, construiu-se um banco de dados com base em 167.315 patentes concedidas pelo USPTO em 2009, das quais 86.652 têm citações de outros documentos que não sejam patentes (NPR non-patent reference). O processamento dessas citações e uma busca no ISI levaram à identificação de 22.577 artigos indexados nesse banco de dados. As citações entre as empresas detentoras das patentes e as instituições autoras dos artigos citados estabelecem os fluxos aqui apresentados.

O primeiro passo consiste em arquivar as informações das patentes concedidas pelo USPTO em 2009. O segundo, em identificar os NPRs e baixar todas as informações relacionadas a esses NPRs. O terceiro passo é identificar potenciais NPRs que sejam artigos científicos (SNPR - scientific nonpatent reference) por meio de uma análise da estrutura textual da citação. Na quarta etapa recorre-se às informações sobre potenciais SNPRs para pesquisar na base de dados web do ISI e, ao se identificar o artigo, arquivar suas informações.

Com base no nome das instituições autoras de artigos científicos e utilizando as informações das listas disponíveis da Global Fortune 500 (Fortune, 2014) e da United Nations Conference on Trade and Development (UNCTAD, 2005, 2006, 2011) e as informações de sites institucionais, classificamos as instituições como: sede de transnacionais (TNH, transnational headquarter); subsidiária de transnacional (TNS, transnational subsidiary); empresa local (LF, local firm) ou instituição de pesquisa (RI, research institute). Essa classificação se faz importante devido à crescente internacionalização das firmas e ao seu papel no desenvolvimento econômico mundial e nos sistemas nacionais de inovação dos países em que se instalam, conforme visto em Cantwell (2009, 1995), Cantwell \& Janne 1999), Carlsson (2006), Caves (1996), Dunning (1998, 1995), Dunning \& Lundan (2008), Ernst \& Kim (2002), Freeman (2007), Hymer (1976), Macher \& Mowery (2008), Narula \& Zanfei (2005), Patel (1995), Patel \& Pavitt (1998), UNCTAD (2005, 2006, 2011) e Zitt \& Bassecoulard (2004).

Com essa metodologia é possível ligar uma empresa detentora de patente, localizada em um país específico, com o instituto de pesquisa, universidade ou até mesmo uma empresa que seja autora do artigo científico citado no pedido de patente. Como o autor do artigo pode estar em um país diferente do detentor da patente, tal análise adquire uma escala global, o que permite identificar os fluxos globais de conhecimento (codificados nos artigos) utilizados para embasar o desenvolvimento tecnológico. Especificamente no presente trabalho, é feito o recorte para analisar somente as redes globais de inovação para a biotecnologia em saúde. Tal recorte é feito segundo a mesma metodologia 
descrita na seção anterior, na qual são analisadas apenas as patentes com as classes internacionais de aplicação em saúde dentro do subdomínio tecnológico "biotecnologia".

Na primeira etapa foram analisadas 167.315 patentes concedidas pelo USPTO em 2009. Na segunda etapa, 1.135.582 NPRs foram listados. Na terceira etapa, foram identificadas 33.767 patentes com 324.844 potencialmente SNPRs e agrupadas pelos nomes das revistas, que foram, então, classificadas. As cinco mil revistas mais citadas tiveram 117.770 SNPRs potenciais, que foram pesquisados. A busca desses SNPRs potenciais resultou na identificação de 76.987 documentos ISI indexados, escritos por 138.712 autores institucionais. Cada artigo pode ser autorado por mais de uma instituição. Esses 76.987 documentos ISI indexados foram citados por 10.985 patentes.

Na Tabela 6a se apresenta a lista dos maiores patenteadores em biotecnologia aplicada à saúde no USPTO em 2009 e na Tabela 6b se encontra a lista dos patenteadores cujas patentes citaram ao menos uma SNPR ISI indexada.

Tabela 6a - Ranking dos países das patentes em biotecnologia. USPTO - 2009

\begin{tabular}{|l|c|}
\hline País & n. de patentes \\
\hline US & 584 \\
\hline JP & 93 \\
\hline DE & 40 \\
\hline FR & 40 \\
\hline GB & 33 \\
\hline CA & 27 \\
\hline NL & 26 \\
\hline KR & 25 \\
\hline DK & 18 \\
\hline SE & 15 \\
\hline AU & 15 \\
\hline CH & 14 \\
\hline TW & 12 \\
\hline BE & 11 \\
\hline IE & 9 \\
\hline IN & 8 \\
\hline FI & 7 \\
\hline AT & 7 \\
\hline IT & 6 \\
\hline RU & 6 \\
\hline
\end{tabular}

Tabela 6b - Ranking dos países das patentes em biotecnologia que citaram artigos ISI. USPTO 2009

\begin{tabular}{|c|c|}
\hline País & n. de patentes \\
\hline US & 249 \\
\hline JP & 35 \\
\hline DE & 19 \\
\hline FR & 13 \\
\hline NL & 12 \\
\hline CA & 12 \\
\hline GB & 10 \\
\hline SE & 7 \\
\hline CH & 7 \\
\hline DK & 6 \\
\hline BE & 5 \\
\hline AU & 5 \\
\hline KR & 5 \\
\hline IT & 4 \\
\hline AT & 4 \\
\hline RU & 3 \\
\hline FI & 3 \\
\hline ES & 2 \\
\hline IE & 1 \\
\hline SK & 1 \\
\hline
\end{tabular}

Fonte: elaboração própria com base em dados do USPTO, 2009. 
A posição de liderança dos EUA, do Japão e de alguns países europeus é imediatamente evidente. Em relação ao número total de patentes, a posição de países como Coreia do Sul e Taiwan (na oitava e décima quarta posições) e Índia (na décima sexta posição) pode ser destacada.

Em relação ao número total de patentes que citam SNPRs ISI indexadas, as principais posições de EUA, Japão e Alemanha são preservadas, ao passo que a Coreia do Sul cai para $13^{a}$ posição e Taiwan e Índia saem do rol das vinte maiores patenteadoras em biotecnologia.

As tabelas 7a e 7b evidenciam uma diferença interessante entre a classificação das empresas (ou instituições) com maior patenteamento em biotecnologia aplicada à saúde e a classificação daquelas com patentes que citam SNPRs ISI indexados.

Tabela7a-Ranking dos titulares das patentes em biotecnologia. USPTO - 2009

\begin{tabular}{|c|c|}
\hline Titular & n. de patentes \\
\hline E.I. Du Pont de Nemours and Company & 18 \\
\hline Martek Biosciences Corporation & 17 \\
\hline Institut Pasteur & 16 \\
\hline $\begin{array}{l}\text { The United States of America as } \\
\text { represented by the Department of } \\
\text { Health and Human Services }\end{array}$ & 15 \\
\hline Genentech Inc. & 14 \\
\hline Ajinomoto Co. Inc. & 14 \\
\hline Wyeth & 13 \\
\hline $\begin{array}{l}\text { E. I. Du Pont de Nemours and } \\
\text { Company }\end{array}$ & 13 \\
\hline Novozymes A/S & 13 \\
\hline Human Genome Sciences Inc. & 13 \\
\hline Genencor International Inc. & 13 \\
\hline $\begin{array}{l}\text { The Regents of the University of } \\
\text { California }\end{array}$ & 11 \\
\hline Millennium Pharmaceuticals Inc. & 10 \\
\hline Coley Pharmaceutical Group Inc. & 8 \\
\hline $\begin{array}{l}\text { The United States of America as } \\
\text { represented by the Secretary of the } \\
\text { Department of Health and Human } \\
\text { Services }\end{array}$ & 8 \\
\hline Crucell Holland B.V. & 8 \\
\hline Zymogenetics Inc. & 7 \\
\hline Intralytix Inc. & 7 \\
\hline North Carolina State University & 7 \\
\hline $\begin{array}{l}\text { The United States of America as } \\
\text { represented by the Secretary of } \\
\text { Agriculture }\end{array}$ & 7 \\
\hline
\end{tabular}

Tabela $7 \mathrm{~b}$ - Ranking dos titulares das patentes em biotecnologia que citaram artigos ISI. USPTO - 2009

\begin{tabular}{|c|c|}
\hline Titular & n. de patentes \\
\hline Martek Biosciences Corporation & 12 \\
\hline Ajinomoto Co. Inc. & 11 \\
\hline Genentech Inc. & 9 \\
\hline Human Genome Sciences Inc. & 8 \\
\hline $\begin{array}{l}\text { The United States of America as } \\
\text { represented by the Department of } \\
\text { Health and Human Services }\end{array}$ & 7 \\
\hline Millennium Pharmaceuticals Inc. & 7 \\
\hline GenencorI nternational Inc. & 7 \\
\hline Crucell Holland B.V. & 7 \\
\hline Wyeth & 5 \\
\hline $\begin{array}{l}\text { The United States of America as } \\
\text { represented by the Secretary of the } \\
\text { Department of Health and Human } \\
\text { Services }\end{array}$ & 5 \\
\hline The General Hospital Corporation & 4 \\
\hline $\begin{array}{l}\text { The Regents of the University of } \\
\text { California }\end{array}$ & 4 \\
\hline Ceres Inc. & 4 \\
\hline Basf Plant Science GMBH & 4 \\
\hline Institut Pasteur & 4 \\
\hline North Carolina State University & 3 \\
\hline Amgen Inc. & 3 \\
\hline $\begin{array}{l}\text { Sloan-Kettering Institute for Cancer } \\
\text { Research }\end{array}$ & 3 \\
\hline Immunex Corporation & 3 \\
\hline Medimmune LLC & 3 \\
\hline
\end{tabular}

Fonte: elaboração própria com base em dados do USPTO, 2009. 
Esse ranking identifica os principais patenteadores, o que em uma análise prospectiva permite inferir, com certa probabilidade devido às incertezas do processo inovativo, as empresas potencialmente entrantes no mercado a curto ou médio prazo. Além disso, permite identificar diferenças no ranking entre empresas detentoras de patentes que citam SNPRs ISI indexados e as que não os citam.

A Tabela 8 apresenta um resultado da análise da outra ponta dessas interações globais: as instituições em que o conhecimento científico que embasou a patente foi desenvolvido. Nesta tabela se apresenta a distribuição por país dos autores dos 76.987 artigos indexados no ISI citados em patentes concedidas pelo USPTO em 2009.

Tabela 8 - Ranking dos países das instituições que desenvolveram as SNPRs citadas pelas patentes da área de biotecnologia em saúde. USPTO - 2009

\begin{tabular}{|l|c|}
\hline \multicolumn{1}{|c|}{ País } & n. de citações \\
\hline EUA & 6.239 \\
\hline Japão & 809 \\
\hline Alemanha & 723 \\
\hline França & 504 \\
\hline Canadá & 477 \\
\hline Inglaterra & 476 \\
\hline Países Baixos & 227 \\
\hline Suíça & 226 \\
\hline Itália & 217 \\
\hline Austrália & 174 \\
\hline Suécia & 173 \\
\hline Espanha & 134 \\
\hline Bélgica & 131 \\
\hline Finlândia & 114 \\
\hline Israel & 108 \\
\hline Coreia do Sul & 101 \\
\hline Dinamarca & 84 \\
\hline Taiwan & 57 \\
\hline Escócia & 47 \\
\hline China & 45 \\
\hline
\end{tabular}

Fonte: elaboração própria com base em dados do USPTO, 2009.

A Tabela 8 destaca, mais uma vez, a posição de liderança dos EUA - 6.239 documentos ISI indexados (de 88.032, uma vez que um papel pode ter autores localizados em diferentes países) foram escritos com autores dos EUA. Este é quase oito vezes o total de SNPRs ISI indexados do Japão, na segunda posição, e quase dez vezes o total da Alemanha e da França, na terceira e quarta posições. No entanto, a Tabela 3 também mostra como é generalizada a autoria desses papéis, uma vez que quase 
metade é de autores de fora dos EUA, o que fornece uma pista importante da internacionalização dos fluxos de conhecimento que servem de base para o desenvolvimento tecnológico em biotecnologia.

A Tabela 9 apresenta as vinte principais instituições autoras dos SNPRs ISI indexados citados. A posição de liderança das universidades dos EUA é predominante: há apenas quatro universidades não americanas dentro das vinte principais instituições citadas, e essas instituições são do Japão, Alemanha e Canadá. Uma vez mais, há um viés EUA nesses dados, certamente relacionado com o viés evidenciado na Tabela 2: a maior propensão para citar artigos em patentes dos EUA pode estar relacionada com a propensão para citar universidades nacionais. A força da infraestrutura científica dos EUA é um fator importante aqui.

Vale ressaltar também a presença de uma firma transnacional na terceira posição e uma firma local alemã na $13^{\mathrm{a}}$ posição, o que mostra um fluxo de conhecimento científico vindo de empresas que alimenta o desenvolvimento tecnológico de outras empresas.

Tabela 9 - Ranking das instituições que desenvolveram as SNPRs citadas pelas patentes da área de biotecnologia em saúde. USPTO - 2009

\begin{tabular}{|l|l|l|c|}
\hline \multicolumn{1}{|c|}{ Instituição } & Tipo da instituição & País & n. de citações \\
\hline Harvard University & RI & EUA & 347 \\
\hline University of Texas & RI & EUA & 179 \\
\hline Genentech Inc. & TNH & EUA & 165 \\
\hline National Cancer Institute & LF & EUA & 144 \\
\hline University of California San Francisco & RI & EUA & 128 \\
\hline Washington University & RI & EUA & 126 \\
\hline University of Washington & RI & EUA & 111 \\
\hline University of California Los Angeles & RI & EUA & 102 \\
\hline University of California San Diego & RI & EUA & 96 \\
\hline North Carolina State University & RI & EUA & 95 \\
\hline University of Michigan & RI & EUA & 93 \\
\hline University of Pennsylvania & RI & EUA & 92 \\
\hline Medical Research Council & LF & Alemanha & 91 \\
\hline Stanford University & RI & EUA & 88 \\
\hline Kyoto University & RI & Japão & 81 \\
\hline Massachusetts Institute of Technology & RI & EUA & 80 \\
\hline University of Cambridge & RI & Alemanha & 75 \\
\hline University of Toronto & RI & Canadá & 73 \\
\hline Johns Hopkins University & RI & EUA & 65 \\
\hline Osaka University & RI & Japão & 65 \\
\hline
\end{tabular}

RI, research institute, instituição de pesquisa; TNH, transnational headquarter, sede de transnacionais; LF, local firm, empresa local.

Fonte: elaboração própria com base em dados do USPTO, 2009. 
Na Tabela 10 apresentam-se as instituições autoras dos artigos indexados no ISI citados pelas patentes dos EUA. Esta é a variável relevante, que permite identificar a localização geográfica da origem do conhecimento codificado no artigo e dá ideia da propagação das redes originadas em cada país. Na tabela mostram-se os dados para os vinte países mais citados, sendo que no total foram citados 53 países diferentes, além de sua própria infraestrutura científica. Este é um primeiro sinal da amplitude das redes que se originam nos EUA.

Tabela 10 - Rede global de inovação gerada a partir dos EUA - 2009

\begin{tabular}{|l|r|r|r|r|r|}
\hline \multicolumn{1}{|c|}{ País } & Citações & RI & TNH & TNS & \multicolumn{1}{|c|}{ LF } \\
\hline EUA & 4.964 & 3.975 & 261 & 206 & 522 \\
\hline Japão & 532 & 454 & 10 & 2 & 66 \\
\hline Alemanha & 461 & 318 & 0 & 41 & 102 \\
\hline Inglaterra & 321 & 292 & 0 & 9 & 20 \\
\hline Canadá & 286 & 245 & 0 & 8 & 33 \\
\hline França & 252 & 190 & 24 & 9 & 29 \\
\hline Países Baixos & 154 & 133 & 0 & 1 & 20 \\
\hline Suíça & 143 & 107 & 4 & 17 & 15 \\
\hline Itália & 138 & 105 & 1 & 2 & 30 \\
\hline Austrália & 113 & 96 & 0 & 0 & 17 \\
\hline Suécia & 100 & 87 & 0 & 4 & 9 \\
\hline Bélgica & 86 & 76 & 0 & 8 & 2 \\
\hline Espanha & 70 & 58 & 0 & 2 & 10 \\
\hline Israel & 66 & 64 & 0 & 0 & 2 \\
\hline Finlândia & 60 & 57 & 0 & 1 & 2 \\
\hline Dinamarca & 44 & 31 & 4 & 1 & 8 \\
\hline Escócia & 39 & 36 & 0 & 0 & 3 \\
\hline China & 34 & 33 & 0 & 0 & 1 \\
\hline Coreia do Sul & 30 & 29 & 0 & 0 & 1 \\
\hline Taiwan & 28 & 28 & 0 & 0 & 0 \\
\hline
\end{tabular}

RI, research institute, instituição de pesquisa; TNH, transnational headquarter, sede de transnacionais; TNS, transnational subsidiary, subsidiária de transnacional; LF, local firm, empresa local.

Fonte: elaboração própria com base em dados do USPTO, 2009. 


\section{Tendências Tecnológicas, Lacunas, Desafios e Potencialidades}

Realizada a análise empírica dos principais patenteadores na área de biotecnologia aplicada à saúde na qual o foco recai sobre as potenciais empresas entrantes no mercado a curto e médio prazos, nesta seção o foco se dirige para o estágio atual de desenvolvimento e as perspectivas de futuro para as principais tecnologias relacionadas à biotecnologia. Para tanto, foram consideradas as áreas de Medicina e saúde e Biofármacos e feito o levantamento do cenário atual do seu desenvolvimento tecnológico. E, levando-se em conta a contínua projeção da dinâmica evolutiva das tecnologias avaliadas, foram construídas as rotas tecnológicas tendo em vista o horizonte de 2016 a 2030.

\section{Principais tecnologias em biotecnologia aplicada à saúde}

A Agência Brasileira de Desenvolvimento Industrial (ABDI) e o Centro de Gestão e Estudos Estratégicos (CGEE) realizaram em conjunto um estudo prospectivo com o intuito de proporcionar uma visão de futuro da biotecnologia no Brasil no período de 2008 a 2025 (CGEE, 2008). Tal iniciativa, finalizada em 2008, tinha como objetivo subsidiar a Iniciativa Nacional de Inovação em Biotecnologia (INI-Biotecnologia).

O escopo desse trabalho compreendeu cinco setores considerados fortemente impactados pelas biotecnologias de fronteira: Medicina e saúde; Biofármacos; Agroindústria; Energia e biocombustíveis; Meio ambiente. Como metodologia, o estudo recorreu a entrevistas estruturadas presenciais com especialistas de cada área sobre as questões gerais acerca do desenvolvimento da biotecnologia no Brasil e à construção coletiva da visão de futuro, compreendendo o desenho dos mapas tecnológicos e estratégicos dos temas.

No desenvolvimento da referida pesquisa foram definidas, dentro dos setores considerados, as principais tecnologias, das quais duas relacionadas à biotecnologia aplicada à saúde - Medicina e saúde; Biofármacos -, que tomamos como insumo para o desenvolvimento do presente estudo prospectivo.

Biotecnologia aplicada em medicina e saúde

Desdobramos as aplicações das áreas de fronteira no setor de Medicina e saúde em nove tópicos tecnológicos associados. No Quadro 1 se apresentam a descrição de cada tópico tecnológico e as áreas de fronteira que têm impacto sobre o seu desenvolvimento. 
Quadro 1 - Tópicos associados às aplicações das áreas de fronteira no setor de Medicina e saúde

\begin{tabular}{|c|c|c|}
\hline Ref. & Tópicos associados & Descritivo \\
\hline $\mathrm{T} 1 \mathrm{a}$ & Diagnóstico e terapia molecular & $\begin{array}{l}\text { Desenvolvimento de metodologia de diagnóstico } \\
\text { molecular de doenças degenerativas, neoplasias e doenças } \\
\text { cardio/cerebrovasculares utilizando novas nanoestruturas } \\
\text { que permitam interação específica para reconhecimento, } \\
\text { diagnóstico, prevenção e tratamento. }\end{array}$ \\
\hline \multirow[t]{2}{*}{$\mathrm{T} 1 \mathrm{~b}$} & T1b1 - Terapia celular: uso terapêutico & \multirow{2}{*}{$\begin{array}{l}\text { As terapias celulares se baseiam na utilização de células } \\
\text { para substituir tecidos afetados por doenças ou lesões. } \\
\text { Sua principal fonte são as chamadas células-tronco, que } \\
\text { têm a capacidade de se reproduzir e, simultaneamente, se } \\
\text { diferenciar em todos os tipos celulares que constituem um } \\
\text { organismo adulto. }\end{array}$} \\
\hline & $\begin{array}{l}\text { T1b2 - Terapia celular: outros usos, p. } \\
\text { ex., testes toxicológicos }\end{array}$ & \\
\hline $\mathrm{T} 1 \mathrm{c}$ & Biomateriais e materiais biocompatíveis & $\begin{array}{l}\text { Desenvolvimento de materiais sintéticos ou metálicos, } \\
\text { naturais, complexos ou mistos com características } \\
\text { de biocompatibilidade e/ou biorreabsorbilidade } \\
\text { para promover regeneração e reparação por meio de } \\
\text { substituição sintética ou biológica. }\end{array}$ \\
\hline T1d & Nanobiomateriais & $\begin{array}{l}\text { Produção de nanomateriais e nanodispositivos para } \\
\text { diagnósticos, tratamento e funcionalização molecular de } \\
\text { superfícies na interação com sistemas biológicos. }\end{array}$ \\
\hline T1e & $\begin{array}{l}\text { Insumos biológicos ou bioativos para } \\
\text { diagnóstico e tratamento }\end{array}$ & $\begin{array}{l}\text { Identificação de novos alvos e compostos terapêuticos } \\
\text { e desenvolvimento de formulações para melhorar a } \\
\text { assimilação e a biodisponibilidade; adoção do conceito de } \\
\text { reconhecimento molecular. }\end{array}$ \\
\hline T1f & $\begin{array}{l}\text { Medicina intervencionista: } \\
\text { procedimentos minimamente invasivos }\end{array}$ & $\begin{array}{l}\text { Procedimentos que evitam o uso de cirurgia invasiva } \\
\text { aberta em favor de cirurgia fechada ou local, pela } \\
\text { aplicação de materiais estruturais biocompatíveis com } \\
\text { ação terapêutica e preventiva. }\end{array}$ \\
\hline \multirow[t]{2}{*}{$\mathrm{T} 1 \mathrm{~g}$} & $\begin{array}{l}\text { T1g1 - Bancos de criopreservação: pele, } \\
\text { ossos, córnea e cartilagens }\end{array}$ & \multirow{2}{*}{$\begin{array}{l}\text { Construção de órgãos e tecidos (total ou parcial) pela } \\
\text { interação de células com estruturas tridimensionais } \\
\text { artificiais. Desenvolvimento de mecanismos tecnológicos } \\
\text { para viabilizar a construção dos substitutos biológicos }\end{array}$} \\
\hline & $\begin{array}{l}\text { T1g2 - Bancos de criopreservação: } \\
\text { órgãos internos, dentes, gengivas, ossos } \\
\text { da face }\end{array}$ & \\
\hline
\end{tabular}

Fonte: CGEE, 2008.

\section{Biotecnologia aplicada em biofármacos}

Desdobramos as aplicações das áreas de fronteira no setor de biofármacos em seis tópicos tecnológicos associados. No Quadro 2 se apresentam a descrição de cada tópico tecnológico e as áreas de fronteira que têm impacto sobre o seu desenvolvimento. 
Quadro 2 - Desdobramento dos tópicos associados às aplicações das áreas de fronteira no setor de Biofármacos

\begin{tabular}{|c|c|c|c|c|}
\hline Ref. & Tópicos associados & Descritivo & $\begin{array}{l}\text { Foco de } \\
\text { análise }\end{array}$ & Tópicos desdobrados \\
\hline \multirow{6}{*}{ T2a } & \multirow{6}{*}{$\begin{array}{l}\text { Biofármacos e } \\
\text { biomarcadores } \\
\text { baseados na genômica }\end{array}$} & \multirow{6}{*}{$\begin{array}{l}\text { Identificação de novos } \\
\text { alvos terapêuticos, } \\
\text { preventivos, de } \\
\text { diagnóstico e } \\
\text { biomarcadores. }\end{array}$} & T2a1 & $\begin{array}{l}\text { Medicamentos personalizados com } \\
\text { base na genômica individual. }\end{array}$ \\
\hline & & & $\mathrm{T} 2 \mathrm{a} 2$ & Vacina contra Aids. \\
\hline & & & $\mathrm{T} 2 \mathrm{a} 3$ & Anticorpos monoclonais contra câncer. \\
\hline & & & $\mathrm{T} 2 \mathrm{a} 4$ & $\begin{array}{l}\text { Kit de diagnóstico para câncer e kit de } \\
\text { transfecção gênica e análise. }\end{array}$ \\
\hline & & & $\mathrm{T} 2 \mathrm{a} 5$ & $\begin{array}{l}\text { Marcadores de doenças } \\
\text { neurodegenerativas. }\end{array}$ \\
\hline & & & $\mathrm{T} 2 \mathrm{a} 6$ & $\begin{array}{l}\text { Identificação e validação de } \\
\text { alvos; produtos e terapias para } \\
\text { câncer, doenças negligenciadas e } \\
\text { degenerativas. }\end{array}$ \\
\hline \multirow{4}{*}{$\mathrm{T} 2 \mathrm{~b}$} & \multirow{4}{*}{$\begin{array}{l}\text { Desenvolvimento } \\
\text { de plataformas } \\
\text { de produção de } \\
\text { biofármacos }\end{array}$} & \multirow{4}{*}{$\begin{array}{l}\text { Utilização de células de } \\
\text { mamíferos, bactérias, } \\
\text { fungos, insetos, plantas } \\
\text { e animais como } \\
\text { biorreatores para a } \\
\text { produção de proteínas } \\
\text { recombinantes, vacinas } \\
\text { (proteicas e de DNA) e } \\
\text { terapia gênica. }\end{array}$} & T2b1 & $\begin{array}{l}\text { Produtos e plataformas de bactérias e } \\
\text { leveduras humanizadas e murínicas. }\end{array}$ \\
\hline & & & T2b2 & $\begin{array}{l}\text { Animais transgênicos para produção de } \\
\text { biofármacos e órgãos. }\end{array}$ \\
\hline & & & T2b3 & Plataforma de células humanas \\
\hline & & & $\mathrm{T} 2 \mathrm{~b} 4$ & $\begin{array}{l}\text { Produtos e plataformas para produção } \\
\text { de bactéria minimAbs, RNAi. }\end{array}$ \\
\hline \multirow{8}{*}{$\mathrm{T} 2 \mathrm{c}$} & \multirow{8}{*}{$\begin{array}{l}\text { Plataforma para a } \\
\text { produção de nano/ } \\
\text { microssistemas } \\
\text { voltados para a saúde }\end{array}$} & \multirow{8}{*}{$\begin{array}{l}\text { Materiais e } \\
\text { dispositivos nano e } \\
\text { microestruturados para } \\
\text { uso em terapêutica } \\
\text { (sistemas de liberação } \\
\text { controlada de fármacos) } \\
\text { ou diagnóstico (imagem } \\
\text { ou análise). }\end{array}$} & $\mathrm{T} 2 \mathrm{c} 1$ & $\begin{array}{l}\text { Nanodispositivos para diagnóstico de } \\
\text { imagem. }\end{array}$ \\
\hline & & & $\mathrm{T} 2 \mathrm{c} 2$ & Nanossistemas para vetorização ativa. \\
\hline & & & $\mathrm{T} 2 \mathrm{c} 3$ & $\begin{array}{l}\text { Nanossistemas para vetorização } \\
\text { passiva. }\end{array}$ \\
\hline & & & $\mathrm{T} 2 \mathrm{c} 4$ & $\begin{array}{l}\text { Nanossistemas e nanodispositivos para } \\
\text { aplicação cutânea. }\end{array}$ \\
\hline & & & T2c5 & $\begin{array}{l}\text { Microssistemas para medicamentos via } \\
\text { nasal, oral e cutânea. }\end{array}$ \\
\hline & & & T2c6 & $\begin{array}{l}\text { Nanossistemas para medicamentos via } \\
\text { nasal e oral. }\end{array}$ \\
\hline & & & $\mathrm{T} 2 \mathrm{c} 7$ & $\begin{array}{l}\text { Nanodispositivos para diagnóstico } \\
\text { (análise). }\end{array}$ \\
\hline & & & $\mathrm{T} 2 \mathrm{c} 8$ & $\begin{array}{l}\text { Medicamentos neurotrópicos para } \\
\text { distúrbios psiquiátricos. }\end{array}$ \\
\hline $\mathrm{T} 2 \mathrm{~d}$ & $\begin{array}{l}\text { Produtos à base de } \\
\text { ácidos nucleicos }\end{array}$ & $\begin{array}{l}\text { RNA de interferência, } \\
\text { vacinas de DNA, DNA } \\
\text { plasmidial e viral para } \\
\text { fins profiláticos ou } \\
\text { terapêuticos. }\end{array}$ & $\mathrm{T} 2 \mathrm{~d}$ & Terapiagênica para câncer. \\
\hline
\end{tabular}


Quadro 2 - Desdobramento dos tópicos associados às aplicações das áreas de fronteira no setor de Biofármacos (cont.)

\begin{tabular}{|c|c|c|c|c|}
\hline Ref. & Tópicos associados & Descritivo & $\begin{array}{l}\text { Foco de } \\
\text { análise }\end{array}$ & Tópicos desdobrados \\
\hline \multirow{8}{*}{$\mathrm{T} 2 \mathrm{e}$} & \multirow{8}{*}{ Bioprospecção } & \multirow{8}{*}{$\begin{array}{l}\text { Uso da biodiversidade } \\
\text { para identificação de } \\
\text { novas moléculas com } \\
\text { fins terapêuticos. }\end{array}$} & T2e1 & Anti-inflamatórios. \\
\hline & & & $\mathrm{T} 2 \mathrm{e} 2$ & Anticoagulantes e antitrombóticos. \\
\hline & & & $\mathrm{T} 2 \mathrm{e} 3$ & Cardiovasculares. \\
\hline & & & $\mathrm{T} 2 \mathrm{e} 4$ & Antifúngicos. \\
\hline & & & $\mathrm{T} 2 \mathrm{e} 5$ & Ansiolíticos. \\
\hline & & & T2e6 & Produtos dermatológicos. \\
\hline & & & $\mathrm{T} 2 \mathrm{e} 7$ & Fitoterápicos. \\
\hline & & & $\mathrm{T} 2 \mathrm{e} 8$ & Tratamento do câncer. \\
\hline T2f & $\begin{array}{l}\text { Desenvolvimento de } \\
\text { softwares e bancos de } \\
\text { dados }\end{array}$ & $\begin{array}{l}\text { Modelagem molecular } \\
\text { para melhoramento } \\
\text { de moléculas e } \\
\text { estratégias terapêuticas, } \\
\text { identificação de alvos e } \\
\text { farmacovigilância. }\end{array}$ & T2f & $\begin{array}{l}\text { Modelagem molecular; banco de } \\
\text { dados; softwares customizados. }\end{array}$ \\
\hline
\end{tabular}

Fonte: CGEE, 2008.

\section{Marcos temporais para desenvolvimento das tecnologias em biotecnologia}

Considerando essas áreas-chave relacionadas à biotecnologia aplicada à saúde - Medicina e saúde; Biofármacos -, foi feito, por meio de entrevistas com especialistas, o levantamento do cenário atual do seu desenvolvimento tecnológico e aplicadas projeções de desenvolvimento, também propostas pelos especialistas, para construir a rota de desenvolvimento das tecnologias dessas duas áreas no horizonte temporal de 2016 a 2030.

\section{Estágio atual}

A capacidade nacional de ciência e tecnologia no campo da biotecnologia, aplicada seja à medicina ou à saúde, encontra-se aquém da capacidade mundial. No panorama mundial, a maior parte das tecnologias que representam as áreas de fronteira apresenta-se distribuída nos estágios de produção/processo e comercialização, ao passo que no Brasil a maior parte está concentrada nas fases de P\&D e inovação/implantação.

\section{Medicina e saúde}

Há oportunidades tecnológicas que, se bem aproveitadas, podem tornar o país mais competitivo em âmbito internacional. Muitas estratégias, ações e programas têm sido conduzidos para estimular o desenvolvimento tecnológico em áreas estratégicas para o sistema de saúde. As políticas têm priorizado tanto a base tecnológica existente quanto nossa capacidade para desenvolver tecnologias em rotas paralelas às que estão em curso, tais como a incorporação e transferência de tecnologias que poderão resultar em saltos tecnológicos para o complexo industrial da saúde. 
$\mathrm{Na}$ área dos biomateriais a maioria dos produtos utilizados no Brasil é importada, e, apesar do crescimento do número de grupos de pesquisa, há necessidade de apoio mais estruturado, seja por fomento ou pela construção de redes de laboratórios que possam participar do desenvolvimento tecnológico e análise dos protótipos que estão em curso. Apesar de uma característica intrínseca ao desenvolvimento tecnológico no segmento de órteses e próteses ser a alta dependência de inovações radicais, algumas iniciativas importantes são observadas nessas áreas.

Percebe-se que o país tem avançado nas oportunidades estratégicas identificadas pelo estudo no campo do diagnóstico e terapia molecular (T1a); em biomateriais (T1c), no que diz respeito aos bancos de criopreservação, em particular o de cordão umbilical (T1g). No campo da terapia celular aplicada à prática clínica (T1b), a iniciativa elencada no estudo do CGEE não logrou êxito.

Em relação ao diagnóstico e terapia molecular (T1a), o país avançou além das suas capacidades de P\&D; com a nacionalização dos insumos para diagnóstico molecular dos programas nacionais de triagem sanguínea - os testes de ácido nucleico (NAT) -, a produção pública nacional superou as expectativas para o período definido.

No campo das vacinas, o Brasil continua investindo de maneira consistente ao longo das últimas três décadas, o que gerou o domínio na produção de imunobiológicos estratégicos, com estrutura de produção e inovação mundialmente reconhecida.

O país, hoje, também se prepara para se tornar competitivo em insumos biológicos e bioativos para diagnóstico e tratamento (T1e); há um nicho tecnológico privilegiado que ele poderá desenvolver, pois está em estágio avançado entre as etapas de inovação/implantação e de produção/processo.

No campo dos produtos biológicos ocorre um fenômeno diferente em âmbito nacional, observado em particular quando se comparam as PDPs da área de base química com as da área de biológicos. As principais diferenciações encontram-se na estratégia de absorção da tecnologia. A primeira diferença está na competição entre os entes participantes: para a maioria dos produtos há mais de uma parceria firmada, conforme o Quadro 3. A segunda diz respeito ao posicionamento, por indução, das empresas de capital nacional, como as recentemente criadas Bionovis e Orygen, como partícipes do processo de construção da PDP com fabricantes detentores de tecnologia e de capital estrangeiro. 
Quadro 3 - Parcerias para o desenvolvimento produtivo firmadas. Brasil - 2013

\begin{tabular}{|c|c|c|c|c|}
\hline Produto & $\begin{array}{l}\text { Ano previsto para } \\
\text { início do processo } \\
\text { de produção } \\
\text { nacional }\end{array}$ & Indicação & $\begin{array}{l}\text { Laboratório } \\
\text { público }\end{array}$ & Parceiro privado \\
\hline \multirow{3}{*}{ Adalimumabe } & \multirow{3}{*}{2018} & \multirow{3}{*}{ Artritereumatoide } & Bahiafarma & Libbs, Mabxience \\
\hline & & & Biomanguinhos & Orygen, Alteogen \\
\hline & & & IVB & PharmaPraxis \\
\hline Certolizumabe & $2015-2016$ & Artritereumatoide & Biomanguinhos & $\begin{array}{l}\text { UCB Pharma, } \\
\text { Meizler }\end{array}$ \\
\hline \multirow{4}{*}{ Etanercepte } & \multirow{4}{*}{$2016-2017$} & \multirow{4}{*}{ Artritereumatoide } & Bahiafarma & Orygen, Alteogen \\
\hline & & & Butantan & Libbs, Mabxience \\
\hline & & & IVB & \multirow{2}{*}{ Bionovis } \\
\hline & & & Biomanguinhos & \\
\hline Infliximabe & 2015 & Artritereumatoide & IVB & Bionovis \\
\hline \multirow{5}{*}{ Rituximabe } & & & Biomanguinhos & \\
\hline & \multirow{4}{*}{$2015-2016$} & \multirow{4}{*}{$\begin{array}{l}\text { Oncológico/Artrite } \\
\text { Reumatoide }\end{array}$} & Butantan & Libbs, Mabxience \\
\hline & & & FUNED & Orygen, Alteogen \\
\hline & & & IVB & Bionovis \\
\hline & & & Biomanguinhos & \\
\hline \multirow{4}{*}{ Bevacizumabe } & \multirow{4}{*}{$2017-2018$} & \multirow{4}{*}{ Oncológico/DMRI } & Tecpar & Biocad \\
\hline & & & Butantan & Libbs, Mabxience \\
\hline & & & Biomanguinhos & Orygen, Alteogen \\
\hline & & & IVB & Bionovis \\
\hline \multirow{3}{*}{ Cetuximabe } & \multirow{3}{*}{2017} & \multirow{3}{*}{ Oncológico } & Butantan & Libbs, Mabxience \\
\hline & & & IVB & Bionovis \\
\hline & & & Biomanguinhos & \\
\hline \multirow{2}{*}{ Trastuzumabe } & \multirow{2}{*}{2017} & \multirow{2}{*}{ Oncológico } & Bahiafarma & Libbs, Mabxience \\
\hline & & & IVB & Bionovis \\
\hline \multirow[t]{2}{*}{ Somatropina } & \multirow[t]{2}{*}{ 2016-2017 } & \multirow[t]{2}{*}{$\begin{array}{l}\text { Hormônio do } \\
\text { crescimento }\end{array}$} & Biomanguinhos & Cristália \\
\hline & & & FUNED & Pfizer \\
\hline
\end{tabular}

Fonte: elaboração própria com base em dados da Secretaria de Ciência, Tecnologia e Insumos Estratégicos do Ministério da Saúde (Brasil, 2014).

Entre 2016 e 2020, as tecnologias desenvolvidas mediante processos de transferência de tecnologia permitirão posicionar o país em um estágio que lhe possibilitará participar em bases competitivas do mercado mundial até 2030 .

A maioria das tecnologias de fronteira relacionadas à saúde humana tem associação com o desenvolvimento de nanobiomateriais (T1d). Os programas de incentivo e fomento aplicados nesse campo no período recente, como as chamadas públicas para infraestrutura laboratorial, programas especiais em nanociências e nanomateriais (2007 e 2010) e a criação do Sistema Nacional de Laboratórios em Nanociências e Nanotecnologias (SisNano), que objetiva buscar maior interação entre os pesquisadores e facilidade para que se conheçam e se utilizem os equipamentos de nanotecnologia dos institutos nacionais de Ciência e Tecnologia, têm surtido efeitos no campo da pesquisa e do desenvolvimento. 
Se, de um lado, a tendência mundial da atenção médica é caminhar para a medicina personalizada, a aceitação de procedimentos minimamente invasivos (T1f) tem se mostrado como vertente indutora e impulsionada por tecnologias de fronteira. O país se posiciona como forte adepto do uso dessas tecnologias, embora o desenvolvimento tecnológico nacional esteja muito aquém do atual estágio mundial.

Em menor intensidade, o desenvolvimento de tecnologias aplicadas a bancos de criopreservação de pele, osso, cartilagem e córnea (T1g1) tem potencial de, no período de 2016 a 2020, estar próximo do avanço tecnológico no cenário internacional. E mesmo que as pesquisas com órgãos e tecidos artificiais para transplantes (T1g1 e T1g2) não tenham avançado no ritmo de outras áreas, permanece a perspectiva de fortalecimento das competências nessa área no próximo período.

De maneira geral, o SUS tem sido o maior incorporador dessas tecnologias, sobretudo por sua escala e capacidade de serviços. A incorporação tecnológica tem sido cada vez mais rápida e com critérios mais bem estruturados e definidos de avaliação de sua qualidade, custo-efetividade e segurança, e caminha para complementar a tomada de decisão mediante o monitoramento da resposta terapêutica à sua incorporação.

\section{Biofármacos}

As trajetórias de alguns tópicos - "produtos e plataformas para produção de bactéria minimAbs" (T2b4), "produtos e plataformas de bactérias e leveduras humanizadas e murínicas" (T2b1) e "identificação de alvos para câncer, doenças negligenciadas e degenerativas" (T2a6) - encontram-se na fase de inovação/implantação, com perspectivas de produção em larga escala nos períodos 20162020 e $2020-2030$.

Quando o foco de uma pesquisa é a bioprospecção (T2e), a Amazônia continua aparecendo na cena internacional como um lugar privilegiado para a descoberta de novas moléculas. No Brasil, atualmente, várias agências federais financiam projetos em bioprospecção que estão sendo desenvolvidos por grupos de pesquisa nas universidades brasileiras e também por empresas farmacêuticas na fase de P\&D.

Inúmeras moléculas foram identificadas em nível nacional e levadas para pesquisas em laboratórios, particularmente de universidades, sendo alvos de testes toxicológicos e de atividade.

Paralela à bioprospecção, mas tão importante quanto, é a expressão heteróloga de proteínas. A indústria farmacêutica tem encontrado grandes desafios quando o desenvolvimento de um novo fármaco está vinculado a uma molécula complexa. Os principais resultados obtidos pelos pesquisadores para minimizar esse problema estão relacionados à humanização de bactérias e leveduras (T2b1). Já são vários os produtos disponíveis no mercado e essa tecnologia despontou como um campo de extrema relevância da indústria.

São vários os grupos de pesquisa no país que trabalham na expressão de anticorpos monoclonais os minimAbs, RNAi (T2b4). Entretanto, a maioria das pesquisas se mantém em escala laboratorial, mas o setor industrial demonstra um forte e crescente interesse no escalonamento produtivo dessa tecnologia. 
Na mesma linha de desenvolvimento, o tratamento sistêmico para câncer, que consiste em terapia com agentes citostáticos, tem sido um dos grandes alvos para a inserção de novas moléculas obtidas por rotas biotecnológicas. A identificação de novos alvos para o tratamento tem sido um campo científico de contínuo e crescente interesse no Brasil (T2b1), com grupos de pesquisa altamente qualificados. As principais pesquisas nessa linha buscam identificar as proteínas associadas ao tumor que podem se tornar alvos para o tratamento com anticorpos monoclonais ou ainda outros agentes quimioterápicos.

Os tópicos associados à bioprospecção (T2e) não foram considerados nesta análise.

Um exemplo claro do interesse da indústria nacional em avançar no desenvolvimento tecnológico no campo dos biofármacos foi o número de propostas enviadas até 2014 ao Inova Saúde, programa fruto de parceria entre Ministério da Saúde, Ministério da Ciência, Tecnologia e Inovação, Agência Brasileira de Inovação (Finep) e Conselho Nacional de Desenvolvimento Científico e Tecnológico (CNPq). As demandas enviadas para o desenvolvimento de produtos fármacos e biofármacos de interesse público no país somaram $\mathrm{R} \$ 3,6$ bilhões, e os editais publicados para impulsionar o setor disponibilizaram $\mathrm{R} \$ 1,3$ bilhão.

O maior número de projetos apresentados foi no campo de biofármacos, e as empresas líderes dos projetos nesse campo firmaram pelo menos dez parcerias com universidades brasileiras para o desenvolvimento de produtos.

No campo da pesquisa, um exemplo que identifica a priorização de tecnologias de fronteira são as chamadas públicas em apoio à pesquisa em terapia celular. Os editais apoiam projetos de pesquisa básica, pré-clínica e clínica, relacionados ao desenvolvimento de procedimentos terapêuticos inovadores em terapia celular, visando à produção de conhecimentos e ao desenvolvimento de tecnologias sobre terapias celulares, para utilização e incorporação nos serviços de atenção à saúde. Já foram investidos cerca de R $\$ 100$ milhões de reais em 64 grupos de pesquisa, para o financiamento de 154 projetos, até 2014.

Esses são apenas alguns exemplos concretos de que o Brasil tem buscado desenvolver competências para atuar de forma competitiva em áreas de fronteira mundial.

O Brasil também tem buscado desenvolver competências na área de terapia gênica para o tratamento do câncer (T2d).

A grande maioria dos demais tópicos encontra-se situada no centro do mapa tecnológico, nos estágios de inovação/implantação ou de produção em larga escala, e com potencial de comercialização previsto para o médio ou longo prazo.

Os tópicos em que se vislumbra maior vantagem competitiva para o Brasil, considerando-se horizontes a partir de 2020, são aqueles situados na chamada área de apostas: esses tópicos requerem alto grau de esforço para seu desenvolvimento, como pode ser observado na análise da trajetória desenhada no mapa tecnológico, contudo podem representar inovações com alto conteúdo tecnológico e, consequentemente, recompensa para o país. 
Os tópicos que se referem a essas apostas foram identificados pelos especialistas e podem ser observados no Gráfico 9. São eles: animais transgênicos para produção de biofármacos e órgãos (T2b2); anticorpos monoclonais contra o câncer (t2a3); medicamentos personalizados com base na genômica individual (T2a1); identificação e validação de alvos, produtos e terapias para câncer, doenças negligenciadas e degenerativas (T2a6).

\section{Rotas tecnológicas}

Com base no cenário atual aqui apresentado para as principais tecnologias relacionadas à biotecnologia aplicada à saúde e levando em conta a contínua projeção da dinâmica evolutiva das tecnologias avaliadas, o que inclui as opiniões dos especialistas da área apresentadas no trabalho CGEE (2008), construímos as rotas tecnológicas para medicina e saúde e para biofármacos.

No Gráfico 8 se apresenta a rota para medicina e saúde tendo em vista o horizonte de 2016 a 2030.

Gráfico 8 - Mapa tecnológico das aplicações das áreas de fronteira da biotecnologia no setor de Medicina e saúde. Brasil - 2014-2015, 2016-2020, 2020-2030

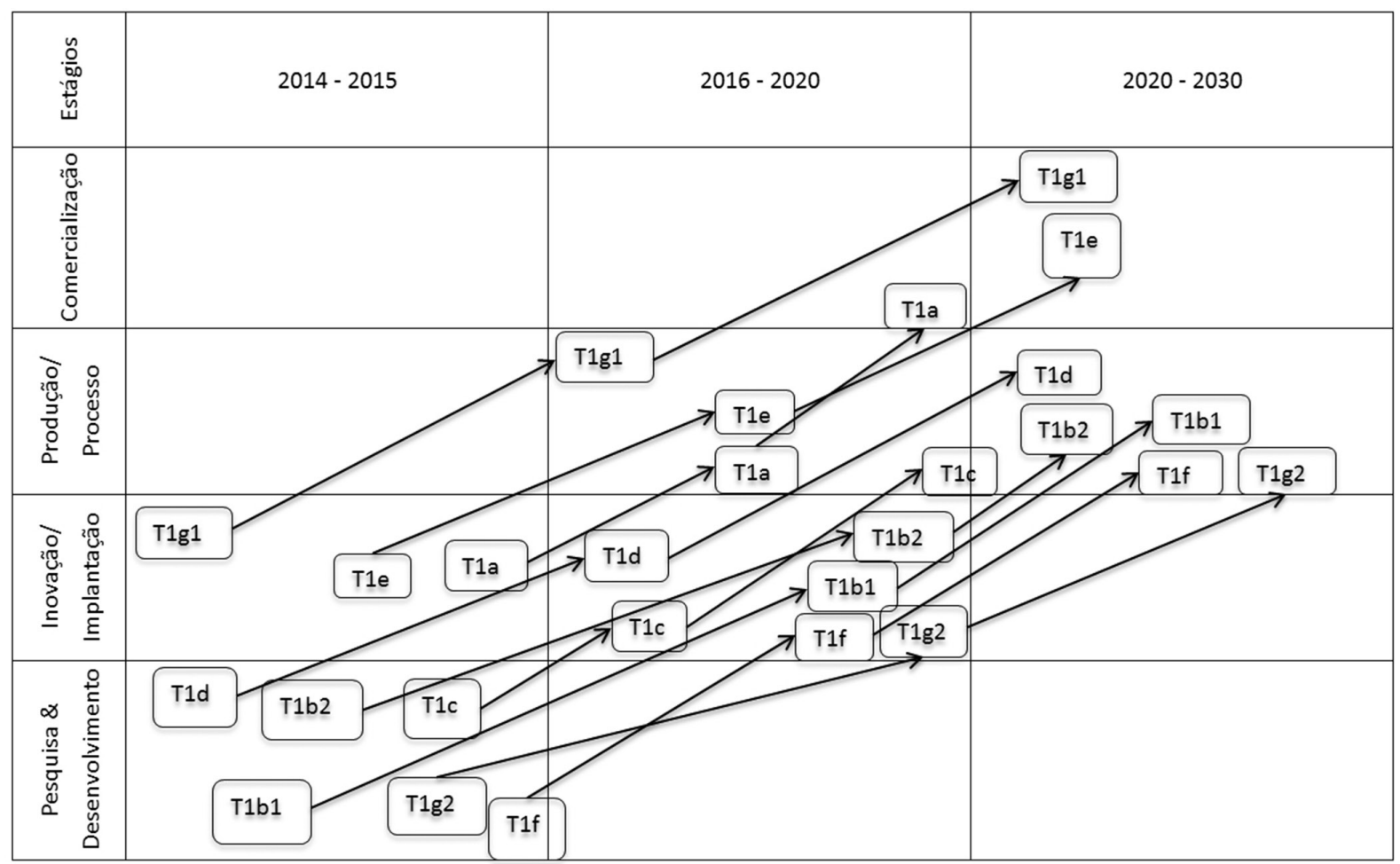

Fonte: elaboração própria com base no layout de CGEE, 2008. 
No Gráfico 9 se apresenta a rota para biofármacos tendo em vista o horizonte de 2016 a 2030.

Gráfico 9 - Mapa tecnológico das aplicações das áreas de fronteira da biotecnologia no setor de Biofármacos. Brasil - 2014-2015, 2016-2020, 2020-2030

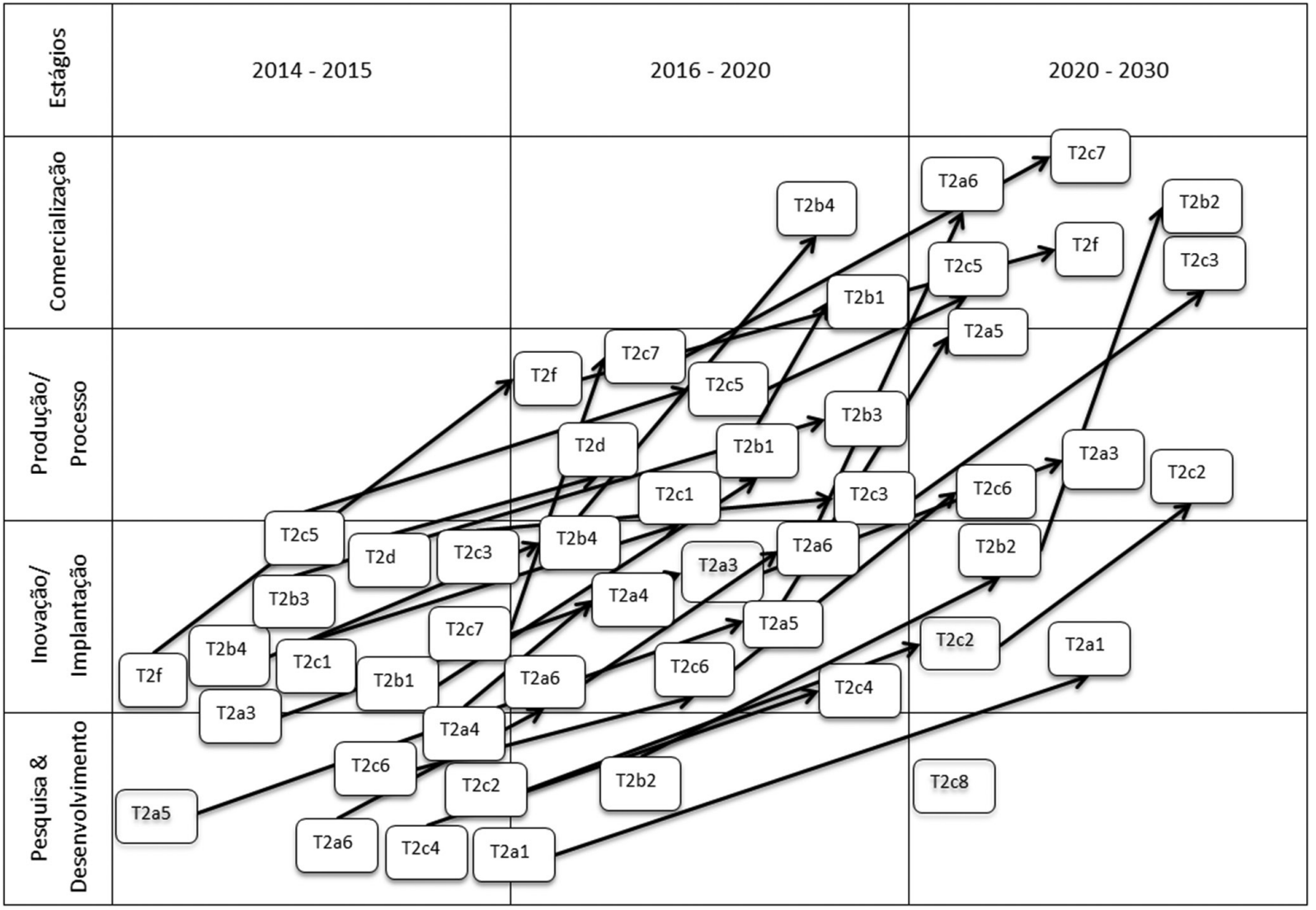

Fonte: elaboração própria com base no layout de CGEE, 2008.

\section{Conclusões e Recomendações}

A análise de mercado sugere a biotecnologia como uma rota para que o setor farmacêutico possa reverter a tendência de redução dos retornos sobre investimento da indústria farmacêutica. Some-se a esse cenário a crescente demanda social por medicamentos biológicos, particularmente por sua aplicação nos casos de doenças relacionadas ao envelhecimento populacional.

Entretanto, em geral, as inovações necessárias para o desenvolvimento da biotecnologia são disruptivas, de sorte que praticamente toda a cadeia do processo inovativo será percorrida até a entrada de novo produto ou processo no mercado.

E sendo a propriedade intelectual um dos caminhos para a proteção do desenvolvimento tecnológico, que é um passo intermediário do processo inovativo, uma análise de depósito de patentes pode ser utilizada como forma de análise prospectiva e permite inferir, com certo grau de confiança, 
visto que o processo inovativo não é determinístico, certas perspectivas de futuro para o mercado em análise. Por essa razão analisamos as patentes depositadas no Instituto Nacional da Propriedade Industrial (INPI) no período de 2000 a 2011 e os despachos relativos a essas patentes, visando a identificar as patentes da área biotecnologia em saúde.

Observamos uma tendência de crescimento do depósito de patentes na área; entretanto, quando se identifica o país de origem da patente e se analisa a distribuição entre residente e não residente, vê-se que a parcela de depósitos de residente apresenta uma tendência de declínio no período de 2007 a 2011. Tal cenário é danoso para o mercado nacional de biotecnologia em saúde, pois mostra o atual domínio tecnológico e um possível futuro domínio de mercado por empresas estrangeiras no momento em que se finalizar a cadeia da inovação relativa à tecnologia que está sendo protegida (ou seja, o produto no mercado).

A identificação dos titulares dessas patentes, a classificação das instituições com maior número de depósitos e a separação dos depósitos de residentes e daqueles não residentes no Brasil permitiram constatar a baixa frequência de universidades ou instituições de pesquisa na lista dos depositantes não residentes, na qual a maioria dos titulares são empresas privadas. Observam-se também nomes de grandes farmacêuticas que estão entrando na área biotecnológica e novas empresas especializadas apenas em biotecnologia. Por sua vez, na lista de titulares residentes com maior número de patentes, em contraponto ao caso dos não residentes, é evidente o predomínio de universidades, seguidas de instituições públicas de pesquisa, como maiores patenteadores nacionais em biotecnologia em saúde. São poucas as empresas privadas encontradas na lista, e até mesmo pessoas físicas são encontradas como titulares, o que evidencia certo descolamento entre o desenvolvimento das pesquisas na área e o interesse do setor empresarial, que certamente dificulta a conclusão da cadeia da inovação com o produto final no mercado.

A identificação do país de origem das patentes de não residente e a classificação daqueles com maior número de patentes evidenciam a liderança dos EUA, com mais que o dobro de patentes do que o segundo lugar na lista. Nos segundo e terceiro lugares se alternam Japão e Alemanha, exceto nos anos 2002 e 2003, em que a França aparece em terceiro lugar.

Para avaliar a inserção do Brasil no cenário internacional de desenvolvimento tecnológico em biotecnologia em saúde, analisamos as patentes depositadas em 2009 no USPTO. Construímos a matriz de interações entre ciência e tecnologia e seu recorte para a área de biotecnologia em saúde, que permite identificar as áreas científicas que têm sido base teórica para o desenvolvimento tecnológico, e com que intensidade.

Esse recorte permite observar, para as patentes dos EUA, Alemanha e França (grandes patenteadores na área), a frequência das citações de artigos de cada uma das áreas científicas definidas pelo ISI, o que possibilita elencar as áreas científicas mais utilizadas para embasar os desenvolvimentos tecnológicos em biotecnologia aplicada à saúde. Proporcionalmente não há grandes variações na distribuição de citações entre áreas científicas para os três países analisados, o que favorece o delineamento de um padrão no uso de conhecimento científico para o desenvolvimento tecnológico em biotecnologia em saúde e, assim, permite identificar as áreas científicas necessárias para embasar tal desenvolvimento. 
A inexistência de patentes brasileiras em biotecnologia em saúde na base USPTO no ano em análise evidencia a baixa inserção nacional no cenário de desenvolvimento tecnológico internacional na área.

No cenário internacional, aplicamos uma metodologia para identificar empiricamente as redes globais de inovação, que são interações entre empresas e universidades, em nível global, para desenvolvimento tecnológico. Essa metodologia utiliza patentes concedidas pelo USPTO e suas citações de artigos indexados no ISI para rastrear os fluxos entre as empresas e universidades que fazem parte dessas redes globais de inovação, o que torna possível vincular uma empresa detentora de patente, localizada em um país específico, com o instituto de pesquisa, universidade ou até mesmo uma empresa que seja autora do artigo científico citado no pedido de patente. Cria-se, assim, uma rede de fluxo de conhecimento com origem na instituição autora do artigo científico e destino na instituição depositária da patente. Como a instituição do artigo pode estar em um país diferente do detentor da patente, tal rede adquire uma escala global, permitindo identificar os fluxos globais de conhecimento (codificados nos artigos) utilizados para embasar o desenvolvimento tecnológico.

Especificamente para a biotecnologia em saúde, na análise do país de origem da patente a posição de liderança dos EUA, do Japão e de alguns países europeus é imediatamente evidente. Analogamente, identificando-se o titular da patente e gerando-se a classificação dos maiores patenteadores, novamente observam-se nomes de grandes farmacêuticas que estão entrando na área biotecnológica e também novas empresas especializadas apenas em biotecnologia.

Analisando-se o país da instituição da SNPRs ISI indexada nas patentes, observa-se a posição de liderança dos EUA, cujas citações são quase oito vezes o total de SNPRs ISI indexadas do Japão, na segunda posição, e quase dez vezes o total da Alemanha e da França, respectivamente na terceira e quarta posições. Vale ressaltar também a distribuição entre diversos países da autoria desses artigos, uma vez que quase metade é de autores de fora dos EUA, o que fornece uma pista importante sobre a internacionalização dos fluxos de conhecimento que servem de base para o desenvolvimento tecnológico em biotecnologia Analogamente, das vinte instituições autoras dos SNPRs ISI indexados mais citadas, há apenas quatro universidades não americanas; tais instituições são do Japão, da Alemanha e do Canadá.

A descrição dos autores institucionais presentes nas citações de artigos ISI indexados das patentes dos EUA permite identificar a localização geográfica da origem do conhecimento codificado no artigo. Tal identificação dá ideia da propagação das redes originadas em cada país, para os vinte países mais citados (entre 53 países diferentes), e de sua própria infraestrutura científica. Este é um primeiro sinal da amplitude das redes que se originam nos EUA.

Entretanto, o Brasil não se insere nessa rede global de desenvolvimento tecnológico em biotecnologia para saúde, o que gera preocupação sobre o futuro do desenvolvimento nacional nesta área, que ainda se encontra na etapa de intensiva utilização da base científica que é, por natureza, internacionalizada e construída, em geral, em rede de pesquisadores e instituições de pesquisa (dadas as coautorias interinstitucionais e citações entre artigos). Para obter os ganhos da utilização de conhecimento externo que a organização em rede permite, o Brasil precisa desenvolver mecanismos (inclusive de política pública) que o levem a se inserir na rede identificada e descrita neste trabalho 
prospectivo. Essa inserção na rede contribuirá fortemente para acelerar as rotas tecnológicas desenhadas nos mapas da seção "Tendências tecnológicas, lacunas, desafios e potencialidades" deste trabalho, aproximando-as das rotas internacionais, que estão, certamente, em um estágio mais avançado de desenvolvimento.

Para desenhar as rotas tecnológicas, valemo-nos das principais tecnologias para Medicina e saúde e Biofármacos, tendo avaliado nove tecnologias da área Medicina e saúde e 28 tecnologias da área Biofármacos. Por meio de entrevistas com especialistas identificamos o estágio atual de desenvolvimento de cada uma delas e, aplicando a projeção de desenvolvimento proposta pelos especialistas na área em CGEE (2008), construímos a rota de desenvolvimento das tecnologias dessas duas áreas no horizonte temporal de 2016 a 2030.

Diversas das rotas prospectadas no Brasil estão distantes das rotas internacionais: algumas estão em estágio de P\&D quando no cenário mundial já se encontram em estágio de comercialização, razão pela qual estratégias complementares devem ser traçadas para reposicionar as rotas nacionais, aproximando-as mais das mundiais. Uma proposta de estratégia já citada aqui é a inclusão do Brasil na rede global de inovação na área de biotecnologia em saúde, caracterizada na seção "Tendências tecnológicas, lacunas, desafios e potencialidades". Especialmente nas etapas mais avançadas da cadeia de inovação, são necessárias ações que vão além de investimento em infraestrutura, pois envolvem frentes como desenvolvimento de recursos humanos, aprimoramento do marco regulatório, aspectos éticos e aceitação pela sociedade, além de aspectos de mercado. No entanto, identificamos no âmbito das políticas públicas para a biotecnologia em saúde uma forte concentração em ações de financiamento de infraestrutura, o que poderá gerar, no futuro, empecilhos ao desenvolvimento de certas tecnologias.

\section{Referências}

BRASIL. Ministério da Ciência, Tecnologia e Inovação. Brasil + BIOTEC: Estratégia Nacional de Ciência, Tecnologia e Inovação em Biotecnologia. Brasília: MCTI, 2013.

BRASIL. Ministério da Saúde. Secretaria de Ciência, Tecnologia e Insumos Estratégicos. Disponível em: < http:// portalsaude.saude.gov.br/index.php/o-ministerio/principal/secretarias/sctie>. Acesso em: jan. 2014.

BRAUN, T.; GLANZEL, W. \& GRUPP, H. The weight of 50 nations in 27 science areas, 1989-1993 (Part I). Scientometrics, 33(3): 263-293, 1996.

BRITTO, G. et al. Global interactions between firms and universities: global innovation networks as first steps towards a Global Innovation System. Innovation and Development, 3(1): 71-88, 2013.

CALIXTO, J. B. Challenges and opportunities for development of biopharmaceuticals in Brazil. In: CONGRESSO BRASILEIRO DE BIOTECNOLOGIA, 3, 2010, Fortaleza.

CALLAERT, J.; GROUWELS, J. \& VAN LOOY, B. Delineating the science footprint in technology: identifying scientific publications within non-patent references. Scientometrics, 91(30): 383-398, 2012.

CALLAERT, J. et al. Traces of prior art: an analysis of non-patent references found in patent documents. Scientometrics, 69(1): 3-20, 2006.

CAMPBELL, D. Pharmerging markets. In: PARTNERING FOR GLOBAL HEALTH FORUM, BIOTECHNOLOGY, 2011, Washington. 
CANTWELL, J. The globalization of technology: what remains of the product cycle model. Cambridge Journal of Economics, 19(1): 155-174, 1995.

CANTWELL, J. Innovation and information technology in the MNE. In: RUGMAN, A.M. (Ed.). The Oxford Handbook of International Business. 2. ed. Oxford: Oxford University Press, 2009.

CANTWELL, J. \& JANNE, O. Technological globalisation and innovative centres: the role of corporate technological leadership and locational hierarchy. Research Policy, 28: 119-144, 1999.

CARLSSON, B. Internationalization of innovation systems: a survey of the literature. Research Policy, 35(1): 56-67, 2006.

CAVES, R. Multinational Enterprise and Economic Analysis. Cambridge: Cambridge University, 1996.

CENTRO DE GESTÃO E ESTUDOS ESTRATÉGICOS (CGEE). Estudo prospectivo: Visão de Futuro e Agenda INI Biotecnologia, 2008-2025. Relatório final. Brasília, 2008.

COHEN, W.; NELSON, R. \& WALSH, J. Links and impacts: the influence of public R\&D on industrial research. Management Science, 48(1):1-23, 2002.

DUNNING, J. Multinational Enterprises and the Global Economy. Workingham: Addison-Wesley Publishing Company, 1995.

DUNNING, J. Globalization, technological change and the spatial organization of economic activity. In: CHANDLER, A.; HAGSTROM, P. \& SOLVELL, O. (Eds.). The Dynamic Firm: the role of technology, strategy, organization and regions. Oxford: Oxford University Press, 1998.

DUNNING, J. \& LUNDAN, S. Multinational Enterprises and the Global Economy. 2. ed. Cheltenham: Edward Elgar, 2008.

DUTRÉNIT, G. Introduction to special issue: interactions between public research organizations and industry in Latin America. Science and Public Policy, 37(7): 471-472, 2010.

ERNST, D. Innovation Offshoring: Asia's emerging role in Global Innovation Networks. Honolulu: East-West Center, 2006.

ERNST, D. \& KIM, L. Global production networks, knowledge diffusion and local capability. Research Policy, 31(8/9): 1.417-1.429, 2002.

EVALUATE PHARMA. World Preview 2016, Outlook to 2022. Disponível em < http://info.evaluategroup.com/ rs/607-YGS-364/images/wp16.pdf>. Acesso em: jan. 2016.

FERMAN, M. K. S. Capacitação Brasileira para Produção de Medicamentos Biológicos Similares, 2010. Dissertação de Mestrado, Rio de Janeiro: Universidade Federal do Rio de Janeiro.

FORTUNE. Global 500 2014. Disponível em: <http://fortune.com/global500/>. Acesso em: 25 jan. 2014.

FREEMAN, R. The challenge of the growing globalization of labor markets to economic and social policy. In: PAUS, E. (Ed.). Global Capitalism Unbound: winners and loosers from offshore outsourcing. New York: Palgrave Macmillan, 2007.

GADELHA, C. Sistema produtivo: Complexo Industrial da Saúde. Projeto Perspectivas do Investimento no Brasil. Rio de Janeiro, São Paulo: UFRJ, Unicamp, 2009.

HAGEDOORN, J. Inter-firm R\&D partnership: an overview of major trends and patterns since 1960. Research Policy, 31: 477-492, 2002.

HYMER, S. The International Operations of National Firms: a study of direct foreign investment. Cambridge: MIT Press, 1976. 
JAFFE, A. \& TRAJTENBERG, M. Patent, Citations, and Innovation. Cambridge: MIT Press, 2002.

KLEVORICK, A. et al. On the sources and significance of New York: inter-industry differences in technological opportunities. Research Policy, 24: 185-205, 1995.

KUEMMERLE, W. Building effective R\&D capabilities abroad. Harvard Business Review, 75(2): 61-70, 1997.

LEMLEY, M. \& SAMPAT, B. Examiner characteristics and patent office outcomes. Review of Economics and Statistics, 94(3): 817-827, 2012.

MACHER, J. T. \& MOWERY, D. (Eds.).Innovation in Global Industries: US firms competing in a new world. Washington: The National Academies Press, 2008.

MOED, H.; GLANZENL, W. \& SCHMOCH, U. (Eds.).Handbook of Quantitative Science and Technology Research: the use of publication and patent statistics in studies of S\&T systems. Dordrecht: Kluwer Academic Publishers, 2004.

MOWERY, D. \& SAMPAT, B. Universities in national innovation systems. In: FAGERBERG, J.; MOWERY, D. \& NELSON, R. (Eds.). The Oxford Handbook of Innovation. Oxford: Oxford University Press, 2005.

NARIN, F. \& NOMA, E. Is technology becoming science? Scientometrics, 7(3-6): 369-381, 1985.

NARIN, F; HAMILTON, K. S. \& OLIVASTRO, D. The increasing linkage between U.S. technology and public science. Research Policy, 26(3): 317-330, 1997.

NARULA, R. \& ZANFEI, A. Globalization of innovation: the role of multinational enterprises. In: FAGERBERG, J.; MOWERY, D. \& NELSON, R. (Eds.). The Oxford Handbook of Innovation. Oxford: Oxford University Press, 2005.

OBSERVATOIRE DES SCIENCES ET DES TECHNIQUES (OST). Science \& Technologie: indicateurs 2006. Paris: Economica.

ORGANISATION FOR ECONOMIC COOPERATION AND DEVELOPMENT (OECD). L'Internationalisation de la R\&D Industrielle: structures et tendances. Paris: OECD, 1998.

ORGANISATION FOR ECONOMIC COOPERATION AND DEVELOPMENT (OECD). The Internationalization of Business R\&D: evidence, impacts and implications. Paris: OECD, 2008a.

ORGANISATION FOR ECONOMIC COOPERATION AND DEVELOPMENT (OECD). Open Innovation in Global Networks: policy issues. Paris: OECD, 2008b.

ORGANISATION FOR ECONOMIC COOPERATION AND DEVELOPMENT (OECD). The Biotechnology to 2030: designing a policy agenda. Paris: OECD, 2009.

PATEL, P. Localised production of technology for global markets. Cambridge Journal of Economics, 19(1): 141153, 1995.

PATEL, P. \& PAVITT, K. National Systems of Innovation under Strain: the internationalization of corporate R\&D. Brighton: SPRU, 1998.

PAVITT, K. Uses and abuses of patent statistics. In: VAN RAAN, A. F. J. (Ed.). Handbook of Quantitative Studies of Science and Technology. Amsterdam: North Holland, 1988.

PAVITT, K. What makes basic research economically useful. Research Policy, 20(2): 109-119, 1991.

POWELL, W. W. \& GRODAL, S. Networks of innovators. In: FAGERBERG, J.; MOWERY, D. \& NELSON, R. (Eds.). The Oxford Handbook of Innovation. Oxford: Oxford University Press, 2005.

REDE ALICE/Ministério do Desenvolvimento, Indústria e Comércio Exterior. Dados disponíveis em: <http:// aliceweb.mdic.gov.br/>. Acesso em: jan. 2014. 
REIS, C.; LANDIM, A. \& PIERONI, J. P. Lições da experiência internacional e propostas para incorporação da rota biotecnológica na indústria farmacêutica brasileira. BNDES Setorial, 34: 5-44, 2011.

REIS, C.; PIERONI, J. P. \& SOUZA, J. O. B. Biotecnologia para Saúde no Brasil. BNDES Setorial, 32: 193-230, 2010.

RIBEIRO, L. C. et al. Matrices of science and technology interactions and patterns of structured growth: implications for development. Scientometrics, 83(1): 55-75, 2010.

RIBEIRO, L. C. et al. Unveiling Global Innovation Networks. Belo Horizonte: Cedeplar-UFMG, 2012.

ROACH, M. \& COHEN, W. Lens or prism: Patent citations as a measure of knowledge flow from public research. Management Science, 59(2): 504-525, 2013.

SCHUMPETER, J. A. Teoria do Desenvolvimento Econômico. 2. ed. São Paulo: Nova Cultural, 1985.

TIJSSEN, R. Measuring and evaluating science-technology connections and interactions. In: MOED, H.; GLANZEL, W. \& SCHMOCH, U. (Eds.). Handbook of Quantitative Science and Technology Research: the use of publication and patent statistics in studies of S\&T systems. Dordrecht: Kluwer Academic Publishers, 2004.

TIJSSEN, R.; BUTER, R. K. \& VAN LEEUWEN, N. Technological relevance of science: an assessment of citation linkages between patents and research papers. Scientometrics, 47(2): 389-412, 2000.

UNITED NATIONS CONFERENCE ON TRADE AND DEVELOPMENT (UNCTAD). World Investment Report 2005: transnational corporations and the internationalization of $R \& D$. Geneva: United Nations Conference on Trade and Development, 2005.

UNITED NATIONS CONFERENCE ON TRADE AND DEVELOPMENT (UNCTAD). World Investment Report 2006. FDI from Developing and Transition Economies: implications for development. Geneva: United Nations Conference on Trade and Development, 2006.

UNITED NATIONS CONFERENCE ON TRADE AND DEVELOPMENT (UNCTAD). World Investment Report 2011: non-equity modes of international production and development. Geneva: United Nations Conference on Trade and Development, 2011.

VERBEEK, A.; DEBACKERE, K. \& LUWEL, M. Science cited in patents: a geographic "flow" analysis of bibliographic citation patterns in patents. Scientometrics, 58(2): 241-263, 2003.

VERBEEK, A. et al. Science and Technology Interplay: a modelling approach on a regional level. Brussels: EC DG Research, 2002.

ZITT, M. \& BASSECOULARD, E. Internationalization of science in the prism of bibliometric indicators: journals, collaboration, and geographic distribution. In: MOED, H.; GLANZEL, W. \& SCHMOCH, U. (Eds.). Handbook of Quantitative Science and Technology Research: the use of publication and patent statistics in studies of S\&T systems. Dordrecht: Kluwer Academic Publishers, 2004. 



\title{
BASE MECÂNICA, ELETRÔNICA E DE MATERIAIS
}

\author{
José Maldonado \\ Eduardo Jorge Valadares Oliveira
}

Dentre as atividades produtivas no âmbito do complexo econômico-industrial da saúde (CEIS) e em consonância com a base de conhecimento e tecnológica, destaca-se o subsistema de base mecânica, eletrônica e de materiais, que congrega um conjunto bastante díspar de atividades, usualmente agregadas na designada indústria de equipamentos e materiais médico-hospitalares e odontológicos. Essa indústria se constitui em uma área estratégica para a saúde, por representar uma fonte contínua de mudanças nas práticas assistenciais, exercendo particular influência na prestação de serviços de saúde. Tem, ademais, potencial de promover o adensamento do sistema nacional de inovação e de ampliar a competitividade industrial como um todo, dado que articula tecnologias portadoras de futuro.

A indústria de equipamentos e materiais médico-hospitalares e odontológicos tem um papel de destaque no âmbito do CEIS, tanto por seu potencial de inovação - incorpora fortemente os avanços associados ao paradigma microeletrônico - quanto por seu impacto nos serviços, e representa uma fonte constante de mudanças nas práticas assistenciais, trazendo permanentemente para o debate a tensão entre a lógica industrial e a sanitária. Esta indústria engloba grande variedade de produtos e tecnologias. Tomamos como referência a Global Medical Device Nomenclature (GMDN), cuja lista tem mais de oito mil nomes técnicos distintos. Estes se desdobram, de acordo com a Organização Mundial da Saúde (OMS), em cerca de 1,5 milhão de produtos diferentes, desde os mais tradicionais, como seringas e curativos, até os mais sofisticados, como os que incorporam bioinformática, nanotecnologia, eletrônica embarcada e engenharia de células e materiais.

A rigor, as indústrias de bioinformática, nanotecnologia, eletrônica embarcada e engenharia de células e materiais fogem ao escopo industrial tradicional. Entretanto, em virtude da grande variedade de produtos e serviços e da constante interação dessas indústrias com outros setores em geral e com a indústria de equipamentos e materiais médico-hospitalares e odontológicos em particular, criam um modelo de convergência tecnológica que, efetivamente, forma a base para uma importante fonte geradora de inovação.

A despeito de ser tratada como uma indústria, essa atividade abrange grande heterogeneidade tecnológica, pois incorpora, como já afirmado, segmentos bastante diversificados, desde bens de capital de alta complexidade até materiais de consumo de uso rotineiro. No Brasil, a Associação Brasileira da Indústria de Artigos e Equipamentos Médicos, Odontológicos, Hospitalares e de Laboratórios 
(Abimo), entidade que congrega as empresas dessa indústria, classifica as empresas conforme os seguintes segmentos: equipamentos médico-hospitalares; implantes; laboratório; odontologia; radiologia e materiais de consumo (Abimo, 2014).Essa característica abre amplas perspectivas em termos de diversos nichos competitivos que se configuram em oportunidades para empresas de diversas especialidades e porte.

No Brasil, apesar de tal indústria ter conhecido um crescimento significativo nos últimos anos, tem-se verificado um crescente déficit na balança comercial desses equipamentos e materiais. Tal incompatibilidade entre as necessidades nacionais de saúde e a base produtiva e inovativa da indústria aponta para fragilidades estruturais desta. Discutir as principais tendências que condicionam o desenvolvimento dessa indústria no Brasil e identificar nichos de mercado nos quais seja possível construir vantagens competitivas nacionais para 2030 são o objetivo central deste trabalho.

Dada a característica de grande heterogeneidade da indústria, na identificação de nichos de mercado optamos por dirigir um olhar mais minucioso para os segmentos de equipamentos médico-hospitalares, de implantes e de odontologia. Os dois primeiros por se tratar de produtos prioritários tanto para o Ministério da Saúde quanto para o Sistema Único de Saúde (SUS). E os equipamentos de odontologia, em função do seu desempenho competitivo: é o único segmento dessa indústria superavitário em termos de balança comercial.

\section{Panorama Global}

A indústria de equipamentos e materiais médico-hospitalares e odontológicos (produtos médicos) se constitui em um oligopólio baseado na diferenciação de produtos. Sua dinâmica de funcionamento assenta-se no fornecimento de bens, em grande parte altamente especializados, com grande quantidade de produtos sendo lançados continuamente, com novas opções de tratamento e diagnóstico, com ciclos tecnológicos curtos (com duração de menos de dois anos), e que são comercializados em associação com serviços e outros produtos (Leão, Oliveira \& Albornoz, 2008).

Nessa indústria, altamente concentrada, ${ }^{1}$ a diferenciação de produtos se baseia na intensidade dos gastos em pesquisa e desenvolvimento (P\&D), sendo que as grandes empresas concentram seus esforços competitivos em segmentos de maior intensidade tecnológica. Uma característica marcante dessa indústria é sua crescente absorção de avanços tecnológicos oriundos de indústrias tradicionalmente inovadoras, como as de microeletrônica, nanotecnologia, automação, mecânica de precisão, materiais etc.

Esse processo tem se tornado imprescindível para os avanços tecnológicos do setor, pois grande parte das incorporações tecnológicas nos produtos comercializados atualmente são desdobramentos (spill-overs) de outras indústrias. Dessa forma, os maiores atores (players) mundiais do setor não têm

\footnotetext{
${ }^{1}$ De acordo com ABDI (2009), as vinte maiores empresas respondem por aproximadamente $70 \%$ da produção mundial.
} 
o negócio "produto médico"2 como motor principal, capaz de impulsionar grandes investimentos em P\&D e arcar com os elevados custos da corrida tecnológica. Nessas empresas, o principal investimento em P\&D no setor (aproximadamente 13\% do faturamento para as empresas americanas e 7\% para as empresas europeias) consiste na adequação e adaptação do conteúdo tecnológico dos outros setores industriais para a área médica (Gadelha et al., 2012).

Isso explica o fato de as grandes empresas internacionais da indústria terem adotado estratégias comerciais em âmbito global, defendendo suas posições nos grandes mercados já estabelecidos Estados Unidos da América (EUA), Comunidade Europeia e Japão -, o que demanda produtos de alto conteúdo tecnológico. Além disso, estão buscando dominar mercados emergentes que crescem a taxas bastante elevadas e nos quais o mercado é caracterizado por produtos com conteúdo tecnológico inferior e custo-efetividade comprovados. Nesses mercados, à exceção dos EUA, a atenção à saúde é predominantemente patrocinada com recursos públicos e, com o aperfeiçoamento dos sistemas de saúde público e privado, a extensão da cobertura das redes de assistência a uma parcela cada vez maior da população e a expansão do gasto público em saúde têm demonstrado que os países emergentes passaram a ser o principal atrativo para as empresas do setor.

Apesar dessa forte característica de atividades intensivas em P\&D associadas a estratégias empresariais de penetração em diferentes mercados, grande quantidade de equipamentos e materiais de uso em saúde obedece a padrões de competição baseados em preços. É o caso de mercados de materiais médicos como seringas, luvas e equipamentos médicos para diagnósticos e terapias mais convencionais, em que a produção e os ganhos de competitividade se dão em largas escalas e as margens de lucro são reduzidas. No Brasil, esse é o principal mercado das empresas nacionais, conforme observado nos dados sobre comercialização do Sistema de Análise das Informações de Comércio Exterior via Internet (Aliceweb/MDIC) e sobre produção da Pesquisa Industrial Anual do Instituto Brasileiro de Geografia e Estatística (PIA/IBGE).

Além do dinamismo da corrida tecnológica, de vendas casadas, soluções integradas e linhas de financiamento atrativas, as grandes empresas que dominam o mercado internacional têm adotado duas outras estratégias fundamentais: a internacionalização e fusões/aquisições. No primeiro caso, as empresas estabelecem uma rede de prestação de serviços técnicos nos países em que atuam, com o intuito de aproximar as atividades de assistência e de manutenção dos usuários, além de distribuir plantas industriais em diversas localidades para minimizar custos de fabricação e aproveitar vantagens de infraestrutura e logística de transporte - especialmente com a produção asiática.

Por outro lado, a estratégia de fusão e aquisição de empresas ${ }^{3}$ em negócios internacionais visa à minimização de custos intangíveis muito importantes, como, por exemplo, a manutenção de pontos

\footnotetext{
${ }^{2}$ Produto médico, conforme a RDC Anvisa n. 185, de 22 de outubro de 2001, é "Produto para a saúde, tal como equipamento, aparelho, material, artigo ou sistema de uso ou aplicação médica, odontológica ou laboratorial, destinado à prevenção, diagnóstico, tratamento, reabilitação ou anticoncepção e que não utiliza meio farmacológico, imunológico ou metabólico para realizar sua principal função em seres humanos, podendo, entretanto, ser auxiliado em suas funções por tais meios".

${ }^{3}$ Na indústria, o processo de fusões e aquisições tem sido intenso. Em 2011, por exemplo, ocorreram 443 transações dessa natureza e, em 2012, 330 (Medical..., 2013).
} 
de promoção de vendas e redes de assistência técnica especializada. No Brasil, nos últimos dois anos, tem-se observado que essas empresas iniciaram um processo de aquisição das principais empresas nacionais nas áreas de imagem e monitoramento de sinais vitais. Os produtos fabricados localmente têm custo-efetividade e preço tais que lhes garantem uma significativa participação na rede pública de saúde. Em outras palavras, os equipamentos produzidos por essas empresas dominavam a base da pirâmide de um mercado público de saúde em expansão. Isso fez com que as grandes empresas internacionais vislumbrassem a possibilidade concreta de expandir seus negócios mediante a aquisição das principais empresas nacionais que contavam com uma rede de vendas e de assistência técnica capilarizada e grande inserção no mercado.

A curto prazo, essa abordagem se mostra interessante porque se espera observar um ganho de tecnologia nos produtos fabricados localmente e disponibilizados no sistema público de saúde, principalmente na melhoria dos aspectos de confiabilidade e usabilidade dos produtos. Contudo, a longo prazo não há garantia concreta da manutenção dessas empresas e da fabricação desses produtos no país, o que pode implicar, no caso de extinção das empresas, um desequilíbrio ainda maior da balança comercial e o aumento no preço para a aquisição de tecnologias médicas, uma vez que sem a presença das tecnologias custo-efetivas, ocorrerá a migração da demanda para as tecnologias consideradas como estado da arte.

O mercado mundial dessa indústria em 2013 era avaliado em US\$ 328 bilhões (The World..., 2013). O Gráfico 1 apresenta para esse ano a participação por região no mercado mundial. A Tabela 1, por sua vez, apresenta para 2013 a participação no mercado mundial, em valor e percentual, por principais países.

Das informações contidas no Gráfico 1 e na Tabela 1, constata-se a forte concentração da indústria nos países da tríade. Os dez maiores mercados respondem, em conjunto, por 77\% do total mundial, sendo que os EUA representam incontestavelmente o maior mercado, com 39\% do total. Dentre os designados Brics, os quatro países de economia mais robusta, Brasil, Rússia, Índia e China, representam em conjunto $10 \%$ do total mundial (a Índia, que no ranking ocupa a $16^{\mathrm{a}}$ posição, detém $1 \%$ do mercado mundial). 
Gráfico 1 - Distribuição percentual do mercado mundial por região - 2013

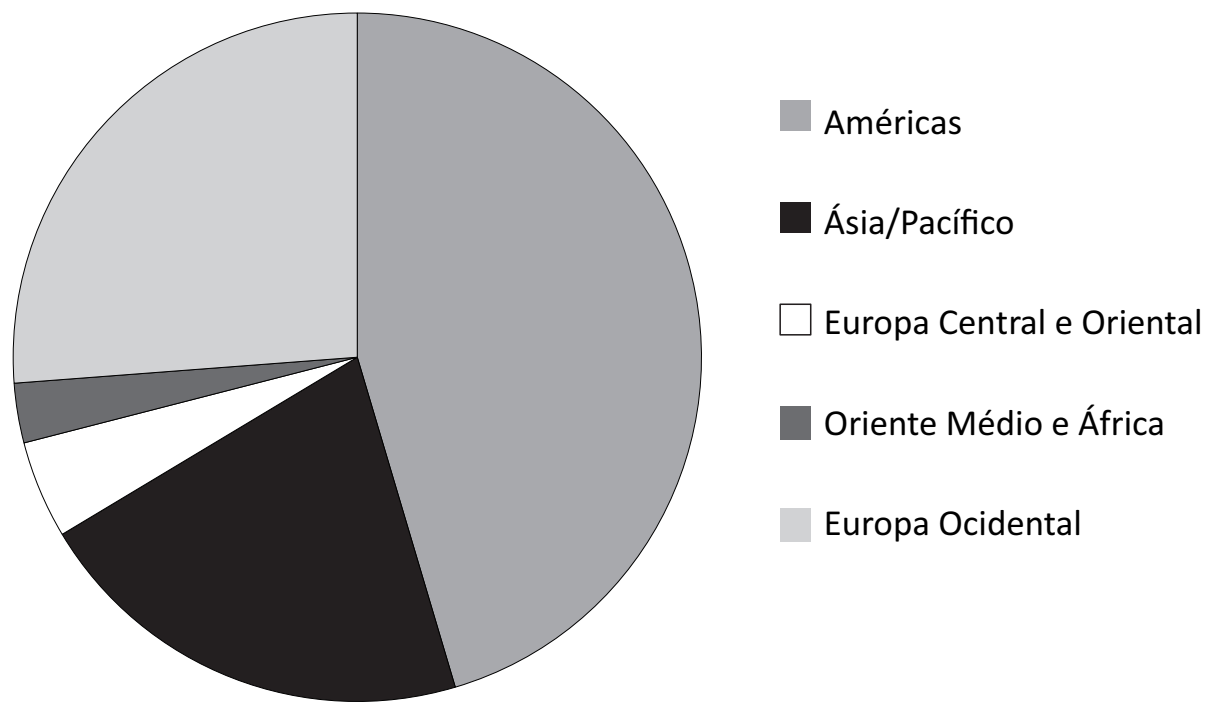

Fonte: The World Medical Markets Fact Book 2013.

A desaceleração das economias europeias nas duas últimas décadas, agravada pela crise mundial recente, tem estimulado a adoção de políticas de contenção de gastos por parte dos governos e das operadoras de saúde, contribuindo para uma estagnação relativa do mercado de equipamentos médicos nos países desenvolvidos. Em contrapartida, as perspectivas em termos de taxa de crescimento encontram-se nos países emergentes e, como afirmado, assiste-se a um crescente interesse das grandes multinacionais da indústria nesses mercados, cristalizado, em muitos casos, em um processo de aquisições e fusões de empresas locais detentoras de ativos estratégicos.

Tabela 1 - Participação no mercado mundial por principais países - 2013

\begin{tabular}{|ll|r|r|}
\hline & País & US\$ milhões & $\%$ \\
\hline 1 & EUA & 127.098 & 39,0 \\
\hline 2 & Japão & 29.750 & 9,0 \\
\hline 3 & Alemanha & 25.662 & 8,0 \\
\hline 4 & China & 17.146 & 5,0 \\
\hline 5 & França & 14.863 & 4,0 \\
6 & Grã-Bretanha & 9.896 & 3,0 \\
7 & Itália & 9.096 & 3,0 \\
\hline 8 & Rússia & 7.434 & 2,0 \\
\hline 9 & Canadá & 7.277 & 2,0 \\
10 & Brasil & 5.919 & 2,0 \\
& Outros & 73.571 & 23,0 \\
\hline
\end{tabular}

Fonte: The World Medical Markets Fact Book 2013. 
Os EUA são, sem dúvida, o grande player da indústria em termos de dimensão do mercado doméstico, tamanho das suas empresas e participação no comércio mundial. De acordo com Leão, Oliveira e Albornoz (2008), o sucesso das empresas norte-americanas nessa indústria é resultado da convergência de um conjunto de fatores: o ambiente institucional e empresarial no qual as empresas estão inseridas; a extensão do mercado privado dos serviços de saúde com ampla capacidade de absorção de uma oferta crescente de novos produtos; a forte atuação do governo na abertura e acesso a novos mercados e o engajamento tradicional das empresas em P\&D. Além de cadeias produtivas em todos os segmentos, a existência de indústrias correlatas como as de microeletrônica, telecomunicações, instrumentação, biotecnologia, desenvolvimento de software, entre outras, completa essa perspectiva (Selan, Porto \& Kannebley, 2007).

Por não terem a mesma capacidade tecnológica e industrial, os demais países concorrentes, especialmente os europeus e o Japão, desenvolvem estratégias de especialização e de segmentação. A Alemanha, por exemplo, procurou se especializar no segmento de diagnóstico por imagem, no qual a principal empresa é a Siemens, e no de implantes. O Japão, por sua vez, se destaca principalmente em aparelhos de ultrassonografia, aparelhos de eletrodiagnóstico e de instrumentos oftálmicos (Selan, Porto \& Kannebley, 2007).

\section{Dinâmica de inovação}

A competência tecnológica de um setor é um conjunto que engloba desde a habilidade individual até a capacidade de integração e sinergia das empresas, envolvendo perícia, especialidade técnica, gerencial e institucional. Essa articulação é altamente dependente, entre outras coisas, de educação e qualificação de pessoal. É graças à capacitação e qualificação de seu pessoal técnico que uma nação ou região pode assimilar os novos conhecimentos e aplicá-los nos processos produtivos e nas atividades de pesquisa, desenvolvimento e inovação (PD\&I), criando assim um ambiente favorável à inovação tecnológica (Oliveira, 2001). Ainda de acordo com esse autor, "o fator tecnológico é imprescindível para a vitalidade da economia. A inovação tecnológica é responsável pelo rompimento ou aperfeiçoamento das técnicas e processos de produção. Pode, desta forma, trazer ganhos em termos de competitividade" (Oliveira, 2001: 6).

Segundo Cassiolato e Lastres (2000), os principais fatores que contribuíram para o melhor entendimento do processo de inovação nos últimos anos foram:

1) o reconhecimento de que inovação e conhecimento (ao invés de serem considerados como fenômenos marginais) colocam-se, cada vez mais visivelmente, como elementos centrais da dinâmica e do crescimento de nações, regiões, setores, organizações e instituições;

2) a compreensão de que a inovação constitui-se em processo de busca e aprendizado, o qual, dependente de interações, é socialmente determinado e fortemente influenciado por formatos institucionais e organizacionais específicos;

3) a ideia de que há marcantes diferenças entre os agentes e suas capacidades de aprender (as quais refletem e dependem de aprendizados anteriores, assim como da própria capacidade de esquecer); 
4) o entendimento de que há importantes diferenças entre sistemas de inovação de países, regiões, setores, organizações etc. em função de cada contexto social, político e institucional específico;

5) a visão de que, se por um lado informações e conhecimentos codificados apresentam condições crescentes de transferência - dada a eficiente difusão das tecnologias da informação e comunicação (TICs) -, conhecimentos tácitos de caráter localizado e específico continuam tendo papel primordial para o sucesso inovativo e permanecem de difícil (senão impossível) transferência.

Assim, as principais tendências relativas às novas especificidades do processo inovativo, observadas na última década do século XX, podem ser destacadas. Inicialmente observou-se significativa aceleração da mudança tecnológica nas últimas décadas. O acontecimento é constantemente ilustrado pelos fatos de que: o tempo necessário para o lançamento de novos produtos tem se reduzido; o processo que leva à produção do conhecimento até a comercialização é mais curto; e os ciclos de vida dos produtos são também menores. Ademais, o uso amplo das TICs desempenha, certamente, papel fundamental nessa mudança (Cassiolato \& Lastres, 2000).

Simultaneamente, a cooperação entre as empresas e a estruturação de redes industriais intersetoriais têm marcado o processo inovativo. O desenvolvimento de novos produtos é cada vez mais corriqueiro a partir da integração de diferentes tecnologias, estas crescentemente baseadas em conhecimentos multidisciplinares. Até mesmo as grandes corporações têm dificuldade em dominar os vastos domínios científicos e tecnológicos já conhecidos, o que torna necessária a expansão de acordos de cooperação e a crescente expansão de redes industriais intersetoriais.

Na visão de Cassiolato e Lastres (2000), a integração funcional e a montagem de redes têm oferecido vantagens às empresas na busca da rapidez no processo inovativo. A flexibilidade, a interdisciplinaridade e a fertilização cruzada de ideias, nos níveis administrativo e laboratorial, são importantes elementos do sucesso competitivo das empresas.

Nesse contexto, constata-se que o desenvolvimento econômico não está condicionado à idade de uma sociedade ou de um país. Para Furtado (1964), o subdesenvolvimento e o desenvolvimento estão relacionados ao grau de acumulação de capital aplicado aos processos produtivos e à heterogeneidade tecnológica de uma economia. Foi o processo de acumulação de capitais, avanços e difusão tecnológica que possibilitou e promoveu a diferenciação entre as sociedades industriais e as agrárias (Cassiolato \& Lastres, 2000).

Neste ponto, é necessário esclarecer a diferença entre modernização e difusão da inovação. O primeiro caso se refere à transferência, a partir do ente mais desenvolvido industrialmente para o menos desenvolvido, da imagem projetada do próprio futuro deste último. O segundo está relacionado ao reconhecimento do conhecimento como principal elemento do processo de inovação e de que seu uso geralmente proporciona o seu incremento.

Na visão de Furtado (1964), a modernização é o processo de adoção de modelos sofisticados de consumo sem que haja uma correspondente acumulação de capitais ou de progresso nos meios de produção, ou seja, a modernização está relacionada ao subdesenvolvimento, isto é, ao desenvolvimento 
dependente. Desenvolvimento, por sua vez, pode ser definido como "um processo de mudança social pelo qual o crescente número de necessidades humanas (...) são satisfeitas através de uma diferenciação no sistema produtivo, gerado pela introdução de inovações tecnológicas" (Furtado, 1964: 27).

A relação entre saúde e desenvolvimento começa a ser analisada por alguns autores (Viana, Gadelha, Machado, Lima, Baptista, Maldonado, Oliveira, Costa, Vargas, Cassiolato, por exemplo) que, utilizando-se do arcabouço teórico da economia política, propõem uma análise sistêmica dos seus condicionantes, superando assim uma abordagem estritamente setorial (social). Em relação à saúde, destaca-se tanto sua importância sociossanitária como elemento estruturante do Estado de bem-estar e condição básica de cidadania para a população quanto seus aspectos econômicos relacionados à sua base produtiva e inovativa (CEIS) naquilo que diz respeito à geração de investimento, emprego, renda e, sobretudo, na inovação, isto é, variáveis cruciais para o desenvolvimento.

Como elemento constituinte do CEIS, a indústria de equipamentos e materiais médico-hospitalares e odontológicos, por ser intensiva em CT\&I, é responsável pela permanente introdução de inovações no que tange a novos equipamentos e materiais que propiciem aumento da qualidade dos padrões de tratamento e diagnóstico para que estes sejam mais efetivos, mais rápidos, mais seguros e menos invasivos. Assim, se constitui em uma área-chave por seu potencial intrínseco de promover o adensamento do sistema nacional de inovação e de ampliar a competitividade da indústria como um todo. Trata-se de uma indústria portadora do futuro, por ser fonte geradora de inovações, por demandar e incorporar fortemente avanços tecnológicos oriundos de outras indústrias tradicionalmente inovadoras, e por suas inter-relações dinâmicas tanto no interior do CEIS, em particular, como no âmbito da atividade econômica como um todo.

Ao se constituir num oligopólio diferenciado, a competição na indústria, como afirmado, se dá via diferenciação de produtos, baseada na intensidade dos gastos em P\&D. A Tabela 2 apresenta, para 2006 e 2011, as dez empresas do mundo que mais investem em P\&D na indústria, especificando para cada uma o montante investido e o percentual sobre vendas.

Constata-se o significativo percentual dos recursos aplicados na rubrica P\&D sobre vendas, o que atesta claramente a importância da intensidade de gastos em P\&D na dinâmica competitiva da indústria. Verifica-se, igualmente, a forte presença de empresas norte-americanas dentre aquelas que mais investem em P\&D.

A indústria de equipamentos e materiais médico-hospitalares e odontológicos tem apresentado um dinamismo significativo, nos últimos anos decorrente da incorporação de avanços tecnológicos, que tem significado o constante desenvolvimento de novos produtos com novas funções, a ampliação da demanda por serviços de saúde em função do envelhecimento da população, sobretudo nos países desenvolvidos, e o crescimento do mercado principalmente dos países emergentes, no que tange à reformulação e ampliação dos sistemas de saúde (Gutierrez \& Alexandre, 2004). 
Tabela 2 - Empresas que mais investem em pesquisa e desenvolvimento na indústria - 2006 e 2011(em $£$ milh.)

\begin{tabular}{|c|c|c|c|c|c|c|c|}
\hline \multicolumn{4}{|c|}{2006} & \multicolumn{4}{|c|}{2011} \\
\hline Empresa & País & $\begin{array}{l}\text { Inv. P\&D } \\
\text { ( } £ \text { milh.) }\end{array}$ & $\begin{array}{c}\% \text { das } \\
\text { vendas }\end{array}$ & Empresa & País & $\begin{array}{l}\text { Inv. P\&D } \\
\text { ( } £ \text { milh.) }\end{array}$ & $\begin{array}{c}\% \text { das } \\
\text { vendas }\end{array}$ \\
\hline Medtronic & USA & 633,05 & 10,1 & Medtronic & USA & $1.165,5$ & 9,3 \\
\hline $\begin{array}{l}\text { Boston } \\
\text { Scientific }\end{array}$ & USA & 515,02 & n. d. & $\begin{array}{l}\text { Baxter } \\
\text { International }\end{array}$ & USA & 731,1 & 6,8 \\
\hline $\begin{array}{l}\text { Baxter } \\
\text { International }\end{array}$ & USA & 313,71 & 5,9 & $\begin{array}{l}\text { Boston } \\
\text { Scientific }\end{array}$ & USA & 691,7 & 11,7 \\
\hline $\begin{array}{l}\text { Saint Jude } \\
\text { Medical }\end{array}$ & USA & 220,27 & 13,1 & Olympus & JPN & 610,1 & 7,2 \\
\hline $\begin{array}{l}\text { Becton } \\
\text { Dickinson }\end{array}$ & USA & 183,94 & 6,2 & $\begin{array}{l}\text { Saint Jude } \\
\text { Medical }\end{array}$ & USA & 544,9 & 12,6 \\
\hline Carl Zeiss & CHN & 167,59 & 10,2 & Covidien & IRL & 428,2 & 5,0 \\
\hline Stryker & USA & 165,85 & 6,0 & $\begin{array}{l}\text { Becton } \\
\text { Dickinson }\end{array}$ & USA & 368,3 & 6,3 \\
\hline $\begin{array}{l}\text { Beckman } \\
\text { Coulter }\end{array}$ & USA & 135,35 & 10,5 & Stryker & USA & 357,1 & 5,6 \\
\hline Fresenius & DEU & 112,52 & 1,6 & Carl Zeiss & DEU & 354,5 & 8,4 \\
\hline Zimmer & USA & 96,21 & 5,4 & Fresenius & DEU & 267,0 & 1,6 \\
\hline
\end{tabular}

n. d. - dado não disponível.

Fontes: European Commission, 2007, 2013.

A ampliação da demanda e da oferta dos serviços de saúde e o próprio desenvolvimento tecnológico da indústria estão estreitamente ligados. De um lado, as empresas, ao disponibilizarem novos equipamentos, direcionam a demanda dos serviços da saúde no sentido da incorporação destes novos equipamentos e tratamentos alternativos. De outro, essa incorporação retroalimenta o processo de inovação das empresas ao impor melhorias sucessivas nos equipamentos. Ou seja, a esfera do consumo desempenha também um papel crucial no processo inovativo das empresas.

Vale salientar que nessa indústria o processo de inovação não ocorre somente nos laboratórios industriais, mas também na prática clínica, uma vez que é nela que se identificam a necessidade e a possibilidade de um novo equipamento, a criação do primeiro protótipo e aprimoramentos decisivos para o desenvolvimento do equipamento (Albuquerque \& Cassiolato, 2000).

Em um ambiente crescentemente competitivo, além da atividade formal de P\&D, as empresas desenvolvem outras estratégias de apropriação externa de conhecimento, seja na forma de acordos de colaboração, seja em processos interativos com outros agentes socioeconômicos, isto é, fusões e aquisições, alianças (joint ventures, acordos de $\mathrm{P} \& \mathrm{D}$, acordos de marketing) e acordos de financiamento (Gadelha et al., 2012).

Um dos focos centrais do debate da inovação tecnológica em nível mundial e o seu impacto sobre o gasto em saúde diz respeito à sustentabilidade da incorporação de novas tecnologias, 
tratamentos e métodos de diagnóstico no gasto social (privado e público) com saúde. Evidências empíricas e estudos de caso em diversos países têm indicado o surgimento, progressivamente mais acentuado, de novas tecnologias para a saúde como o principal responsável pela expansão da proporção do gasto com saúde na renda nacional. A dinâmica de constantes incrementos tecnológicos da indústria de equipamentos e materiais médico-hospitalares e odontológicos, aliada à expansão da cobertura da assistência à saúde, nos países desenvolvidos (e mais recentemente nos países em desenvolvimento) são, atualmente, os dois fatores que mais influenciam o aumento explosivo do custo da assistência à saúde.

Em meio a um padrão global de inovações tecnológicas, que se move da pesquisa básica de novos tratamentos para soluções tecnologicamente mais sofisticadas, a introdução de novos produtos e soluções tecnológicas tem se tornado cada vez mais frequente, reduzindo os ciclos tecnológicos dos produtos (Rasmussen, Annerstedt \& Graham, 2007).

Por outro lado, em decorrência do envelhecimento da população, o aumento da renda per capita - que possibilita o aumento da demanda por serviços de saúde - e a própria problemática da incorporação de tecnologias nos sistemas de saúde têm sido os maiores responsáveis pelo aumento dos gastos em saúde. Do ponto de vista das contas nacionais, o problema da expansão do gasto com saúde é que o seu crescimento tem sido maior que o crescimento da renda nacional de diversos países, especialmente dos países europeus, onde a expectativa de vida e a renda per capita são extremamente elevadas e o serviço de saúde é majoritariamente público.

Nas últimas duas décadas, com a desaceleração do ritmo de crescimento das economias europeias, a pressão sobre o orçamento público advinda dos cuidados com a saúde da população tem representado um dos maiores desafios em termos de política pública no mundo ocidental (Pammolli et al., 2005). Portanto, fica evidente a existência de um trade-off (acordo) entre o incentivo à inovação tecnológica no seio dessa indústria e a necessidade atual dos governos em todo o mundo, especialmente no Brasil, de conter a expansão desordenada dos gastos públicos com assistência à saúde.

O que se divulga na literatura sobre o tema é que há uma relação de causa e consequência entre o comportamento inovador das empresas da indústria e a expansão dos serviços de atenção à saúde, de maneira que o crescimento dos gastos nacionais com cuidados da saúde tende, a longo prazo, a crescer ininterruptamente em ritmos cada vez mais acentuados. De maneira geral, a avaliação dos benefícios oriundos da ampliação dos padrões tecnológicos carece de bases teóricas mais sólidas, o que torna difícil avaliar, do ponto de vista do bem-estar social, se a expansão do gasto com novas tecnologias é acompanhada por um incremento, pelo menos na mesma proporção, dos benefícios aos pacientes e aos sistemas de saúde. Assim, não se sabe, a priori, se o aumento do gasto é justificado ou não (do ponto de vista econômico, isto é, considerando-se o custo-efetividade das novas tecnologias). Nessa perspectiva, há duas formas de relacionar o gasto com pesquisa e desenvolvimento de novas tecnologias e a expansão dos sistemas de serviços de saúde: na primeira se afirma que o gasto com P\&D em saúde é uma resposta à expansão dos serviços de saúde, e na segunda se diz que a maior cobertura dos serviços é uma consequência do aumento do gasto com P\&D (Pammolli et al., 2005).

No primeiro caso, a intensidade do gasto com P\&D depende de uma série de fatores, dentre os quais o retorno esperado do investimento, o tamanho do mercado para o novo produto ou serviço 
disponível e o seu preço esperado, que é determinado pelos sistemas públicos e privados de assistência à saúde. Neste último fator, a ação dos planos de saúde privados e os programas públicos têm influência significativa sobre a aceitação da nova tecnologia e seus reais usos no sistema de saúde, determinando assim, em última instância, a intensidade do investimento em P\&D. Uma vez que ampliam seus recursos de investimentos, os sistemas de saúde (públicos e privados) permitem que os pacientes tenham acesso a novas soluções tecnológicas, incentivando ainda mais o incremento dos investimentos em inovação tecnológica.

No segundo caso, a demanda por planos de saúde (públicos ou privados) depende, em parte, de mudanças e avanços tecnológicos: se uma nova solução tecnológica coloca à disposição da sociedade um novo tratamento - mais eficaz ou inédito - que possibilita a cura ou aumenta a expectativa de vida de pacientes, mesmo que com custo muito mais elevado que a opção trivial, então a sociedade pode, a longo prazo, expandir suas possibilidades de gasto com serviços de saúde e, assim, exigir ou demandar ainda mais coberturas assistenciais que possam oferecer os novos tratamentos. Portanto, o eventual benefício da "nova solução tecnológica" pode resultar em pressão política e social sobre as autoridades públicas, para que estas tornem as inovações acessíveis e disponíveis para a coletividade, independentemente da capacidade de pagamento existente. Isso é observado no processo de judicialização do SUS, situação que não apenas leva ao aumento da demanda nos planos privados, mas também aumenta as pressões para que a cobertura do sistema público seja cada vez maior.

Novas tecnologias e novos tratamentos aumentam a magnitude do gasto com serviços de saúde, e assim direcionam a demanda por programas públicos e privados de assistência à saúde - programas estes que incluam não somente mais pessoas, mas cada vez mais tecnologias e tratamentos alternativos e inovadores. Por outro lado, a expansão da cobertura e a incorporação de novos tratamentos e soluções, por parte dos programas de saúde, incentivam a inovação tecnológica e o aparecimento, cada vez maior, de produtos e serviços de saúde, pois facilita à população o acesso a novos tratamentos e tecnologias. Para se ter uma ideia disso, dados da OMS registram que no ano 2000 oito mil novos produtos foram inseridos no mercado americano (WHO, 2012) e, de acordo com dados da Agência Nacional de Vigilância Sanitária (Anvisa), em 2012 cerca de 14.300 novos produtos foram disponibilizados no Brasil (Anvisa, 2012).

Outra questão relacionada à influência dos planos de saúde sobre a inovação tecnológica concerne ao modelo de pagamento dos serviços de saúde. Até meados dos anos 1980, os planos de saúde pagavam os tratamentos com base nos custos incorridos e derivados de cada caso específico. Esse modelo de pagamento incentivava o uso irracional e abusivo de diagnósticos, tratamentos e soluções apresentados ao paciente, o que ocasionava uma pressão muito grande sobre o orçamento do plano de saúde, pois o médico/hospital tinha flexibilidade para induzir o consumo do paciente, tendo a garantia de que o plano de saúde cobriria todos os custos. Depois de perceberem essa prática de mercado, os planos de saúde dos EUA inovaram no modelo de pagamento de serviços de saúde, estabelecendo preços e pagamentos em pacotes fechados, que independiam do total dos custos incorridos pelo médico/hospital no tratamento ou uso de qualquer solução tecnológica disponível.

Nesse caso, no qual a receita do hospital é dada de forma exógena e fixa, a lucratividade dos hospitais passou a depender da sua eficiência administrativa em gerir os custos e as consequências 
de suas decisões no tratamento de enfermidades (Pammolli et al., 2005). No primeiro modelo, a sinalização de mercado no que concerne à inovação tecnológica levava as indústrias de equipamentos e materiais de uso em saúde a lançarem novos produtos e serviços tecnologicamente mais sofisticados, independentemente de seus potenciais custos. No segundo modelo, a sinalização de mercado é mais parcimoniosa: as indústrias passaram a ter o incentivo para desenvolver novas tecnologias capazes de reduzir os custos dos tratamentos, sem prejuízo da qualidade.

Antes da pressão sobre os orçamentos públicos e privados de saúde e da demasiada expansão da demanda por serviços de saúde, novas tecnologias e serviços mais avançados que possibilitassem pequenas melhorias de tratamento e diagnósticos eram incondicionalmente incorporados aos sistemas de saúde, de maneira que a sinalização de mercado para a indústria era sempre focada no incremento e na melhoria do produto ou serviço de saúde, e não em eficiência e redução de custos. No entanto, com o aumento continuamente crescente da pressão do gasto com saúde nos orçamentos públicos e privados, a mudança do modelo de pagamento ocorrida nos anos 1980 não deixou de influenciar a indústria no investimento em melhorias tecnológicas e aumento dos padrões de tratamento e diagnóstico, mas a levou a considerar a eficiência e o custo de suas soluções tecnológicas no desenvolvimento de novas tecnologias de saúde.

Mesmo a partir dessa mudança no sistema de pagamentos dos serviços de saúde, com o incentivo e a consequente introdução de tecnologias cada vez mais eficientes, que proporcionaram reduções do custo médio dos tratamentos disponíveis, o gasto com saúde continuou crescente, sem perspectivas de redução do seu custo total. A explicação para esse fenômeno está em cinco causas distintas (Pammolli et al., 2005):

1) várias tecnologias médicas que se mostraram eficientes e proporcionaram reduções de custo unitário passaram a ser utilizadas em uma variedade cada vez maior de tipos de doença e opções de tratamento alternativas, o que acabou levando ao aumento do custo total com essas tecnologias;

2) as novas soluções tecnológicas possibilitaram à medicina condições de adentrar em tratamentos e diagnósticos antes inexplorados, o que ampliou o gasto com saúde, por abrir novos mercados para novos tratamentos;

3) quando novas tecnologias permitem avanços nos tratamentos e redução de custos dos tratamentos já disponíveis, é de se esperar que essas soluções tecnológicas sejam estendidas a um número maior de pacientes - quando uma tecnologia reduz o custo unitário e aumenta a qualidade do tratamento, o custo total com essa tecnologia tende a aumentar;

4) a melhoria das condições de tratamento de doenças e os avanços tecnológicos da medicina moderna têm ampliado o conceito de doença e enfermidade, o que leva os sistemas de saúde a incorporar esses novos conceitos, provocando aumento de custos;

5) o avanço das técnicas de tratamento proporcionado pelos avanços tecnológicos aumenta a expectativa de vida, e mesmo que o custo unitário e anual dos tratamentos seja reduzido, o custo total aumenta devido à sobrevida dos pacientes. 


\section{Panorama Nacional}

A indústria brasileira de produtos médicos surgiu na década de 50 do século XX e alcançou o seu ápice nos anos 70. Nas últimas três décadas, transformações no cenário nacional e internacional trouxeram novos desafios à indústria. A abertura de mercado na década de 1990 esgotou o modelo formal de substituição de importações e promoveu o surgimento de um novo ambiente concorrencial. A regulação do mercado iniciada pelo Ministério da Saúde em 1992 e seus desdobramentos catalisados pela Anvisa trouxeram à tona novos conceitos e a exigência de padrões mínimos de qualidade para a indústria.

É importante destacar que se, por um lado, novos fatores regulatório-econômicos tornaram mais árdua a expansão da indústria, por outro induziram uma significativa melhora na qualidade das tecnologias fabricadas no país. Isso pode ser observado quando se analisam os dados da Pesquisa Industrial de Inovação Tecnológica (Pintec), do IBGE, na qual a indústria de produtos médicos aparece como uma das mais inovadoras. Desde então, novos conceitos regulatórios foram fortemente introduzidos no mercado: boas práticas de fabricação (BPF) e certificação compulsória de equipamentos, no âmbito do Instituto Nacional de Metrologia, Normalização e Qualidade Industrial (Inmetro).

Esses aspectos, associados ao crescimento da demanda interna, à ampliação do SUS e ao peso da demanda pública nesse mercado, foram responsáveis pela significativa expansão da indústria a partir da segunda metade da década de 1990. Nesse contexto, assistiu-se a um significativo crescimento da indústria nos anos recentes, capaz de responder por cerca de $50 \%$ da demanda nacional, gerando cerca de cem mil empregos no país e atingindo um valor da produção industrial de $\mathrm{R} \$ 4,8$ bilhões em 2012 (Abimo, 2013a).

O Gráfico 2 apresenta a evolução do valor da produção no período 2005-2012, desagregado por principais segmentos. Verifica-se que o valor da produção da indústria tem crescido de modo expressivo, sobretudo a partir de 2009. Descontada a variação de preços, a produção setorial cresceu em média 3,9\% a. a. no período de 2007 a 2012 (Abimo, 2013b).

Considerando os quatro segmentos analisados, o desempenho real da produção para esse mesmo período foi de 5,5\% para equipamentos médicos, $16,2 \%$ para implantes, 7,2\% para materiais odontológicos e uma variação negativa, de $-6,3 \%$, para materiais de consumo. Vale mencionar que a produção da indústria de transformação brasileira cresceu apenas 0,6\% ao ano em média, o que mostra a evolução bastante favorável da indústria (Abimo, 2013b). 
Gráfico 2 - Evolução do valor da produção, por segmento. Brasil - 2005-2012 (em R\$ bilhões)

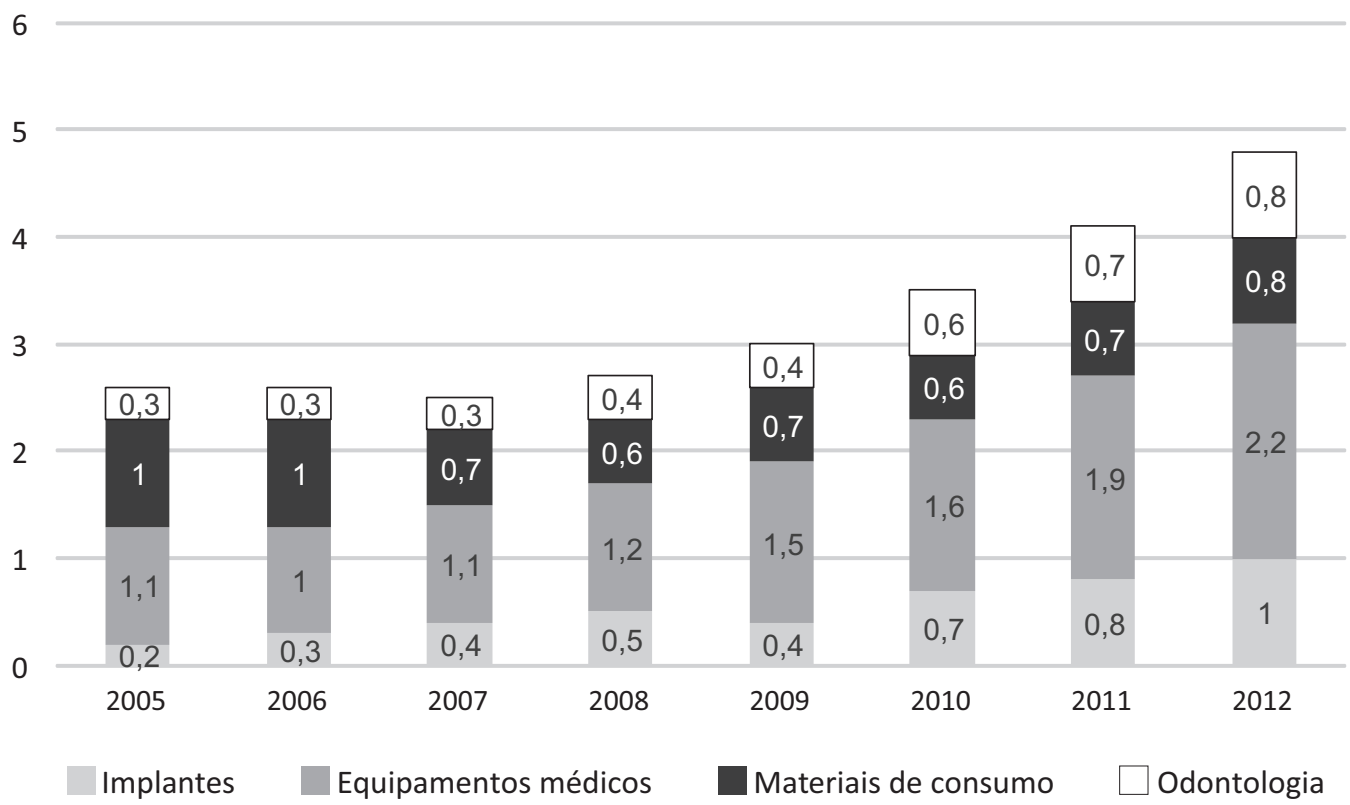

Fonte: Abimo, 2013b.

Apesar desse comportamento positivo, tem-se assistido a um crescimento do déficit comercial nos anos recentes, o que sinaliza a perda de competitividade da indústria, notadamente nos produtos de maior intensidade tecnológica. Além disso, a produção realizada por empresas situadas no território nacional ainda depende fortemente de insumos importados de maior conteúdo tecnológico, com tal dependência chegando a atingir 50\% em alguns segmentos. O Gráfico 3 apresenta a evolução da balança comercial da indústria de 1996 a 2013.

O déficit comercial, que em meados da década de 1990 e início dos anos 2000 girava em torno de US $\$ 800$ milhões ao ano, a partir de 2007 conhece um crescimento acentuado, chegando em 2013 ao patamar de US\$ 3 bilhões. Deve-se salientar que o déficit da indústria de equipamentos e materiais médico-hospitalares e odontológicos representa $24 \%$ do total do CEIS, logo atrás do déficit da indústria farmacêutica, de $25 \%$ do total (GIS, 2014). 
Gráfico 3 - Evolução da balança comercial de equipamentos e materiais. Brasil - 1996-2013 (valores em US\$ bilhões, atualizados pelo IPC/EUA)

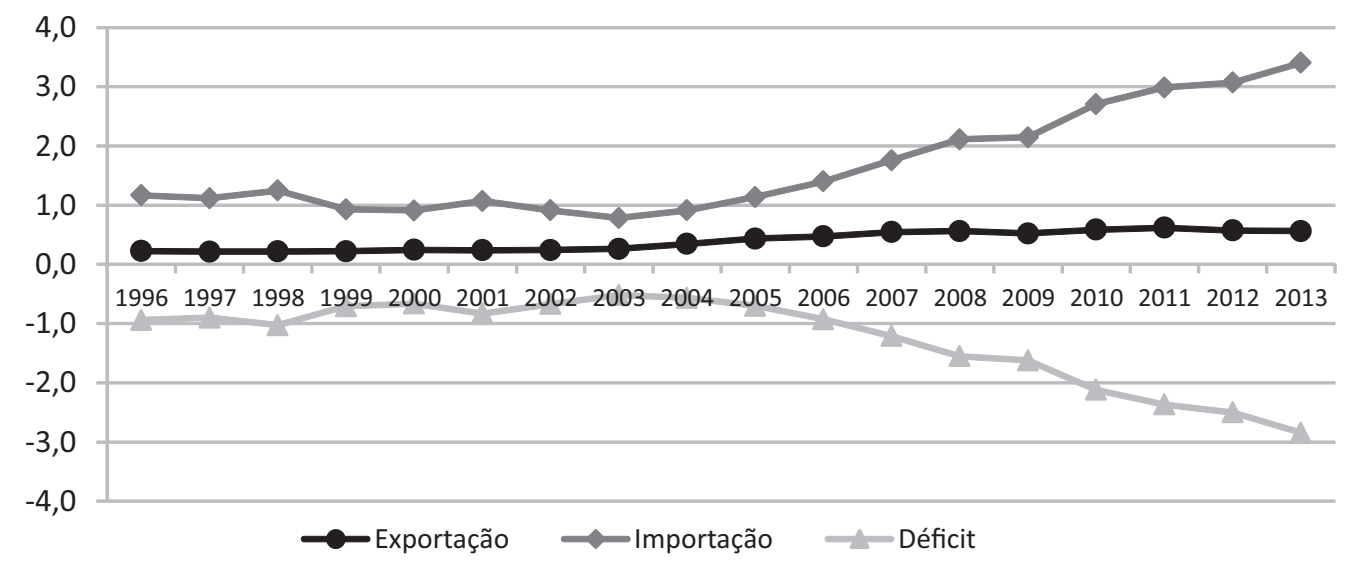

Fonte: elaborado pelo Grupo de Pesquisa de Inovação em Saúde da Escola Nacional de Saúde Pública Sergio Arouca (GIS/Ensp/Fiocruz), com base em dados da Rede Alice/MDIC.

Esse déficit comercial sinaliza a defasagem tecnológica da indústria, que, associada a diversos fatores institucionais, limita o potencial inovador das empresas nacionais. O Brasil não tem condições de reverter o quadro de dependência de importações de produtos tecnologicamente complexos, e muito menos de organizar estratégias reais de inserção nos mercados de alta tecnologia, pelo menos a curto prazo. Por outro lado, o país, paulatinamente, vem, ao longo das últimas décadas, perdendo competitividade no nicho de mercado em que se especializou - produtos de baixa intensidade tecnológica, produzidos em larga escala e com baixas margens de lucro - para países como China e Cingapura. Nesses países, diversas questões institucionais (baixos padrões de regulação sanitária e ausência de legislação trabalhista, por exemplo) reduzem de maneira expressiva os custos de produção e permitem colocar produtos no mercado internacional a preços extremamente competitivos.

\section{Dinâmica de inovação}

De modo geral, os produtos médicos podem ser agrupados em dois segmentos: os de alta tecnologia e os mais convencionais. O segmento de alta tecnologia é composto por dispositivos sofisticados destinados a usos terapêuticos e diagnósticos. Estão associados a atividades de P\&D de alto risco, pesquisas clínicas e processos administrativos e regulatórios para acesso ao mercado. Os produtos desse segmento têm um grande potencial de crescimento, principalmente, nos mercados privado e suplementar de saúde. Contudo, nele o risco da rápida obsolescência da tecnologia é elevado.

O segmento de produtos convencionais consiste em produtos como seringas, gaze, produtos intravenosos, bem como em uma grande gama de produtos para fins de diagnóstico e terapia. Está associado a baixas margens de lucro e grandes volumes de produção.

Observa-se que a dinâmica tecnológica do setor permite inferir como tendências a miniaturização, dispositivos inteligentes minimamente invasivos, produtos combinados, órgãos artificiais, tecnologia da informação, uso doméstico e produtos destinados a populações especiais. Os produtos com maior 
intensidade tecnológica são, geralmente, destinados aos mercados de saúde privada e suplementar, uma vez que, notadamente, oneram os custos da atenção à saúde.

Um fato a ser observado é que a constante evolução tecnológica dos materiais e componentes utilizados na fabricação dos produtos médicos faz com que haja no mercado produtos com ciclo de vida cada vez mais curto (de 18 a 24 meses). Isso traz duas consequências: a primeira é que, para os produtos de alta tecnologia, é muito provável que ocorra obsolescência antes de se conhecerem todos os seus potenciais benefícios, ou malefícios. A segunda é que muitas empresas estão deixando de patentear seus produtos, o que leva a resultados negativos na avaliação de seus bens intangíveis.

No Brasil, essa dinâmica da evolução tecnológica do setor, aliada à defasagem tecnológica, configura uma crescente dependência em importações sobretudo em produtos de alta tecnologia. Isso inclui desde produtos de alto valor unitário, como equipamentos de ultrassom e de ressonância magnética, tomógrafos etc., até, como afirmado, produtos de menor densidade tecnológica como stents, luvas, marca-passos e outros produtos de preço relativo baixo, vendidos em grande volume. Os principais importadores são hospitais públicos, instituições não lucrativas e empresas importadoras.

Essa crescente dependência atesta, na realidade, a baixa capacidade inovativa do parque fabril brasileiro. Tendo como base as informações da pesquisa Pintec/IBGE 2003, 2005 e 2011, a Tabela 3 apresenta alguns indicadores relacionados ao esforço inovativo da indústria de equipamentos e materiais médico-hospitalares e odontológicos comparativamente à indústria nacional, naqueles anos.

Tabela 3 - Atividades inovativas. Brasil - 2003, 2005 e 2011

\begin{tabular}{|l|c|c|c|c|c|c|}
\hline & \multicolumn{7}{c|}{ Incidência sobre receita líquida de vendas dos gastos em } \\
\hline & \multicolumn{5}{c|}{ Atividades inovativas } & \multicolumn{3}{c|}{ P\&D internos } \\
\hline $\begin{array}{l}\text { Total da indústria } \\
\text { brasileira }\end{array}$ & 2003 & 2005 & 2011 & 2003 & 2005 & 2011 \\
\hline $\begin{array}{l}\text { Indústria de } \\
\text { equipamentos } \\
\text { médicos }\end{array}$ & 3,1 & 2,8 & 4,6 & 0,5 & 0,6 & 2,2 \\
\hline
\end{tabular}

Fonte: Pintec (IBGE, 2003, 2005, 2011).

No âmbito da Pintec, esforço inovativo refere-se à P\&D (pesquisa básica, aplicada ou desenvolvimento experimental) e a outras atividades complementares tais como aquisição de equipamentos, serviços e conhecimentos externos. Deve-se considerar que a relação de gastos com atividades inovativas sobre vendas da indústria brasileira como um todo foi em 2003, 2005 e 2011, respectivamente, de 2,5\%, 2,8\% e 4,6\% (IBGE, 2003, 2005, 2011). Quando se confrontam com os percentuais da indústria de equipamentos e materiais médico-hospitalares e odontológicos, que foram, respectivamente, de $3,1 \%, 5,3 \%$ e 3,7\%, verifica-se, com exceção de 2011 , que as empresas da indústria apresentaram taxa de inovação acima da média nacional, estando incluídas, portanto, entre as atividades de alta intensidade tecnológica, o que claramente está relacionado às características inerentes a tais ativida- 
des. Entretanto, esse dinamismo relativo situa-se muito aquém do verificado em nível mundial, não conferindo à indústria local competitividade internacional. Essa situação é claramente exemplificada pela relação entre os gastos com atividades de P\&D e as vendas. Conforme visto anteriormente, esse percentual varia de 7 a 13\% entre as empresas líderes mundiais, ao passo que para a indústria de equipamentos brasileira é de apenas 1,2\% para 2003, 2,3\% para 2005 e 1,2\% para 2011.

Em especial nos anos de 2003 a 2005, o novo aparato regulatório teve efeito positivo sobre o segmento de produtos médicos, ao induzir compulsoriamente o investimento em inovações incrementais em produtos e processos produtivos, o que de forma notória demonstra o "efeito colateral" positivo da regulação no setor de produtos médicos, que foi o de induzir compulsoriamente o investimento em inovações incrementais em produtos e processos produtivos. Contudo, apesar de catalisar a indução de atividades de inovação, a regulação não pode ser considerada como o principal drive de inovação nas empresas (Oliveira \& Button, 2012).

Além de ter estrutura bastante segmentada, a indústria congrega grande número de empresas de pequeno e médio porte, especializadas, na sua maioria, nos segmentos de baixa e média densidade tecnológica. Muitas delas têm formatos gerenciais inadequados para a competitividade, como estrutura familiar e baixo grau de profissionalização da gestão. Esses fatores ajudam a explicar o afastamento da indústria da fronteira tecnológica, em termos dos grupos de produtos, a despeito do processo de expansão observado no período recente.

Assistiu-se no Brasil a mudanças significativas a partir de 2002, no primeiro governo Lula, quando se retomou o papel do Estado de formulador de políticas e estratégias de desenvolvimento nacional. As novas orientações cristalizaram-se em um conjunto de ações governamentais que buscaram reforçar a estrutura produtiva e inovativa do tecido industrial brasileiro em geral, e das indústrias da saúde em particular.

Dentre as novas orientações, mencione-se a Política Industrial e Tecnológica e de Comércio Exterior (PITCE) do Ministério de Desenvolvimento, Indústria e Comércio Exterior de 2003, e a Política Nacional de Ciência, Tecnologia e Inovação em Saúde (PNCTIS) de 2004 e o Programa Mais Saúde (que define o complexo industrial da saúde como um dos eixos estratégicos para a política de saúde) de 2007, ambos do Ministério da Saúde. Destaca-se ainda o Programa de Aceleração do Crescimento (PAC) da Inovação de 2007, do Ministério de Ciência e Tecnologia, e a Política de Desenvolvimento Produtivo (PDP) de 2008, mais uma vez do Ministério de Desenvolvimento, Indústria e Comércio Exterior.

Paralelamente à PDP foi criado, no âmbito do Ministério da Saúde, o Grupo Executivo do Complexo Industrial da Saúde (Gecis), um fórum permanente que, envolvendo vários ministérios e instituições estratégicas para o CEIS, objetivou uma articulação entre atores do campo da política industrial e de CT\&I e da Saúde e a sociedade civil, para a proposição de ações consideradas relevantes e estratégicas para o desenvolvimento do marco regulatório de implantação da estratégia de desenvolvimento para a área da saúde (Brasil, 2008).

Entre as mais recentes ações com impactos na saúde, destacam-se o Brasil Maior, lançado em 2011, e a Estratégia Nacional de Ciência, Tecnologia e Inovação 2012-2015 (ENCTI), do Ministério da Ciência, Tecnologia e Inovação, lançada em 2012. 
O Programa Brasil Maior compreende uma nova política industrial, tecnológica, de serviços e de comércio exterior visando ao estímulo à inovação e à produção nacional para alavancar a competitividade da indústria e a geração de emprego e renda em benefício do povo brasileiro. Entre as medidas previstas, saliente-se a Lei de Compras Governamentais, que estipula uma margem de preferência de até $25 \%$ nos processos de licitação para produtos manufaturados e serviços nacionais que atendam às normas técnicas brasileiras (Brasil, 2011). Essas margens são definidas levando-se em consideração a geração de emprego e renda e o desenvolvimento e a inovação tecnológica realizados no país; abrangem remédios, produtos biológicos e equipamentos de saúde fabricados no Brasil.

A ENCTI, por sua vez, reafirma a prioridade do segmento de fármacos e do complexo produtivo e enfatiza a necessidade de promover mecanismos de estímulo à inovação em saúde e intensificar a transferência tecnológica para os laboratórios públicos nacionais (Brasil, 2012). Com a ENCTI, o Estado assume mais uma vez o seu papel no enfrentamento do desafio de redefinir e impulsionar o desenvolvimento do sistema produtivo da saúde por meio da articulação de várias instâncias da área da saúde, bem como das demais esferas de governo.

Destaque-se, no âmbito do CEIS, a indução ao estabelecimento de parcerias entre agentes públicos e privados, as designadas parcerias para o desenvolvimento produtivo (PDPs). Essa iniciativa de 2009 do Ministério da Saúde, a qual o Programa Brasil Maior de 2011 consolida como estratégia de desenvolvimento do parque produtivo e inovativo da saúde, visa à melhoria do suprimento em saúde e do acesso a medicamentos e produtos médicos (equipamentos e materiais de uso) essenciais à população, ao fortalecimento de empresas e laboratórios nacionais, à redução de dependência nas importações e, concomitantemente, à diminuição do déficit comercial.

No âmbito de produtos médicos foram realizadas 11 PDPs envolvendo 15 produtos para a saúde nos campos da hemodiálise, cardiologia, cirurgia geral, urgência e emergência, diagnóstico e monitoração, oftalmologia, kits para diagnóstico e transplante de órgãos. A Tabela 4 detalha essas PDPs, que envolvem as instituições públicas Fundação para Remédio Popular, Laboratório Farmacêutico do Rio Grande do Sul, Indústria Química do Estado de Goiás, Núcleo de Tecnologias Estratégias em Saúde da Universidade Estadual da Paraíba, Centro de Tecnologia e Geociências da Universidade Federal de Pernambuco (CTG), a parceria do Instituto de Biologia Molecular do Paraná com a Fundação Oswaldo Cruz e o Instituto Vital Brasil -, as empresas privadas nacionais Lifemed, Scitech, Opto Eletrônica e Cristália - e as empresas de capital estrangeiro Johnson \& Johnson, Medtronic, ST Electronics e IGL Group (Gadelha, 2013).

Conforme se verifica na tabela, a expectativa somente no primeiro ano era de que as compras públicas realizadas pelo Ministério da Saúde atingissem o montante de R \$ 364 milhões e o potencial de compras do SUS desses produtos correspondesse a R \$ 573 milhões. Tais compras deviam representar uma economia de divisas, ao final dos projetos, de US\$ 370 milhões ao ano (Gadelha, 2013).

No âmbito das PDPs, a transferência de tecnologia e a integração gradativa do processo produtivo são a base de sustentação para que seja firmado um compromisso de compra desses produtos pelo Ministério da Saúde. A viabilização da parceria se dá por meio da associação de pelo menos um agente público com um agente privado, que realiza o desenvolvimento e transferência de tecnologia de produção para o primeiro. 
Outro importante instrumento de política industrial recentemente criado são as chamadas medidas de compensação comercial, industrial e tecnológica. Esse importante instrumento, inserido na lei federal n. 8.666/1993, permite que, mediante prévia justificativa da administração, os editais de licitação para a contratação de bens, serviços e obras exijam que o contratado promova, em favor de órgão ou entidade integrante da administração pública, qualquer prática compensatória estabelecida como condição para o fortalecimento da produção de bens, do desenvolvimento tecnológico ou da prestação de serviços, com a intenção de gerar benefícios de natureza industrial, tecnológica ou comercial.

Tabela 4 - Parcerias para o desenvolvimento produtivo (PDPs) em equipamentos médicos. Brasil - 2013

\begin{tabular}{|c|c|c|c|}
\hline Indicação & Produto & $\begin{array}{l}\text { n. de } \\
\text { PDPs }\end{array}$ & $\begin{array}{c}\text { Compras públicas } \\
\text { Expectativa para o ano } 1 \text { (R\$ milhões) }\end{array}$ \\
\hline \multirow[t]{2}{*}{ Hemodiálise } & Dialisador & \multirow[b]{2}{*}{1} & 84,6 \\
\hline & Máquina para hemodiálise & & 82,6 \\
\hline \multirow[t]{6}{*}{ Cardiologia } & Stent coronariano & 2 & 49 \\
\hline & Stent arterial & \multirow[t]{2}{*}{1} & 2,6 \\
\hline & Cateter balão para stent arterial & & 1,4 \\
\hline & Cateter balão para stent coronário & & 9,8 \\
\hline & Marca-passo câmara única & \multirow[b]{2}{*}{1} & 6,3 \\
\hline & Marca-passo câmara dupla & & 25,3 \\
\hline \multirow[t]{2}{*}{ Cirurgia geral } & Grampeador cirúrgico & \multirow[t]{2}{*}{1} & 1,4 \\
\hline & Cargas para grampeador cirúrgico & & 0,5 \\
\hline $\begin{array}{l}\text { Urgência e } \\
\text { emergência }\end{array}$ & Desfibrilador/cardioversor & 1 & 29,5 \\
\hline $\begin{array}{l}\text { Diagnóstico e } \\
\text { monitoração }\end{array}$ & Monitor multiparâmetros & 1 & 35,1 \\
\hline Oftalmologia & $\begin{array}{l}\text { Conjunto oftalmológico para diagnóstico } \\
\text { e tratamento de cegueiras evitáveis } \\
\text { composto de nove equipamentos: } \\
\text { 1. Microscópio } \\
\text { 2. Autorrefrator com mesa } \\
\text { 3. Retinógrafo não midriático } \\
\text { 4. Autoprojetores tipo Magis Nano } \\
\text { 5. Oftalmoscópios binoculares indiretos } \\
\text { 6. Greens } \\
\text { 7. Cadeiras com coluna oftálmica } \\
\text { 8. Lâmpada de fenda (LF) tonômetro } \\
\text { 9. Laser verde com LF e mesa }\end{array}$ & 1 & 23,9 \\
\hline $\begin{array}{l}\text { Kits para } \\
\text { diagnóstico }\end{array}$ & $\begin{array}{l}\text { Plataforma multiteste para detecção de } \\
\text { sepse }\end{array}$ & 1 & P\&D \\
\hline $\begin{array}{l}\text { Transplante de } \\
\text { órgãos }\end{array}$ & $\begin{array}{l}\text { Solução para preservação de órgãos para } \\
\text { transplantes }\end{array}$ & 1 & 12,3 \\
\hline $\begin{array}{l}\text { Total } \\
\text { Total potencial }\end{array}$ & lo SUS & & $\begin{array}{l}364,3 \\
573,0\end{array}$ \\
\hline
\end{tabular}

Fonte: Gadelha, 2013. 
A Saúde foi a primeira pasta a utilizar esse instrumento na aquisição de equipamentos para tratamento do câncer (aceleradores lineares). No certame promovido pelo Ministério da Saúde, a centralização das compras permitiu um deságio de 60\% sobre o preço de referência; além disso, o edital previa a obrigação da contratada de instalar no Brasil uma fábrica de aceleradores lineares (Paula, 2014).

O grande objetivo do estabelecimento das PDPs é o fomento ao desenvolvimento endógeno da capacidade produtiva e de inovação da indústria nacional, com a concomitante redução de dependência externa e o aproveitamento da oportunidade de uma demanda crescente e vigorosa em saúde.

Nesse processo, destaca-se o papel do Estado no fortalecimento e ampliação das vantagens competitivas da indústria nacional. De acordo com o Instituto de Estudos e Marketing Industrial (Iemi, 2010), o poder público era responsável por 21,5\% das compras da indústria em 2009; todavia, como ressaltam Pieroni, Reis e Souza (2010), parte significativa das compras de entidades privadas é reembolsada pelo sistema público de saúde, o que, na prática, aponta para uma demanda próxima de 50\% dos produtos vendidos pela indústria. Assim, o Estado, por seu papel de grande consumidor de bens e serviços, pode, valendo-se do seu poder de compra, direcionar o desenvolvimento produtivo e inovativo da indústria.

Nessa direção, o Ministério da Saúde, por meio da portaria n. 3.089 de 2013, identificou um conjunto de equipamentos e materiais de consumo prioritários no âmbito do SUS como itens que deveriam receber apoio em termos do adensamento tecnológico envolvido. ${ }^{4}$ Essa listagem, elaborada pelo Ministério da Saúde e sancionada pelo Gecis, tendo como critérios para a seleção desses produtos as demandas tecnológicas do SUS, a dependência tecnológica e o déficit na balança comercial, orienta as ações estratégicas do ministério referentes ao CEIS no que tange às PDPs, à centralização de compras, à incorporação tecnológica e a encomendas tecnológicas.

Nesse sentido, Gadelha e colaboradores (2012) notam que o uso do poder de compra do Estado orientado para a inovação reside em seu potencial de articular a demanda para alcançar objetivos relacionados ao desenvolvimento nacional, a exemplo da sinalização para o setor privado das necessidades públicas, que estimula o desenvolvimento de soluções inovadoras para o perfil de demanda da sociedade. O uso de poder de compra é uma política emblemática para o desenvolvimento da base de CT\&I em saúde, tendo em vista a complexidade que envolve a orientação de trajetórias tecnológicas que sejam, a um só tempo, economicamente competitivas e socialmente inclusivas.

\section{Tendências}

O mercado mundial de equipamentos médicos dobrou na última década, e a expectativa é de um elevado crescimento, sobretudo nos países emergentes, que devem exibir taxas de 15\% a. a. nos próximos cinco anos em razão das mudanças demográficas e epidemiológicas em curso, o que tem promovido a ampliação da demanda por serviços de saúde (Landim et al., 2013).

\footnotetext{
${ }^{4}$ A atual portaria revoga as duas anteriores, quais sejam, a n. 978, de maio de 2008, e a n. 1.284, de 2010, mantendo no seu conteúdo os produtos nelas identificados.
} 
Prevê-se que o mercado mundial para essa indústria atinja o valor de US\$ 455 bilhões em 2018 (Worldwide Medical..., 2013). O Gráfico 4 apresenta para esse ano a participação dos maiores mercados mundiais.

As estimativas indicam que os EUA continuem representando o maior mercado mundial no final da década, embora sua participação relativa apresente tendência decrescente (em 2008, os EUA detinham 40,7\% do mercado mundial). As principais mudanças ficam por conta da crescente importância dos maiores mercados dos países designados Brics, tanto em tamanho absoluto quanto em participação relativa: Brasil, Rússia, Índia e China. A título de exemplo, Canadá, Suíça e Espanha, que em 2008 figuravam entre os dez maiores mercados mundiais dessa indústria, já em 2013 foram substituídos pelas quatro economias emergentes (Gadelha et al., 2012). O Gráfico 5 apresenta a evolução de 2009 a 2018 da participação dos Brics no mercado mundial, em termos percentuais.

Gráfico 4 - Distribuição dos dez maiores mercados mundiais - 2018 (em \%)

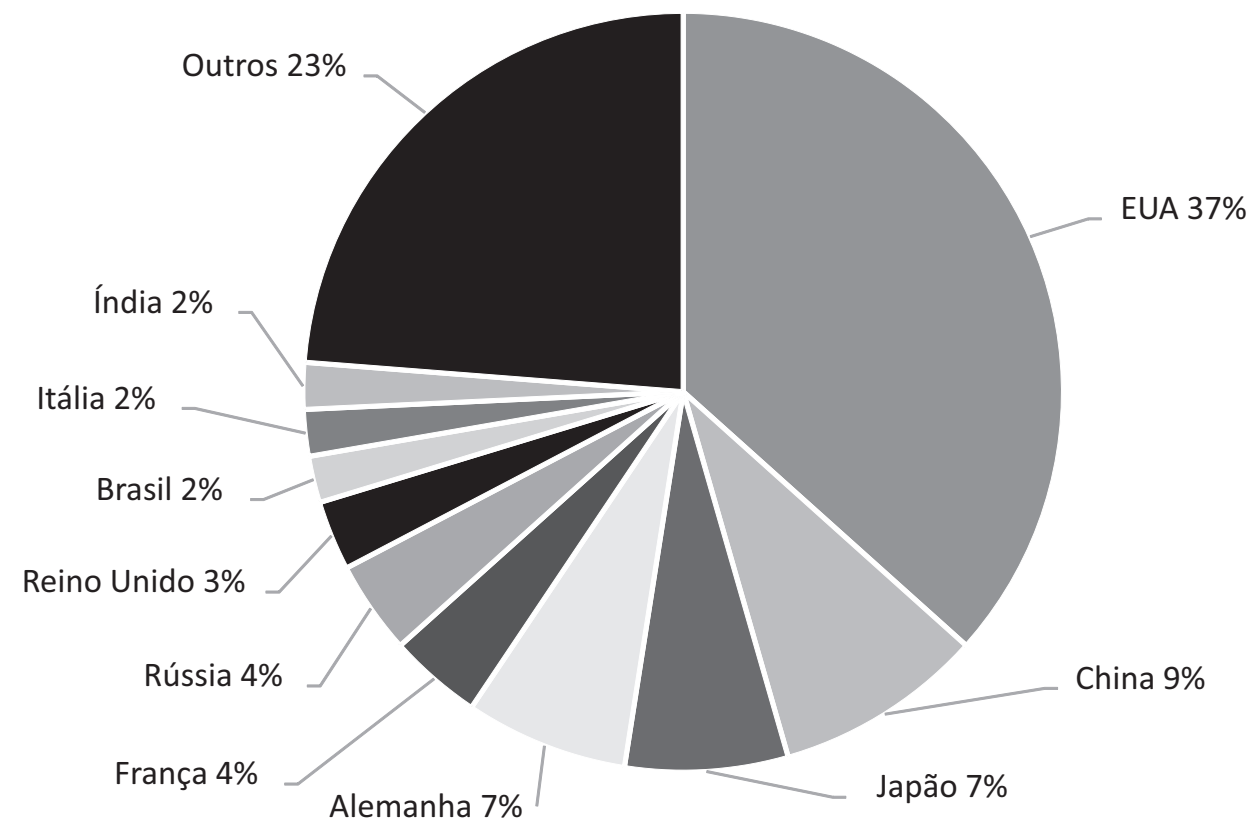

Fonte: Worldwide Medical Market Forecasts to 2018, 2013.

Embora o crescimento da China se destaque em relação aos demais países, a participação dos quatro maiores países do Brics representa uma variação de praticamente $200 \%$ de 2009 a 2018 . Em 2009, esses países participavam com 7\%, em 2013 esse percentual era de 10,4\% e a perspectiva para 2018 é de que os quatro mercados juntos representem 15,8\% do mercado mundial para essa indústria. Em termos de ranking mundial em 2018, o mercado chinês será o segundo maior mercado, a Rússia estará na sétima posição, o Brasil na oitava e a Índia na décima (Worldwide Medical..., 2013). 
Gráfico 5 - Evolução da participação dos maiores mercados do Brics no mercado mundial - 2009$2018(\mathrm{em} \%)$

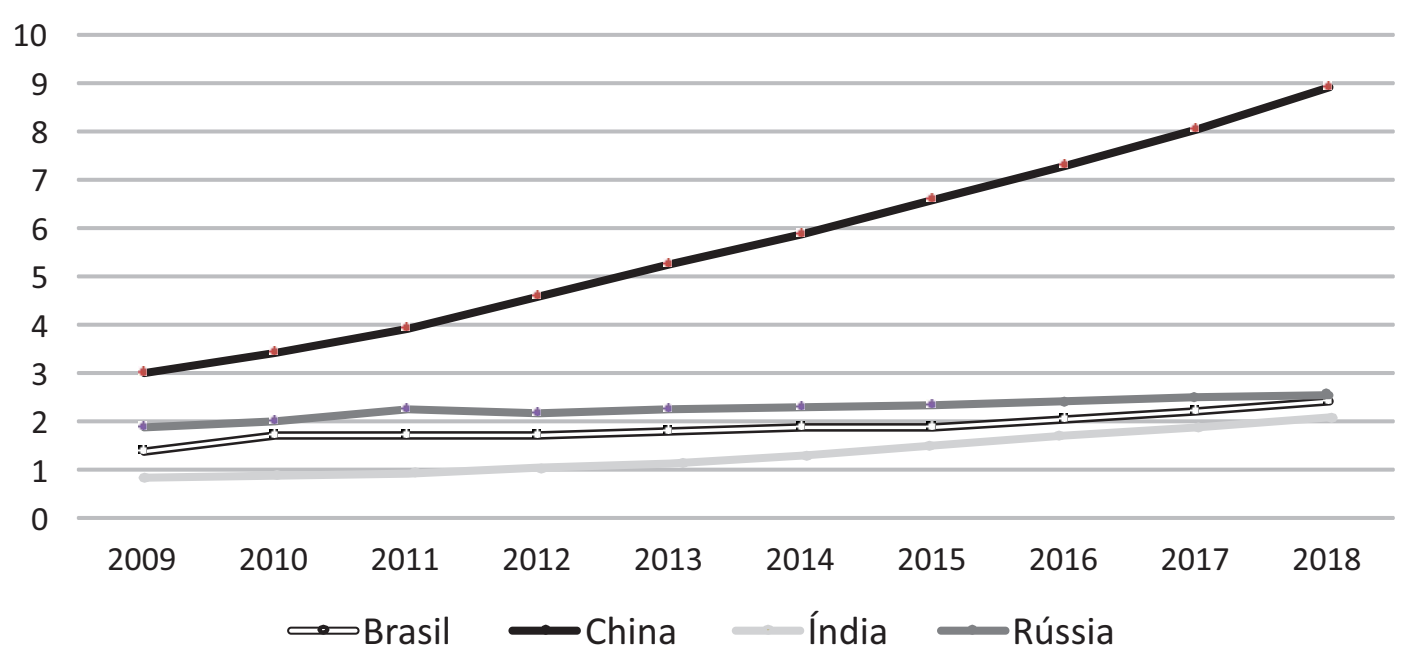

Fonte: Worldwide Medical Market Forecasts to 2018, 2013.

Mudanças demográficas e epidemiológicas, ampliação da demanda por serviços de saúde, reformulação dos sistemas de saúde, aumento dos gastos em saúde, população urbanizada com crescente poder de compra, dinamismo econômico e perspectivas de crescimento são considerados as principais razões para a ampliação da participação dos Brics no mercado mundial.

De acordo com as perspectivas, o Brasil deverá ser em 2018 o oitavo maior mercado mundial de equipamentos médicos, com um valor de vendas de US\$10.981 milhões (Worldwide Medical..., 2013).

Em que pese a fragilidade relativa da indústria nacional de equipamentos médicos, há um importante parque industrial específico instalado; o mercado brasileiro ocupava, já em 2013, a décima posição no ranking mundial, e o Brasil é praticamente o único país na América do Sul e Central dotado de uma indústria relativamente completa de fabricação de equipamentos e materiais médico-hospitalares e odontológicos

Apesar de se constituir em um oligopólio diferenciado, com predomínio de grandes empresas multinacionais, a indústria mundial comporta, até por sua característica de heterogeneidade tecnológica, diversos nichos competitivos que se configuram em oportunidades para empresas de diversas especialidades e diferentes portes. A identificação desses nichos para a indústria brasileira relativamente a equipamentos médico-hospitalares, implantes e odontologia é o tema da próxima seção.

\section{Equipamentos médico-hospitalares}

O segmento de equipamentos médico-hospitalares compreende empresas fabricantes de:

1) Mobiliário: camas, carros, mesas, estantes, poltronas, armários etc.;

2) Eletromédicos: mesa cirúrgica, cama, bisturi, incubadora, aparelhos de anestesia, ventiladores, monitor cardíaco, autoclaves, respiradores, eletrocardiógrafo, lâmpada cirúrgica, 
bomba de infusão, equipamentos para hemodiálise, endoscópios, aparelhos para tomografia computadorizada e para diagnóstico por ressonância magnética etc.;

3) Instrumental cirúrgico: pinças, tesouras, cabo bisturi, fórceps, afastadores etc.;

4) Equipamentos fisioterápicos: barras, andadores, aparelhos de ultrassom e de ondas curtas, turbilhão, banho de parafina etc.;

5) Hotelaria: máquinas de lavar, calandra, centrifugadoras, esterilizadores, cozinha etc. (Iemi, 2010)

Os equipamentos eletromédicos são os de maior intensidade tecnológica e compreendem ampla gama de equipamentos e dispositivos cuja base técnica é a eletroeletrônica. Dentre os produtos, destacam-se marca-passo cardíaco, desfibrilador e cardioversor, ventilador pulmonar, mesa cirúrgica, máquinas de hemodiálise, incubadoras, aparelhos de ultrassom, equipamentos de monitoração etc. (ABDI, 2009).

Nesse segmento, portanto, a heterogeneidade tecnológica característica da indústria de equipamentos e materiais médico-hospitalares e odontológicos encontra todo o seu significado. Abarcando diversas áreas como cuidados intensivos, neonatologia, hemodiálise, equipamentos médico-cirúrgicos, entre outras, a competição se dá em termos de segmentos de mercado. Em cuidados intensivos, por exemplo, o mercado mundial era de US $\$ 47$ bilhões em 2011, e 80\% desse mercado eram dominados por três empresas: GE, Drager e Philips (Landim et al., 2013). Em equipamentos de monitoração, os principais fabricantes mundiais são a ArtemaMEC, Biocare, Card Guard Scientific Survival, Criticare Systems, Datascope, Datex, Drager e GE. Em equipamentos utilizados em processos cirúrgicos, destacam-se a ACMI, Asap, Fujinon, Karl Storz, Olympus, Pentax, Richard Wolf e Stryker (ABDI, 2009).

Nessa área, o desenvolvimento de novos produtos carece da integração de diferentes tecnologias crescentemente baseadas em conhecimentos multidisciplinares, como design de produto, desenvolvimento de softwares de controle e componentes mecânicos e eletrônicos (Landim et al., 2013). Até mesmo as grandes corporações têm dificuldade em incorporar os vastos domínios científicos e tecnológicos necessários ao desenvolvimento de novos produtos, o que transforma a empresa de equipamentos médicos em um agente agregador de insumos, tecnologias e know-how de diferentes fontes em um único equipamento (Pieroni, Reis \& Souza, 2010). Isso leva à necessidade de expansão de acordos de cooperação e crescente ampliação de redes industriais intersetoriais, especialmente no que tange à cadeia de fornecedores. Ao mesmo tempo, esse modelo permite que empresas menores ocupem nichos de mercado, como é o caso das empresas nacionais, já que não é necessário deter todas as competências do processo produtivo.

Simultaneamente, as grandes empresas que estabelecem o padrão e o ritmo de incorporação tecnológica da indústria têm, crescentemente, adotado estratégias de integração de suas atividades industriais e comerciais mediante o estabelecimento da oferta de soluções integradas, isto é, produtos associados a serviços: rede de prestação de serviços técnicos, de assistência e manutenção, programas de software e serviços financeiros. O uso desses equipamentos está, de modo geral, associado à necessidade de reposição de insumos, de peças ou de produtos químicos, o que, ao reforçar os custos de mudança, também gera uma dependência prolongada entre fornecedores e consumidores. 
Marca, reputação, confiança e qualidade dos produtos e serviços são outros ativos complementares que promovem a fidelização dos usuários. Tais estratégias têm significado um aumento das barreiras à entrada nos segmentos em que as grandes empresas atuam, impedindo ou mesmo excluindo as empresas de menor porte que dispõem de menos recursos (Gadelha et al., 2012).

No Brasil, o segmento de equipamentos médico-hospitalares foi responsável, em termos do valor da produção, por R\$ 2,2 bilhões (ver Gráfico 2) em 2012, o que correspondeu a cerca de 46\% do total da indústria de equipamentos e materiais médico-hospitalares e odontológicos.

Esse segmento conta com um parque produtivo diversificado, com cerca de duas centenas de empresas operando no país, sendo 192 delas associadas à Abimo (Abimo, 2014). Por exemplo, os principais fabricantes nacionais de equipamentos utilizados em processos cirúrgicos são a H. Strattner e a Komlux. Em equipamentos de monitoração destaquem-se Anamed, Braile, CMOS Drake, Dixtal, Intermed, Instramed, JG Moriya, Omnimed, Protec, TEB, Transform, Transmai e Ventura (ABDI, 2009).

Relativamente ao comércio exterior, o segmento de equipamentos médico-hospitalares foi responsável por, respectivamente, 19,5\% e 10,3\% das importações e exportações do total da indústria de equipamentos e materiais médico-hospitalares e odontológicos em 2013. Entre 2009 e 2013 o segmento apresentou um crescimento de $67 \%$ nas exportações, com destaque para incubadoras de recém-nascidos, e de apenas 25\% nas importações (Brazilian Health Devices, 2014), concentrando-se em aparelhos e instrumentos para medicina. Todavia, apesar de em termos relativos as exportações terem apresentado um crescimento superior ao das importações, em valores absolutos registrou-se um déficit na balança comercial de US\$ 913 milhões em 2013, conforme mostrado na Tabela 5, que apresenta a evolução de tal déficit de 2009 a 2013.

Tabela 5 - Evolução do déficit comercial do segmento de equipamentos médico-hospitalares. Brasil 2009-2013(em US\$ milhões)

\begin{tabular}{|c|c|c|c|c|c|}
\hline & 2009 & 2010 & 2011 & 2012 & 2013 \\
\hline Equipamentos & $-393,3$ & $-678,9$ & $-612,5$ & $-797,7$ & $-913,5$ \\
\hline Outros segmentos & $-1.838,4$ & $-2.355,1$ & $-2.746,7$ & $-2.937,7$ & $-3.249,9$ \\
\hline $\begin{array}{l}\text { Total da indústria } \\
\text { de equipamentos } \\
\text { médicos }\end{array}$ & $-2.231,7$ & $-3.034,0$ & $-3.359,2$ & $-3.735,4$ & $-4.163,4$ \\
\hline
\end{tabular}

Fonte: Brazilian Health Devices, 2014.

Em que pese esse comportamento no que tange ao comércio exterior, pode-se considerar que o segmento de equipamentos médico-hospitalares apresenta um dinamismo significativo, atestado pelas taxas de crescimento dos últimos anos, pelo atendimento da demanda interna, por exportações sustentáveis e por maior conteúdo tecnológico relativo(por exemplo, monitores de sinais vitais multiparamétricos, ventiladores pulmonares, incubadoras para recém-nascidos, berços radiantes, equipamentos de fototerapia, esterilizadores médico-cirúrgicos, bombas de infusão, bisturis elétricos, equipamentos de mecanoterapia e fisioterapia, mesas cirúrgicas, focos cirúrgicos e camas 
hospitalares elétricas). Os fabricantes desse segmento representam uma parcela significativa da produção nacional, inovam frequentemente suas linhas de produtos e alcançaram, nos últimos anos, presença relevante no mercado internacional (ABDI, 2009).

A título de exemplo, salientem-se incubadoras para recém-nascidos. Empresas como Fanem, Olidef e Gigante já ocupam posição de relativo destaque e exportam para algumas dezenas de países. Em 2013, o Brasil exportou mais de US\$ 10 milhões em incubadoras para bebês (GIS, 2014), segmento que apresenta potencial de crescimento significativo, inclusive exportador, tendo grande importância para o SUS no que diz respeito aos impactos nas taxas de mortalidade infantil. O fortalecimento da expansão da competitividade internacional, mediante ênfase na inovação e lançamento de novos produtos, é fundamental em equipamentos de neonatologia.

Em sentido oposto, ressaltem-se os sistemas de hemodiálise, que são formados pelas máquinas (equipamentos) e pelos descartáveis; estes incluem o hemodialisador, que é o filtro, elemento essencial e de maior valor agregado em todo o sistema. No caso de hemodialisadores de alta densidade tecnológica não existe produção nacional. O SUS gasta em torno de R $\$ 2,5$ bilhões com terapia renal substituta, sendo que $75 \%$ desse montante referem-se à aquisição de filtros hemodialisadores. O tratamento da hemodiálise é integralmente realizado pela saúde pública, que atende cerca de oitenta mil pacientes por ano. O uso do poder de compra do Estado poderá viabilizar a produção nacional em curto período, ao mesmo tempo que ensejaria condições para que o SUS beneficie um maior número de pacientes, já que atualmente apenas um terço da demanda é atendido (Landim et al., 2013). Essa área representa uma oportunidade a médio prazo; equipamentos de hemodiálise estão incluídos na portaria n. 3.089 de 2013 e são objeto das PDPs.

A longo prazo, os principais elementos no campo da saúde que terão influência no comportamento da indústria de equipamentos médicos referem-se a pressões por redução de custos, medicina preventiva, telemedicina, atenção domiciliar e crescente incorporação de novas tecnologias.

O envelhecimento da população e a ampliação dos serviços de saúde no sentido da universalização e da integralização são dois elementos que, conjugados, deverão exercer forte pressão sobre os gastos públicos e privados com a saúde. Nesse cenário, a indústria de equipamentos deverá sofrer fortes e crescentes pressões para que seus desenvolvimentos tecnológicos levem ao aumento não somente da qualidade dos padrões de tratamento e diagnóstico, no intuito de serem mais efetivos, mais rápidos, mais seguros e menos invasivos para uma grande variedade de doenças, mas também da sua capacidade de reduzir o custo dos tratamentos (Gadelha et al., 2012).

Em um quadro geral de ampliação de serviços de saúde e seus custos, dever-se-á dar importância crescente à medicina preventiva, isto é, ao diagnóstico precoce. Os serviços de saúde em geral e os equipamentos neles utilizados deverão responder ao caráter cada vez mais preventivo dos atendimentos, reduzindo tempos de internação e de recuperação, custos e, concomitantemente, a taxa de prestação de serviços.

A monitoração de parâmetros fisiológicos e sinais vitais de pacientes é utilizada em quase todos os procedimentos médicos e hospitalares, incluindo cirurgias, processos de recuperação, terapias específicas e diagnósticos. Entre os equipamentos relacionados ao monitoramento do paciente incluem-se 
monitores, aparelhos de ventilação, aparelhos de anestesia e bombas de infusão. Tendências no Brasil no que tange ao envelhecimento populacional e a mudanças no perfil epidemiológico, com o predomínio de doenças crônico-degenerativas, associadas à crescente importância de medicina preventiva e atendimento domiciliar, fazem desta uma área de suma importância. O Brasil tem competência razoável, no entanto os fabricantes nacionais produzem equipamentos específicos, ao passo que a tendência mundial é a oferta de soluções integradas (Pieroni, Reis \& Souza, 2010). Fortalecimento das competências tecnológicas das empresas, que lhes permita o desenvolvimento de novos produtos, consolidação patrimonial e uso do poder de compra do Estado (vários desses equipamentos estão incluídos na portaria n. 3.089, de 2013, e são objeto das PDPs) estão entre as medidas a serem adotadas para a ampliação das vantagens competitivas das empresas nacionais.

Uma das tendências no campo das tecnologias de monitoração, por exemplo, é o desenvolvimento de moléculas com capacidade de se reconhecerem mutuamente, que podem viabilizar novos sensores químicos e biossensores para uso em equipamentos como capinógrafos (monitoramento do dióxido de carbono), oximetria (medição do nível de oxigênio), detectores de nível de glicose e pressão sanguínea. Pelo tamanho e dimensão desses sensores será possível colocá-los dentro do paciente de forma que transmitam, por meio de pequenos dispositivos de comunicação eletrônica, dados nele coletados. A grande vantagem dessas tecnologias será a de disponibilizar a monitoração, em tempo real, de parâmetros biológicos e bioquímicos do paciente (Gadelha et al., 2012).

Telemedicina compreende a oferta de serviços ligados aos cuidados com a saúde, nos casos em que a distância é um fator crucial; tais serviços são prestados por profissionais da área da saúde, usando tecnologias de informação e de comunicação para o intercâmbio de informações válidas para diagnósticos, prevenção e tratamento de doenças e a contínua educação de prestadores de serviços em saúde, assim como para fins de pesquisa e avaliação. Outrossim, equipamentos médicos de alto custo de aquisição e de manutenção poderão se concentrar em locais estratégicos e conectados em rede a uma série de usuários. Abre-se, assim, uma área de grande potencial, que é o campo de equipamentos de baixo custo, com o aproveitamento, por exemplo, das potencialidades dos microcomputadores (Gadelha et al., 2012).

A atenção domiciliar, viabilizada pelas TICs, é uma modalidade de cuidado com a saúde na qual o paciente pode tratar da sua doença em casa junto da família, o que possibilita uma recuperação mais rápida. A atenção domiciliar constitui uma estratégia de desospitalização e é uma das áreas na qual se prevê um forte crescimento. Essa modalidade, que deverá crescer em razão do envelhecimento da população e da necessidade de humanização do atendimento, bem como da economia de recursos gerada e da redução do tempo de internação, abre amplas oportunidades para equipamentos eletroportáteis. Tais condições forçarão as empresas a buscar alternativas que resultem em equipamentos dotados de portabilidade, conectividade e segurança para que possam ser operados por não especialistas. Monitores de glicose, dispositivos para aplicação de insulina, nebulizadores e concentradores de oxigênio são exemplos de equipamentos que se enquadram nessa categoria (Gadelha et al., 2012).

Outra tendência em equipamentos de monitoramento é a crescente incorporação das TICs. Essas tecnologias viabilizam o monitoramento remoto e geram potencial para redução do tempo de internação e para solução da escassez de profissionais, o que estimula a redução de custos 
(Landim et al., 2013). Entre as principais tendências, ressalte-se a informática na saúde, que compreende o armazenamento, a recuperação e o uso da informação, de dados e conhecimentos biomédicos para a resolução de problemas e tomada de decisão; a bioinformática, que é o estudo da aplicação de técnicas computacionais e matemáticas à geração e gerenciamento de (bio)informação; e a engenharia biomédica, que cuida da concepção de equipamentos médicos, biomédicos e odontológicos voltados para diagnóstico ou tratamento terapêutico (ABDI, 2010).

No âmbito dos chips dedicados à indústria de equipamentos médico-hospitalares, por exemplo, que podem ser utilizados em inúmeros equipamentos eletromédicos, deve-se ressaltar que, atualmente, todos os equipamentos eletromédicos utilizam placas eletrônicas e chips de prateleira, ou seja, componentes genéricos que, para cumprir uma função específica, demandam diferentes níveis de softwares. Os chips dedicados, considerados de alta densidade tecnológica, são projetados para cumprir funções específicas e não dependem de programação. Com isso agregam inúmeras vantagens, como, por exemplo: apresentam maior confiabilidade no funcionamento; não demandam a elaboração de programação específica, que é de alto custo, e por isso têm seu funcionamento simplificado; são de fácil manutenção; o chip dificilmente apresenta problema, e quando apresenta é de fácil substituição; representam amplos ganhos de escala. Embora o chip exija um grande investimento na sua concepção, este pode ser diluído por um número infinito de unidades, o que acaba por reduzir o custo do equipamento (Gadelha et al., 2012).

No caso de equipamentos médicos fundamentados em ótica - endoscópios e similares -, os produtos locais apresentam poucos desenvolvimentos, sobretudo em processamento de imagens. Como os produtores locais têm pouca capacitação, sobretudo em produtos mais intensivos em tecnologia, a demanda nacional é atendida via importações, o que tem gerado um déficit na balança comercial - em 2013, por exemplo, as importações com endoscópios totalizaram cerca de US\$ 40 milhões (GIS, 2014). As grandes oportunidades nessa área se referem à consolidação dos procedimentos médicos de videolaparoscopia, que contam com uma forte cobertura do SUS, e de aplicações para inúmeras áreas da medicina nas quais a tônica é a convergência tecnológica entre a área médica e as tecnologias de imagem.

Note-se que diversas modalidades diagnósticas utilizam sistemas de imagens digitais. Um sistema de informação hospitalar contém as mais diversas informações digitais e, em função da tecnologia empregada, as imagens médicas são consideradas como um sistema à parte, organizadas em um sistema de transmissão e arquivamento de imagens médicas chamado PACS (picture archiving and communication system).

O PACS é um sistema que proporciona o armazenamento e a comunicação de imagens geradas por equipamentos médicos, possibilitando que as informações dos pacientes e suas respectivas imagens sejam compartilhadas e visualizadas em monitores de alta resolução, distribuídos em locais fisicamente distintos. Essa tecnologia proporciona inúmeras vantagens, nomeadamente em telemedicina no que tange ao envio de imagens e informações de pacientes para polos especializados, e no ensino e pesquisa, pois viabiliza a criação de uma biblioteca digital de imagens médicas que podem ser compartilhadas (Oftalmologia, 2014).

Ainda no âmbito das novas tecnologias crescentemente incorporadas em equipamentos médicos, saliente-se a automação. Cada vez mais os novos desenvolvimentos focam equipamentos projetados 
para operações automatizadas, complexas e de precisão. Esses equipamentos podem executar uma variedade de operações, incluindo a montagem de dispositivos médicos e de preparação de receitas, automação de laboratórios, maquinário de monitoração, manuseio de materiais, embalagem e montagem eletrônica (Medical..., 2010).

A cirurgia robótica é um tipo de cirurgia minimamente invasivo em que são usados dispositivos robotizados controlados pelo cirurgião. Apesar de os primeiros passos terem sido dados no fim dos anos 1980, aperfeiçoamentos tecnológicos posteriores, sobretudo no que tange a técnicas operatórias, têm permitido expandir as áreas de aplicação da cirurgia robótica. Uma delas é a telecirurgia, isto é, cirurgia a distância (Hospital da Luz, 2014). Em um país de dimensões continentais como o Brasil, essa é uma área que apresenta francas oportunidades de desenvolvimento.

A intensificação das pressões para a redução dos custos dos sistemas de saúde, uma vez que estes precisam incorporar parcelas cada vez maiores da população, que crescentemente se torna mais longeva, e o caráter cada vez mais preventivo da medicina, reduzindo tempos de internação e recuperação, têm estimulado o desenvolvimento de novas tecnologias que possibilitem processos de recuperação nas próprias residências, apoiados pelo desenvolvimento da telemedicina. Nesse contexto, o incentivo a novos procedimentos clínicos minimamente invasivos e menos agressivos, a personalização do atendimento e a monitoração remota potencializam a miniaturização e o desenvolvimento de dispositivos inteligentes, privilegiando a convergência entre diferentes campos do conhecimento como as TICs, a nanotecnologia, a eletrônica embarcada, a microeletrônica, a engenharia de software, a mecânica fina e os novos materiais. Tal sinergia viabilizará o alcance de benefícios clínicos sem precedentes (Gadelha et al., 2012).

\section{Implantes}

Implante é um dispositivo médico feito para substituir ou atuar como uma estrutura biológica ausente do corpo. Quanto ao uso, existem implantes ortopédicos (próteses de quadril, joelho, úmero, membro, implantes para coluna, buco-maxilares, placas e parafusos etc.), cardíacos (marca-passo, desfibrilador, válvula, stent, cateter etc.), neurológicos (válvula, cateter etc.) e outros (implantes cocleares, de mama etc.).

Em termos mundiais, esse segmento é fortemente concentrado; nele predominam empresas norte-americanas com atuação global, com participações distintas em cada especialidade. Em 2012, o mercado mundial de implantes ortopédicos era avaliado em cerca de US\$ 31 bilhões, com crescimento médio esperado de $8 \%$ a. a., e o de implantes cardiovasculares em US\$ 85 bilhões, com crescimento médio esperado de 5\% a. a. (BNDES, 2013).

No Brasil, o mercado de implantes é regulado pela legislação sanitária e suprido pela oferta de fabricantes nacionais e por produtos importados. O controle sanitário é exercido, desde 1999, pelo Sistema Nacional de Vigilância Sanitária, cabendo à Anvisa a sua coordenação, incluindo a concessão de registros dos produtos comercializados e respectiva fiscalização sanitária.

No que concerne aos fabricantes nacionais, o parque é, atualmente, constituído por algumas dezenas de empresas, 62 delas associadas à Abimo, em sua maioria concentradas no estado de São 
Paulo (Abimo, 2014). Suas atividades dividem-se entre os seguintes segmentos de implantação: artroplastia; buco-maxilo; coluna e osteossíntese (traumatologia) (Neto, 2007).

Em 2012, o mercado nacional de implantes ortopédicos era avaliado em R \$ 1,1 bilhão. As projeções indicam um crescimento médio esperado de 15\% para os próximos anos; o perfil demográfico e epidemiológico do país e a ampliação de cobertura do SUS são mencionados como as principais razões para esse comportamento (BNDES, 2013).

O mercado nacional de implantes ortopédicos é extremamente concentrado: em 2010 as sete maiores empresas detinham 60\% de participação, conforme é apresentado na Tabela 6.

Em 2012, o mercado nacional de implantes cardiovasculares foi de R\$ 1,2 bilhão, e as projeções são de um crescimento médio esperado de 6\% para os próximos anos em função de doenças do coração, que já são a principal causa de morte no Brasil (BNDES, 2013).

Estrutura oligopólica e forte concentração também caracterizam o mercado de implantes cardiovasculares no país. A Tabela 7 apresenta as maiores empresas de dispositivos cardiovasculares atuantes no Brasil em 2009.

Tabela 6 - Brasil: maiores fabricantes de implantes ortopédicos - 2010

\begin{tabular}{|c|c|c|}
\hline Empresa & País & Participação (\%) \\
\hline B. Braun/Aesculap & EUA & 13,9 \\
\hline Medtronic & EUA & 10,5 \\
\hline Stryker & EUA & 10,2 \\
\hline Synthes & EUA/Suíça & 6,9 \\
\hline MDT & Brasil & 6,7 \\
\hline Depuy & EUA & 6,4 \\
\hline Baumer & Brasil & 6,0 \\
\hline Total & & 60,6 \\
\hline
\end{tabular}

Fonte: Landim et al., 2013.

Tabela 7 - Brasil: maiores fabricantes de dispositivos cardiovasculares - 2009

\begin{tabular}{l|c|c|}
\hline \multicolumn{1}{c}{ Empresa } & País & Participação (\%) \\
\hline Medtronic & EUA & 18,0 \\
\hline Boston Scientific & EUA & 17,0 \\
\hline Str. Jude Medical & EUA & 9,0 \\
\hline Cordis & EUA & 9,0 \\
Terumo & Japão & 6,0 \\
Abbot & EUA & 5,0 \\
Sorin & Itália & 4,0 \\
Total & & 68,0 \\
\hline
\end{tabular}

Fonte: Landim et al., 2013. 
Em termos gerais, o mercado nacional de implantes é dominado por importações com pequena participação de produtos nacionais. Além de sua dependência externa em produtos acabados, o país também importa matérias-primas, tais como componentes eletrônicos e ligas especiais de uso médico (Landim et al., 2013). A Tabela 8 apresenta a evolução, de 2009 a 2012, do déficit comercial do segmento de implantes, bem como o total da indústria de equipamentos médicos.

Tabela 8 - Evolução do déficit comercial do segmento de implantes. Brasil - 2009-2013 (US\$ milhões)

\begin{tabular}{|l|c|c|c|c|c|}
\hline & 2009 & 2010 & 2011 & 2012 & \multicolumn{1}{c|}{2013} \\
\hline Implantes & $-358,2$ & $-446,9$ & $-505,9$ & $-597,5$ & $-587,9$ \\
\hline Outros segmentos & $1.873,5$ & $2.587,1$ & $2.853,3$ & $3.137,9$ & $3.575,5$ \\
\hline $\begin{array}{l}\text { Total da indústria de } \\
\text { equipamentos médicos }\end{array}$ & $-2.231,7$ & $-3.034,0$ & $-3.359,2$ & $-3.735,4$ & $-4.163,4$ \\
\hline
\end{tabular}

Fonte: Brazilian Health Devices, 2014.

Em 2013, o déficit comercial com implantes foi de US\$ 588 milhões, o que representa um aumento de mais de $160 \%$ em relação a 2009. Essa situação claramente atesta a fragilidade da capacidade inovativa e produtiva da indústria nacional e a necessidade de se identificar nichos de mercado nos quais seja possível construir vantagens competitivas.

Em implantes ortopédicos, é recorrente a menção a duas áreas que carecem de desenvolvimentos tecnológicos do ponto de vista nacional: materiais e instrumentos.

Os materiais utilizados na substituição de ossos enquadram-se em uma classe denominada biomateriais e devem apresentar propriedades físicas e biológicas compatíveis com os tecidos vivos hospedeiros, propriedades que caracterizam a biocompatibilidade. O conhecimento sobre os fatores que determinam a biocompatibilidade de um material pode contribuir significativamente para desvendar os mecanismos de interação entre o tecido vivo e o implante, possibilitando o desenvolvimento e aumento da vida útil dos biomateriais, como também criar as bases para a escolha de materiais adequados para cada caso. Os materiais sintéticos utilizados para esses fins, e sobre os quais incidem as maiores pesquisas que visam a ampliar a resistência ao desgaste e ao impacto, podem ser metais, polímeros, compósitos, cerâmicas e vidros (Kawachi et al., 2000).

Sugerem-se ainda desenvolvimentos na área de projeto e fabricação de novos componentes em polímeros bioabsorvíveis para uso como implantes temporários visando a diminuir os efeitos nocivos relacionados ao uso de materiais metálicos.

Grandes instrumentos resistentes e, normalmente, perfurocortantes - tais como rugina, cinzel, osteótomos, goiva, martelos e curetas - são necessários nos procedimentos ortopédicos. Instrumentos delicados também são utilizados; os instrumentos necessários para dividir, retrair, levantar e reparar os tecidos leves das estruturas ósseas são menores e mais leves. Entre estes, incluem-se os osteótomos, o cinzel, a goiva e as curetas (Nasce, 2014).

No campo dos instrumentos sugere-se o aprimoramento de tecnologias de projeto e fabricação de ferramental cirúrgico visando a aumentar sua vida útil mantendo-se a qualidade e precisão de corte, de modo a tornar a implantação cirúrgica mais simples e segura. 
Em implantes cardiovasculares, despontam algumas tendências que carecem de desenvolvimentos: ${ }^{5}$

1) revestimento de stents metálicos com polímeros e/ou fármacos com função antineoplasia, antiproliferação ou fatores de crescimento, entre outros, para minimizar a reestenose em casos clínicos específicos;

2) polímeros bioabsorvíveis (PLA, PGA, PCL, entre outros) funcionalizados, ou não, com fármacos de ação antiplaquetária para diminuir os efeitos indesejáveis relacionados à utilização de stents metálicos;

3) descelularizaçao e recelularização de membranas xenógenas para reduzir inconvenientes associados às próteses mecânicas;

4) liga com memória de forma, como a nitinol, para expandir o stent sem balão, reduzindo os inconvenientes do uso do balão;

5) dispositivos com microeletrônica embarcada, como marca-passos, cardioversores e desfibriladores implantáveis.

Ainda em implantes, saliente-se a engenharia tecidual, a área da ciência especializada em aplicar conhecimentos de biologia, física e química no desenvolvimento de tecidos artificiais a serem inseridos no corpo humano, como, por exemplo, no desenvolvimento de pele artificial, cartilagens e tecidos ósseos, geralmente a partir de células do próprio paciente. Esse campo de pesquisa, que emergiu a partir dos anos 1990 para corrigir as limitações do enxerto de tecidos e do uso de materiais sintéticos, tem crescido significativamente nos últimos anos (Engenharia..., 2013).

Com o desenvolvimento da ciência de materiais, da engenharia biológica, da biologia das célulastronco e da biologia molecular, o potencial da engenharia de tecidos para acelerar a regeneração óssea tem se tornado uma possibilidade efetiva.

\section{Odontologia}

O mercado mundial de odontologia era de US\$ 22 bilhões em 2013, estimando-se que atinja o montante de US\$ 30 bilhões em 2018 (Worldwide Medical..., 2013).

As perspectivas para o crescimento desse segmento são extremamente positivas em função, entre outros, do envelhecimento populacional, da conscientização do consumidor, de mudanças culturais e de inovações no âmbito das práticas restaurativas e cirúrgicas (Judy \& Levin, 2010).

No Brasil, em 2013 esse mercado representava US\$ 442 milhões, e as previsões indicam que em 2018 estará no patamar de US\$ 773 milhões. No país, o crescimento desse segmento tem sido significativo e as tendências indicam que deverá se manter nos próximos anos. De 2013 a 2018, por exemplo, as projeções indicam uma evolução positiva de 75\%. Demanda reprimida, crescente envelhecimento da população, aumento da demanda por odontologia estética, crescente preocupação com a saúde bucal e distribuição de renda são tidos como as principais razões para esse comportamento. A título de exemplo, o número de beneficiários de planos odontológicos passou de quatro milhões em 2003 para 18 milhões em 2012 (Rosseto, 2013).

\footnotetext{
${ }^{5}$ Reunião de especialistas em órteses e próteses. ABDI, Rio de Janeiro, fev. 2014.
} 
O segmento é formado por mais de uma centena de empresas, 109 delas associadas à Abimo, sendo que, destas, mais de 70\% estão sediadas no estado de São Paulo (Abimo, 2014). 88\% das vendas destinam-se ao mercado nacional privado. Em 2009, dos oitocentos mil implantes realizados e 2,4 milhões de componentes protéticos e acessórios utilizados, 90\% foram fornecidos pela indústria nacional. O mercado público é responsável por 10,5\% das vendas do segmento (Rohan, 2013), mas essa participação deverá crescer em função de compras governamentais.

Saliente-se, a esse respeito, uma importante ação governamental cristalizada na Política Nacional de Saúde Bucal - Brasil Sorridente, um programa do Ministério da Saúde. De modo a garantir ações de promoção, prevenção e recuperação da saúde bucal, o Brasil Sorridente reúne uma série de ações para ampliação do acesso ao tratamento odontológico gratuito, no âmbito do SUS. As principais linhas de ação do programa são a implantação de equipes de saúde bucal no âmbito da Estratégia Saúde da Família, de centros de Especialidades Odontológicas (CEOs) e de laboratórios regionais de próteses dentárias (Brasil, 2014).

Lançado em março de 2004, o programa já beneficiou quase oitenta milhões de brasileiros, mil CEOs foram inaugurados e outros 205 estão em fase de construção. Em 2013, mais de 415 mil próteses dentárias foram entregues, por intermédio dos laboratórios regionais de próteses dentárias presentes em 1.465 municípios. Somente em 2013, o Ministério da Saúde investiu R\$ 1 bilhão, em todo o país, em recursos destinados às equipes de saúde bucal e também em investimentos nesses centros (CFO, 2009).

Embora ainda tenha uma representação modesta, a participação das vendas do segmento no mercado externo tem sido crescente. Aliás, esse é o único segmento no âmbito da indústria de equipamentos médicos que apresenta sistematicamente superávit na balança comercial - a exceção se deu em 2013, quando houve déficit associado à crise internacional. A evolução do saldo comercial de 2009 a 2013 do segmento de odontologia pode ser visualizada na Tabela 9.

Tabela 9 - Evolução do saldo comercial do segmento de odontologia. Brasil - 2009-2013 (em US\$ milhões)

\begin{tabular}{|l|c|c|c|c|c|}
\hline & 2009 & 2010 & 2011 & 2012 & \multicolumn{1}{c|}{2013} \\
\hline Odontologia & 24,6 & 25,2 & 6,3 & 13,5 & $-14,1$ \\
\hline $\begin{array}{l}\text { Outros segmentos } \\
\text { Total da indústria } \\
\text { de equipamentos } \\
\text { médicos }\end{array}$ & $-2.256,3$ & $-3.059,2$ & $-3.365,5$ & $-3.748,9$ & $-4.149,3$ \\
\hline
\end{tabular}

Fonte: Brazilian Health Devices, 2014.

Mais de 56\% das empresas do segmento vendem para o mercado externo, exportando para 180 países. Entre os produtos exportados, destacam-se instrumentos e aparelhos de odontologia, cadeiras de dentista, próteses de acrílico, artigos e dispositivos para próteses dentárias, brocas, aparelhos de raios X, entre outros produtos para obturação dentária. Alemanha, EUA e países da América do Sul são os principais mercados consumidores. Venezuela, Bolívia, Argentina, Peru e Chile respondem, em conjunto, por 28,5\% das exportações brasileiras (Garcia, 2009). 
Entre as principais tendências tecnológicas para o segmento, é de se notar o crescente uso de TICs, o que aprofundará a relação entre dentista e laboratório protético, estimulará novas abordagens de diagnóstico e tratamento e promoverá a crescente digitalização da odontologia. Internet, vídeo chat, fotografia e design digital, imagem 3D, software de projeto, scanners, moldagem digital, entre outros avanços, estimularão um trabalho crescentemente colaborativo ao longo do processo, de tal modo que os dentistas possam enviar eletronicamente medições e imagens para o laboratório, a restauração seja projetada virtualmente e, no final, o único produto a ser enviado para o consultório odontológico seja a prótese dentária (Trends..., 2012).

Uma das razões do aprofundamento da comunicação laboratório-dentista é a explosão de novas tecnologias e de materiais. A variedade de opções restaurativas exige que o clínico e o laboratório tomem uma série de decisões conjuntas em cada etapa do processo. Aspectos tais como o material a ser usado na restauração, se ela será toda de metal ou metalocerâmica - por exemplo, de PFM (porcelainfused-to-metal) -, são objeto de decisões a serem tomadas em conjunto. Existem também diversas opções cerâmicas tais como CAD/CAM (computer-aided design and computer-aided manufacturing) versus restaurações cerâmicas prensadas, formas monolíticas ou em camadas, modelos virtuais versus modelos tradicionais. A decisão por prótese ou por implante afeta significativamente todos os fatores mencionados (Trends..., 2012).

Zircônia e dissilicato de lítio são os materiais mais promissores nessa área. Zircônia apresenta como vantagens excelente estética e biocompatibilidade, ausência de margem metálica, alta fidelidade marginal, elevada resistência à flexão e ruptura e baixa condutibilidade térmica. Dissilicato de lítio, por sua vez, oferece excelente resistência e aparência estética e é facilmente usinável. Outra tendência situa-se no campo dos compósitos - por exemplo, resina com nanocristais (Vieira, 2011).

Inovações no campo de materiais odontológicos objetivando melhorar a estética e a resistência dos materiais, bem como facilitar e ampliar sua utilização, permanecerão constantes nos próximos anos.

Outra área de crescimento extremamente promissora é a de implantes. De acordo com a American Association of Oral and Maxillo Facial Surgeons, 69\% dos adultos com idades entre 35 a 44 anos perderam pelo menos um dente permanente e $26 \%$ dos adultos com idade de 74 anos perderam todos os dentes permanentes (Judy \& Levin, 2010).

Estima-se que em 2018 o mercado mundial de implantes seja da ordem de US\$ 9,1 bilhões. Melhoria da qualidade e da facilidade de colocação, o que tem significado taxas extremamente elevadas de sucesso para essa tecnologia, questões demográficas, aspectos estéticos, diminuição de contraindicações do tratamento e redução do tempo do procedimento, entre outras, são vistas como as principais razões para o crescimento potencial dessa área (Rohan, 2013).

Sobressai, entre as principais tendências tecnológicas, o desenvolvimento de revestimentos da superfície de implantes para acelerar o processo de integração óssea com nanotecnologia e/ou associação de fatores de crescimento (biomoléculas), ou mesmo com medicamentos que acelerem o processo e/ou evitem infecção. 
Existe um grande potencial para a cura de fraturas do complexo orofacial, o aumento ósseo, o reparo e regeneração da articulação temporomandibular (ATM), o reparo pulpar, a regeneração do ligamento periodontal e a osseointegração de implantes, por meio da engenharia de tecidos. Os tratamentos regenerativos demandam três elementos-chave: matriz extracelular/scaffold (pode ser sintético), células-tronco/progenitoras e sinais morfogenéticos indutores. A grande vantagem da cavidade oral sobre outras partes do corpo, com relação à engenharia de tecidos, é sua fácil observação (Engenharia..., 2013).

Registre-se que já foi criado um dente completo por uma empresa norte-americana denominada Dentigenix, que "tem uma série de programas de engenharia de tecidos: DTx 41, para a remineralização do esmalte; DTx 21, para a remineralização da dentina, e DTx DR -1, para a indução local de dentina" (Engenharia..., 2013).

Um dos grandes objetivos da odontologia restauradora é a preocupação constante dos pesquisadores em encontrar um material que apresente adesão às estruturas dentárias, impedindo assim a infiltração de fluidos bucais e microrganismos que possam comprometer as estruturas remanescentes. Cimento de fosfato de zinco, resinoso, de óxido de zinco e eugenol, de hidróxido de cálcio e de ionômero de vidro têm sido os materiais mais empregados e estudados (Equipamentos Odontológicos, 2006).

Ainda no campo dos materiais, sobressai o desenvolvimento de biomateriais (apatita carbonatada, por exemplo) que sejam absorvíveis e promovam a regeneração óssea, de materiais dentários com maior vida útil e de elementos estéticos.

A convergência entre avanços biomédicos e odontologia também é indicada como uma tendência futura. A odontologia estará cada vez mais dependente de testes de diagnóstico e de soluções farmacêuticas que provejam ao paciente os melhores resultados. Essas soluções farmacêuticas podem incluir testes de câncer oral, antibióticos em periodontia, tratamento químico de doenças periodontais e mesmo formas de estética odontológica (Trends..., 2012).

O Brasil é o segundo maior mercado de implante dentário do mundo (atrás apenas dos EUA), avaliado em 2012 em U\$ 260 milhões de dólares e com expectativa de atingir U\$ 430 milhões em 2016. Por ano, cerca de 800 mil implantes odontológicos são consumidos no Brasil, além de 2,4 milhões de acessórios e componentes protéticos (Rosseto, 2013).

O desempenho competitivo das empresas nacionais faz desse segmento uma das áreas mais promissoras no âmbito da indústria de equipamentos médicos. Além do número de empresas atuantes, existem no país, por exemplo, 211 faculdades públicas e privadas de odontologia e 1.778 laboratórios de prótese dentária (CFO, 2009). Em termos de publicações científicas na área, já em 2006 o Brasil havia ultrapassado países como a Suíça e a Suécia, ocupando a $15^{a}$ posição mundial (Dias, 2008). Essas condições claramente indicam que esse é um segmento que tem todo o potencial de se destacar em termos de capacitação inovativa e produtiva, reforçadas pelos seguintes fatores:

1) atualmente, $11 \%$ da população brasileira nunca foram ao dentista e praticamente $85 \%$ não têm nenhum tipo de assistência odontológica; 
2) faltam mecanismos eficientes de financiamento e de gestão do sistema, o que faz com que o Brasil, mesmo tendo a maior oferta de dentistas do mundo (220 mil), não consiga fornecer assistência odontológica de forma democrática;

3) o aumento dos empregos formais e o aquecimento do mercado de trabalho têm significado aumento do benefício odontológico por parte das empresas;

4) é precário o acesso ao sistema público de assistência odontológica;

5) o mercado brasileiro é considerado incipiente quando comparado com países maduros; nos EUA, por exemplo, $60 \%$ da população contam com planos odontológicos, ao passo que no Brasil esse percentual não chega a 10\% (Rosseto, 2013).

\section{Conclusão}

Há ampla evidência, baseada especialmente nos países europeus e nos EUA, de que as novas tecnologias médicas são um dos principais responsáveis pelo aumento dos custos dos sistemas de saúde e, aparentemente, a solução mais óbvia é direcionar os sistemas de saúde no caminho do uso mais racional de tecnologias médicas e, de preferência, optando-se por tecnologias mais tradicionais e menos caras. Assim, nos países europeus a pressão pela adoção de modelos alternativos de financiamento do gasto com a saúde tem sido cada vez maior (Leão, Oliveira \& Albornoz, 2008).

A maioria dos sistemas públicos de saúde elimina o poder de escolha dos pacientes sobre os tratamentos e tecnologias que podem ser usados, e a preocupação crescente com o problema do gasto público com saúde faz dos sistemas públicos de saúde um ambiente pouco propício à introdução e incorporação de novas tecnologias médicas. Na Comunidade Europeia, por exemplo, a assistência à saúde é caracterizada por tratamentos de baixa intensidade tecnológica, e a incorporação de novas tecnologias pelos sistemas de saúde é amplamente refreada pela necessidade de contenção do gasto público e por uma natural burocracia em processos públicos de aquisição e implementação de novas soluções tecnológicas de tratamento. Os EUA, por sua vez, têm um sistema de assistência à saúde majoritariamente privado, caracterizado por tratamentos extremamente intensivos em tecnologia, o que torna o país o mercado mais atrativo do mundo para equipamentos e materiais de uso em saúde.

Portanto, apesar de haver um esforço muito grande por parte dos governos e das empresas em prol do avanço tecnológico e da competitividade de seus produtos no mercado mundial, o mercado público de equipamentos de uso em saúde está assentado na necessidade de tecnologias custo-eficazes que possam atender de forma adequada às demandas que se apresentam.

O gasto com saúde nos EUA alcança a marca de aproximadamente 17\% do produto interno bruto (PIB), mas é financiado majoritariamente por recursos privados (65\%), ao passo que na Europa o gasto com saúde responde por $10 \%$ do PIB, sendo que apenas $17 \%$ desse gasto vêm da iniciativa privada. No Brasil, o CEIS responde por aproximadamente 9\% do PIB. Assim, as possibilidades de financiamento e expansão dos gastos com saúde nos EUA são mais flexíveis e independem da capacidade fiscal do Estado para angariar recursos para prover o sistema de saúde público (WHO, 2012).

Nos casos europeu e brasileiro, nos quais responde pela maioria esmagadora do gasto com saúde, o Estado desempenha um papel importantíssimo nas sinalizações de mercado no que diz respeito à 
inovação tecnológica nas indústrias e à expansão dos mercados de saúde, bem como à incorporação de novas tecnologias e tratamentos pelos sistemas de saúde. E atua como agente regulador e fiscalizador dos programas privados de assistência à saúde, além de ser, ele próprio, o maior provedor de serviços de saúde. Por outro lado, de acordo com Gadelha (2003), o Estado constitui uma instância determinante da dinâmica industrial do complexo, graças a seu elevado poder de compra de bens e serviços, ao seu poder de indução e às atividades regulatórias que desempenha, em forte interação com a sociedade civil organizada.

Diante disso, pode-se concluir que o Brasil enfrenta um grande desafio na área da inovação tecnológica em produtos e serviços para saúde, pois tem que lidar, por um lado, com o trade-off entre a difusão acelerada de novos tratamentos, procedimentos médicos e soluções tecnológicas (além da escalada em nível global da competitividade das indústrias do setor), e por outro com a necessidade de racionalizar o uso abusivo e irracional de novas tecnologias em saúde, contendo um dos principais fatores da crescente pressão dos gastos em saúde sobre o orçamento público e, concomitantemente, no déficit comercial.

Torna-se imperiosa uma ação efetiva e contrabalançada do Estado na construção de um sistema universal de saúde, que tanto atenda às crescentes demandas sanitárias da população quanto promova o desenvolvimento inovativo e produtivo da indústria brasileira de equipamentos e materiais médico-hospitalares e odontológicos. Trata-se de uma área estratégica por seu potencial intrínseco de promover o adensamento do sistema nacional de inovação e de ampliar a competitividade da indústria como um todo. Em virtude da grande variedade de produtos e serviços e da constante interação da indústria de equipamentos médicos com outros setores em geral, cria-se um modelo de convergência tecnológica que, efetivamente, forma a base para uma importante fonte geradora de inovação. Constitui-se, igualmente, em área estratégica no âmbito da saúde por ser responsável pela oferta permanente de novos de equipamentos e materiais que propiciem aumento da qualidade dos padrões de tratamento e diagnóstico para que estes sejam mais efetivos, mais rápidos, mais seguros e menos invasivos.

O fortalecimento e a consolidação da indústria de equipamentos e materiais médico-hospitalares e odontológicos impõem-se, ademais, como condição absolutamente primordial para a redução da vulnerabilidade da política de saúde. Esta não pode depender tão fortemente de importações com gasto excessivo de divisas, o que a torna sujeita às oscilações do mercado financeiro internacional e refém de estratégias competitivas completamente alheias ao interesse nacional. Do mesmo modo, o apoio ao seu desenvolvimento representa a possibilidade de se articular a política de saúde com a política industrial e tecnológica, buscando-se a convergência entre a lógica sanitária e a econômica, de forma a associar o financiamento social com o desenvolvimento tecnológico e industrial nacional. 


\section{Referências}

AGÊNCIA BRASILEIRA DE DESENVOLVIMENTO INDUSTRIAL (ABDI). Estudo Prospectivo: cadeia de equipamentos médicos, hospitalares e odontológicos. Brasília: ABDI, 2009. (Cadernos da Indústria ABDI, VIII)

AGÊNCIA BRASILEIRA DE DESENVOLVIMENTO INDUSTRIAL (ABDI). Sistemas Aplicados a Saúde Humana. Brasília: ABDI, 2010 (Cadernos Temáticos TICs, 4)

AGÊNCIA NACIONAL DE VIGILÂNCIA SANITÁRIA (ANVISA). Relatório Gerencial Datavisa, GGTPS. Brasília: Anvisa, 2012.

ALBUQUERQUE, E. \& CASSIOLATO, J. As Especificidades do Sistema de Inovação do Setor Saúde: uma resenha da literatura como introdução a uma discussão sobre o caso brasileiro. Belo Horizonte: Federação de Sociedades de Biologia Experimental, 2000. (Estudos Fesbe, 1)

ASSOCIAÇÃO BRASILEIRA DA INDÚSTRIA DE ARTIGOS E EQUIPAMENTOS MÉDICOS, ODONTOLÓGICOS E HOSPITALARES E DE LABORATÓRIO (ABIMO). Dados Econômicos. São Paulo: Abimo, 2013a. Disponível em: <www.abimo.org.br/modules/content/pdf/pdf.php?page=dados-economicos > . Acesso em: 1 abr. 2014.

ASSOCIAÇÃO BRASILEIRA DA INDÚSTRIA DE ARTIGOS E EQUIPAMENTOS MÉDICOS, ODONTOLÓGICOS E HOSPITALARES E DE LABORATÓRIO (ABIMO). Análise de Estrutura Setorial de Artigos e Equipamentos Médicos, Odontológicos, Hospitalares e de Laboratório. São Paulo: FGV Projetos, 2013b.

ASSOCIAÇÃO BRASILEIRA DA INDÚSTRIA DE ARTIGOS E EQUIPAMENTOS MÉDICOS, ODONTOLÓGICOS E HOSPITALARES E DE LABORATÓRIO (ABIMO). Site. Disponível em: <www.abimo.org.br>. Acesso em: 1 mar. 2014.

BANCO NACIONAL DE DESENVOLVIMENTO ECONÔMICO E SOCIAL (BNDES). Atuação do BNDES no apoio à indústria de equipamentos e tecnologias para saúde. In: CONGRESSO DE INOVAÇÃO EM MATERIAIS E EQUIPAMENTOS PARA SAÚDE, 2, 2013, São Paulo. Disponível em: <www.cimes.org.br/uploads/paginas/file/ palestras/Jo\%C3\%A3o\%20Paulo\%20Pieroni\%20-\%20BNDES.pdf>. Acesso em: 20 jan. 2014.

BRASIL. Decreto Presidencial de 12 maio 2008. Cria, no âmbito do Ministério da Saúde, o Grupo Executivo do Complexo Industrial da Saúde - GECIS, e dá outras providências. Brasília, Diário Oficial da União, 2008.

BRASIL. Presidência da República. Plano de Inovação do Brasil. Plano Brasil Maior. Inovar para competir. Competir para crescer: plano 2011/2014, 2011. Disponível em: <www.abic.com.br/publique/media/PlanoEstrat_Cafes_Brasil_Plano_BrasilMaior_RitaMilagres_MDIC.pdf $>$. Acesso em: abril 2014.

BRASIL. Ministério da Ciência, Tecnologia e Inovação. Estratégia Nacional de Ciência, Tecnologia e Inovação 2012-2015: balanço das atividades estruturantes 2011. Brasília: Ministério da Ciência, Tecnologia e Inovação, 2012. Disponível em: <www.mct.gov.br/upd_blob/0218/218981.pdf>. Acesso em: 29 jul. 2014.

BRASIL. Ministério da Saúde. Brasil Sorridente. Disponível em: <http://dab.saude.gov.br/portaldab/ape_brasil_sorridente.php>. Acesso em: mar. 2014.

BRAZILIAN HEALTH DEVICES. Dados do mercado, 2014. Disponível em: < http://brazilianhealthdevices.com. br/market>. Acesso em: 12 mar. 2014.

CASSIOLATO, J. E. \& LASTRES, H. M. M. Sistemas de inovação: políticas e perspectivas. Parcerias Estratégicas, 8: 237-255, 2000. Disponível em: <www.cgee.org.br/parcerias/p08.php>. Acesso em: 29 jul. 2014.

CONSELHO FEDERAL DE ODONTOLOGIA (CFO). Rio de Janeiro, 2009. Disponível em: < http://cfo.org.br/ noticias>. Acesso em: mar. 2014.

DIAS, A. A. Pesquisa Odontológica no Brasil: características da produção científica no século XXI, 2008. Tese de Doutorado, Natal: Universidade Federal do Rio Grande do Norte. Disponível em: <ftp://ftp.ufrn.br/pub/ biblioteca/ext/bdtd/AldoAD.pdf> . Acesso em: mar. 2014. 
ENGENHARIA de tecidos e pesquisa com células-tronco. Portal Educação, 21 fev. 2013. Disponível em: <www. portaleducacao.com.br/odontologia/artigos/34651/engenharia-de-tecidos-e-pesquisa-com-celulas-tronco $>$. Acesso em: mar. 2014.

EQUIPAMENTOS Odontológicos. EASY - Equipamentos Odontológicos. Materiais obturadores em endodontia, 2006. Disponível em: <www.easy.odo.br/casos_clinicos/materiais-obturadores-em-endodontia-novastendencias/>. Acesso em: mar. 2014.

EUROPEAN COMMISSION. The 2007 EU Industrial R\&D Investment Scoreboard. Luxembourg: European Comission, 2007.

EUROPEAN COMMISSION. The 2012 EU Industrial R\&D Investment Scoreboard. Luxembourg: European Comission, 2013.

FURTADO, C. Dialética da Inovação: a economia da tecnologia. Rio de Janeiro: Fundo de Cultura, 1964.

GADELHA, C. A. G. O complexo industrial da saúde e a necessidade de um enfoque dinâmico na economia da saúde. Ciência \& Saúde Coletiva, 8(2): 521-535, 2003.

GADELHA, C. A. G. Gecis dos Equipamentos e Materiais de Uso em Saúde (produtos para a saúde). In: REUNIÃO DO CONSELHO DE COMPETITIVIDADE DO COMPLEXO DA SAÚDE, $6^{\circ}$ Encontro do Grupo Executivo do Complexo Industrial da Saúde. Apresentação institucional, 2013, Brasília.

GADELHA, C. A. G. et al. A Dinâmica do Sistema Produtivo da Saúde: inovação e complexo econômico-industrial. Rio de Janeiro: Editora Fiocruz, 2012.

GARCIA, R. M. O voo do mercado odontológico. Dental Press, 2009. Disponível em: <www.dentalpress.com. br/v5/noticias.php?id=5681>. Acesso em: mar. 2014.

GRUPO DE INOVAÇÃO EM SAÚDE (GIS). Escola Nacional de Saúde Pública Sergio Arouca. Fundação Oswaldo Cruz. Dados da Rede Alice/MDIC, 2014. Disponíveis em: < http://aliceweb.desenvolvimento.gov.br>. Acesso em: jan. 2014.

GUTIERREZ, R. M. V. \& ALEXANDRE, P. V. M. Complexo Industrial da Saúde: uma introdução ao setor de insumos e equipamentos de uso médico. Rio de Janeiro: BNDES, 2004.

HOSPITAL DA LUZ: Espírito Santo Saúde, 2014. Disponível em: <www.hospitaldaluz.pt/pt/centros-multidisciplinares/centro-de-cirurgia-robotica-e-cirurgia-minimamente-invasiva/o-centro/cirurgia-robotica/>. Acesso em: 12 mar. 2014.

INSTITUTO BRASILEIRO DE GEOGRAFIA E ESTATÍSTICA (IBGE). Pesquisa Industrial de Inovação Tecnológica 2003. Rio de Janeiro: Ministério do Planejamento, Orçamento e Gestão.

INSTITUTO BRASILEIRO DE GEOGRAFIA E ESTATÍSTICA (IBGE). Pesquisa Industrial de Inovação Tecnológica 2005. Rio de Janeiro: Ministério do Planejamento, Orçamento e Gestão.

INSTITUTO BRASILEIRO DE GEOGRAFIA E ESTATÍSTICA (IBGE). Pesquisa Industrial de Inovação Tecnológica 2011. Rio de Janeiro: Ministério do Planejamento, Orçamento e Gestão.

INSTITUTO DE ESTUDOS E MARKETING INDUSTRIAL (IEMI). Estudo Setorial da Indústria de Equipamentos Odonto-Médico-Hospitalar e Laboratorial no Brasil. São Paulo: Iemi, Abimo, 2010.

JUDY, K. W. M. \& LEVIN, R. P. Trends in implant dentistry. The Dentistry,100(12), 2010. Disponível em: <www. dentaleconomics.com/articles/print/volume-100/issue-12/features/trends-in-implant-dentistry.html > . Acesso em: mar. 2014.

KAWACHI, E. et al. Biocerâmicas: tendências e perspectivas de uma área interdisciplinar. Campinas: Unicamp, 2000. Disponível em: <www.scielo.br/pdf/qn/v23n4/2652.pdf>. Acesso em: 12 mar. 2014. 
LANDIM, A. et al. Equipamentos e Tecnologias para Saúde: oportunidades para uma inserção competitiva da indústria brasileira. Rio de Janeiro: BNDES, 2013.

LEÃO, R.; OLIVEIRA, E. \& ALBORNOZ, L. Estudo Setorial: setor de equipamentos e materiais de uso em saúde. Brasília: Secretaria de Ciência, Tecnologia e Insumos Estratégicos, Departamento de Economia da Saúde, Coordenação Geral de Economia da Saúde, 2008.

MEDICAL equipment industry: the new trends and focuses. Pharmaceutical Drug Manufacturers, 5 mar. 2010. Disponível em: <www.pharmaceutical-drug-manufacturers.com/articles/medical-equipment-trends.html> . Acesso em: 29 jul. 2014.

MEDICAL equipment and supplies report 2013: a Clearwater healthcare team report. Clearwater, 2012. Disponível em: <www.kurmannpartners.com/fileadmin/user_upload/MR-MedTech/2013_Medical_Equipment_Supplies_final.pdf >. Acesso em: 13 fev. 2014.

NETO, H. L. Monitoramento da Qualidade dos Implantes Ortopédicos Comercializados no Brasil e a Importância da Estruturação da Rede Multicêntrica para Avaliação de Implantes Ortopédicos. Rio de Janeiro: Centro de Ensino e Pesquisa do Pró-Cardíaco, 2007.

NÚCLEO DE ASSESSORIA, CAPACITAÇÃO E ESPECIALIZAÇÃO (NASCE). Instrumental cirúrgico ortopédico. Disponível em: <www.nascecme.com.br/artigos/ortopedia.pdf>. Acesso em: 12 mar. 2014.

OFTALMOLOGIA: PACS (Picture Archiving and Communication System). Disponível em: <www. linkedin.com/groups/Qual-objetivo-do-pacs-4887656.S.220194297?qid=0f94d8a9-ec25-4f29-99a2b452f988d8ea\&trk=groups_guest_most_popular-0-b-ttl\&goback=\%2Egmp_4887656>. Acesso em: 23 abr. 2014.

OLIVEIRA, E. J. V. \& BUTTON, V. L. S. N. Uma estratégia de desenvolvimento para o sistema nacional de inovação de produtos médicos. Revista Brasileira de Engenharia Biomédica, 28(2): 124-139, 2012.

OLIVEIRA, G. B. Algumas considerações sobre inovação tecnológica, crescimento econômico e sistemas nacionais de inovação. Revista FAE, 4(3): 5-12, 2001.

PAMMOLLI, F. et al. Medical devices competitiveness and impact on public health expenditure. Rome and Florence: CERM - Competitiveness, Markets and Regulation, University of Florence, 2005. Disponível em: <http:// mpra.ub.uni-muenchen.de/16021/1/MPRA_paper_16021.pdf>. Acesso em: 15 jan. 2014.

PAULA, P. Brasil terá primeira fábrica de equipamentos para radioterapia da América Latina. Portal da Saúde. Disponível em: < http://portalsaude.saude.gov.br/index.php/cidadao/principal/agencia-saude/18385-brasiltera-primeira-fabrica-de-equipamentos-para-radioterapia-da-america-latina >. Acesso em: 5 jul. 2014.

PIERONI, J. P; REIS, C. \& SOUZA, J. O. B. A Indústria de Equipamentos e Materiais Médicos, Hospitalares e Odontológicos: uma proposta de atuação do BNDES. Rio de Janeiro: BNDES, 2010.

RASMUSSEN, J.; ANNERSTEDT, J. \& GRAHAM, H. Innovation financing in the European medical device sector. In: INTERLACE-INVENT, 2007, Denmark. (Work-package n. 1).

REDE ALICE/MIDC. Disponível em: <http://aliceweb.mdic.gov.br/>. Acesso em: jan. 2014.

ROHAN. Dental implants and prosthetics market. Markets and Markets, 2013. Disponível em: <www.marketsandmarkets.com/PressReleases/dental-implants-market.asp>. Acesso em: mar. 2014.

ROSSETO, F. Odontologia em pleno voo. Gestão em Saúde Diagnóstico web, mar. 2013. Disponível em: <www. diagnosticoweb.com.br/blogs/fabio-rossetto/odontologia-em-pleno-voo.html>. Acesso em: mar. 2014.

SELAN, B.; PORTO, G. \& KANNEBLEY, S. Parque tecnológico de Ribeirão Preto. Relatório Setorial de Inovação Tecnológica: indústria de produtos e equipamentos médico-hospitalares e odontológicos brasileira. Ribeirão Preto: Fipase, 2007. 
THE WORLD Medical Markets Fact Book 2013. Market Watch, 14 ago. 2013. Disponível em: <www.marketwatch. com/story/the-world-medical-market-fact-book-2013-2013-08-14> . Acesso em: 20 jul. 2014.

TRENDS in dentistry. Dentalaegis, 3(11), 2012. Disponível em: <www.dentalaegis.com/idt/2012/12/trendsin-dentistry >. Acesso em: mar. 2014.

VIEIRA, B. Zircônia como Material de Escolha para Infraestrutura de Próteses Fixas, 2011. Monografia de Especialização em Prótese Dentária, Florianópolis: Instituto de Ciências da Saúde, Faculdades Integradas do Norte de Minas, Associação Educativa do Brasil. Disponível em: <www.cursospos.com.br/arquivos_biblioteca/7176 a3876e0e46bde950b009f7ce94c9105e1113.pdf > . Acesso em mar. 2014.

WORLD HEALTH ORGANIZATION (WHO). Site. Disponível em: <www.who.int/en/> . Acesso em: maio 2012. WORLDWIDE MEDICAL Market Forecasts to 2018. Great Britain: Espicon Business Intelligence, 2013. 


\title{
COMPLEXO ECONÔMICO-INDUSTRIAL DA SAÚDE, SEGURANÇA E AUTONOMIA ESTRATÉGICA: A INSERÇÃO DO BRASIL NO MUNDO
}

\author{
Raphael Padula \\ Gustavo Souto de Noronha \\ Thiago Leone Mitidieri"
}

A genoterapia continuou a ser aprimorada velozmente. Mas, por ser um procedimento extremamente caro, só estava ao alcance de famílias bastante ricas, de países ricos e estáveis que nela podiam investir. (...)

As pessoas beneficiadas pela nova terapia foram chamadas de genos e, em pouco tempo, seu número cresceu o suficiente para que os laboratórios pudessem passar a viver exclusivamente da genoterapia. Os lucros se tornaram de tal modo elevados que os laboratórios deixaram de fabricar os medicamentos convencionais, responsáveis por uma relação custo-benefício insignificante.

Alguns governos de países desenvolvidos, e outros do mundo em desenvolvimento, tentaram obrigar os laboratórios a seguir fabricando medicamentos convencionais, capazes de atender os que não podiam pagar pela nova terapia. Mas esses governos foram derrubados por processos de impeachment, mecanismo previsto em suas Constituições e votado por Parlamentos democráticos. Ou foram eliminados por revoluções sangrentas, feitas em nome da liberdade, do livre-arbítrio e do direito de escolha.

Apesar da decadência da medicina convencional, a parcela grandemente majoritária da população de países ricos e estáveis que não tinha condições financeiras para se beneficiar da genoterapia continuou a crescer, embora a elevação estatística dos óbitos infantis causasse preocupação. Esses não genos, cumprindo o dever de proteger a saúde de suas famílias, se organizaram para evitar a exportação do que havia restado de médicos e de medicamentos convencionais.

Essa política protecionista provocou guerras localizadas, e focos de conflitos regionais explodiram pelo mundo afora. Os genos não se envolveram, limitando-se a agir por motivos humanitários e, sempre que necessário, procuraram evitar graves prejuízos ao meio ambiente, ao planeta e à civilização, impedindo o uso de armas químicas e nucleares de destruição em massa. Graças a essas intervenções, aprovadas pelos organismos internacionais, as consequências desastrosas das guerras ficaram restritas aos combatentes e suas regiões. Os "lucros com esta se tornaram de tal modo elevados que os laboratórios deixaram de fabricar os medicamentos convencionais" para os homens comuns. (...)

Logo os genos sofreram uma mutação genética, tornando-se uma nova espécie, dentro do gênero humano. Lembrando a origem fundadora de sua evolução, antropólogos e biólogos convencionaram chamar a nova espécie de Homo ricus.

Carlos Diegues, “Seleção artificial”, 2008

* As opiniões do autor não refletem a opinião do BNDES. 
O trecho em epígrafe foi extraído de artigo publicado pela revista Piauí em que o cineasta Carlos Diegues vislumbra o surgimento, no futuro, do Homo ricus, desenvolvido como uma evolução artificial do Homo sapiens a partir de uma parcela da população com acesso a serviços de terapia genética na fronteira tecnológica dissociada dos demais humanos. Nessa análise ficcional, o autor delineia um futuro em que a divisão da sociedade em classes sociais pode se transformar numa divisão em espécies. Diante das disputas geoeconômicas e geopolíticas internacionais, os avanços e inovações que têm se desenvolvido na genética, na biotecnologia, na nanotecnologia, na química, na neurociência e em outros campos de ponta na pesquisa biomédica, não se pode descartar de todo a ficção de Diegues, que talvez apresente contornos mais vinculados às relações de poder global, e não apenas a aspectos econômicos.

Nosso primeiro objetivo aqui é realizar uma reflexão sobre o conceito de complexo econômicoindustrial da saúde (CEIS) formulado por Carlos Gadelha (Gadelha \& Costa, 2013a), propondo sua ampliação tendo em vista a economia política internacional. Para isso, recorreremos aos conceitos de autonomia estratégica e segurança em saúde em uma perspectiva nacional, inserindo uma visão político-estratégica, apoiada na perspectiva geopolítica e realista das relações internacionais, condizente com a abordagem do poder global de José Luís Fiori (2013). O segundo objetivo é olhar para o Brasil e o CEIS, e suas tendências para os próximos 15 anos, tomando como base os conceitos de autonomia estratégica e de segurança em saúde.

Na primeira seção deste texto empreendemos uma análise da concepção do CEIS considerando três aspectos: o conceito de autonomia estratégica; a importância da segurança nacional, e mais especificamente da segurança em saúde e suas conexões com o CEIS; as relações entre Estados e tecnologias estratégicas, e as sinergias entre saúde e complexo industrial-militar.

Na segunda parte delineamos um panorama e as macrotendências globais do jogo entre as grandes potências e as chamadas potências emergentes, a aceleração da competição interestatal, os grandes acordos bilaterais, regionais e multilaterais - envolvendo acesso a mercados, compras governamentais, investimentos e propriedade intelectual. Trataremos do papel do Brasil no sistema internacional, seus potenciais conflitos de interesses estratégicos (não necessariamente bélicos) em torno do tema da saúde, na procura pela autonomia estratégica brasileira, associada à política nacional de defesa e à oportunidade de formação de clusters produtivos e científico-tecnológicos com o CEIS.

Na terceira seção concentraremos a análise no panorama nacional, com ênfase no papel do Estado no concernente à dinâmica de mercado e da inovação tecnológica na universalização do acesso à saúde com equidade. Observaremos a vulnerabilidade externa nos campos produtivo, comercial, tecnológico e político-estratégico, em diferentes segmentos do CEIS.

Na quarta seção trataremos das macrotendências para os próximos vinte anos - nos quais o Brasil e seu entorno estratégico estarão inevitavelmente inseridos na crescente disputa por mercados e recursos, envolvendo potências tradicionais e emergentes - que terão impactos sobre a indústria de saúde. 


\section{Questões Preambulares e Revisão Conceitual: o CEIS, a autonomia e a segurança estratégica}

Nunca é alto o preço a pagar pelo privilégio de pertencer a si mesmo.

Friedrich Nietzsche

Esta seção é dedicada à concepção de complexo econômico-industrial da saúde (CEIS), considerada com base em três aspectos: o conceito de autonomia estratégica e a importância do CEIS quando se trata de conquistá-la; a importância da segurança nacional, e mais especificamente da segurança em saúde, e suas conexões com o CEIS e a autonomia estratégica; as relações entre Estados e tecnologias estratégicas, destacando as conexões entre a área de saúde e a indústria militar, com menção às experiências de potências tradicionais (Estados Unidos) e emergentes (China). Ademais, apontamos nesta seção questões preambulares, muitas das quais não serão tratadas aqui por questões de espaço e escopo, mas podem servir para uma agenda de pesquisa futura.

\section{CEIS e autonomia estratégica}

Como destacam Gadelha e Costa (2013a), a análise do CEIS ${ }^{1}$ se debruça sobre a relação sistêmica estabelecida entre segmentos industriais e o setor de serviços de saúde e, consequentemente, sobre sua construção sistêmica no âmbito de uma economia nacional. Ademais, as análises de crescimento econômico, mudanças na estrutura produtiva e melhoria do padrão de vida da população em uma economia nacional devem colocar em evidência a importância do CEIS. A análise do CEIS coadunase com a utilização do arcabouço teórico-conceitual da economia política da saúde, que coloca em relevo as tensões relativas aos interesses sociais diante dos econômicos envolvidos, politizando o debate e evidenciando a necessidade de atuação do Estado na construção de seu arcabouço legal-institucional. Tal perspectiva retoma e atualiza a abordagem estruturalista, "que privilegia os fatores histórico-estruturais característicos da sociedade brasileira", passando pela sua "inserção internacional, assim como sua relação com uma difusão extremamente assimétrica do progresso técnico e, nos termos atuais, do conhecimento e do aprendizado, dissociados das necessidades locais" (Gadelha \& Costa, 2013a:109).

Tal abordagem enfatiza questões fundamentais como o caráter estratégico do CEIS e da universalização do acesso à saúde do ponto de vista econômico e social, e ressalta potenciais conflitos decorrentes dessa lógica, na dimensão política interna - principalmente entre empresas e Estado - e na arena internacional - no concernente à atuação das empresas transnacionais ou às relações econômicas (comerciais, financeiras e acerca de direitos de propriedade intelectual) entre Estados. Em acordo com essa visão, apresentamos uma concepção político-estratégica mais ampla na agenda de saúde, concernente às relações interestatais, com base no arcabouço teórico da economia política internacional (EPI), na qual os conflitos não resultam somente de interesses econômicos, mas também

1 "Gadelha e colaboradores (2012) caracterizam este complexo a partir de uma segmentação em indústrias de base química e biotecnológica (farmacêutica, vacinas, hemoderivados e reagentes para diagnóstico); indústrias de base mecânica, eletrônica e de materiais (equipamentos e materiais médico-hospitalares e odontológicos); e serviços de saúde (produção hospitalar, laboratorial e de serviços de diagnóstico e tratamento)" (Gadelha \& Costa, 2013a: 109). 
de interesses eminentemente político-estratégicos presentes nas relações de poder. Uma abordagem geopolítica e realista das relações internacionais, condizente com a concepção do poder global de José Luís Fiori (2013).

A análise do sistema interestatal capitalista parte de sua natureza anárquica: os Estados são os principais atores do sistema (não há nenhuma unidade política superior a eles) e, para cumprir suas funções básicas de prover segurança e desenvolvimento para suas sociedades, atuam de forma autointeressada na busca pelo acúmulo relativo de poder e riqueza frente a outros Estados. Assim, o sistema é dinâmico e caracterizado pela sua pressão competitiva permanente. Os Estados têm diferentes graus de poder e riqueza, mas tal hierarquia não elimina a competição entre as grandes potências: os que estão em posições privilegiadas tentam manter o status quo e os que estão em posições inferiores tentam mudar sua condição. Há uma diversidade de atores atuando no sistema internacional, em diferentes escalas político-geográficas. No entanto, os Estados, como atores formalmente independentes e soberanos, detêm o monopólio da coerção e da legislação dentro de suas fronteiras nacionais, ao passo que no sistema internacional são os atores que constroem as regras do jogo, o arcabouço jurídico-institucional com base no qual atuam os demais atores e os próprios Estados - uma moldura que reflete as relações de poder interestatais.

Assim, nessa abordagem, riqueza e poder não devem ser vistos em separado, em um sistema de Estados que perseguem seu interesse próprio (não atuam de forma cosmopolita). O acúmulo de poder e riqueza atua de forma coadunada e sinérgica: um Estado rico e sem poder é encarado como débil e vulnerável diante dos interesses e ações de potências externas. E o aumento de poder seria fundamental não só para a segurança da riqueza, mas também como um meio para ampliá-la. Portanto, os Estados tentam construir molduras jurídico-institucionais no sistema internacional que sejam favoráveis à atuação e expansão de suas grandes empresas transnacionais e de seu capital financeiro, visando a acumular capital, mas ao mesmo tempo maior poder relativo. Estados fortes atuam de acordo com os interesses das suas empresas e da manutenção de assimetrias estruturais no sistema internacional, promovendo acordos e usando sua influência em organizações internacionais como forma de legitimar seus interesses, construindo regras e regimes internacionais que lhes sejam favoráveis. $^{2}$

É com base nesse arcabouço teórico que analisamos a agenda de saúde. Consideramos que a indústria de saúde tem papel fundamental no desenvolvimento sistêmico, tecnológico e socioeconômico de uma economia nacional, assim como na universalização do acesso à saúde com equidade e desconcentração geográfica pelo território nacional. Além disso, buscamos inserir tais questões e objetivos em um contexto mais amplo, na perseguição da autonomia estratégica e da segurança nacional, de forma coadunada com a questão do desenvolvimento socioeconômico e da universalização do atendimento em saúde.

2 Para Krasner (2009: 13), "regimes internacionais são definidos como princípios, normas, regras e procedimentos de tomada de decisão, sobre os quais as expectativas dos atores convergem em uma determinada área temática". Princípios são formados por um conjunto coerente de afirmações teóricas sobre como o mundo funciona. Normas especificam padrões gerais de comportamento. Princípios e normas definem a característica básica de qualquer regime. 
A análise sobre o CEIS, e suas possibilidades de desenvolvimento e inovação tecnológica deve partir da centralidade da autonomia estratégica como objetivo político de um Estado em relação ao sistema internacional. A concepção de autonomia estratégica tem caráter político e vai além da concepção jurídica internacional de soberania (entendida como o mútuo reconhecimento e igualdade jurídica dos Estados, que antecede a prática de autonomia). Autonomia estratégica refere-se ao grau de liberdade política de um Estado de tomar decisões para, tanto no âmbito da política interna quanto na sua política externa, perseguir e construir regras favoráveis ao seu desenvolvimento socioeconômico e à sua segurança diante dos interesses, ações e vontades de atores externos no sistema internacional - que muitas vezes se articulam com interesses de grupos políticos internos. Nesse sentido, a autonomia estratégica pode lembrar a busca pela autarquia econômica (não como um modelo ideal inalcançável, mas como uma direção a ser perseguida), que deve ser relativizada como a autonomia estratégica na produção de bens estratégicos, considerando ainda a importância do comércio exterior (exportações) para que países não emissores da moeda de curso internacional tenham acesso a divisas internacionais. A ideia de que a autonomia estratégica está relacionada com a industrialização como política de Estado esteve presente em autores de economia política, usualmente referidos na literatura sobre história do pensamento econômico como industrialistas ou nacionalistas econômicos, como Alexander Hamilton e Friedrich List. ${ }^{3}$ Mais propriamente, esses autores viam o processo de industrialização não só como o motor do progresso econômico, mas como uma forma de internalizar a produção dos bens estratégicos como um meio para alcançar maior independência (liberdade) política no sistema internacional, ou reduzir as vulnerabilidades externas nos campos econômico e político. Segundo Gilpin (2001), a procura pela autonomia nacional envolve a inevitável colisão entre a lógica do mercado e a lógica do Estado. ${ }^{4}$ No entanto, do nosso ponto de vista, envolve também conflitos de interesses interestatais. Conforme Krasner (1985), embora sejam fracos politicamente nas suas dimensões interna e externa, os Estados subdesenvolvidos ${ }^{5}$ querem mais do que riqueza: querem mais poder e mais controle em relação a vulnerabilidades e ameaças, por meio de estratégias de reformistas (mudando regras e os regimes internacionais), o que é incompatível

\footnotetext{
${ }^{3}$ A leitura atenta das obras Relatório sobre as Manufaturas, de 1791, e Sistema Nacional de Economia Política, de 1841, respectivamente de Alexander Hamilton, um dos fundadores e primeiro secretário de Tesouro dos Estados Unidos, e de Friedrich List, promotor do Zollverein, a união aduaneira alemã, permite compreender que a concepção industrialista-nacionalista, na direção da autonomia estratégica, vai muito além de uma análise meramente econômica. No plano mais geral, esses autores têm uma visão clara de que riqueza e poder não devem ser encarados de forma separada em um sistema de Estados autointeressados que perseguem seu interesse próprio (não atuam de forma cosmopolita). Um Estado deve acumular poder e riqueza de forma coadunada e sinérgica, pois um Estado rico e sem poder é considerado débil e vulnerável diante dos interesses e ações de potências externas, como já previa Maquiavel. E o aumento de poder seria fundamental para a segurança da riqueza e também um meio para ampliá-la, e vice-versa.

4 "Um dos temas dominantes no estudo da economia política internacional (EPI) é o persistente conflito entre a crescente interdependência da economia internacional e o desejo de Estados individuais de manterem sua independência econômica e autonomia política. Ao mesmo tempo que os Estados querem os benefícios da liberalização do comércio, investimento estrangeiro e equivalentes, eles também desejam proteger sua autonomia política, valores culturais, e estruturas sociais. (...) Ao passo que a lógica do mercado é alocar atividades econômicas onde elas forem mais eficientes e lucrativas, a lógica do Estado é capturar e controlar o processo de crescimento econômico e acumulação de capital com o objetivo de aumentar o poder e o bem-estar econômico da nação" (Gilpin, 2001: 81, tradução nossa).

${ }^{5}$ Na época, Krasner (1985) utiliza o termo corrente Terceiro Mundo para se referir aos Estados subdesenvolvidos.
} 
com os interesses a longo prazo das grandes potências do hemisfério norte. Assim, da distribuição de poder assimétrica do sistema interestatal emergem conflitos estruturais. Em outras palavras, caso queiram alterar sua condição de vulnerabilidade e dependência, os Estados subdesenvolvidos não podem deixar de desafiar princípios, normas e regras que são de interesse das potências do norte e de suas grandes corporações.

Os bens estratégicos seriam aqueles fundamentais para a segurança estratégica e o funcionamento, bem-estar econômico e desenvolvimento de uma nação (de sua sociedade e economia), incluindo os setores industriais com maiores efeitos de encadeamento produtivo e de transbordamento de tecnologia para outros setores da economia, que sejam intensivos em avanços tecnológicos de ponta e para a defesa nacional. Mesmo que a produção interna envolva temporariamente um custo contábil-econômico superior, a autonomia estratégica seria compensada pelos ganhos da independência política, ou redução da dependência econômica e política externa. A dependência das relações exteriores e da lógica do mercado (a interdependência tão badalada pela ideologia da globalização) é essencialmente assimétrica, de forma desfavorável aos países periféricos, representando uma fonte de vulnerabilidade, visto que conflitos e decisões políticas externas (de outros Estados e empresas e investidores privados) poderiam prejudicar ou interromper fluxos comerciais, financeiros e tecnológicos, causando danos à segurança e ao bem-estar econômico. Mais que isso, pode ensejar o poder de veto e a projeção de poder e influência de potências externas em decisões de política interna e externa. A visão defendida aqui difere da (neo)schumpeteriana ou estruturalista latino-americana (ou cepalina clássica), segundo a qual o avanço tecnológico depende unicamente das decisões do empresário e/ou das políticas adotadas por um Estado em relação à sua economia "para dentro" (o que afetaria inclusive a atuação de empresas transnacionais). Na abordagem aqui apresentada, além dessas decisões, ganham relevo as relações interestatais - as pressões exercidas e os acordos firmados - na criação, difusão e/ou concentração de avanços tecnológicos, com destaque para a relação virtuosa entre o desenvolvimento da indústria militar e os avanços produtivos e científico-tecnológicos.

Argumentamos aqui que o CEIS é uma indústria fundamental para a autonomia estratégica do Brasil. O CEIS tem importante peso no produto interno bruto (PIB), é intensivo em tecnologias de ponta (portadoras de futuro), que se espalham ou se conectam com outros setores (de caráter transversal), especialmente a indústria militar - principalmente se considerados a biotecnologia e a nanotecnologia e o setor de equipamentos e materiais de saúde -, e a oferta/demanda dos bens e serviços de saúde é essencial para o funcionamento e o desenvolvimento da economia e da sociedade. Por isso, a indústria de saúde é considerada estratégica nos Estados fortes e influentes do sistema internacional, e tem sido tratada da mesma forma nos projetos nacionais de potências emergentes, como a China e a Índia.

\section{Segurança em saúde, segurança nacional e autonomia estratégica}

As funções básicas de um Estado são prover segurança e desenvolvimento para sua sociedade, tão essenciais que este não pode delegá-las ou submetê-las à vontade e às ações de terceiros. Sem segurança não pode haver desenvolvimento em uma sociedade, e sem desenvolvimento não pode 
haver segurança. A indústria de saúde tem papel central na segurança e no desenvolvimento de uma nação. E mesmo países tradicionalmente pacíficos como o Brasil precisam se preocupar com sua segurança (no sentido dissuasivo) diante de possíveis ameaças e de interesses externos. Isso é fundamental para sua liberdade política e capacidade de dizer não quando lhe for conveniente.

No período pós-Guerra Fria, a evolução dos estudos estratégicos, e especificamente da segurança internacional, ampliou a agenda de segurança para além da questão militar; procurou-se reestruturar o discurso da segurança com base na noção de "ameaças" que partem de outras áreas, e não somente da agressão militar de um Estado contra outro. Na evolução da agenda de estudos de segurança, ganha destaque Barry Buzan como autor proeminente sobre o tema. Para ele, no século XXI, a agenda de segurança, além da segurança militar, deveria se ampliar para abranger temas como segurança política, segurança econômica, segurança societária e segurança ambiental - temas de segurança (security issues) que teriam interconexões. ${ }^{6}$ Segundo Buzan (1991), a segurança militar compreende a capacidade ofensiva e a capacidade defensiva e dissuasória das Forças Armadas, assim como as percepções do Estado sobre as intenções de outros atores e seus poderes, e vice-versa. A segurança política abrange a estabilidade organizacional dos Estados, dos sistemas de governo e as ideologias que os legitimam. A segurança econômica trata do acesso a recursos, financiamento e mercados necessários à sustentação de níveis aceitáveis de bem-estar social e poder estatal. Esses são os temas de segurança abordados em Buzan (1991) que mais interessam neste estudo e que têm uma interconexão forte com o que podemos chamar de segurança em saúde como integrante da agenda de segurança nacional.

Em ampla literatura sobre segurança em saúde passou-se a defender uma visão coerente com a perspectiva liberal de um mundo economicamente globalizado e interdependente, pacífico e livre de disputas interestatais após o fim da Guerra Fria. Segundo essa visão, a agenda de segurança deveria ser tratada de forma coletiva, colaborativa e cooperativa, como um tema global e transfronteiriço, ou com foco na segurança humana de indivíduos, e não mais de nações, mas confiando-se em organizações internacionais, como a Organização das Nações Unidas (ONU) e a Organização do Tratado do Atlântico Norte (Otan), e na atuação benevolente dos Estados mais ricos e poderosos. A distinção tradicional entre atividades do setor Saúde doméstico e esforços internacionais na área seria desafiada pela globalização.

Segundo Colin McInnes (2008), a agenda de segurança em saúde trata de epidemias que, em um mundo globalizado com significativo fluxo de pessoas entre países, deveriam ser tratadas predominantemente de forma coletiva ou focada no indivíduo, o que não justificaria sua inclusão no campo da segurança nacional. Segundo Simon Dalby (2008), a segurança humana deve implicar um deslocamento do foco do Estado e território para as pessoas. A segurança humana significa a segurança relacionada a ameaças crônicas como fome, doença e repressão - que pode se relacionar com miséria

\footnotetext{
${ }^{6}$ Não concordamos com todas as especulações e visões de Buzan, especialmente sobre o cenário pós-Guerra Fria. No entanto, o autor tem contribuição fundamental para os estudos de segurança, por ter ampliado a agenda para outros temas, e para os fins deste estudo não é relevante discorrer sobre divergências em relação à visão e às especulações de Buzan sobre o futuro.
} 
e falta de acesso a condições mínimas de alimentação e salubridade em países subdesenvolvidos. ${ }^{7}$ Caroline Thomas (2008) reforça tal mudança ao afirmar que: 1) a questão da segurança se volta para seres humanos individuais e a proteção e cumprimento de seus direitos humanos; 2) a procura de outros níveis de seguridade - global, regional ou nacional - tem relevância e legitimidade na medida em que apoia a segurança humana; 3) a segurança humana não pode ser definida ou constrangida dentro de limites territoriais de uma unidade política exclusiva; 4) ao perseguir a segurança nacional, um Estado não deve comprometer a segurança humana de seus cidadãos ou ainda de pessoas que vivem além de seus limites territoriais.

Conforme McInnes (2008), na agenda de segurança sobre saúde têm sido tratados três temas principais: 1) a propagação de doenças infecciosas - tuberculose, gripe aviária, Aids, síndrome respiratória aguda severa (SARS, na sigla em inglês para severe acute respiratory syndrome), ebola para o "Ocidente" (como elemento exógeno); 2) pandemia de Aids/HIV (que pode ser inserido no anterior); 3) guerra biológica, em função da difusão e uso de armas biológicas por grupos radicais (bioterrorismo). Nesses temas, a saúde estaria diretamente ligada à questão da segurança, em função de potenciais efeitos desestabilizadores. Epidemias podem provocar, em curto período, um nível elevado de absenteísmo ou mesmo mortes, prejudicando o funcionamento do Estado e da economia, além de gerar um ônus significativo nos gastos públicos. Há também a possibilidade de revolta política, especialmente caso a população não acredite que está sendo atendida de forma adequada, ou que apenas segmentos mais privilegiados da população estão tendo acesso à assistência médica adequada. McInnes (2008) destaca o relatório da Central Intelligence Agency (CIA) de 1999 em que se argumenta que, com a globalização e os crescentes movimentos de pessoas e mercadorias, emerge o risco de que doenças infecciosas se espalhem globalmente e atinjam os cidadãos dos Estados Unidos da América (EUA), podendo afetar o crescimento econômico e a estabilidade internacional, e, consequentemente, tornar-se um problema de segurança nacional.

Em 2000, o Conselho de Segurança da ONU registra que a pandemia de Aids ameaça a segurança em razão de três efeitos: 1) o risco que representa para o funcionamento e a estabilidade do Estado nos campos econômico, social e político; 2) o fato de as forças de segurança (militares) e de paz serem potenciais difusores, pelo seu deslocamento; 3) a exacerbação de sua propagação em condições de violência. Levando em conta a hipótese de mobilidade de tropas em conflitos como vetor transmissor de doenças, McInnes (2008) argumenta que a relação entre epidemia de HIV e segurança não é muito conclusiva, visto que conflitos podem tanto impulsionar quanto restringir o deslocamento de tropas e civis, e, portanto, a disseminação do HIV. Além disso, programas de prevenção podem reduzir e efetivamente reduzem a propagação do HIV entre as tropas. Para o autor, as conexões alegadas - mecanismos de transmissão duvidosos - não garantem (não há evidências) que essas epidemias desestabilizem Estados.

\footnotetext{
7 Segundo Célia Almeida (2013: 239), "Na sequência do fim da Guerra Fria a principal mudança na nova agenda de segurança foi em relação ao próprio objeto da segurança - dos Estados para as pessoas - fragmentando a segurança nacional em várias subcategorias, procurando mudar o foco de análise do sistema interestadual para a sociedade e os indivíduos, seja dentro de determinado Estado ou entre Estados. Em 1994, o PNUD lançou a perspectiva da 'segurança humana', com o Relatório do Desenvolvimento Humano, acompanhada de várias recomendações para a institucionalização do conceito. O Fundo Monetário Internacional (FMI) e o Banco Mundial (BM) adotaram o conceito nas suas formulações, de forma bastante particular, assim como alguns países, sendo pioneiros a Noruega e o Canadá".
} 
Almeida (2013: 238-239) constata que

com o final da bipolaridade a "saúde global" deixou o espaço de low politic que ocupava desde a Segunda Grande Guerra e passou a integrar as agendas do Conselho de Segurança das Nações Unidas e do G-8, como tema importante do debate sobre a globalização e a segurança global. Na realidade é a "doença" e não "a saúde" que se transforma numa questão geopolítica. (...)

Entretanto, a partir dos meados dos 1990, com o fim da bipolaridade, as questões de segurança nacional começaram a ser revistas e as doenças infecciosas voltaram a ser consideradas nessa agenda. Pelo menos três desenvolvimentos chamam a atenção nessa nova articulação entre política externa e saúde: 1) o expressivo aumento no financiamento para a saúde; 2) o crescente número de atores e instituições que atuam nessa área; e 3) o impactante foco em apenas uma (HIV/Aids) ou poucas doenças (como tuberculose, malária).

Do nosso ponto de vista, atualmente, tratar o tema das guerras biológicas como tema de segurança em saúde não parece de interesse de países periféricos, especialmente de tradição pacífica, como o Brasil. No entanto, caso o país almeje obter uma projeção de ator global e influenciar o sistema internacional, deve estar preparado para possíveis ações hostis originadas de divergências de interesses com outros Estados militarmente fortes e/ou que dominam tecnologias de armas biológicas. McInnes (2008) sugere que não há evidências de que na mão de grupos radicais tais armas possam ser usadas como vetores eficazes na difusão de agentes biológicos ou químicos. Esses temas envolvem também o dilema entre cooperação coletiva e uma abordagem nacional para prevenção ou solução. Por outro lado, no discurso das grandes potências, os países periféricos podem ser identificados pelas potências como abrigos (voluntários ou não) de grupos radicais ou como focos de epidemias, o que justificaria práticas de "ajuda" e/ou intervenções.

A concepção aqui defendida, apoiada na perseguição a autonomia estratégica estatal em um sistema interestatal competitivo e anárquico, é de que a segurança em saúde deve ser tratada em perspectiva nacional, como tema de segurança e desenvolvimento nacional. A saúde deve ser encarada como um bem em si mesmo. A Organização Mundial da Saúde (OMS) define saúde como "um estado de completo bem-estar físico, mental e social, e não apenas a ausência de doenças". Seguindo a definição de Buzan (1991) para segurança econômica, poderíamos definir a segurança em saúde como o acesso a recursos, financiamento e mercados na área de saúde, necessários à sustentação de níveis aceitáveis de bem-estar social e poder estatal. Por seu caráter estratégico, o setor Saúde não pode ser tratado como parte da segurança econômica. E a segurança em saúde pode ser vista como a capacidade de um Estado (economia nacional) de produzir internamente os bens e serviços de saúde que atendam às necessidades de sua população, de forma a universalizar o acesso tanto em tempos de paz como diante de contenciosos e conflitos político-econômicos. Depende, assim, do domínio de tecnologias, da capacidade financeira e produtiva, e de mobilização de recursos em tempo hábil. Sobretudo, depende de um projeto nacional e de capacidade e coesão política interna para articular diferentes setores em prol desse objetivo superior, diante de possíveis constrangimentos e ações externas. É importante sublinhar que a segurança sanitária tem interconexões com outros temas de segurança, como a segurança econômica, a segurança política, a segurança militar e a segurança alimentar. 
Diante da necessidade ou da conveniência de importação, ou da inviabilidade da produção interna, seria fundamental para a segurança em saúde, nos termos definidos acima, que o país: em períodos de conflitos ou diante de contenciosos políticos, seja capaz (em tempo hábil) de mobilizar recursos para a produção de medicamentos antes importados; não dependa de fontes restritas de importação - seja(m) país(es) ou empresa(s); diversifique o máximo possível as fontes de importações (em termos de países e empresas, ou coalizões destes, consideranado a propriedade do capital das empresas); diversifique as rotas comerciais de abastecimento e fontes de financiamento. Sem embargo, a segurança sanitária e a segurança econômica têm relações estreitas, e vale aqui citar algumas delas.

Em relação à hierarquia monetário-financeira do sistema internacional, a proeminência do dólar como moeda internacional, assim como o papel desempenhado pelos serviços financeiros estadunidenses, dão maior liberdade e poder de arbítrio aos EUA. Assim, as relações comerciais e financeiras baseadas em dólar (como unidade de conta nos contratos ou meio de troca nas transações) podem ter seu valor alterado, e seu fluxo e acesso a crédito podem ser moldados (e dificultados ou mesmo interrompidos) a partir de decisões políticas nos EUA. É muito importante identificar origens e fluxos de financiamento e a denominação de contratos e de moedas em comércios bilaterais. Quando se trata de segurança em saúde, é necessário identificar a propriedade do capital das empresas que atuam no Brasil no âmbito do CEIS, especialmente as que participam de projetos produtivos (como as parcerias para o Desenvolvimento Produtivo, PDPs) com possibilidades de transferência tecnológica, assim como das empresas que fazem comércio com o Brasil (independentemente de sua localização territorial). Processos de concentração global da propriedade das empresas (por meio de fusões e aquisições) e da inovação tecnológica (patentes), com consequente processo de desnacionalização da indústria nacional, tendem a gerar vulnerabilidades econômicas e políticas, tornando vulneráveis a segurança em saúde e, de forma mais ampla, a segurança nacional.

A universalização do atendimento, com equidade e desconcentração geográfica pelo território nacional, tem papel fundamental na segurança política. A percepção de exclusão, por parte das classes menos favorecidas, de que somente a população mais rica (o Homo ricus de Diegues) tem acesso a bens e tecnologias de saúde de ponta, o que lhe provê uma qualidade e perspectiva de vida diferenciada, pode levar à fragmentação e a conturbações políticas internas e, consequentemente, a ameaçar a estabilidade organizacional do Estado, seu sistema de governo e a ideologia que o legitima. No tocante ao desenvolvimento e à ocupação do território nacional, além do caráter socioeconômico desenvolvimentista, a distribuição geográfica equitativa da oferta de saúde e (na medida do possível) da produção tem papel importante no domínio político do território e na sua segurança.

O economista norte-americano Thorstein Veblen (2001) afirma que capitalismo como um sistema social e econômico natural é um mito alimentado pela necessidade de justificar a forma como a produção e a riqueza são distribuídas entre os homens. Para Veblen, a produção só é possível em comunidade e, em uma perspectiva ontológica, depende da criatividade humana (instinct of workmanship). O estoque comum de conhecimentos, hábitos, costumes e meios de vida relativos à produção são, informalmente, mantidos pelo corpo social, constituindo-se em ativos intangíveis e equipamentos imateriais de toda a comunidade humana. 
Em uma perspectiva evolucionária da economia, torna-se cada vez mais difícil identificar a contribuição específica de um único indivíduo para o estado da arte da tecnologia ao longo da evolução histórica. Seguindo essa lógica poderíamos questionar, por exemplo, se Thomas Edison inventou a lâmpada (sozinho) fazendo uso exclusivo e estrito de sua capacidade individual ou se sua invenção foi o resultado final da aplicação de um estoque comum de conhecimentos da humanidade utilizados por ele para esse fim específico. Desse ponto de vista, relativiza-se a atribuição individual do monopólio sobre qualquer descoberta. A propriedade, para Veblen (2001), representa um confisco de uma parte, elemento ou fração determinada do equipamento imaterial da comunidade e tem um papel irrelevante na determinação da produtividade per se.

O sistema industrial, na lógica vebleniana, é identificado com a comunidade, e por sua interdependência fundamental (divisão do trabalho) corresponde à materialização ou à aplicação de uma herança de conhecimentos humanos (equipamentos imateriais e ativos intangíveis) cujo objetivo é servir à melhoria material e moral da comunidade. A tendência para a padronização dos produtos e processos industriais é consequência do fato de a indústria de massa requerer planejamento e coordenação, considerando-se que o modo de vida da comunidade seria mais bem atendido por um funcionamento ininterrupto e equilibrado do processo industrial. Além disso, para Veblen (2001), a ênfase nos processos de consolidação (fusões e aquisições, verticalização etc.) se dá mais por sua vantagem em relação ao controle do mercado e dos preços, e menos por sua maior eficiência e pela redução dos custos de transação.

O business é erigido sobre a indústria e a propriedade, e os lucros resultantes dessa atividade provêm da habilidade de excluir proporcionada pela propriedade. Negócios não são empreendidos por consideração à melhoria da vida da comunidade, mas, simplesmente, pelo objetivo de lucro. Sendo assim, os meios, métodos e objetivos do business são diferentes dos objetivos da indústria. Nesse sentido, o business é visto como uma atividade contraproducente no que diz respeito às atividades produtivas humanas, à sua criatividade e ao seu potencial econômico. A pergunta que deve ser feita, sob essa lógica, não é o que as empresas e corporações estão fazendo para o progresso da civilização em geral e da saúde, em particular, mas sim o que elas estão deixando de fazer.

A dicotomia entre indústria e business no campo da saúde é particularmente preocupante porque a saúde é um fator essencial ao bem-estar geral da humanidade. Se os objetivos do business farmacêutico divergirem dos objetivos da indústria farmacêutica, no sentido atribuído por Veblen (2001), um potencial avanço ou progresso para o bem-estar e a melhoria da saúde da população pode ser obstaculizado caso não atenda ao principal objetivo do business. Esse comportamento foi batizado por Veblen de sabotage. Um exemplo clássico de sabotage é o fenômeno da obsolescência planejada, em que o tempo de vida útil de um produto é restringido propositalmente pelos fabricantes, tornando o conserto e a reparação mais caros do que a compra de um produto novo.

Estendendo a visão de Veblen (2001) para a análise da indústria de saúde, uma questão a ser considerada em relação ao CEIS, e à indústria de saúde internacional de modo geral, é que as grandes empresas, em busca de lucros extraordinários a partir de posições privilegiadas, podem preferir não utilizar e não difundir, ou mesmo retardar a utilização, de avanços tecnológicos já alcançados - pro- 
movendo, assim, a sabotagem tecnológica ao invés do avanço tecnológico, o que seria contrário ao interesse público e à promoção da autonomia estratégica. Por outro lado, as empresas que concentram as inovações podem querer se aproveitar da sua posição privilegiada para impor altos custos à sua utilização, enquanto esta não for difundida, o que afeta o papel do Estado de universalizar o acesso de forma equânime atendendo a critérios de custo-efetividade. Esse debate sempre tem como pano de fundo a questão do Homo ricus (saúde para todos versus saúde para os ricos); no Brasil, a política do governo federal até 2014 deveria ter sido ampliada e intensificada, pois a doutrina básica que a orientava enfrentava tal questão na articulação entre poder de compra do Estado e desenvolvimento científico, tecnológico e industrial.

Defendemos, portanto, que o CEIS tem papel central tanto no âmbito socioeconômico quanto no político-estratégico. A construção do CEIS deve ter papel fundamental na autonomia estratégica e na segurança nacional, principalmente no que diz respeito à segurança econômica e à segurança política, além do potencial de conexão com a indústria de defesa (e consequentemente com a segurança militar). Por sua importância socioeconômica, sua participação no PIB e seu caráter tecnológico, e por reunir um conjunto de tecnologias portadoras de futuro e apresentar estreita interligação com a base industrial de defesa (que pode se tornar um complexo industrial de defesa), o desenvolvimento do CEIS é fundamental como vetor de crescimento, para a estabilidade interna, para a segurança interna e externa do país, para a redução de sua vulnerabilidade econômica e política, e para a ampliação do seu grau de independência nas suas relações exteriores. Além do caráter social, a universalização do acesso trabalha em favor da estabilidade política interna, ao eliminar diferenças internas em relação ao acesso da população a bens e serviços básicos. É importante para a segurança nacional do país também por torná-lo autossuficiente em períodos de conflitos ou interrupção de fluxos, e, assim, menos vulnerável a pressões internacionais e aos interesses (poder de barganha) de potências externas. Além disso, a distribuição das atividades do CEIS e a universalização do acesso aos bens e serviços de saúde por todo o território nacional (pelas suas diferentes regiões, inclusive fronteiriças) são importantes para o desenvolvimento socioeconômico do território nacional, para o seu aproveitamento em todas as suas potencialidades geográficas e da segurança do território nacional - ao promover o domínio político e a ocupação demográfica, econômica e militar adequada de todo o território e de seus recursos. Assim, considerando sua importância econômica, tecnológica, social, política e militar, o CEIS é uma indústria de caráter estratégico cujo destino não pode ser deixado ao mercado global, à vontade de potências externas e de organizações internacionais.

\section{Estados e tecnologias estratégicas: a área de saúde e o empreendimento militar}

Como fatores importantes na apropriação de poder e riqueza, a inovação tecnológica e, consequentemente, a capacidade de inovar são fundamentais na assimétrica e hierárquica distribuição de poder e riqueza no sistema interestatal, por sua relevância nos campos produtivo e militar, no aproveitamento e domínio de recursos, espaços e mercados.

Nas grandes potências, o papel do Estado e suas prioridades regulatórias refletem seus objetivos de manter a liderança nos campos produtivos de maior valor agregado e no campo científico e tecnológico de ponta, o que se reproduz no campo da indústria de saúde. Para as potências emergentes, os 
processos de catching up tecnológico se tornam a preocupação central no tocante à produção física e científico-tecnológica, para que o Estado alcance uma inserção ativa e favorável, e não subordinada, no sistema internacional (Chang, 2002; Medeiros, 2004; Chase-Dunn, Niemeyer \& Allison, 2005). Nesses processos, as ciências e as tecnologias ligadas à saúde são reconhecidas como ramos estratégicos, do ponto de vista social, econômico e de segurança nacional. As ligações entre a indústria militar e a indústria de saúde são aproveitadas e exploradas em suas potencialidades, ganhando centralidade tanto nos processos de manutenção de liderança quanto nos de emparelhamento tecnológico. E mesmo que os Estados usem estratégias para atrair para o seu território atividades produtivas e de pesquisa e desenvolvimento (P\&D) estrangeiras, trabalham para envolver atores nacionais, privados e até mesmo governamentais, para assegurar acesso e controle sobre o processo, tendo em vista a autonomia futura. Os setores que têm se destacado mais recentemente são ligados à biotecnologia e à nanotecnologia (Vargas, neste volume).

Uma questão fundamental a ser considerada é o tratamento especial dispensado à indústria de saúde e o papel determinante que esta desempenha na estratégia das grandes potências e tem exercido na estratégia de potências emergentes como a China e a Índia. No complexo industrial-militar dos EUA, as relações com o setor Saúde são intrínsecas, um modelo que tem sido copiado pelo complexo industrial-militar chinês (Medeiros, 2004; Medeiros \& Trebat, 2013). O setor Saúde sempre foi tido como estratégico pelas grandes potências, tanto em sua política interna quanto para sua projeção externa (o que transparece em sua postura de procurar acordos internacionais relativos a comércio, serviços, investimentos, propriedade e compras governamentais), e tem sido considerado dessa forma pelas potências emergentes. Por isso, o estudo de experiências comparadas, identificando benchmarks e ressaltando as particularidades brasileiras, pode ser um instrumento fundamental para recomendações políticas sobre como desenvolver a área de saúde e identificar os setores dentro do CEIS que podem ser priorizados, mas sempre levando em conta as particularidades do Brasil. Se observarmos as empresas líderes globais na produção e nas inovações, vamos encontrar predominantemente empresas estadunidenses, europeias e japonesas, e, em um processo de catching up, empresas chinesas, indianas e israelenses.

Ao longo de sua história e principalmente após a Segunda Guerra Mundial, no período da Guerra Fria, os EUA desenvolveram um arranjo institucional complexo e eficiente envolvendo empresas, universidades e agências governamentais, o chamado complexo industrial-acadêmico-militar, que teve nesse período e tem até hoje papel fundamental na sua liderança científica e tecnológica desde a ciência básica até tecnologias de ponta (cf. Smith, 1985). São inovações que transbordam do setor militar para o setor civil - caracterizando efeitos de spill over ou de spin off. Conforme destaca Medeiros (2004: 9),

O Advanced Research Projects Agency (Darpa), subordinado ao DOD [Departamento de Defesa], teve especial liderança na criação de novas tecnologias. Para este esforço, o fator limitante não era a disponibilidade de recursos financeiros. Depois da guerra, os militares obtiveram amplo apoio financeiro e as políticas de compra do DOD criaram uma vigorosa demanda protegida para as principais indústrias fornecedoras de armamentos. $\mathrm{O}$ fator limitante era o estoque de conhecimento e a estrutura operacional do sistema de inovações. Deste modo, a tarefa não se 
circunscrevia à provisão de incentivos para $P \& D$ nas indústrias ou nas universidades, mas na montagem de um extenso e dinâmico sistema de inovação. O desafio era reduzir o período de tempo entre as invenções e inovações acelerando o progresso técnico e dirigindo-o para a produção de "armamentos radicalmente novos". Este desafio foi assumido pelo DOD.

Diversos projetos e escritórios dentro do Darpa objetivam o desenvolvimento e a liderança científica e tecnológica, incluindo vários campos que exercem impacto sobre a indústria de saúde, como química, novos materiais, microeletrônica, ciência da computação, robótica, automação, biotecnologia, nanotecnologia, tecnologia nuclear, neurociências, entre outros. Entre eles destacamos o Defense Sciences Office (DSO), o Microsystems Technology Office (MTO) ${ }^{8}$ e o Biological Technologies Office (BTO), este último criado em abril de 2014.

Na página na internet do BTO, lançado em abril de 2014, o discurso do diretor do Darpa, Arati Prabhakar, salienta a relevância da biologia e define seu campo de inovação:

A biologia é o inovador final da natureza, e qualquer órgão focado na inovação seria insensato se não olhasse para esse mestre da complexidade em rede na busca de inspiração e soluções. (...)

[O BTO] irá fundir biologia, engenharia e ciência da computação para aproveitar o poder dos sistemas naturais para a segurança nacional.

Tecnologia, como a biologia, evolui constantemente. É missão do Darpa permanecer à frente da curva de mudança tecnológica, fazendo os investimentos fundamentais e iniciais em áreas que cubram os domínios da pesquisa e permitam novas capacidades revolucionárias para a segurança nacional dos EUA. Agora o Darpa está pronto para dar destaque sem precedentes para um campo de investigação que não pode mais ser considerado periférico à tecnologia envolvendo a natureza. A partir de hoje, a biologia toma o seu lugar no núcleo duro das ciências que representam o futuro da tecnologia de defesa. (Darpa, 2014, tradução nossa)

A liderança tecnológica em setores estratégicos é um dos elementos centrais para que um Estado consiga alcançar e manter uma posição hegemônica no sistema interestatal, tanto por seu impacto vantajoso na produção física quanto no poder militar, ou para que pelo menos figure no andar superior da hierarquia econômica e político-militar do sistema. Chase-Dunn, Niemeyer e Allison (2005:

4-5) argumentam que

Novas indústrias líderes têm sido elementos importantes no aumento e prolongamento das hegemonias econômicas no passado. Os poderes político e militar dos Estados são sustentados e facilitados por vantagens competitivas na produção de bens altamente rentáveis. Hegemonias crescentes (ou "líderes mundiais", na terminologia de Modelski e Thompson, 1996) conseguem

\footnotetext{
${ }^{8}$ Em sua página na internet, o BTO declara sua missão: "In recent years, the proliferation of commercial components and manufacturing processes has made advanced technologies accessible to all, leveling the playing field. In response, MTO is dedicated to leveraging, countering and transcending these commercial-off-the-shelf (COTS) approaches. MTO aims to multiply the power of COTS by aggregating, adapting and integrating components into networks and systems for the benefit of the warfighter. MTO seeks methods for countering threats (both incidental and intentional) that arise from sustained advancements in cheap and readily available technologies. Lastly, MTO develops high-risk, high-reward technologies outside and beyond the scope of the commercial industry to secure the DoD's technological superiority. By continuing to create revolutionary capabilities, MTO seeks to 'un-level' the playing field" (www.darpa.mil/Our_Work/MTO/).
} 
inovar novos modos rentáveis de comércio e produção que lhes permitam financiar vantagens políticas e militares em relação a outros Estados. Assim, a sequência de novas tecnologias líderes e sua distribuição pelo núcleo de Estados potencialmente concorrentes é um importante objeto de estudo para se compreender tanto o passado como o futuro da ascensão e queda de hegemonias. (tradução nossa)

Os autores chamam de "novas indústrias líderes" aquelas que transbordam tecnologias para outros setores, têm capacidade de gerar "rendas tecnológicas" (monopolísticas) por determinado período, influenciando inclusive a indústria militar. Assim, o domínio de tecnologias líderes ou estratégicas tem implicações geopolíticas sobre a distribuição de poder econômico e militar, e suas rivalidades. Olhando especificamente para a hipótese de declínio da hegemonia dos EUA, os autores afirmam:

Depois que surgiu maior competição internacional, os EUA continuaram a angariar rendas tecnológicas por inventar, produzir e exportar novos produtos, incluindo equipamentos de energia nuclear, tecnologia militar e tecnologia da informação. Agora, muitos acreditam que as vantagens dos EUA no campo da biotecnologia poderão contribuir substancialmente para uma nova rodada de hegemonia econômica dos EUA nas próximas duas décadas. (Chase-Dunn, Niemeyer \& Allison, 2005: 5, tradução nossa)

Assim, apostam as indústrias de biotecnologia, de alimentos e medicina na posição futura dos EUA nos próximos dois séculos, fazendo uma associação entre ciclos de liderança tecnológica e ciclos hegemônicos. ${ }^{9}$

Chase-Dunn, Niemeyer e Allison (2005) registram que, em 1984, o Office of Technology Assessment (OTA) do Congresso dos EUA realizou um influente estudo comparativo sobre as vantagens do país na área biotecnológica e concluiu que esta deveria ser impulsionada com significativos investimentos privados e públicos. No mesmo estudo, o OTA indica os dez fatores-chave para a competitividade internacional na biotecnologia (em ordem decrescente de importância):

1) financiamento e incentivos fiscais para empresas;

2) fundos governamentais para pesquisa básica e aplicada;

3) treinamento e disponibilidade de pessoal;

4) regulação de saúde, seguridade e ambiental;

5) lei de propriedade intelectual (no caso dos EUA, importante para proteger suas firmas em seu processo de expansão global);

6) relações indústria-universidade;

7) lei antitruste;

8) transferência de tecnologia, investimentos e comércio internacionais;

9) metas de políticas públicas em biotecnologia; e

10) percepções públicas (mais importante no caso dos alimentos).

\footnotetext{
${ }^{9}$ Esse argumento foi utilizado anteriormente por Joachim K. Rennstich (2001, 2004).
} 
Para Chase-Dunn, Niemeyer e Allison (2005), alguns importantes fatores foram esquecidos nessa lista. Os acordos e instituições internacionais, as trajetórias de competição econômica, política e militar, e possibilidades de conflitos, assim como as condições da economia política global como um todo devem ser levadas em conta, porque influem nas regras do jogo e nas possibilidades e formas de acesso a financiamento, comércio, investimentos e transferências tecnológicas. Essa abordagem indica que, além da importância do comportamento dos agentes (Estados), é preciso olhar para o comportamento da estrutura, que pode gerar constrangimentos e fatores balizadores. Do nosso ponto de vista, além de um projeto nacional liderado pelo Estado, coeso internamente e em sua projeção externa, a distribuição de poder e as possibilidades de cooperação e conflito no sistema internacional são fatores importantes para quem larga atrás na busca por novas tecnologias e posições políticas e econômicas no sistema internacional.

Olhando para as barreiras à entrada na indústria biotecnológica, um consenso na literatura, Chase-Dunn, Niemeyer e Allison (2005) aceitam que existem altos custos de entrada em P\&D para nações e firmas retardatários. No entanto, argumentam que esses custos não são tão altos, visto que há exemplos de países que superaram essas barreiras, como a China e Cingapura - o primeiro deles contando com um amplo mercado e mobilização de recursos. Isso revela que a competição pela liderança tecnológica (e seus benefícios) tende a se acelerar nos próximos anos:

Supostamente, os altos custos iniciais de pesquisa e desenvolvimento de biotecnologia deveriam retardar o surgimento de concorrentes. Isso tem sido visto como parte da explicação para o fato de a pesquisa em biotecnologia, desenvolvimento e comercialização na Europa e no Japão ter ficado para trás em relação aos EUA. Entretanto, tem havido alguns desenvolvimentos que lançam dúvidas sobre essas caracterizações. A República Popular da China começou uma iniciativa em biotecnologia substancial patrocinada pelo Estado nos anos 1980, e muitas inovações importantes desse programa foram implementadas em larga escala na agricultura chinesa, com, em tese, grandes efeitos benéficos. Talvez o grande tamanho da China semiperiférica tenha permitido que os recursos maciços fossem concentrados em esforços de pesquisa e desenvolvimento direcionados, de forma que esse desenvolvimento não se mostra tão surpreendente. Mas Cingapura, uma cidade-estado no sudeste da Ásia, também conseguiu estabelecer uma indústria de biotecnologia com sucesso, importando talento científico do exterior. Esses iniciantes demonstram que a entrada no setor de biotecnologia não é tão restrita como se supunha, e que a concorrência por fatias da demanda mundial dos produtos biotecnológicos acelerará o ciclo do produto, tornando mais difícil para determinados países, incluindo os EUA, angariar rendas tecnológicas por muito tempo. (Chase-Dunn, Niemeyer \& Allison, 2005: 11, tradução nossa)

Em interessante artigo sobre o complexo industrial da saúde e a rota biotecnológica, Reis, Landim e Pieroni (2011) tratam de lições da experiência internacional examinando o processo de catching up de China, Índia e Israel. Os autores enfatizam a importância do papel do Estado na contrução de um arcabouço regulatório e institucional favorável ao desenvolvimento produtivo e científico-tecnológico da rota biotecnológica. No entanto, por questões de escopo, no artigo não salientam que esses três países contam com uma vigorosa indústria militar e lidam com questões geoestratégicas (principalmente, vizinhanças conturbadas) que criam pressões por avanços em áreas-chave e, ao menos no caso de China e Israel, uma intensa ligação entre indústria de saúde e complexo industrial-militar. 
A Índia, embora não tenha um complexo industrial-militar bem formado, constituiu uma estratégia estatal e regulatória com o objetivo de avançar na biotecnologia e conta com uma base de cientistas habilidosos e um aparato regulatório que facilitam as transferências e a apropriação de tecnologias de empresas estrangeiras. No caso de Israel, conta seu papel como aliado estratégico e receptor de amplo apoio dos EUA nos campos militar, econômico e tecnológico.

Medeiros e Trebat (2013) mostram que a China tem se inspirado no complexo militar-acadêmicoindustrial estadunidense para constituir seu poder militar-tecnológico, envolvendo setores ligados à indústria de saúde:

O pensamento de elite na China no que diz respeito à integração civil-militar sofreu uma mudança significativa na segunda metade da década de 1980. O foco intenso na conversão de defesa, acompanhado da Iniciativa de Defesa Estratégica da administração Reagan, convenceu oficiais e cientistas proeminentes de que não estava sendo feito o suficiente para promover investimentos em áreas de alta tecnologia fundamentais para a segurança e a competitividade econômica da China. Para resolver esse problema, a China criou o "Programa 863 de pesquisa em alta tecnologia" em 1986, com foco em automação, biotecnologia, energia, tecnologia da informação (TI), laser, novos materiais e espaço. Como o Darpa, porém com um foco maior na pesquisa aplicada, o Programa 863 oferece financiamento numa base competitiva para as universidades, institutos de pesquisa do governo e laboratórios industriais envolvidos em pesquisa de alta tecnologia com potenciais aplicações militares.

Embora os níveis de financiamento fossem bastante baixos até o início da década de 1990, o 863 evoluiu para o "principal instrumento de política para a indústria de alta tecnologia" e "o maior programa nacional da China" para a pesquisa e desenvolvimento. O financiamento aumentou no fim dos anos 1980 e 1990 com o aumento da importância de programas científicos de base militar no processo de modernização da China. (Medeiros \& Trebat, 2013: 7-8, tradução nossa)

Os autores destacam oito indústrias civis que apresentam maior potencial para a tecnologia militar. Muitas delas exercem impacto sobre a indústria de saúde:

microeletrônica, computadores, equipamentos de telecomunicações, energia nuclear, biotecnologia, química, aviação e espaço. Embora a China fique atrás dos EUA e de outros países industrializados em todas essas áreas, a distância está encurtando em relação à maioria deles e o complexo militar-industrial-científico chinês está rapidamente se tornando mais sofisticado. (Medeiros \& Trebat, 2013: 14, tradução nossa)

As experiências históricas de grandes potências e das potências emergentes apontam para o desenvolvimento prioritário da indústria de saúde em suas estratégias nacionais de segurança e desenvolvimento. O Estado tem o papel de liderar o processo de construção da indústria de saúde. Estratégias lideradas pelo Estado, bem planejadas, com adequadas regulações, mobilização de recursos e arranjos institucionais envolvendo setores estatais, acadêmicos e empresariais são condições necessárias para um processo bem-sucedido de catching up nas indústrias estratégicas. É importante notar o potencial de conexão entre o desenvolvimento tecnológico no setor militar e no CEIS, no campo nuclear, da biotecnologia, da nanotecnologia, das ciências de materiais e nos equipamentos. 
Em geral, essa percepção costuma vir das estratégias de formação da indústria de defesa, ao envolver a área da saúde. Os segmentos que formam o CEIS são constituídos por indústrias portadoras de tecnologias de futuro, com caráter estratégico, que se espalham por outros setores da economia e são fundamentais para o desenvolvimento e a segurança nacional.

Se o Brasil quiser trilhar um caminho bem-sucedido na consolidação do CEIS, é preciso que este seja considerado como um setor estratégico para o desenvolvimento e a segurança nacional, e que se explorem as articulações entre o CEIS e a base industrial de defesa em todas as suas potencialidades, com intensa participação do Estado. A articulação entre a estratégia nacional de defesa e a política nacional de defesa com as políticas do Ministério da Saúde e do Ministério de Ciência e Tecnologia para a área da saúde seria imprescindível para a formação de clusters ou arranjos produtivos envolvendo empresas privadas nacionais e estrangeiras, universidades e o Estado, especialmente na questão do financiamento, na qual o Banco Nacional de Desenvolvimento Econômico e Social (BNDES) pode ter papel fundamental. Tais arranjos deveriam se direcionar para uma pujante dinâmica produtiva física e científico-tecnológica, garantindo transferências e autonomia tecnológica a longo prazo.

\section{O Brasil e as Macrotendências Globais}

A partir dos anos 1970, o sistema interestatal presenciou um ciclo geopolítico e geoeconômico de aceleração de sua permanente competição entre Estados pelo controle e acesso privilegiado a mercados e territórios que contenham recursos estratégicos ou sejam importantes rotas para comercialização eficiente e segura (Klare, 2008; Fiori, Padula \& Vater, 2013). Trata-se de recursos que, em termos globais, são relativamente escassos e/ou estão concentrados em alguns territórios, predominantemente nos países de menor grau de desenvolvimento socioeconômico e poder político-militar, e que ao mesmo tempo são cruciais para a expansão industrial e do poder militar de países ricos e militarmente fortes, com maior influência no sistema internacional.

A recente aceleração competitiva se deve a diversos fatores. A perda relativa de poder ou "crise de hegemonia" - impulsionada, desde a crise do padrão dólar-ouro, pelo fracasso no Vietnã e pela perda de influência em posições importantes no Oriente Médio nos anos 1970 - levou os EUA a retraçarem sua estratégia de expansão para enquadrar possíveis rivais e vencer a Guerra Fria, abandonando sua "hegemonia benevolente" - que inclusive apoiava ou tolerava políticas desenvolvimentistas e de welfare state em Estados da periferia capitalista. Além disso, no pós-Guerra Fria, o surgimento das chamadas potências emergentes da Ásia (com grandes populações e crescentemente demandantes de recursos), principalmente China e Índia, e a retomada de uma política nacionalista da Rússia, nos anos 2000, fazendo frente ao desejo de potências tradicionais de manterem suas posições, pressionam ainda mais essa corrida dentro da dinâmica do sistema estatal (Fiori, Padula \& Vater, 2013).

A prevalência da potência capitalista na confrontação bipolar e o discurso da globalização trouxeram a promessa de um mundo mais pacífico (o fim da história de Fukuyama, 1992) e convergente em termos de renda, riqueza e tecnologia, entre os países subdesenvolvidos e os desenvolvidos, promovido por meio das livres forças de mercado e da interdependência econômica global (comercial, financeira e tecnológica). Com base nessa ideologia ou por meio de pressões políticas - lideradas pelos Estados 
centrais e organizações internacionais sob sua influência (como o Fundo Monetário Internacional e o Banco Mundial) -, foi promovido um amplo processo de liberalização econômica global no setor industrial, mediante iniciativas unilaterais ou acordos bilaterais entre Estados, e ainda no âmbito multilateral por intermédio da Rodada Uruguai do Acordo Geral sobre Tarifas e Comércio (Gatt) e da Organização Mundial do Comércio (OMC). Dessa agenda de acordos liberalizantes baseados na ideologia da globalização resultaram o Gatt e o Gats, sobre liberalização e transparência no comércio, respectivamente, de bens e de serviços; o Trade-Related Aspects of Intellectual Property (Trips), relativo à propriedade intelectual; o Agreement on Trade-Related Investment Measures (Trims), relativo a investimentos, e mesmo o Tratado de Não Proliferação Nuclear (TNPN). Nessa perspectiva de mundo pacífico e livre de disputas interestatais, a segurança deveria ser tratada de forma cooperativa, como um tema global e transfronteiriço, confiando-se em organizações internacionais (como a ONU e a Otan) e na atuação benevolente dos Estados mais ricos e poderosos, tirando a nação do centro do debate. Daí surge a ideia de que epidemias, em um mundo globalizado e com significativo fluxo de pessoas entre países, deveriam ser tratadas predominantemente de forma coletiva. Ou de que o tema da segurança humana em países subdesenvolvidos deveria ser tratado em uma perspectiva focada no indivíduo ou cosmopolita (McInnes, 2008).

No entanto, o sistema internacional pós-Guerra Fria continuou sendo caracterizado por sua estrutura assimétrica de distribuição de poder e riqueza e por sua natureza anárquica e competitiva interestatal. Ampliaram-se as divergências de renda, riqueza e tecnologia (revelada no registro de patentes de tecnologias de ponta), ao mesmo tempo que a atividade industrial se concentrou cada vez mais nos países desenvolvidos e militarmente poderosos (com exceção dos países do sudeste asiático) ${ }^{10}$ e os conflitos militares não foram eliminados, só se aceleraram (Fiori, Padula \& Vater, 2013). No mesmo sentido, aumentou a dependência econômica e tecnológica dos países subdesenvolvidos, inclusive na área da saúde, ${ }^{11}$ e a diferença entre seu poder militar e político e aquele dos países desenvolvidos foi se acentuando.

Por suas dimensões, seus mercados e recursos estratégicos, o Brasil, a América do Sul e a África estão inevitavelmente inseridos na crescente competição das grandes potências. O Brasil é um país continental. Se fizermos listas de países segundo tamanho do território, população e PIB, apenas cinco países estarão entre os dez primeiros de cada uma delas: os Estados Unidos, a China, Índia, Rússia e Brasil. O Brasil é o quinto país do mundo em território e população, e oscila entre a sexta e sétima posição em termos de PIB nominal. Assim, é um país grande, com dimensões que trazem grandes oportunidades, desafios e responsabilidades, e não pode sofrer com o que Reis (2011: 63, 64) chama de "síndrome de Costa Rica". É um país que tem que trilhar um caminho próprio e buscar o lugar que lhe cabe no mundo, e cujo crescimento e projeção externa impactam na expectativa de outros atores e desperta rivalidades com outros Estados.

\footnotetext{
${ }^{10}$ Ao longo dos anos 2000, os relatórios da UNCTAD (Trade and Development Report) abordam esse processo impulsionado pela liberalização dos anos 1980 e 1990.

${ }^{11}$ Ver volumes 1 e 5 da série A Saúde no Brasil em 2030: prospecção estratégica do sistema de saúde brasileiro: desenvolvimento, Estado e políticas de saúde. Rio de Janeiro: Fiocruz, Ipea, Ministério da Saúde, Secretaria de Assuntos Estratégicos da Presidência da República, 2013.
} 
Especificamente no concernente à América do Sul e seu lugar na política de segurança dos EUA, é importante considerar sua posição geográfica relativa em área geoestratégica, de interesse e ação permanente por parte dos EUA. A postura intervencionista e imperialista estadunidense na região se respalda na sua geoestratégia de se tornar árbitro político e exercer controle sobre a massa de recursos do hemisfério ocidental, não deixando que surja nenhuma potência ou coligação de países no continente americano, ou mesmo aliada a uma potência do hemisfério oriental, que possa vir a contestar ou a ameaçar seu predomínio hemisférico, por razões de segurança territorial. Essa concepção geopolítica foi formulada por Nicholas Spykman (1942), para quem a supremacia estadunidense no continente deve ser incontestável e irrevogável para a sua segurança territorial. ${ }^{12}$ Em resumo, a atuação intervencionista e a manutenção da hegemonia dos EUA no hemisfério teriam basicamente duas razões entrelaçadas: a construção de um possível sistema econômico e político autárquico sob a hegemonia de Washington e sua segurança territorial, que quando ameaçados poderiam provocar respostas, em última instância, baseadas no uso da força (Padula, 2013).

Durante o segundo governo Lula, o Estado brasileiro definiu uma nova política de desenvolvimento e de defesa, a partir da formulação do seu Plano Nacional de Defesa (PND) e da sua Estratégia Nacional de Defesa (END), aprovados pelo Congresso Nacional, respectivamente, em 2005 e 2008, e de suas reformulações em 2012. Na END, declara-se:

O Brasil é pacífico por tradição e por convicção. Vive em paz com seus vizinhos. Rege suas relações internacionais, dentre outros, pelos princípios constitucionais da não intervenção, defesa da paz e solução pacífica dos conflitos (...).

Porém, se o Brasil quiser ocupar o lugar que lhe cabe no mundo, precisará estar preparado para defender-se não somente das agressões, mas também das ameaças. Vive-se em um mundo em que a intimidação tripudia sobre a boa-fé (...).

Estratégia nacional de defesa é inseparável de estratégia nacional de desenvolvimento. Esta motiva aquela. Aquela fornece escudo para esta. Cada uma reforça as razões da outra. Em ambas, se desperta para a nacionalidade e constrói-se a Nação. Defendido, o Brasil terá como dizer não, quando tiver que dizer não. Terá capacidade para construir seu próprio modelo de desenvolvimento (...).

Difícil - e necessário - é para um país que pouco trato teve com guerras convencer-se da necessidade de defender-se para poder construir-se. (Brasil, 2008: 8)

A END baseia-se na noção de que para a independência nacional é essencial a autonomia tecnológica e produtiva na área de defesa, formando a base industrial de defesa nacional.

Esses documentos delimitam o "entorno estratégico" do Brasil como espaço de atuação prioritário de sua política externa e de defesa, definindo a região sobre a qual o Brasil se propõe irradiar a sua influência e projetar sua liderança diplomática, econômica e militar, que engloba a América do Sul, a costa ocidental da África, a Antártida e o Atlântico Sul. Dentro do seu próprio território, o Brasil

${ }^{12}$ No entanto, suas raízes podem ser encontradas nos founding fathers, na Doutrina Monroe (1823) e seu Corolário Roosevelt (início do século XX), que pretendiam, em uma perspectiva estadunidense, afastar as potências europeias do continente de modo a preservá-lo para a hegemonia e controle dos EUA. 
definiu como regiões prioritárias para ocupação econômica e defesa de suas áreas a bacia Amazônica e a bacia do Prata, além da conquista de um acesso múltiplo e contínuo à bacia do Pacífico, por meio da construção de um sistema integrado de transporte, comunicação e defesa do território sul-americano (Fiori, Padula \& Vater, 2013).

As potências tradicionais e emergentes têm promovido uma série de acordos bilaterais e regionais, principalmente diante das complicações persistentes na conclusão da Rodada de Doha da OMC. Com os acordos regionais recém-firmados, EUA e União Europeia procuram aprofundar a regulação em temas já presentes na agenda da OMC, os chamados OMC-plus - regras de origem, salvaguardas, serviços e propriedade intelectual - e em novos temas, os OMC-extra - concorrência, compras governamentais, meio ambiente e legislação trabalhista. Uma diferença relevante é que os EUA e a União Europeia têm procurado firmar acordos focados no aprofundamento de compromissos relativos à propriedade intelectual e nos novos temas, sem discutir subsídios agrícolas. China e Índia têm promovido uma série de acordos, no entanto mais focados na liberalização de mercados, no acesso a investimentos e na regulação de subsídios.

Esses acordos chegam com força à América Latina, e mais especificamente à América do Sul, no entorno estratégico brasileiro. Os acordos bilaterais de livre-comércio realizados entre EUA e Chile, Colômbia e Peru apresentam como característica comum a ampla abrangência de temas. Indo além da redução de tarifas, envolvem questões negociadas na OMC (OMC-plus) e não tratadas no âmbito da organização (OMC-extra), como: regras de origem, salvaguardas, serviços, proteção à propriedade intelectual, transparência regulatória, controle de pirataria, falsificação e invasão virtual, proteção de copyright, patentes e marcas registradas, acesso a compras governamentais, leis de concorrência (e livre acesso a mercados), leis trabalhistas - com incentivo à fiscalização e ao cumprimento das leis contidas na Declaração da Organização Internacional do Trabalho (OIT) de 1998 -, regulação ambiental, comércio eletrônico e melhoria no setor de telecomunicações. Os tratados bilaterais apresentam resoluções que conferem a empresas estadunidenses a ampliação de sua atuação no outro país sem discriminação e a proteção a esses investidores, sem discriminação em relação às empresas nacionais, para estabelecer a livre concorrência (Padula, 2013).

Embora os países subdesenvolvidos tenham se articulado e alcançado a Declaração de Doha para flexibilizar o Trips em favor da área da saúde (Almeida, 2013: 276), ${ }^{13}$ atualmente as grandes

\footnotetext{
${ }^{13}$ Para Almeida (2013: 276): "As implicações do Acordo TRIPS para a saúde pública levaram os países em desenvolvimento a proporem, e obterem, a adoção da Declaração de Doha, cujas flexibilidades seriam 'necessárias à proteção da saúde pública e nutrição'. Isso ocorreu em abril de 2001, quando o governo norueguês sediou uma reunião que incluiu OMS, UNICEF, Banco Mundial, as grandes indústrias farmacêuticas transnacionais e poucas ONGs, para discutir estratégias que possibilitassem melhoria de acesso dos países pobres a drogas e medicamentos de alto custo. Embora a questão de licença compulsória tenha sido considerada, a reunião terminou por aprovar a proposta de 'preços diferenciais' para países de baixa renda, que continuou a favorecer a indústria farmacêutica. Essa proposta foi endossada sete meses depois, na reunião do Conselho de Ministros da OMC, em Doha em 2001, que adotou a Declaração de Doha (o Doha Statement on TRIPS and Public Health), que reafirmou as flexibilidades previstas no Trips para apoiar problemas relacionados à saúde e reiterou os direitos dos países de usarem a licença compulsória para a produção e melhoria do acesso aos medicamentos genéricos. O princípio subjacente a essa Declaração é que a saúde pública teria prioridade sobre as regras do comércio internacional e, para tal, afirma a legitimidade da licença compulsória assim como certas flexibilidades no Acordo TRIPS para países que não dispõem de desenvolvimento industrial. A reunião de Doha comissionou um processo de elaboração de regulamentos para essas situações".
} 
potências, e especialmente os EUA, têm firmado acordos bilaterais e regionais que estabelecem regras e direitos de propriedade intelectual que vão além do Trips (conhecidos como Trips Plus). ${ }^{14}$

Os Estados Unidos têm promovido acordos de livre-comércio e arranjos de integração aberta no hemisfério ocidental, na Ásia-Pacífico e no Atlântico Norte. Assim, tais acordos alcançam cada vez mais o entorno estratégico brasileiro. Na América Latina, os EUA lideraram a criação do Nafta (Área de Livre Comércio da América do Norte) em 1994. Em relação aos países da América do Sul, após o fracasso do seu projeto da Área de Livre Comércio das Américas (Alca) - entravado sob a liderança de Argentina, Brasil e Venezuela na Cúpula de Mar del Plata de 2005 -, têm estabelecido tratados de livre-comércio (TLCs) bilaterais, especialmente com as pequenas economias exportadoras de commodities da costa do Pacífico - Chile e Peru - e com seu aliado estratégico na região - Colômbia. Nas negociações bilaterais, os EUA exercem um poder de barganha mais direto e assimétrico, alcançando maiores vantagens que em negociações multilaterais - como acesso a compras governamentais, investimentos e serviços financeiros, direitos de propriedade intelectual, e mesmo acordos militares. A partir de uma teia de acordos bilaterais, os EUA tentam liderar um bloco econômico liberal na América do Sul, contraposto ao Mercado Comum do Sul (Mercosul) e minando a União de Nações Sul-Americanas (Unasul) - projetos liderados pelo Brasil -, para conter a influência do Brasil e o avanço da China (Fiori, Padula \& Vater, 2013; UNCTAD, 2007).

Com abrangência geográfica mais ampla, os EUA assinaram em 4 de fevereiro de 2016 o acordo da Trans-Pacific Partnership (TPP), ainda a ser aprovado no seu Congresso, e têm liderado as negociações da Transatlantic Trade and Investiment Partnership (TTIP), ${ }^{15}$ que somadas atuam para isolar os Brics - Brasil, Rússia, Índia, China e África do Sul (Padula, 2013; Fiori, Padula \& Vater,

\footnotetext{
14 “A resposta dos EUA e da Europa foi desconsiderar esse acordo negociado na OMC e começar a negociar acordos livres bilaterais e regionais, o que envolve a aceitação de concessões dos países em desenvolvimento, parceiros desses acordos (...). A questão da propriedade intelectual nesses acordos bilaterais e regionais (chamados 'TRIPS plus') proporciona muito mais proteção para as grandes indústrias farmacêuticas do que os TRIPS originais da OMC. (...) Desde 2001 qualquer acordo comercial norte-americano inclui aspectos relativos à proteção do direito de propriedade intelectual dos fármacos por período mais longo que os 20 anos previstos no TRIPS. Esse padrão 'TRIP-plus' erodiu de forma importante as flexibilidades previstas na Declaração de Doha" (Almeida, 2013: 278).

${ }^{15}$ De 11 a 14 de março foi realizada em Bruxelas, Bélgica, a quarta rodada de negociações do Acordo de Parceria Transatlântica de Comércio e Investimento (TTIP, sigla em inglês) entre os Estados Unidos e a União Europeia (UE). Foram registrados progressos nas três áreas principais de negociação. Primeiro, com relação a acesso a mercados, examinaram-se maneiras de avançar para o intercâmbio de ofertas sobre contratação pública e comércio de serviços (tal intercâmbio já havia sido realizado para as mercadorias). Segundo, foram discutidos assuntos relacionados com regulamentação: coerência e compatibilidade regulatória, barreiras técnicas ao comércio e medidas sanitárias e fitossanitárias. Terceiro, deu-se continuidade ao desenvolvimento de enfoques inovadores relacionados com regras sobre desenvolvimento sustentável, padrões trabalhistas e ambientais, comércio de energia e matérias-primas, e facilitação do comércio e procedimentos alfandegários. Deve-se mencionar também que os Estados Unidos e a UE publicaram em conjunto um documento sobre as oportunidades que o TTIP dispõe para as pequenas e médias empresas e como se planeja ajudar essas empresas a aproveitar o acordo. A 15 a rodada ocorreu em outubro de 2016 em Nova York, ainda sem conclusão das negociações.
} 
2013). ${ }^{16}$ O TPP foi a pedra angular da política econômica do governo Obama na Ásia-Pacífico. O acordo inclui Chile, México e Peru, e exclui a China. No âmbito do TPP foi negociado um amplo e ambicioso acordo de liberalização, que envolve amplos pacotes, abrangendo: livre circulação de bens (com eliminação de tarifas em cerca de 11 mil linhas tarifárias), serviços (especialmente financeiros) e investimentos; asseguração do máximo acesso recíproco a compras governamentais; estabelecimento de regras comuns de origem; eliminação de obstáculos ao comércio e ao investimento dentro das fronteiras dos países (com apoio técnico e financeiro dos países do TPP); respeito aos direitos de propriedade; acordos relativos a propriedade intelectual (inclusive em farmacêuticos), visando a reforçar e desenvolver o acordo da OMC sobre os Trips, mas supostamente comprometidos com a Declaração de Doha. O texto negociado garante a um investidor privado o direito de iniciar o processo de resolução de litígios contra um governo estrangeiro em seu próprio direito sob a lei internacional, caso o governo viole tratados ou mude regras de forma a prejudicar o investidor e suas possibilidades de lucro. Sem dúvida, tal texto implica uma violação do princípio da soberania nacional.

Os congressistas estadunidenses ${ }^{17}$ têm mostrado preocupação com a possibilidade de que o TPP se concentre em proteger a propriedade intelectual em detrimento dos esforços para proporcionar o acesso a medicamentos a preços acessíveis nos países em desenvolvimento. Há também um temor de que o TPP não seja suficientemente flexível para acomodar os programas de reembolso de medicamentos não discriminatório e os diversos sistemas de saúde dos países-membros já existentes. Entre diversos exemplos, os opositores do TPP argumentam que as corporações estadunidenses teriam acesso a mercados e minariam esforços para proporcionar o acesso a medicamentos a preços acessíveis no Vietnã, e estariam esperando para enfraquecer a capacidade da Pharmac de obter medicamentos genéricos de baixo custo, forçando a Nova Zelândia a pagar por medicamentos de marca. Médicos e organizações como Médicos Sem Fronteiras também manifestaram preocupação.

As negociações ocorreram em ritmo acelerado, e o presidente Barack Obama assinou o acordo em fevereiro de 2016, dependendo apenas da aprovação do Congresso dos EUA. ${ }^{18}$ As empresas estadunidenses, principalmente a indústria farmacêutica, que tem lobby fortíssimo, mostraram enorme interesse em resguardar seus direitos de propriedade intelectual nos moldes do Trips e ter acesso às

${ }^{16}$ Originado em 2005 como um acordo limitado entre quatro países do Pacífico - Brunei, Chile, Nova Zelândia e Cingapura -, contou com a adesão às negociações de Austrália (2008), Canadá (2012), EUA (2008), Japão (2013), Malásia (2010), México (2012), Peru (2010) e Vietnã (2008). O TPP ganhou relevância na Ásia-Pacífico em novembro de 2009, quando o presidente Obama anunciou a intenção dos EUA de participar de suas negociações para concluir um ambicioso acordo na Ásia-Pacífico (um "novo acordo do século XXI", de "nova geração") e de reforçar a sua participação nas economias dinâmicas da Ásia. Desde então, Washington ditou o ritmo das negociações até sua assinatura em fevereiro de 2016 para o acordo que refletir as suas prioridades econômicas e a ampliação da participação de países da região - como anunciado por Obama.

${ }^{17}$ As informações constantes neste parágrafo estão disponíveis nos seguintes documentos: Letter from 10 Representatives asking for a meeting to discuss IP policies that could undermine public health and access to medicines, 3 August 2011; Letter from Senator Sanders to US Trade Representative Ron Kirk, 1 December 2011; Letter from Representatives Levin, Waxman, McDermott, and Conyers to US Trade Representative Ron Kirk.19 October 2011; Letter from Reps. Lewis, Stark, Rangel, Blumenauer, and Doggett asking that the May $10^{\text {th }}$ agreement serve as a "non-negotiable starting point" for access to medicines, 8 September 2011.

${ }^{18}$ Em 12 de novembro de 2011, os líderes de nove países do TPP - Austrália, Brunei, Chile, Malásia, Nova Zelândia, Peru, Cingapura, Vietnã e EUA - anunciaram a concretização do esboço de um acordo e, após 16 rodadas de negociações e progressos significativos, as negociações estão em ritmo acelerado (cf. USTR, 2011). 
compras governamentais e mercados dos demais países do TPP. É exatamente por isso que reafirmamos que a pedra angular da política econômica da administração Obama na Ásia Pacífico manifesta-se no TPP, para impulsionar

o crescimento econômico dos EUA e apoiar a criação e manutenção de empregos americanos de alta qualidade por meio do aumento das exportações em uma região que inclui algumas das economias mais robustas do mundo e representa mais de $40 \%$ do comércio mundial. (...) [o governo dos EUA] está tentando concluir um acordo forte, que aborda as questões que as empresas norte-americanas e os trabalhadores estão enfrentando no século 21. (USTR, 2011, tradução nossa)

Assim como nas negociações bilaterais, no âmbito do TPP, países com enormes assimetrias se envolvem na negociação de amplos acordos de liberalização, muito além do campo comercial, que almejam assegurar um amplo mercado e posições privilegiadas com ganhos extraordinários para as grandes empresas transnacionais estadunidenses, especialmente as relacionadas à área da saúde. Ao mesmo tempo, minam a possibilidade de florescimento de indústrias nesses países e dificultam a competitividade de empresas de países que não tenham os mesmos acordos, ou deles façam parte, e que poderiam promover suas indústrias ou arranjos cooperativos. Por isso, do ponto de vista das grandes potências, e especialmente dos EUA, é mais viável negociar e costurar tais acordos vantajosos fora da OMC e das negociações multilaterais da Rodada de Doha, onde enfrentam os países subdesenvolvidos de forma organizada (pela oposição do G-20, liderado por Brasil, Índia e China) (Padula, 2013; UNCTAD, 2007).

Tais acordos visam à manutenção da hegemonia (político-militar, econômica, monetário-financeira e ideológica) dos EUA e à preservação da supremacia e/ou à expansão de suas empresas (detentoras de direitos de propriedade intelectual, marcas etc.) e investidores nessas áreas geográficas. O TPP e o TTIP articulam-se aos acordos militares bilaterais com aliados estratégicos na Ásia-Pacífico (como Japão, Coreia do Sul e Filipinas) e a aliança estratégica no Atlântico Norte (Otan), que permitem presença militar dos EUA predominante nestas áreas. Não se pode perder de vista que os acordos e arranjos de livre-comércio promovidos pelos EUA reforçam ainda mais a hierarquia monetária e financeira internacional baseada no dólar, que resguarda o privilégio de emissor da moeda internacional (sem lastro metálico, mas assentada no poder militar estadunidense).

Vale ressaltar que esses mesmos países sul-americanos da costa do Pacífico - Chile, Peru e Colômbia - têm acordos de livre-comércio com vários países, entre os quais China, Coreia do Sul, Índia, Japão e União Europeia (Padula, 2013). Além disso, formam, junto com o México, a Aliança do Pacífico, um acordo de integração regional neoliberal que pretende predominantemente maior aproximação com as economias da Ásia-Pacífico. São economias pequenas e neoliberais que, por sua inserção histórica, política e econômica, desenvolveram economias baseadas na exploração e na renda de recursos naturais, o que influencia suas instituições e coalizões políticas. Na falta de um processo de integração regional coeso e mutuamente benéfico, liderado por uma potência regional com capacidade política e econômica para levá-lo adiante, essas economias seguem a opção neoliberal.

Estados fortes atuam de acordo com os interesses das suas empresas e da manutenção de assimetrias estruturais no sistema internacional, promovendo acordos e usando sua influência em orga- 
nizações internacionais como forma de legitimar seus interesses, construindo regras que lhes sejam favoráveis. No âmbito global, a busca por acesso facilitado a mercados na área de saúde coloca em foco os países emergentes, visto que as previsões são de aumento da participação de seus mercados nas vendas globais de medicamentos, devido à maior incorporação de contingentes populacionais ao mercado consumidor de produtos de saúde. Assim, esse crescimento leva a mudanças nas estratégias competitivas e de inovação das grandes empresas farmacêuticas globais e de seus Estados fortes. Segundo Vargas (neste volume), baseado em estimativas e dados da IMS Health (companhia estadunidense que fornece informações, serviços e tecnologia para as indústrias do cuidado em saúde), "nos próximos anos cerca de dois terços do crescimento das vendas globais do mercado farmacêutico decorrerão do crescimento dos mercados emergentes". Entre 2012-17, "Estima-se que boa parte desse aumento nos gastos globais com medicamentos estará associada com o crescimento do consumo nos mercados emergentes", com destaque para a China em primeiro lugar, seguida de Brasil, Rússia e Índia. Essas estimativas colocam em evidência a importância dos Brics como mercado.

É importante observar que a indústria farmacêutica sofre um processo de crescente concentração, mas essa não é uma tendência recente. Segundo Almeida (2013: 276),

O mercado global de fármacos é altamente concentrado e polarizado: a) 10 grandes empresas transnacionais produzem cerca de $50 \%$ do total do mercado e as 20 corporações mais importantes estão localizadas nos EUA, Reino Unido, Europa e Japão, sendo que cada uma delas tem, em média, cerca de 100 afiliados em mais de 40 países (dos quais 19 são países em desenvolvimento); b) EUA, Europa e Japão respondem por cerca de $75 \%$ das vendas e, incluindo-se a América Latina, essa porcentagem sobe para 85\%; c) os países desenvolvidos produzem e exportam medicamentos de alto valor agregado e protegidos por patentes e os demais países em desenvolvimento importam esses medicamentos, sendo que alguns produzem genéricos de baixo valor ou medicamentos alternativos e tradicionais. Embora os países desenvolvidos sediem essas corporações, o consumo global de medicamentos evidencia que mesmo em alguns desses países (como nos EUA) permanece um déficit de mercado.

Como parte de um amplo processo de fusões e aquisições da indústria farmacêutica, ao longo dos anos 2000 as grandes empresas transnacionais do setor adotaram novas estratégias que envolvem a convergência entre a indústria farmacêutica e a indústria biotecnológica voltada para a saúde; esse processo foi intensificado nos últimos anos em termos de número de operações de fusões e aquisições e de volume médio de recursos envolvidos em cada operação (Vargas, neste volume). No mesmo sentido, como observamos anteriormente, Reis, Landim e Pieroni (2011) destacam o processo de catching up de China, Índia e Israel na rota biotecnológica, por meio de estratégias lideradas pelo Estado, de incentivos regulatórios, de financiamento e de uma política industrial abrangente. ChaseDunn (2005) considera a liderança biotecnológica dos EUA fundamental na sua estratégia estatal de prolongamento de sua hegemonia, e demonstra como o Estado e suas agências lideraram iniciativas para o setor desde a década de 1980. No mercado de medicamentos biológicos, é digna de registro a problemática relacionada aos biossimilares: embora equivalentes aos genéricos dos produtos de origem sintética, no processo de seu registro e produção não é possível aproveitar o mesmo arcabouço regulatório (Vargas, neste volume). 
A análise de mercado revela uma crescente demanda por produtos biotecnológicos e da nanotecnologia, de maior valor agregado e intensidade tecnológica, o que os torna um meio para as grandes empresas do setor farmacêutico seguirem sua rota de crescimento e concentração de mercado e superarem a tendência de redução dos retornos sobre o investimento (inclusive em P\&D). Segundo Ribeiro e Paiva (neste volume), no período de 2004 a 2011 registrou-se uma tendência de crescimento dos depósitos na área de biotecnologia em saúde. Ao mesmo tempo, a indústria de rota biotecnológica apresenta altas barreiras à entrada, por razões de dificuldades tecnológicas, custo de desenvolvimento e produção, o que tende a levar a um mercado concentrado com menor número de empresas e de empresas de maior porte. ${ }^{19}$

Diante da postura agressiva dos Estados fortes, que buscam abrir mercados e garantir e ampliar direitos de propriedade às suas empresas, e das grandes empresas, o padrão de concentração (e não de reversão) da indústria de fármacos tende a se aprofundar, visto que persistem os mesmos fatores que o consolidaram. As grandes empresas farmacêuticas concentram as atividades e os gastos em P\&D tecnológicos, aproveitando escalas de recursos, encaminhando-se cada vez mais para setores de maior valor agregado e intensidade tecnológica, como biotecnologia e nanotecnologia, dominando também esses mercados. No Brasil, as grandes empresas transnacionais do setor de capital estrangeiro concentram seus esforços de inovação em seus países de origem (Vargas, neste volume). ${ }^{20}$ A atividade de inovação tem importância fundamental na sustentabilidade a longo prazo da indústria farmacêutica, principalmente diante do cenário de esgotamento e expiração de patentes na indústria farmoquímica, associada a um aumento da demanda social e a mudanças no perfil epidemiológico. Vale ressaltar que as atividades produtivas e de P\&D tecnológicos das big pharmas têm como objetivo a obtenção de lucros, o que as impede de considerar demandas relacionadas a doenças específicas de países em desenvolvimento, as chamadas doenças negligenciadas.

No Brasil, a demanda social por produtos biotecnológicos tem exercido crescente impacto sobre os gastos do Ministério da Saúde e, diante da baixa produção nacional, feito aumentar o déficit da balança comercial dos produtos de saúde (na qual o aumento das importações desses produtos é maior do que o de outros medicamentos). O número de depósitos de patentes tem crescido, no entanto registra-se um baixo percentual de depósitos de residentes em relação àqueles de não

${ }^{19}$ Conforme destacam Ribeiro e Paiva (neste volume), “com base em informações do Evaluate Pharma, o crescimento das vendas de biológicos foi de $17 \%$ entre 2002 e 2010 , ao passo que o crescimento médio dos demais produtos farmacêuticos foi de 7\%. Fazendo-se uma projeção com essa taxa de crescimento, espera-se que em 2016 os produtos biotecnológicos representem cerca de $21 \%$ das vendas. O indicador desse crescimento é o aumento do número de registros de novos produtos biológicos: em 2010, o registro de novos produtos biológicos nos Estados Unidos da América (EUA) representou 44\% do total de registros novos, contra 35\% em 2002 (...) Espera-se que os medicamentos biotecnológicos passem de cinco para sete entre os dez produtos farmacêuticos mais vendidos".

${ }^{20}$ Para Almeida (2013: 278), "Não existem evidências de reversão desse padrão de concentração da indústria de fármacos ou de sua atuação agressiva, mesmo nos casos de adoção das flexibilidades previstas na legislação. Como os direitos de propriedade intelectual são harmonizados globalmente, tampouco se comprova a promessa de maior investimento direto nos países que assinaram o acordo para o fortalecimento desses direitos. A escalada dos preços dos medicamentos é objeto de grande preocupação para a maioria dos países, sobretudo aqueles em desenvolvimento e os mais pobres. Alguns países - como Índia, Brasil e Tailândia - têm maior capacidade de produção, entretanto, no caso da produção de genéricos na Índia, com preços bem mais baixos que a posiciona como um dos maiores fornecedores dos países de renda média e baixa, as compras e fusões de indústrias pelas transnacionais já começaram a acontecer". 
residentes, com tendência de declínio da participação dos primeiros no período de 2007 a 2011. O governo, até o início de 2016, vinha tomando uma série de medidas para fomentar a produção da rota biotecnológica no país (Ribeiro \& Paiva, neste volume). No entanto, na evolução do cenário nos últimos anos, a tendência é de que o abastecimento nacional se torne cada vez mais dependente de empresas estrangeiras, de seu domínio produtivo e tecnológico, e consequentemente vulnerável em termos econômicos, políticos e de segurança às ações e interesses dessas empresas e de seus Estados fortes. ${ }^{21}$ A produção física e tecnológica nacional no campo biotecnológico poderia ter importantes impactos sobre os gastos do Ministério da Saúde e a universalização do atendimento à demanda, assim como na autonomia estratégica e redução da vulnerabilidade política e econômica externa do Brasil.

Os crescentes gastos com saúde no Brasil nos próximos anos, impulsionados pela transição demográfica associada ao perfil epidemiológico e envolvendo recursos públicos, trazem enormes oportunidades para a criação de vantagens comparativas dinâmicas no CEIS em atividades de maior valor agregado e intensidade tecnológica, tendo em vista a autonomia estratégica e a segurança em saúde do país. Se não for implementado um processo bem-sucedido de formação do CEIS, o aumento dos gastos tende a se transformar em maior concentração de poder, riqueza e tecnologia nas mãos das big pharmas e de seus Estados de origem, assim como em maior dependência e vulnerabilidade externa do país. Na matriz insumo-produto do CEIS, é importante identificar não só a atual participação de importações e empresas estrangeiras no fornecimento de insumos e bens finais, como também as tecnologias e produtos que tendem a ganhar maior importância no futuro, e que por isso terão maior impacto nas demandas sociais do CEIS.

É importante notar que o domínio expansivo (produtivo, tecnológico e de mercado) das grandes empresas transnacionais lhes aufere a oportunidade de moldar a lógica da saúde e do tratamento de doenças, em busca de lucros extraordinários. Por isso é importante que questões éticas sejam observadas e que formas alternativas de medicina e tratamento não sejam descartadas, especialmente no Brasil.

O amplo mercado e o espaço territorial (continental e marítimo), rico em recursos estratégicos, do Brasil despertam interesses de potências externas. A partir de 2003, na política externa brasileira elegeu-se como espaço prioritário de atuação o seu entorno estratégico, que contém um amplo mercado e recursos estratégicos e, inevitavelmente, se choca contra os interesses de potências externas. O entorno estratégico brasileiro envolve o continente sul-americano e, por nossas características marítimas, se estende até a costa ocidental da África subsaariana e à Antártica. Além disso, sua política externa se direcionou para uma maior projeção ao se aproximar de países da América Central e Caribe, da Comunidade de Países de Língua Portuguesa (CPLP), do Brics (grupo marcado pela heterogeneidade entre seus membros) e, de forma geral, privilegiando a cooperação sul-sul (Fiori, Padula \& Vater, 2013).

\footnotetext{
${ }^{21}$ Em Ribeiro \& Paiva (neste volume) é apresentado "o ranking anual dos dez países de origem com maior número de depósitos dentre as patentes de não residentes no período de 2002 a 2011. Em todos os anos os EUA lideram, com mais que o dobro de patentes que o segundo lugar na lista. Nos segundo e terceiro lugares se alternam Japão e Alemanha (sigla DE), com exceção dos anos 2002 e 2003, em que a França aparece em terceiro lugar. Vale destacar a flutuação na posição da França, que em 2004 cai para o nono lugar e depois gradativamente recupera posição, mas sempre com grande variação. Suíça (CH) e Suécia (NL) apresentam, em geral, um bom posicionamento na classificação. E a China (CN) chega a figurar na lista nos anos de 2007 e 2009".
} 
É importante que o Brasil promova segurança e estabilidade no seu entorno estratégico; políticas de cooperação técnica em favor do desenvolvimento dos países dessa área (e diminuição da vulnerabilidade frente a outras potências) têm um papel fundamental por criarem interdependências e afastarem a influência de potências externas, conflitos e movimentos migratórios conturbadores. Ao mesmo tempo, os países do entorno estratégico brasileiro, ao se desenvolverem de forma interdependente com o Brasil, podem gerar oportunidades de desenvolvimento conjunto (planejado) e um mercado mais amplo para o desenvolvimento e inovação da indústria brasileira da área de saúde (CEIS), sem reproduzir os mesmos padrões predatórios do imperialismo das grandes potências e de suas grandes empresas. Por outro lado, a projeção de poder de potências externas no entorno estratégico brasileiro, como se tem registrado - promovendo acordos de livre-comércio de bens e serviços, acesso a investimentos e a compras governamentais, e garantindo significativos direitos de propriedade intelectual, em favor da supremacia de suas grandes empresas e do aumento da dependência e do subdesenvolvimento desses países -, gera um entorno estratégico inseguro e instável para o Brasil, além da perda de oportunidades de mercados e parcerias para seu avanço industrial e cooperativo nessas áreas.

O Brasil é um país superavitário em suas relações comerciais com todos os países sul-americanos (exceto com a Bolívia, em razão do gás natural), exportador de bens de maior intensidade tecnológica e valor agregado e importador de commodities. E no comércio global é um país deficitário, importador de bens de maior intensidade tecnológica e valor agregado e exportador de commodities - uma relação desfavorável (Padula, 2010, 2011). Assim, o mercado sul-americano apresenta enorme potencialidade e um enorme ativo para o florescimento do CEIS no Brasil, aproveitando sua escala e estabelecendo parcerias mutuamente benéficas com os países da região. O mesmo pode ser dito em favor de uma cooperação no âmbito dos Brics, aproveitando seus crescentes mercados e as possibilidades de parcerias tecnológicas - levando em conta que os países-membros têm muitas características e objetivos similares, mas também muitas diferenças entre si.

No âmbito do Brics, é importante salientar seu potencial para a cooperação política em saúde através das tentativas de reformar o sistema internacional e o papel da OMS (frente à OMC). O Brics tem exercido relevante impacto no âmbito da OMS e na agenda internacional de saúde. Os países Brics têm enormes desafios e interesses comuns na agenda de saúde internacional e têm avançado no sentido de estabelecer uma agenda de cooperação e uma posição comum. É possível encontrar uma linha de temas permanentes nas reuniões de ministros da Saúde do Brics, envolvendo: garantia de acesso universal a medicamentos e serviços de saúde (com Brasil, China e Índia liderando a fabricação de medicamentos e vacinas de baixo custo); fortalecimento do sistema de vigilância sanitária; reforma da OMS; flexibilização do Trips; fortalecimento e acesso à saúde nos países em desenvolvimento; transferências e avanço em tecnologias médias (envolvendo biotecnologia e as TICs, por exemplo); estratégicas para doenças transmissíveis; combate e redução de fatores de risco de doenças não transmissíveis (Silva et al., 2014; Acharya et al., 2014; Padula, 2015).

O Brasil possui 60\% da bacia amazônica e a compartilha com mais sete países sul-americanos e a Guiana Francesa, um território ultramarino francês que comporta bases militares estratégicas. A Amazônia é um espaço rico em biodiversidade (entre outros recursos estratégicos), que desperta 
a cobiça externa. O Brasil e os países da região deveriam ter urgência em articular um amplo mapeamento e registro da biodiversidade amazônica (sua variedade genética), pois esta representa uma potencial oportunidade para a engenharia genética, a biotecnologia e a nanotecnologia, inclusive para o desenvolvimento de fitoterápicos e para a absorção de conhecimentos a partir das comunidades tradicionais.

No entanto, o espaço amazônico é subocupado e subdesenvolvido, mal integrado em termos de infraestrutura aos principais centros econômicos e demográficos da América do Sul. Geram-se, assim, oportunidades para a atuação da biopirataria e permite-se que cientistas de outros países conheçam e registrem as espécies presentes na região em seu proveito, garantindo monopólio e propriedade sob o manto do Trips, em desacordo com a valorização dos conhecimentos tradicionais e com a Convenção sobre Biodiversidade Biológica (esta não ratificada por países detentores de tecnologias de ponta, como é o caso dos EUA). A Organização do Tratado de Cooperação Amazônica (OTCA) deveria ser o meio institucional para a articulação entre os países, sob a liderança brasileira. Mas, historicamente, a OTCA enfrenta enormes dificuldades em despertar interesse dos Estados-membros e em ser revitalizada, tornando-se um potencial espaço de penetração de interesses externos na região, inclusive por intermédio de organizações não governamentais que atuam de maneira funcional e sob o financiamento de interesses estrangeiros (Guimarães, 2005). O financiamento de projetos produtivos predatórios, combinados com infraestrutura de corredores de exportação, busca articular os recursos da região aos mercados globais, principalmente da bacia do Pacífico. Ao mesmo tempo, os recursos do pré-sal apresentam oportunidades em termos de geração de recursos financeiros que podem ser utilizados na formação do CEIS. E a formação de mão de obra voltada para engenharia química não absorvida na exploração do pré-sal pode representar um ativo importante. No entanto, tanto o Atlântico sul quanto a Amazônia representam um enorme desafio à segurança territorial brasileira, diante da ação permanente de grandes potências nessas regiões, inclusive a atuação militar dos EUA por meio do estabelecimento de bases militares (na Colômbia, por exemplo), da execução de exercícios militares periódicos e da reativação de sua IV Frota do Atlântico Sul.

O Brasil é o maior país da América Latina, a maior potência tropical e do hemisfério sul. Assim, apesar de sua política externa de projeção de poder ser pacífica e baseada na cooperação, o Brasil inevitavelmente desafiará os interesses de grandes potências em diferentes tabuleiros geopolíticos, o que possivelmente o levará a se envolver em disputas e conflitos de interesses políticos com potências externas (e suas coalizões). Por isso, o país deve se preocupar com sua autonomia estratégica e com sua segurança (no sentido defensivo), estabelecendo um poder dissuasório capaz de repelir ameaças e pressões externas. Em razão da proximidade de interesses políticos e da similaridade de potenciais adversários, os principais parceiros potenciais do Brasil se encontram na América do Sul (Mercosul e Unasul), na África e entre os países do Brics. Uma região onde se concentram recursos e oportunidades, mas onde também estão presentes outras potências, com seus próprios interesses e conflitos, e com suas alianças e apoios, dentro de cada um dos países desse mesmo entorno estratégico. As regiões ricas em recursos estratégicos e com mercados pujantes tendem a ser crescentemente incorporadas como fronteiras geopolíticas da expansão capitalista, sofrendo assédio de grandes potências e suas grandes empresas (privadas e estatais), por serem áreas que contêm mercados e recursos estratégicos 
para o funcionamento da economia, para a expansão das grandes empresas transnacionais e para o desenvolvimento econômico e militar das potências tradicionais e das emergentes.

É ilustrativo mencionar alguns casos que demonstram conflitos potenciais e vulnerabilidades. Não podemos ignorar que todos os setores associados ao CEIS têm sido usados como ferramentas de ação geopolítica das potências centrais. Não nos referimos aqui às ações pontuais da Usaid, Agência dos Estados Unidos para o Desenvolvimento Internacional, ou às agências europeias na África ou mesmo na América Latina e Ásia, em países mais pobres. As disputas de propriedade intelectual e compras governamentais são objeto de impasses nas negociações comerciais multilaterais.

O conflito em torno da liberdade de trânsito de medicamentos genéricos e dos direitos de patentes é um caso ilustrativo. As autoridades europeias realizaram sistemáticas apreensões de medicamentos genéricos em seus portos, restringindo a circulação desses bens essenciais à saúde humana, cujas patentes das grandes empresas multinacionais não encontram direito de proteção nos países de origem e de destino, mas somente direito de propriedade intelectual na Europa. Como os medicamentos se encontravam em trânsito e não se destinavam ao mercado europeu, não caberia a aplicação de direitos de propriedade das empresas farmacêuticas titulares de patentes na Europa, e nem se poderia alegar danos a estas - uma vez que tais patentes ou sequer foram registradas nos países de origem e destino ou expiraram, e que eventualmente o comércio se dá baseado em princípios de saúde pública que prevalecem sobre a propriedade intelectual. Além de violar o Trips e a Declaração de Doha, tais ações arbitrárias e unilaterais violam o artigo V do Gatt, que prevê liberdade de trânsito.

Em 2008, no porto de Roterdã, alegando questões de propriedade intelectual, as autoridades holandesas apreenderam uma carga do genérico Losartan produzido na Índia e destinado ao Brasil. Tal episódio demonstra o grau de acirramento dessa disputa ${ }^{22}$ e como as autoridades europeias colocam a questão da propriedade intelectual acima da saúde pública de outros povos, ou seus interesses políticos e econômicos acima dos interesses socioeconômicos de outros países. Outros carregamentos detidos em portos europeus tinham como destino Nigéria, Vanuatu, Peru, Colômbia, Equador, México e Venezuela. Os carregamentos continham medicamentos essenciais para o tratamento de HIV, doenças coronarianas, esquizofrenia, Alzheimer, colesterol e hipertensão. Obviamente, os atingidos são as populações dos países em desenvolvimento e dos menos desenvolvidos.

A importância dos atrativos portos dos países europeus nas rotas comerciais internacionais - em razão de sua posição geográfica favorável e de seu vigor econômico - aufere a esses países posições importantes em rotas comerciais de bens estratégicos, o que, por sua vez, lhes confere maior poder

\footnotetext{
22 "As apreensões de medicamentos em trânsito têm sido objeto de polêmico debate em diversas instâncias internacionais. O confisco, ocorrido em 4 de dezembro de 2008, de $570 \mathrm{~kg}$ de Losartan Potassium, princípio ativo usado para a produção de medicamentos para o tratamento de hipertensão arterial, recebeu particular destaque. O produto, avaliado em $€ 55$ mil, havia sido negociado entre a empresa indiana Dr. Reddy's e a brasileira EMS e estava a caminho do Brasil, mas não alcançou seu destino final. Apesar de o fármaco não ser protegido por patente nem na Índia nem no Brasil, a carga foi confiscada na Holanda, país onde a multinacional MerckSharp\&Dohme (MSD) detém sua patente em conjunto com a DuPont. A MSD enviou uma carta à Dr. Reddy's por meio de seus advogados em 24 de dezembro de 2008, informando a empresa da retenção e exigindo a renúncia da carga, sob ameaça de destruição do produto. Segundo nota de esclarecimento da Merck do Brasil, a carga retornou à Índia por solicitação da Dr. Reddy's, após permanecer retida por 36 dias no porto de Roterdã" (Reis \& Faria, 2010).
} 
de veto político à circulação desses bens estratégicos/essenciais. Ao mesmo tempo, gera vulnerabilidade nos países dependentes dessas rotas comerciais e bens, caso não possam ou não busquem rotas alternativas.

O caso da influenza A (H1N1) parece-nos emblemático da vulnerabilidade que pandemias podem causar a países que não contem com uma produção autônoma de medicamentos e vacinas. Diante do surto, as potências hegemônicas garantiram em primeiro lugar o atendimento de medicamentos às suas populações, e o governo brasileiro encontrou dificuldades em suprir as necessidades nacionais. No caso de fornecimento de vacinas, as empresas priorizavam contratos já estabelecidos e, diante de pedido da OMS de conceder vacina grátis aos países pobres, concederam-na apenas parcialmente ou a negaram (foi o caso da Novartis). Os casos da influenza A (H1N1) e da SARS demonstraram que, diante de pandemias, as soluções predominantes não são de caráter comunitário (coletivo) e as grandes potências atuavam para garantir seus interesses nacionais, sua estabilidade interna e segurança nacional.

\section{Panorama Nacional: dinâmica de mercado e universalização do acesso à saúde com equidade}

A Constituição de 1988 trouxe a integração, sob a denominação de Seguridade Social, do conjunto das "ações de iniciativa dos poderes públicos e da sociedade destinados a assegurar os direitos relativos à saúde, à previdência e à assistência social", com previsão de fontes específicas para seu financiamento. No texto constitucional se afirma que "a saúde é direito de todos e dever do Estado, garantido mediante políticas sociais e econômicas que visem à redução do risco de doença e outros agravos e ao acesso universal e igualitário às ações e serviços para sua promoção, proteção e recuperação".

Esse componente político também permitiu uma atuação maior do Estado na economia, sem as constantes ameaças dos economistas do mercado. O desmantelamento da União Soviética e a derrota da alternativa socialista deram lugar à vitória do neoliberalismo e às ideias do Estado mínimo, e com elas à tentativa de desmonte de qualquer noção de proteção social.

Ainda assim o setor Saúde movimenta, em média, 8,7\% do PIB (IBGE, 2012), o que evidencia sua importância econômica. Em uma perspectiva economicista, o aumento dos gastos em saúde tem um potencial de incremento no crescimento econômico por seus efeitos multiplicadores, induzindo investimentos em outros setores. Incorporando-se às dimensões sociais do desenvolvimento, como proposto em Sen (2000), o setor ganha ainda mais relevância com a inclusão da mortalidade infantil e expectativa de vida ao nascer como variáveis a serem consideradas na análise das condições de vida de determinado país.

Outra noção a ser acrescentada é a de que uma redução da mortalidade não se acompanha necessariamente de uma redução da incidência de problemas de saúde; pelo contrário, aumenta o número de sobreviventes que estarão sujeitos à ocorrência de problemas de saúde adicionais. Dessa forma, o viés econômico de um debate sobre saúde deve partir da premissa de que quanto mais saúde um povo tem, de mais assistência médica ele precisa. Como corolário, quanto maior o gasto em saúde hoje, maior ele será amanhã. 
Segundo Marco Antonio Vargas (neste volume),

A existência de um modelo de atenção à saúde pautado pelo acesso universal, associada às mudanças nos padrões demográficos e epidemiológicos no país, tem ampliado consideravelmente a demanda por serviços de saúde e pressionado os gastos públicos com medicamentos, principalmente no que se refere à crescente incorporação de terapias baseadas nos avanços da biotecnologia e nanomedicina nas compras do Sistema Único de Saúde (SUS). A busca de competências nessas novas plataformas tecnológicas assume um caráter ainda mais estratégico para o país ao possibilitar o aumento da produção doméstica de medicamentos e fármacos que representam uma parcela significativa do déficit na balança comercial do CEIS

Fica evidente uma forte demanda por produtos e serviços de saúde, a qual deve aumentar, independentemente do direcionamento ideológico do governo. Gadelha e Costa (2013a) elencam diversas iniciativas que, mediante o aumento do uso do poder de compra do Estado, podem contribuir para o desenvolvimento tecnológico em saúde:

1) parcerias para o desenvolvimento produtivo objetivando a transferência de tecnologia entre empresas farmacêuticas nacionais ou estrangeiras e laboratórios oficiais com acesso às compras governamentais;

2) aumento do dispêndio público na compra direta de medicamentos e outros produtos;

3) expansão do Programa Farmácia Popular;

4) associação da estratégia de imunização com a de desenvolvimento tecnológico nacional, fazendo uso do poder de compra do Estado para ter acesso às tecnologias das empresas líderes mundiais.

Gadelha e Costa (2013b: 26) advogam ainda o "uso estratégico, do ponto de vista do desenvolvimento nacional, do poder de compra do Estado, e não apenas de forma racionalmente econômica".

Em sua análise da indústria de base mecânica, eletrônica e de materiais, Maldonado e Oliveira (neste volume) também veem as compras públicas como um agente responsável na indução do setor.

O caráter indutor do desenvolvimento das compras governamentais é tão evidente que, recorrentemente, estas aparecem como um dos impasses nas negociações da Rodada de Doha da Organização Mundial do Comércio.

Outro aspecto ressaltado por Vargas (neste volume) é que,

De maneira geral, as macrotendências, associadas tanto à política de atenção à saúde como ao perfil sociodemográfico e epidemiológico, ressaltam a importância da incorporação das novas plataformas tecnológicas da biotecnologia e da nanotecnologia nas práticas assistenciais em saúde. Tais tendências representam um grande desafio para a base produtiva em saúde do país, seja no tocante ao atendimento das demandas do sistema nacional de saúde, que deve contemplar os princípios de universalidade, integralidade e equidade, seja pela intensificação das pressões competitivas de um sistema produtivo claramente intensivo em conhecimento.

Vargas ainda elenca algumas macrotendências associadas a mudanças nos padrões de demanda, de regulação e de tecnologia: 1) mudanças associadas à política de atenção à saúde - desospitalização, 
medicina personalizada, valorização da qualidade de vida, modelos de financiamento público/privado; 2) mudanças associadas ao perfil socioeconômico e demográfico - envelhecimento populacional, novos padrões de vida, impacto de mudanças ambientais, urbanização; 3) impacto das novas plataformas tecnológicas na biotecnologia e nanotecnologia - biologia molecular (genômica, proteômica etc.), bioinformática e bioimagem, nanobiotecnologia, ciências de materiais, sistemas de informação de alto desempenho e neurociência.

A forma como essa demanda crescente será suprida está diretamente vinculada ao próprio padrão de desenvolvimento e inserção internacional a que o Brasil almeja, tanto como potência regional quanto como membro de uma coligação de potências em nível global (Brics). Nesse sentido, é preciso observar:

1) a capacidade nacional de ofertar os produtos e serviços necessários não apenas para atender à demanda doméstica, mas também para concorrer internacionalmente com a produção das demais potências, que pode inclusive ser um vetor estratégico de nossa inserção geopolítica; e

2) a concorrência internacional das transnacionais fomentadas inclusive pelas estratégias geopolíticas de seus países-sede.

No tocante à capacidade de atender à demanda nacional, é preciso ainda definir setores estratégicos nos quais o desenvolvimento tecnológico é imprescindível para a segurança do país. A capacidade de produção autônoma, ou reversão do parque industrial - que permita uma produção em larga escala e em curto período de vacinas, antibióticos e quaisquer outros medicamentos necessários ao combate a epidemias potencialmente globais -, é fundamental.

Além dos economicistas, é preciso incorporar outros aspectos quando se trata de abordar o problema. O já citado caso da influenza A (H1N1), em que os países avançados garantiram primeiro o atendimento a suas populações e o governo brasileiro encontrou dificuldades em suprir as necessidades nacionais, parece-nos emblemático. A epidemia do ebola de 2014 acendeu um sinal de alerta. Leigh Phillips coloca a questão de maneira bem clara:

Mas o ebola é um problema que não tem sido resolvido porque quase não há dinheiro envolvido em sua solução. É uma doença não lucrativa. (...)

Em tal situação, já não teríamos sequer que discutir se a prevenção da malária, do sarampo ou da poliomielite mereceria maior prioridade; poderíamos focalizar tanto as doenças renomadas quanto as negligenciadas, ao mesmo tempo. Não há garantias de que abrir a torneira do financiamento público produza imediatamente um bom resultado, mas, no momento, as empresas farmacêuticas privadas sequer tentam. (...)

Nossa preocupação aqui não está meramente no fato de que a recusa das big pharma a se envolverem em pesquisa e desenvolvimento de vacinas e antibióticos para as doenças tropicais negligenciadas é grotescamente imoral ou injusta, mas no fato de que a produção de uma abundância de novos produtos e serviços potenciais, que de outra forma poderiam beneficiar nossa espécie e expandir o reino da liberdade humana, são bloqueados devido à letargia do livre mercado e à falta de ambição. 
Concentrar-se em uma vacina ou remédio é fundamental. Contudo, fazer isso sem também dar atenção à deterioração da saúde pública e da infraestrutura geral em toda a África ocidental, bem como às condições econômicas mais abrangentes que contribuem para a maior probabilidade de surtos de doenças zoonóticas como o ebola, é, na melhor das hipóteses, usar um balde para escoar a água de um barco furado e afundando. (Phillips, 2014, tradução nossa)

Não obstante, Garret (2013) alerta para os riscos do duplo uso da pesquisa em biotecnologia. Ela traz, inclusive, o caso de uma pesquisa de 2011 com o vírus H5N1 que fez com que este patógeno, que em princípio infectaria apenas aves, pudesse afetar seres humanos. Naquele momento, pouco menos de seiscentas pessoas haviam sido contaminadas pelo vírus, mas com uma taxa de mortalidade de 59\% - a autora lembra que a gripe espanhola, que matou mais de 50 milhões, tinha uma taxa de mortalidade de 2,5\%. Garret acrescenta a informação de que o governo da Indonésia se recusou a compartilhar as amostras do H5N1 que se espalhava em suas fronteiras, alegando que as farmacêuticas ocidentais tentariam patentear quaisquer descobertas para obter altos lucros vendendo vacinas e medicamentos a altos preços para países pobres.

Garret lembra que não haverá consenso sobre o duplo uso entre os cientistas e os especialistas em segurança, exemplificando com o vigoroso debate sobre a destruição do vírus da varíola 35 anos após sua erradicação. Não haveria clareza sobre os benefícios da pesquisa em biotecnologia, mas os seus defensores alegam que seu potencial é tão revolucionário quanto o da tecnologia da informação, cuja revolução está em curso. Uma ação agressiva contra o duplo uso poderia estancar o desenvolvimento tecnológico, tanto mais porque tal contenção incluiria o controle excessivo sobre o fluxo de informações na internet, por exemplo.

O que isso significa é que os líderes políticos não devem esperar por clareza e informação perfeita, nem correr para desenvolver controles restritivos, nem confiar na autorregulação científica. Em vez disso, eles devem aceitar que a revolução da biologia sintética está aqui para ficar, monitorá-la de perto e tentar tomar as medidas apropriadas para conter alguns dos seus riscos mais óbvios, como o vazamento acidental ou liberação deliberada de organismos perigosos. (Garret, 2013, tradução nossa)

Ou seja, para além das questões econômicas envolvidas em uma análise geopolítica, a segurança estratégica do país deve ser uma variável central no processo de decisão relacionado às políticas públicas do CEIS. O grau de autonomia de um país depende de sua capacidade de resistir a pressões externas. Na Estratégia Nacional de Defesa elaborada pelo governo brasileiro, em que são abordadas as questões de segurança nacional, está registrado que

Todas as instâncias do Estado deverão contribuir para o incremento do nível de Segurança Nacional, com particular ênfase sobre: (...) as medidas de defesa química, bacteriológica e nuclear, a cargo da Casa Civil da Presidência da República, dos Ministérios da Defesa, da Saúde, da Integração Nacional, das Minas e Energia e da Ciência e Tecnologia, e do GSI-PR, para as ações de proteção à população e às instalações em território nacional, decorrentes de possíveis efeitos do emprego de armas dessa natureza; (...) a execução de estudos para viabilizar a instalação de um centro de pesquisa de doenças tropicais para a região amazônica, a cargo dos Ministérios da Defesa, da Ciência e Tecnologia, da Saúde e órgãos de saúde estaduais e municipais; (...) medidas de defesa contra pandemias. (Brasil, 2008: 65) 
Ainda que o foco do debate esteja dirigido para a saúde, a pesquisa e o desenvolvimento para construir capacidade de resposta, tanto para os casos de conflitos (bélicos ou não) quanto para epidemias ou pandemias, podem gerar como externalidade um aumento da capacidade dissuasória do país por meio de descobertas que permitam o domínio sobre processos de elaboração de armamento químico ou biológico.

Em países emergentes como o Brasil a política industrial é necessária. Os países retardatários que encaram com determinação e coragem processos de catching up fazem uso de instrumentos públicos para promover o seu desenvolvimento econômico. As políticas liberais defendidas pelos países mais desenvolvidos constituem suas estratégias de hegemonia e não devem ser vistas pelos países subdesenvolvidos como noções ideais de orientação política (Chang, 2002).

Além disso, deve-se observar ainda a concorrência internacional das empresas transnacionais fomentadas inclusive pelas estratégias geopolíticas de seus países-sede. Particularmente na indústria farmacêutica temos um oligopólio internacional e poucos países têm capacidade de desenvolvimento de um complexo industrial associado. Na base mecânica, eletrônica e de materiais, temos a tecnologia de ponta diretamente associada a sinergias com setores da indústria bélica.

O big business farmacêutico passa atualmente por uma reformulação do seu modelo de negócios, em resposta à crise do modelo anterior relacionada, pelo lado da oferta, ao menor lançamento de novas moléculas no mercado (queda da produtividade de P\&D) diante da expiração conspícua de patentes dos produtos mais rentáveis (blockbusters) e à maior concorrência com os medicamentos genéricos. Pelo lado da demanda, a maior exigência por custo-efetividade por parte dos pagadores de saúde, públicos ou privados, médicos e pacientes, em relação aos produtos inovadores oferecidos pela indústria farmacêutica é outro fator de pressão sobre o business (Burrill \& Company, 2013).

A crise financeira global de 2008 deu início a um processo de endividamento dos Estados, que se viram obrigados a intervir nos bancos, seguradoras e também em empresas não financeiras para mitigar os efeitos desastrosos da crise que afetou principalmente as finanças públicas dos países da tríade EUA, Europa Ocidental e Japão. Em outras partes do mundo, como China, Índia e Israel, novos players farmacêuticos, focados em genéricos, estão emergindo e ganhando cada vez mais participação no mercado mundial (Reis, Landin \& Pieroni, 2011).

O big business farmacêutico, em resposta, promoveu um amplo processo de consolidação, com enormes fusões e aquisições até o ponto em que as empresas já estão se tornando grandes demais para serem compradas. E, além disso, passaram a focar em novos nichos de mercado restringindo seu portfólio a poucos produtos de alto valor agregado, consumidos em pequenos volumes e utilizados em tratamentos muito caros (Burril \& Company, 2013).

Outras estratégias foram adotadas na tentativa de mitigar as perdas do business nesse novo cenário, como, por exemplo, uma atuação litigiosa mais agressiva para estender o período das patentes, estímulo para o uso off label de medicamentos e o forte lobby para acordos internacionais ligados a propriedade industrial e intelectual.

O novo modelo de negócios tem por base os avanços da biologia molecular e conjuga tratamentos com características mais personalizadas. Uma estratégia muito recente tem sido o investimento em 
um nicho conhecido como doenças órfãs, doenças raras que afetam um número muito pequeno de pessoas (Guimarães, 2014). Esse novo modelo está no cerne das preocupações de Carlos Diegues em seu artigo "Seleção artificial" (2008). O business está se voltando cada vez mais para um público de alta renda, negligenciando a realidade da saúde mundial e os problemas que afetam a maioria da população mundial.

Há um crescente distanciamento entre os interesses da saúde como um bem público e os interesses comerciais das grandes corporações farmacêuticas que comandam o processo de inovação. As doenças e medicamentos pouco rentáveis são negligenciados, não obstante afetarem grande número de pessoas e serem extremamente importantes para a medicina (Guimarães, 2014).

São exemplos desse fenômeno as doenças negligenciadas e o problema das superbactérias, resistentes aos antibióticos existentes. O retorno da tuberculose em sua forma fatal em regiões em que havia sido erradicada nos anos 1950, Europa e EUA, representa um grave retrocesso. Os antibióticos não recebem investimentos significativos há três décadas, por não serem rentáveis (Homedical, 2012). Os interesses da saúde e os interesses dos mercados de capitais estão em caminhos opostos, e a contradição levada ao absurdo poderia resultar no surgimento do Homo ricus de Carlos Diegues.

Esse modelo é, a longo prazo, incompatível com um modelo de saúde pública universal como o Sistema Único de Saúde (SUS), em um país de 200 milhões de habitantes. Custo-efetividade e tratamentos mais eficazes, que busquem a cura das doenças e não a sua cronicidade, são fundamentos sólidos para a conformação de um complexo industrial da saúde inovador, porém com o foco mais voltado para os reais interesses da saúde da população como um todo e menos para obter lucros extraordinários.

O setor Saúde, por ser based on science, requer a articulação das políticas científicas, tecnológicas e industriais, que devem, juntas, ser capazes de estruturar um sistema de inovação (infraestrutura e recursos para $\mathrm{P} \& \mathrm{D}$ ) e um sistema produtivo (base industrial) que atenda às necessidades de saúde do país, principalmente do SUS. ${ }^{23}$

Desde 2003, o governo brasileiro promove o fomento ao complexo industrial da saúde brasileiro, impulsionado pelas políticas adotadas pelo Ministério da Saúde, por intermédio de sua Secretaria de Indústria, Ciência e Tecnologia (Brasil, 2003). A política de desenvolvimento industrial promovida pelo Ministério da Saúde, como exemplo do que se pretende com o uso de políticas industriais, está estruturando o setor de biotecnologia brasileiro. A prioridade da política industrial brasileira para a saúde até o início de 2016 era a construção de uma indústria de biotecnologia moderna, aproveitando oportunidades de catching up que se darão no período 2014-2020, quando as patentes dos principais medicamentos biotecnológicos expirarão. Com a instituição de um sistema regulatório pró-desenvolvimento industrial e o uso do poder de compra do Estado como indutor do processo (e garantidor de uma demanda mínima) - combinando o capital privado nacional (capacidade empresarial) e o apoio financeiro do Estado (financiamento com custo compatível com o equilíbrio

\footnotetext{
${ }^{23}$ Segundo Vargas e colaboradores (2013: 34), "Em âmbito internacional a indústria farmacêutica é um oligopólio diferenciado baseado nas ciências, sendo a diferenciação de produtos pautada no esforço de P\&D por um lado, e na força de marketing, por outro".
} 
econômico-financeiro do projeto) -, chega-se a um equilíbrio complexo entre a oferta nacional de produtos biotecnológicos e as vantagens obtidas para o sistema nacional de saúde, que deverá se beneficiar de preços mais baratos. O uso do instrumento das PDPs e a liderança das grandes empresas farmacêuticas brasileiras de capital nacional, que estão capitalizadas e propensas a diversificar seus investimentos, representam para o país a abertura de um novo campo profissional.

Uma iniciativa com esse grau de complexidade, e status de política de Estado, requer continuidade política. Construir um setor de biotecnologia não é tarefa trivial e, portanto, para que a política obtenha sucesso é imprescindível o acompanhamento do desempenho competitivo das novas empresas no âmbito das políticas públicas de fomento industrial.

Todavia, não basta criar um setor e fomentar empresas, esse é apenas o primeiro passo de um processo de longuíssimo prazo. É preciso promover a competitividade do setor e inseri-lo numa trajetória de progresso tecnológico, que resulte para o país em novas instituições que possam dar suporte ao esforço de pesquisa, desenvolvimento e inovação esperados para o sucesso do projeto; ou, do contrário, a indústria se tornará obsoleta e um passivo oneroso para o país.

A política industrial não será bem-sucedida sem uma coordenação eficiente entre as diversas instituições envolvidas, públicas e privadas. O conceito de complexo industrial se aplica muito bem ao setor Saúde pelas suas diversas interfaces com as diversas áreas do conhecimento a serviço da medicina humana. A indústria ligada à saúde, seja no segmento de fármacos, em suas duas plataformas de conhecimento principais, a química e a biologia, seja no segmento de equipamentos médicos, compõe com o sistema de inovação um tecido extenso e complexo, que requer mão de obra altamente qualificada.

A indústria de saúde é intensivamente baseada em conhecimento científico e depende, competitivamente, da inovação para sobreviver. O desenvolvimento de uma indústria nacional de saúde no Brasil depende do concomitante desenvolvimento de um complexo industrial, científico e tecnológico em bases nacionais.

A aposta na biotecnologia faz parte de uma trajetória da indústria farmacêutica brasileira iniciada com a lei dos genéricos e a criação da Agência Nacional de Vigilância Sanitária, a Anvisa. A partir de 2003, sobre as bases da Política Industrial, Tecnológica e de Comércio Exterior, as mudanças implementadas passaram a produzir efeitos e as empresas brasileiras de capital nacional tiveram que se adequar à nova institucionalidade. Com a criação do Profarma, programa de apoio do BNDES ao complexo industrial da saúde, as empresas brasileiras puderam ter acesso aos recursos financeiros para os investimentos demandados pela nova legislação (Vargas, neste volume).

Ao longo da última década, o mercado farmacêutico brasileiro cresceu de modo significativo graças ao fortalecimento do segmento de medicamentos genéricos e ao maior acesso da população ao consumo de medicamentos. Em 2013, o mercado brasileiro passou à sexta posição mundial, chegando à casa dos R $\$ 50$ bilhões (IMS Health, 2013).

A introdução dos genéricos foi uma oportunidade para a indústria brasileira e ampliou o mercado consumidor pelos efeitos redistributivos da redução de preços, impulsionada, por sua vez, 
pelo aumento da concorrência e pelos menores custos para o lançamento de produtos genéricos no mercado (Gomes et al., 2014).

As empresas farmacêuticas de capital nacional conseguiram aproveitar as oportunidades, e o seu desempenho pode ser verificado pelo aumento de market share no mercado nacional - de 33\% em 2003 para 57\% em 2013 - e pelo aumento dos investimentos em inovação, que, segundo a Pesquisa de Inovação realizada pelo Instituto Brasileiro de Geografia e Estatística (IBGE), passaram de 0,5\% da receita em 2003 para 2,7\% em 2011, ao passo que a média da indústria brasileira ficou estagnada. Nesse mesmo período, o número de empresas de capital nacional entre as dez maiores se elevou de uma para quatro companhias (Gomes et al., 2014). Entretanto, segundo Quental e colaboradores,

embora necessário, o incentivo aos genéricos, por si só, não incentiva os fármacos, uma vez que as empresas nacionais de genéricos não se dispõem a entrar nesse segmento, bastante diferente daquele em que atuam até o momento.

O incentivo aos genéricos também não toca na questão da inovação, do desenvolvimento de novas moléculas, o cerne da competição na arena mais nobre e lucrativa da indústria farmacêutica. Ao contrário, não há nem mesmo a possibilidade de inovação incremental em genérico, pois ele deixaria de ser "cópia idêntica" do medicamento de referência, se bem que a própria produção do genérico constitua uma inovação para a empresa produtora.

Não se pode apostar que se incentivando os medicamentos e as empresas de genéricos estas se engajariam no desenvolvimento de atividades de P\&D voltadas para o desenvolvimento de novas moléculas - poucas têm essa intenção. A arena competitiva é outra, os fatores críticos de sucesso são outros e as empresas de genéricos não se sentem nem capacitadas nem atraídas a atuar nessa outra arena. Os incentivos para a inovação têm que ser específicos. (Quental et al., 2008: 625-626)

Em função das mudanças estruturais que ocorrem no país, ligadas ao processo de transição demográfica e epidemiológica, a perspectiva de crescimento do mercado farmacêutico brasileiro se mantém bastante promissora. Segundo o IMS Health (2013), a taxa de crescimento médio anual deverá se situar numa faixa de $13 \%$ a $16 \%$ até 2018 , tornando o Brasil o quarto maior mercado mundial.

Inúmeras companhias brasileiras (Bionovis, Libbs, Orygen, Cristália e Biomm) estão se constituindo e se estruturando, em razão da atuação estatal para promover o desenvolvimento da biotecnologia moderna no Brasil em três grandes frentes: o uso do poder de compra do Estado, a regulação e o apoio financeiro diferenciado (Ibac Brasil, 2013).

Refletindo essa prioridade, o BNDES criou em 2013 o subprograma Profarma Biotecnologia. Nos últimos dois anos foram contratados 11 projetos, totalizando um apoio de $\mathrm{R} \$ 1,3$ bilhão. A carteira total de projetos do Profarma, que apoiou o complexo industrial da saúde de 2003 até julho de 2014, foi, nesse período, de R \$ 4,8 bilhões, em 116 operações.

No segmento de equipamentos médicos, na última década o crescimento do mercado brasileiro também atingiu taxas de dois dígitos. Há uma enorme defasagem no atendimento à população, portanto há uma demanda reprimida que deverá crescer a partir do momento que os hospitais começarem 
a investir. O país importa no setor de equipamentos médicos $68 \%$ do que consome internamente, e, no entanto, a indústria brasileira seria capaz de atender a 95\% das necessidades (Abimo, 2014).

As políticas públicas para o setor devem fortalecer o mercado nacional, que é $60 \%$ público, e incentivar a indústria para que se torne mais competitiva e melhore sua inserção internacional. O país exportou cerca de US\$ 800 milhões em 2013, mas teve déficit comercial de US\$ 4,1 bilhões.

A concorrência que efetivamente ameaça a indústria brasileira se dá com as grandes multinacionais, que são apoiadas pelos seus respectivos Estados de origem, onde estão fincadas as raízes de seu capital. O caso recente de intervenção da opinião pública e do governo ingleses na tentativa de compra da britânica AstraZeneca pela americana Pfizer mostrou, claramente, como os interesses nacionais contam e influenciam nas transações e negócios empresariais (Armitage, 2014). Está em jogo a preservação dos empregos e das atividades mais estratégicas da indústria ligadas à pesquisa, desenvolvimento e inovação (PD\&I) no país. Além disso, pesou o fato de a empresa ter sido objeto de apoio de políticas públicas e ter recebido recursos públicos, importantes para sua trajetória, que provavelmente seriam desperdiçados, do ponto de vista nacional, caso a aquisição pela Pfizer se concretizasse.

Os recursos de que o país precisa dispor para estruturar e organizar um complexo industrial da saúde dinâmico requer a formação e treinamento de mão de obra qualificada e a constituição de uma infraestrutura (capital fixo) adequada. A descoberta de uma nova entidade terapêutica ou o desenvolvimento de um novo equipamento médico para diagnóstico requer pesquisa científica básica. E o financiamento desses investimentos, que envolve grande montante de recursos, na maioria dos países desenvolvidos concentra-se em fontes públicas. Em países subdesenvolvidos e periféricos como o Brasil, a importância do investimento público é ainda mais fundamental, pelas especificidades do setor Saúde e pela própria condição do subdesenvolvimento.

Após a descoberta e o registro de patente de uma nova molécula é necessário submetê-la aos testes pré-clínicos e clínicos até a obtenção de registro ou autorização da autoridade sanitária para sua comercialização. Como base para a evolução dessa indústria requer-se o desenvolvimento de um sistema de inovação (Freeman, 1995) que permita que se realize no Brasil a P\&D das empresas brasileiras. Pelas razões tratadas na primeira seção deste capítulo, no âmbito da economia política internacional, esses objetivos estão circunscritos ao desenvolvimento nacional.

A indústria brasileira pode encontrar novos campos de investimento em nichos de mercado e desenvolver competências com seus próprios esforços em áreas em que os países desenvolvidos não têm interesse ou vantagens comparativas, como é o caso das doenças negligenciadas e da biodiversidade.

Nos últimos dez anos a indústria farmacêutica brasileira de capital nacional está traçando uma trajetória de forte crescimento. As empresas desse setor estão capitalizadas e têm maior capacidade financeira para investir. Numa divisão de trabalho entre setor público e privado, o Estado provê um arranjo de políticas públicas favorável que ajude a promover a indústria, e o setor privado nacional deve ser capaz de liderar os investimentos na expansão da indústria e apoiar o desenvolvimento da capacidade de P\&D no Brasil, demandando, crescentemente, esses serviços internamente (Quental et al., 2013). 
Um dos principais problemas para o desenvolvimento do setor de serviços de P\&D no Brasil está na falta de demanda das empresas brasileiras. Em cada etapa do pipeline há barreiras de todas as ordens - operacionais, institucionais, técnicas, profissionais etc. - e em todas elas há problemas estruturais de fundo que inviabilizam o pleno desenvolvimento do país como um todo (Quental et al., 2013).

Os diagnósticos para nossos problemas estão relativamente bem mapeados e são conhecidos; a maior dificuldade está na capacidade de organização para promover as reformas estruturais que permitam ao Brasil dar um salto e resgatar integralmente sua dívida social.

Nossa particularidade como principal potência tropical nos permite avançar em setores em que temos, além das vantagens comparativas no sentido clássico, o que poderíamos chamar de vantagens estratégicas. Há um conjunto de enfermidades chamadas de doenças tropicais, que apenas os países tropicais enfrentam e sobre as quais os laboratórios das grandes farmacêuticas atreladas às necessidades das potências do hemisfério norte não realizam pesquisas; mesmo quando o fazem, a pesquisa de ponta encontra-se no Brasil, como é o caso da doença de Chagas.

O desenvolvimento de produtos para o segmento de doenças negligenciadas permitiria ao Brasil responder a uma demanda real interna e também aumentar sua inserção internacional, tanto econômica quanto política. Econômica, por promover um aumento de exportações nesse setor. E política porque permite aumentar a capacidade do Brasil de, por meio de cooperações internacionais, se contrapor à hegemonia imposta aos países tropicais e do hemisfério sul, contribuindo para a conformação de um cenário internacional multipolar.

Ademais, a biodiversidade é um ativo brasileiro único. Ela representa uma vantagem comparativa para o país, e transformá-la em riqueza pelos e para os brasileiros é um enorme desafio. A legislação brasileira (medida provisória 2.186-16, de 23/08/2001) que regulava o acesso, o aproveitamento econômico e a repartição dos benefícios com as comunidades provedoras e detentoras de conhecimentos tradicionais, a título de proteger os direitos dessas comunidades acabou por inviabilizar o desenvolvimento de produtos por empresas brasileiras.

Além disso, a legislação não impedia a exportação de elementos da biodiversidade brasileira para estudo, pesquisa e desenvolvimento de produtos fitoterápicos por empresas estrangeiras. Muitos projetos de empresas brasileiras foram cancelados por falta de incentivos para investir; as comunidades provedoras, por sua vez, não se beneficiaram com a exploração de conhecimentos sobre a biodiversidade por elas detidos; e a biopirataria, especialmente a realizada por interesses estrangeiros, capazes de se apropriar dos benefícios da biodiversidade brasileira, permanece incólume.

Os obstáculos criados pela regulação inviabilizaram a P\&D de novos fármacos e também o desenvolvimento do setor de fitoterápicos. Nesse segmento, a baixa e decrescente participação desses produtos no mercado farmacêutico brasileiro é um exemplo inequívoco de desperdício econômico.

Os mercados no mundo nos quais os fitoterápicos mais crescem são exatamente os mercados dos países mais desenvolvidos - EUA, Alemanha e Japão, onde nossos produtos de maior valor agregado têm menor espaço. Se conseguirmos, de forma justa e equilibrada, estruturar uma indústria brasileira de fitoterápicos competitiva, o Brasil poderá se tornar um dos principais produtores e fornecedores de produtos fitoterápicos para o mercado mundial. 
As dificuldades inerentes ao arcabouço regulatório da MP 2.186-16 levaram à mudança da legislação. Em 20 de maio de 2015 foi decretada e sancionada a lei n. 13.123, que alterou o marco regulatório de acesso, repartição de benefícios e aproveitamento econômico da biodiversidade brasileira. A nova lei substitui a necessidade de autorização prévia por um cadastro, estabelece critérios mais objetivos para a repartição de benefícios e regulariza o passivo criado pela legislação anterior. Com essas medidas espera-se tornar o ambiente regulatório brasileiro mais favorável à P\&D e produção de novos fármacos e fitoterápicos no país.

Outro fator de extrema relevância é o recente movimento de consolidação entre as grandes farmacêuticas, que tem gerado uma especialização setorial e criado monopólios por enfermidade. Exemplo disso foi a recente troca de ativos entre a Novartis e a GSK, duas das maiores farmacêuticas do mundo (Copley \& Sandle, 2012). Obviamente que esses acordos não se operam apenas nos planos empresariais, mas estão também inseridos dentro das estratégias nacionais dos países-sede. A concentração não apenas em um país, mas em uma única empresa, coloca o Brasil em uma situação de fragilidade que deve ser evitada a todo custo.

Essas questões podem ser mais bem elucidadas por meio de uma análise mais detalhada dos aspectos econômicos. O mercado farmacêutico mundial, em 2012, atingiu a cifra de US\$ 962 bilhões. A crise global de 2008 impactou fortemente a indústria mundial, que passou a olhar com mais atenção para os mercados emergentes, que têm crescido a taxas bastante expressivas. Entre as principais causas do maior dinamismo dos mercados emergentes destacam-se a elevação da renda, o envelhecimento da população, o maior peso das doenças crônicas degenerativas no perfil epidemiológico e o fortalecimento dos sistemas públicos de saúde (Vargas, neste volume).

Tabela 1 - Mercado mundial por regiões - 2008-2012 (em US\$ bilhões)

\begin{tabular}{|r|r|r|r|r|r|r|}
\hline Ano & $\begin{array}{c}\text { Receita } \\
\text { Mundo }\end{array}$ & $\begin{array}{c}\text { América do } \\
\text { Norte }\end{array}$ & Europa & Japão & $\begin{array}{c}\text { Ásia, África, } \\
\text { Austrália }\end{array}$ & $\begin{array}{c}\text { América } \\
\text { Latina }\end{array}$ \\
\hline 2008 & 773 & 312 & 248 & 77 & 91 & 47 \\
\hline 2009 & 808 & 322 & 248 & 90 & 103 & 46 \\
\hline 2010 & 856 & 335 & 245 & 97 & 127 & 53 \\
\hline 2011 & 956 & 347 & 265 & 111 & 165 & 67 \\
\hline 2012 & 962 & 366 & 231 & 115 & 173 & 77 \\
\hline TCAC & $5,6 \%$ & $4,1 \%$ & $-1,7 \%$ & $10,8 \%$ & $17,5 \%$ & $13,4 \%$ \\
\hline
\end{tabular}

TCAC - Taxa de crescimento anual composta.

Fonte: IMS Health, 2013.

A International Federation of Pharmaceutical Manufacturers \& Associations apresentou alguns dados interessantes sobre a indústria mundial de medicamentos (IFPMA, 2013). Com base nos dados disponíveis nesse documento, elaboramos a Tabela 2 selecionando os países em que vendas no mercado doméstico de medicamentos fossem superiores a US\$ 7 bilhões ou as exportações ultrapassassem US\$ 4 bilhões. Os dados permitem observar que há países que, mesmo com um mercado 
interno modesto, conseguiram uma posição relevante no cenário internacional. O Brasil faz parte de um grupo de países que conjugam déficit comercial bastante relevante no setor com um volume pouco relevante de exportações. Os EUA, por exemplo, apresentam um déficit comercial significativo e ao mesmo tempo grande volume de exportações.

Tabela 2 - Vendas farmacêuticas. Países selecionados - 2011

\begin{tabular}{|c|c|c|c|c|c|c|c|}
\hline País & $\begin{array}{c}\text { Vendas } \\
\text { farmacêuticas } \\
\text { domésticas } \\
\text { US\$ bilhões }\end{array}$ & $\begin{array}{l}\text { Vendas farma- } \\
\text { cêuticas } \\
\text { domésticas } \\
\text { US\$ per capita }\end{array}$ & $\begin{array}{c}\text { Vendas } \\
\text { farmacêuticas } \\
\text { domésticas } \\
\text { \% gasto em saúde }\end{array}$ & $\begin{array}{l}\text { Exportações } \\
\text { farmacêuticas } \\
\text { US\$ milhões }\end{array}$ & $\begin{array}{l}\text { Importações } \\
\text { farmacêuticas } \\
\text { US\$ milhões }\end{array}$ & $\begin{array}{c}\text { Balança } \\
\text { comercial } \\
\text { farmacêutica } \\
\text { US\$ milhões }\end{array}$ & $\begin{array}{l}\text { Importações/ } \\
\text { vendas } \\
\text { domésticas + } \\
\text { exportações }\end{array}$ \\
\hline Alemanha & 55,148 & 671,00 & 14,60 & $61.926,00$ & $44.793,50$ & $17.132,50$ & $38,26 \%$ \\
\hline Argentina & 7,582 & 186,00 & 20,10 & 784,50 & $1.743,80$ & $-959,30$ & $20,84 \%$ \\
\hline Austrália & 13,268 & 587,00 & 10,50 & $3.446,00$ & $9.959,60$ & $-6.513,60$ & $59,59 \%$ \\
\hline Bélgica & 8,507 & 791,00 & 15,70 & $45.278,50$ & $32.171,00$ & $13.107,50$ & $59,81 \%$ \\
\hline Brasil & 28,718 & 146,00 & 12,70 & $1.134,60$ & $6.189,10$ & $-5.054,50$ & $20,73 \%$ \\
\hline Canadá & 26,057 & 759,00 & 13,60 & $5.212,10$ & $11.860,10$ & $-6.648,00$ & $37,93 \%$ \\
\hline China & 66,863 & 50,00 & 18,70 & $2.580,30$ & $9.970,10$ & $-7.389,80$ & $14,36 \%$ \\
\hline Cingapura & 0,716 & 138,00 & 6,90 & $4.864,70$ & $1.452,10$ & $3.412,60$ & $26,02 \%$ \\
\hline Coreia do Sul & 14,796 & 306,00 & 19,60 & 895,10 & $3.548,90$ & $-2.653,80$ & $22,62 \%$ \\
\hline Dinamarca & 2,437 & 437,00 & & $7.735,80$ & $3.275,20$ & $4.460,60$ & $32,20 \%$ \\
\hline Espanha & 28,009 & 603,00 & 19,20 & $13.391,00$ & $13.282,30$ & 108,70 & $32,08 \%$ \\
\hline Estados Unidos & 337,100 & $1.077,00$ & 12,40 & $35.342,20$ & $62.447,20$ & $-27.105,00$ & $16,77 \%$ \\
\hline França & 48,664 & 771,00 & 14,90 & $35.482,00$ & $23.660,70$ & $11.821,30$ & $28,12 \%$ \\
\hline Grécia & 9,347 & 821,00 & 30,80 & $1.196,00$ & $4.046,90$ & $-2.850,90$ & $38,38 \%$ \\
\hline Holanda & 9,380 & 563,00 & 10,70 & $15.047,60$ & $11.880,30$ & $3.167,30$ & $48,63 \%$ \\
\hline Índia & 15,643 & 13,00 & 21,00 & $8.079,10$ & $1.359,40$ & $6.719,70$ & $5,73 \%$ \\
\hline Israel & 1,978 & 262,00 & 10,80 & $7.003,20$ & $1.519,50$ & $5.483,70$ & $16,92 \%$ \\
\hline Itália & 34,630 & 570,00 & 16,40 & $16.960,30$ & $17.987,90$ & $-1.027,60$ & $34,87 \%$ \\
\hline Japão & 127,377 & $1.007,00$ & 21,20 & $3.353,50$ & $19.049,40$ & $-15.695,90$ & $14,57 \%$ \\
\hline México & 12,978 & 113,00 & 18,30 & $1.579,40$ & $4.212,50$ & $-2.633,10$ & $28,94 \%$ \\
\hline Polônia & 11,257 & 294,00 & 29,70 & $2.076,20$ & $5.662,10$ & $-3.585,90$ & $42,47 \%$ \\
\hline Reino Unido & 38,334 & 614,00 & 16,50 & $31.902,40$ & $24.478,40$ & $7.424,00$ & $34,85 \%$ \\
\hline Rússia & 20,653 & 145,00 & 24,20 & 297,60 & $12.730,80$ & $-12.433,20$ & $60,77 \%$ \\
\hline Suécia & 6,597 & 699,00 & 13,10 & $9.916,70$ & $4.485,30$ & $5.431,40$ & $27,16 \%$ \\
\hline Suíça & 7,629 & 991,00 & 10,40 & $52.662,20$ & $19.652,30$ & $33.009,90$ & $32,60 \%$ \\
\hline Turquia & 10,242 & 139,00 & 20,60 & 531,80 & $4.510,90$ & $-3.979,10$ & $41,87 \%$ \\
\hline Venezuela & 8,449 & 287,00 & 56,60 & 39,20 & $2.645,70$ & $-2.606,50$ & $31,17 \%$ \\
\hline Média & 35,273 & 482,96 & 18,43 & $13.656,22$ & $13.280,56$ & 375,67 & $32,16 \%$ \\
\hline
\end{tabular}

Fonte: IFPMA, 2013. 
O mercado brasileiro relacionado ao complexo industrial da saúde, que inclui o mercado farmacêutico e de equipamentos médicos, alcançou em 2013 a marca de R $\$ 70$ bilhões, crescendo a uma taxa média de $12 \%$ ao ano nos últimos cinco anos.

Tabela 3 - Mercado brasileiro. Complexo industrial da saúde - 2009-2013 (em R\$ milhões)

\begin{tabular}{|c|c|c|c|c|c|c|}
\hline Setor & 2009 & 2010 & 2011 & 2012 & 2013 & TCAC \\
\hline Farmacêutico & 33.090 & 38.563 & 40.329 & 44.876 & 50.000 & $11 \%$ \\
\hline Equipamentos médicos & 10.920 & 12.850 & 13.950 & 16.770 & 19.070 & $15 \%$ \\
\hline $\begin{array}{l}\text { Complexo industrial da } \\
\text { saúde }\end{array}$ & 44.010 & 51.413 & 54.279 & 61.646 & 69.070 & \\
\hline
\end{tabular}

TCAC - Taxa de crescimento anual composta.

Fontes: Abiquif, 2014; Abimo, 2014.

No Brasil, as causas desse crescimento estão associadas à introdução dos medicamentos genéricos no mercado, ao aumento do gasto público em saúde e à elevação do poder de compra de parcela mais pobre da população. Pelo lado da indústria, as empresas brasileiras de capital nacional souberam aproveitar o boom e foram paulatinamente ganhando participação no mercado de saúde nacional. No mercado de genéricos, em 2012, das cinco maiores empresas no mercado brasileiro, em faturamento, quatro são empresas brasileiras de capital nacional. Ademais, no âmbito das farmacêuticas de modo geral, de acordo com o ranking "Maiores e melhores" elaborado pela revista Exame, das cinco maiores empresas farmacêuticas instaladas no país, três são estrangeiras: a norte-americana Pfizer e as suíças Novartis e Roche (Maiores..., 2014).

Tabela 4 - Participação das empresas farmacêuticas de capital nacional no mercado brasileiro de genéricos

\begin{tabular}{|l|l|c|r|r|r|r|}
\hline \multicolumn{1}{|c|}{ Laboratório } & Origem & \multicolumn{1}{|c|}{$08 / 11$} & \multicolumn{1}{c|}{$08 / 12$} & Crescimento & Participação \\
\hline 1 & Grupo EMS & Brasil & 2.551 .832 .490 & 3.504 .897 .747 & $37,35 \%$ & $33 \%$ \\
\hline 2 & Grupo Sanofi Aventis & França & 2.592 .710 .209 & 3.100 .610 .851 & $19,59 \%$ & $29 \%$ \\
\hline 3 & Eurofarma & Brasil & 506.971 .912 & 783.912 .795 & $54,63 \%$ & $7 \%$ \\
\hline 4 & Hypermarcas & Brasil & 414.615 .785 & 664.399 .598 & $60,24 \%$ & $6 \%$ \\
\hline 5 & Aché & Brasil & 405.645 .271 & 509.177 .849 & $25,52 \%$ & $5 \%$ \\
\hline 6 & Pfizer & EUA & 312.298 .752 & 454.884 .747 & $45,66 \%$ & $4 \%$ \\
\hline 7 & Novartis & Suíça & 294.056 .052 & 382.053 .849 & $29,93 \%$ & $4 \%$ \\
\hline 8 & Prati Donaduzzi & Brasil & 105.181 .876 & 254.732 .959 & $142,18 \%$ & $2 \%$ \\
\hline 9 & Sankyo & Japão & 178.200 .713 & 156.119 .638 & $-12,39 \%$ & $1 \%$ \\
\hline 10 & Merck Serono & Suíça & 107.737 .972 & 128.711 .999 & $19,47 \%$ & $1 \%$ \\
\hline Total 10 primeiros & & 7.469 .251 .033 & 9.939 .502 .032 & $33,07 \%$ & $94 \%$ \\
\hline Mercado genérico total & & 7.820 .190 .784 & 10.531 .847 .213 & $34,68 \%$ & $100 \%$ \\
\hline
\end{tabular}

Elaboração: Sindusfarma, 2014. Fonte: IMS Health (PMB Plus, 2013). 
Esse grande crescimento, não obstante o bom desempenho das empresas brasileiras, principalmente no segmento farmacêutico de genéricos, foi acompanhado por um grave desequilíbrio externo. Em sua análise de importações e exportações, publicada no documento Conta-Satélite de Saúde Brasil 2007-2009, o IBGE evidencia a vulnerabilidade do país.

$\mathrm{Na}$ Tabela 5 se demonstra um importante déficit comercial no setor Saúde, o qual se acentua nos setores de produtos farmoquímicos, medicamentos para uso humano e aparelhos e instrumentos para usos médico-hospitalares.

Tabela 5 - Balança comercial de bens e serviços de saúde, segundo os produtos. Brasil - 2007-2009

\begin{tabular}{|c|c|c|c|c|c|c|c|c|c|}
\hline \multirow{3}{*}{ Produtos } & \multicolumn{9}{|c|}{ Balança comercial de bens e serviços de saúde (1.000.000 $\mathrm{R} \$$ a preços correntes) } \\
\hline & \multicolumn{3}{|c|}{2007} & \multicolumn{3}{|c|}{2008} & \multicolumn{3}{|c|}{2009} \\
\hline & Exportação & Importação & Saldo & Exportação & Importação & Saldo & Exportação & Importação & Saldo \\
\hline TOTAL & 355.672 & 315.217 & 40.455 & 414.295 & 408.534 & 5.761 & 355.653 & 360.847 & -5.194 \\
\hline TOTAL DA SAÚDE & 2.230 & 11.572 & -9.342 & 2.592 & 13.671 & -11.079 & 3.014 & 14.898 & -11.884 \\
\hline $\begin{array}{l}\text { Produtos } \\
\text { farmoquímicos }\end{array}$ & 187 & 2.089 & -1.902 & 223 & 2.728 & -2.505 & 288 & 2.610 & -2.322 \\
\hline $\begin{array}{l}\text { Medicamentos } \\
\text { para uso humano }\end{array}$ & 817 & 5.704 & -4.887 & 1.042 & 6.445 & -5.403 & 1.368 & 7.252 & -5.884 \\
\hline $\begin{array}{l}\text { Medicamentos } \\
\text { para uso } \\
\text { veterinário }\end{array}$ & 311 & 870 & -559 & 383 & 1.100 & -717 & 404 & 1.312 & -908 \\
\hline $\begin{array}{l}\text { Materiais para } \\
\text { usos médicos, } \\
\text { hospitalares e } \\
\text { odontológicos }\end{array}$ & 294 & 174 & 120 & 310 & 192 & 118 & 321 & 204 & 117 \\
\hline $\begin{array}{l}\text { Aparelhos e } \\
\text { instrumentos } \\
\text { para usos } \\
\text { médicos, } \\
\text { hospitalares e } \\
\text { odontológicos }\end{array}$ & 573 & 2.705 & -2.132 & 569 & 3.175 & -2.606 & 563 & 3.484 & -2.921 \\
\hline $\begin{array}{l}\text { Serviços de } \\
\text { atendimento } \\
\text { hospitalar }\end{array}$ & 48 & 30 & 18 & 65 & 31 & 34 & 70 & 36 & 34 \\
\hline
\end{tabular}

Fonte: elaboração própria com base em IBGE, 2012.

A vulnerabilidade brasileira é apresentada de forma evidente na Tabela 6 . 
Tabela 6 - Déficit comercial do complexo industrial da saúde. Brasil - 2003-2012 (em US\$ milhões FOB)

\begin{tabular}{|c|c|c|c|c|c|c|}
\hline Ano & Biológicos & Medicamentos & $\begin{array}{c}\text { Insumos } \\
\text { Farmacêuticos }\end{array}$ & $\begin{array}{c}\text { Cadeia } \\
\text { Farmacêutica }\end{array}$ & EMHO & Total \\
\hline 2003 & 410 & 844 & 697 & 1.951 & 629 & 2.580 \\
\hline 2004 & 492 & 976 & 829 & 2.297 & 662 & 2.959 \\
\hline 2005 & 465 & 1.110 & 862 & 2.437 & 877 & 3.314 \\
\hline 2006 & 642 & 1.345 & 870 & 2.857 & 1.179 & 4.036 \\
\hline 2007 & 724 & 2.046 & 1.297 & 4.068 & 1.639 & 5.707 \\
\hline 2008 & 1.111 & 2.208 & 1.665 & 4.984 & 2.155 & 7.138 \\
\hline 2009 & 1.273 & 2.126 & 1.667 & 5.066 & 2.232 & 7.298 \\
\hline 2010 & 2.284 & 2.533 & 1.825 & 6.642 & 3.034 & 9.676 \\
\hline 2012 & 2.154 & 2.893 & 1.657 & 6.703 & 3.353 & 10.056 \\
\hline
\end{tabular}

Fontes: Aliceweb/MDIC (Brasil, 2014); Abiquifi, 2014.

Em outra análise interessante, o IBGE apresenta a participação das importações na oferta total de cada um dos setores (Tabela 7).

Tabela 7 - Participação das importações na oferta total. Brasil - 2007-2009

\begin{tabular}{|l|c|c|c|}
\hline \multicolumn{1}{|c|}{ Produtos } & \multicolumn{2}{c|}{ Participação das importações na oferta total } \\
\hline & 2007 & 2008 & 2009 \\
\hline TOTAL DA SAÚDE & $4,50 \%$ & $4,80 \%$ & $4,60 \%$ \\
\hline Produtos farmoquímicos & $82,50 \%$ & $87,10 \%$ & $82,40 \%$ \\
\hline Medicamentos para uso humano & $10,00 \%$ & $10,00 \%$ & $9,80 \%$ \\
\hline Medicamentos para uso veterinário & $17,30 \%$ & $20,80 \%$ & $22,20 \%$ \\
\hline $\begin{array}{l}\text { Materiais para usos médicos, hospitalares e } \\
\text { odontológicos }\end{array}$ & $5,90 \%$ & $5,60 \%$ & $5,30 \%$ \\
\hline $\begin{array}{l}\text { Aparelhos e instrumentos para usos médicos, } \\
\text { hospitalares e odontológicos }\end{array}$ & $22,40 \%$ & & \\
\hline
\end{tabular}

Fonte: IBGE, 2012. 
Identifica-se aí uma relevante vulnerabilidade comercial, particularmente no setor de farmoquímicos. Vargas, neste volume, também identifica o "déficit estrutural na balança comercial dos segmentos de medicamentos, fármacos e hemoderivados" e chama atenção para um dado particularmente preocupante na balança comercial brasileira de antibióticos, que é um déficit no segmento de medicamentos e no de insumos farmacêuticos.

Neste volume, Maldonado e Oliveira também indicam um crescente déficit na balança comercial de equipamentos e materiais, inclusive com risco de extinção de empresas. Aliás, esse quadro se agrava nos produtos com maior intensidade tecnológica.

Em contraponto às nossas fragilidades, é preciso atentar também para as potencialidades. Gadelha e Costa (2013a, 2013b), Vargas (2013) e Maldonado e Oliveira (neste volume) afirmam que um dos principais vetores que podem alavancar o CEIS é o poder de compra do Estado. Entretanto, a descentralização das compras públicas no atual modelo do SUS dilui sobremaneira essa capacidade. Portanto, é necessária a concentração do poder de compra de modo a reforçar o caráter indutor dessa ação governamental.

Não se pode também olvidar as próprias vantagens comparativas brasileiras naturais e construídas. O Brasil está na fronteira tecnológica da neurociência graças às pesquisas desenvolvidas no Instituto Internacional de Neurociências de Natal Edmond e Lily Safra, na Fundação Osvaldo Cruz e nos institutos de Bioquímica Médica e de Biofísica Carlos Chagas Filho, ambos da Universidade Federal do Rio de Janeiro, entre outras instituições. Ademais, o país tem um potencial natural para o desenvolvimento da biotecnologia, e o crescimento exponencial da economia do petróleo tem permitido a formação de um número de engenheiros químicos muito além da capacidade de absorção pelo setor petroleiro. O próprio estudo da IFPMA (2013) mostra instituições brasileiras como absorvedoras de transferências de tecnologia.

Por fim, o Brasil faz parte de uma coligação de potências com um peso cada vez maior na geopolítica mundial, o Brics, e tem papel fundamental na estratégia de integração da América do Sul via Unasul e Mercosul. As ações do país devem ser sempre coordenadas dentro de uma estratégia comum com esses parceiros. Eventuais necessidades de atendimento à demanda interna que a oferta não seja capaz de suprir devem ser atendidas preferencialmente por nações inseridas nessas parcerias estratégicas.

\section{Próximos Vinte Anos}

Nos próximos anos, o sistema interestatal tende a se tornar cada vez mais competitivo e conflituoso, com a expansão das potências emergentes - China e Índia -, a retomada, pela Rússia, de uma política de expansão, a crescente oscilação política e divisão da Europa, os surgimentos de Estados, coalizões de Estados e grupos políticos contestadores na periferia, e a política de manutenção e prolongamento da atual ordem hegemônica por parte dos EUA. Por isso, deve-se acelerar a busca por acesso a mercados e recursos estratégicos na periferia do sistema, incluindo cada vez mais a América do Sul e a África (Fiori, 2013). 
A hegemonia dos EUA será cada vez mais contestada e os estadunidenses se lançarão, cada vez mais, em uma estratégia de expansão para prolongar essa hegemonia. Temos uma Europa débil e sob a tutela dos EUA (e seu braço militar da Otan) e, ao mesmo tempo, com forte dependência energética da Rússia. Esta última, junto com Brasil, China, Índia e África do Sul, tende a se articular diante da perda de poder relativo dos EUA - e China e Rússia já têm ganhado espaço político e se articulado no Conselho de Segurança da ONU, e firmado importantes acordos bilaterais (inclusive nos campos energético e de comércio e financiamento em moedas locais) (Escobar, 2014).

Independentemente de suas escolhas, o Brasil enfrentará a crescente projeção de poder estatal, especialmente dos EUA e da China, e a crescente competição de grandes empresas transnacionais no seu entorno estratégico, apoiados em grandes acordos por acesso facilitado a recursos estratégicos e mercados, envolvendo liberalização comercial de bens e serviços, compras governamentais, liberdade e proteção de investimentos, garantia e ampliação de direitos de propriedade e especialmente de propriedade intelectual. Esse quadro levará a desafios progressivos na possibilidade de exportações e internacionalização de empresas brasileiras, podendo até mesmo prejudicar o processo de formação do CEIS, caso este almeje contar com a ampla escala de um mercado regional sul-americano e com o mercado africano. Além disso, continuará o processo de crescentes fusões e aquisições e trocas de ativos para segmentação e especialização de mercados, nos quais as big pharmas se expandirão e concentrarão, cada vez mais, o mercado e a propriedade intelectual, e avançarão na rota biotecnológica e na nanotecnologia. Em todo caso, a importância das indústrias biotecnológica e nanotecnológica continuará crescendo, a indústria de equipamentos e materiais continuará sendo fundamental e as tecnologias da informação e comunicação (TICs) serão crescentemente importantes. Assim, as escolhas políticas do Estado brasileiro serão fundamentais para sua autonomia estratégica e segurança sanitária, ou, por outro lado, para sua vulnerabilidade política e econômica no sistema internacional (Vargas, neste volume).

Sobretudo na agenda de saúde internacional, as grandes potências continuarão a agir, pressionadas por suas grandes empresas, para a manutenção de regras no sistema internacional que sejam favoráveis à continuidade da expansão e concentração de mercado. Trata-se, portanto, de uma atuação incisiva e contrária a ações que não sejam condizentes com as regras de manutenção do status quo, ou as desafiem seja por questões de saúde, sociais, humanitárias ou protecionistas, ou de desenvolvimento, autonomia estratégica e segurança nacional. Tal quadro sugere a tendência de crescentes conflitos em questões de saúde no âmbito internacional, relativos a comércio de bens e serviços, investimentos e direitos de propriedade intelectual. No âmbito das organizações internacionais Conselho de Segurança da ONU, OMC, OMS -, as grandes potências continuarão se articulando em torno dos seus interesses e marginalizando políticas contrárias.

Os mercados emergentes tendem a ganhar importância nos próximos anos. A política de inserção desses países nos acordos e negociações, no mercado e nos investimentos internacionais será fundamental (Vargas, neste volume). Do contrário, seu crescimento econômico e seus crescentes mercados podem se transformar em maior dependência e vulnerabilidade externa, e não em autonomia estratégica, transferindo recursos públicos para grandes empresas transnacionais sediadas em países centrais. No âmbito do Brics, China e Índia têm levado adiante estratégias bem-sucedidas de 
catching up na rota biotecnológica. Negociando de forma conjunta, os países emergentes alcançam maior poder de barganha em negociações internacionais e maior força para desafiar os interesses de potências externas e de grandes empresas, o que revela o importante papel de blocos de integração. Embora nos próximos vinte anos os EUA devam continuar sendo a principal potência global (em termos políticos, culturais, militares, tecnológicos e monetário-financeiros), a crescente competição entre potências concorrentes certamente abrirá espaço para negociações políticas que busquem favorecimentos em termos de investimentos, financiamentos e transferências tecnológicas.

O fato é que, nos próximos vinte anos, se o Brasil almeja um projeto de desenvolvimento autônomo e de projeção externa, especialmente para o seu entorno estratégico, no qual a formação do CEIS avance dentro da concepção de autonomia estratégica e segurança sanitária, inevitavelmente colidirá com as estratégias e os interesses de grandes potências e de potências emergentes, e de suas grandes empresas, abrindo espaços para cooperação e gerando conflitos. Tal posicionamento, ainda que condizente com a tradição pacífica da política externa brasileira, demanda a defesa de reformas nas regras e instituições do sistema internacional (e algumas vezes não as cumprir em favor da soberania nacional) e uma postura ativa do Estado na regulação interna e na formação de arranjos institucionais em prol da produção física e científico-tecnológica, estabelecendo políticas que não correspondem ao interesse das grandes empresas e de seus Estados. No âmbito da política interna, além de políticas específicas para o CEIS, uma política macroeconômica que privilegie metas de crescimento e emprego, impulsionada pelo papel do investimento público, pode ser um importante alicerce. E no âmbito das relações externas, o Brasil não poderá deixar de constituir um poder dissuasório condizente com a dimensão e as ambições do país, onde há uma oportunidade de articulação entre o desenvolvimento da base industrial de defesa e do CEIS, especialmente se a formação de ambos continuar sendo vislumbrada nos documentos estratégicos e políticas do governo.

A volta às políticas vigentes nos anos 1990 nos levaria a uma política econômica cada vez mais restritiva e subordinada aos mercados internacionais e suas grandes empresas. A política externa privilegiaria uma relação próxima e colaborativa com as grandes potências, os grandes investidores e empresas internacionais, atuando de forma colaborativa em relação às regras e organizações internacionais, de forma coerente com a agenda política internacional pautada pelos Estados fortes. Tal postura se apoiaria na construção de instituições e regras favoráveis aos interesses do capital privado internacional, com o objetivo de atraí-lo. E, assim, tornaria o país cada vez mais vulnerável e dependente das suas relações exteriores, ao sabor dos interesses das grandes potências e de seus investidores privados. Tais opções não levariam à constituição do CEIS e, no máximo, as empresas brasileiras se dedicariam a atividades de montagem ou de menor valor agregado, baseadas em inovações incrementais.

No entanto, também temos a possibilidade de que governos com projetos de autonomia estratégica esbarrem em constrangimentos internos e externos (articulados entre si), ou seja, na falta de capacidade política para implementá-los. Isso pode resultar até mesmo em uma política macroeconômica que mescle elementos restritivos e expansivos em prol do crescimento econômico, restringindo a atuação do investimento público e do planejamento estatal, tornando-se óbices à construção do CEIS e configurando um quadro de crescente dependência tecnológica, financeira e comercial, apesar do 
incremento da economia e do setor produtivo. No âmbito da política de defesa e da política externa, apesar da intenção de projeção de poder, a falta de capacidade e de bases internas tende a interferir na capacidade de projeção e influência no sistema internacional.

Como já dito aqui, Estados fortes abrem mercados para garantir e ampliar direitos de propriedade às suas empresas e as grandes empresas aprofundam o padrão de expansão e concentração (e não de reversão) da indústria de fármacos sob controle das big pharmas. Assim, independentemente do grupo político que o governe, o Brasil não tem como se isolar desse cenário. E as prospecções que fazemos para o próximo período devem considerar o dilema popular "cabeça de sardinha ou rabo de baleia". Nesse sentido, para projetar os cenários futuros do país, assumimos que, no tocante à autonomia estratégica e à segurança em saúde, o Estado brasileiro poderá ser conduzido em três circunstâncias diferentes:

1) Na direção da construção de um CEIS baseado nos princípios de autonomia estratégica e segurança em saúde como parte de segurança nacional, articulado ao desenvolvimento da indústria militar, buscando reformas no sistema internacional, formando alianças contestadoras da atual ordem hegemônica e projetando-se para o seu entorno estratégico. Tal postura política em relação ao CEIS (e sua articulação com a indústria militar) implica resistir às pressões que virão dos interesses das multinacionais atraídas pelo pujante mercado de saúde brasileiro, e, portanto, enfrentar as articulações das grandes potências em favor de suas empresas e da expansão e concentração do seu capital. Essa política de formação do CEIS demandaria uma política macroeconômica voltada para o desenvolvimento econômico, liderada pelo investimento público e pelos mecanismos de financiamento estatais.

2) Continuidade das políticas atuais - uma política de boas intenções e baixa efetividade - que procura, com a permanência dos problemas identificados e o agravamento de alguns deles, fomentar a indústria nacional de saúde nos ramos dos genéricos e impulsionar inovações incrementais, com a ampliação do parque industrial em setores com tecnologias já difundidas e crescente participação tecnológica, produtiva e comercial de empresas transnacionais, mas sem capacidade de se aprofundar e avançar nas tecnologias de maior valor agregado e intensidade tecnológica. Ainda assim, há a possibilidade de explorar o potencial das doenças negligenciadas (em razão de as margens de lucro não serem atraentes para o capital internacional) e da biodiversidade. Este cenário pode se combinar com uma continuidade na política macroeconômica restritiva baseada em metas de inflação, tendo a realização de superávits primários e a taxa de juros como variáveis de ajuste, não concretizando a devida atenção à área de saúde e o correspondente financiamento. Ou com alguns elementos de uma política macroeconômica mais voltada para o desenvolvimento.

3) Mudanças políticas em favor de maior abertura econômica, participação mínima do Estado e colaboração com as regras propostas pelas grandes potências globais nas organizações internacionais, tentando estabelecer um marco regulatório com o objetivo de atrair o capital privado estrangeiro e as grandes empresas globais, aprofundando a inserção histórica do país na divisão internacional do trabalho baseada na produção e comercialização de commodities de baixo valor agregado, com crescente vulnerabilidade externa e dependência política. Ainda assim, neste cenário, também há a possibilidade de explorar o potencial das doenças negligenciadas, mas não a biodiversidade, setor em que se abrirá cada vez mais 
espaço para participação do capital estrangeiro. Neste quadro, as políticas macroeconômicas se tornariam ainda mais restritivas, com maiores metas de superávit primário e juros, e a capacidade de financiamento do setor Saúde ficaria muito reduzida.

As projeções para as próximas duas décadas dependem das escolhas concernentes às políticas internas e à política externa a serem feitas pelos governos brasileiros que cheguem ao poder. Estas, por sua vez, dependem das coalizões políticas internas, da distribuição de poder no sistema internacional e da economia política global. No Brasil, ainda não temos uma política de Estado, e sim de governo, o que significa que as escolhas de políticas podem mudar de acordo com a coalizão política que chegar ao poder, sem qualquer garantia de continuidade.

\section{Conclusão}

O CEIS, por sua importância social, econômica, tecnológica, política e de segurança, deve ser constituído com base em uma estratégia liderada pelo Estado brasileiro, colocando como questão central a busca pela autonomia estratégica e pela segurança sanitária, como parte da segurança nacional. Uma questão-chave é a possibilidade de firmar parcerias com Estados no seu entorno estratégico e no âmbito dos Brics, aproveitar o mercado regional sul-americano e africano, e trabalhar maior articulação entre o CEIS e a base industrial de defesa, nos campos produtivo e tecnológico.

As potências tradicionais e as potências emergentes tratam a indústria de saúde como um setor estratégico. Potências emergentes como a China e a Índia têm mostrado um processo de catching up bem-sucedido; EUA e China mostram a importância da integração entre o complexo industrial-militar e a indústria de saúde.

Ao mesmo tempo:

1) O sistema interestatal tem passado por uma aceleração permanente de sua competição, com as potências tradicionais e emergentes buscando cada vez maior acesso e controle de mercados e recursos - processo que não deixa escolha ao Brasil e ao seu entorno estratégico quanto a se envolver ou não nessa crescente disputa, restando-lhes a opção quanto a participar de forma ativa ou subordinada.

2) A indústria de saúde global tem registrado uma continuidade na sua tendência à concentração de propriedade, produção de tecnologias de ponta (patentes) e comércio nas mãos das big pharmas, as quais têm cada vez mais se direcionado para os setores de biotecnologia e nanotecnologia, nos seus processos de fusões e aquisições. Além disso, tal processo tem sido reforçado pela troca de ativos entre empresas que objetivam a segmentação e a especialização de mercados.

3) Os mercados emergentes (especialmente dos Brics) tendem a apresentar a maior taxa de crescimento nos últimos anos.

4) Como resultante das três afirmações anteriores, as grandes potências tradicionais e as principais potências emergentes têm construído grandes acordos para garantir acesso a mercados. Os EUA têm procurado incluir outros temas além dos comerciais - como acesso a mercados e compras governamentais e propriedade intelectual -, o que tende a 
concentrar cada vez mais mercados nas mãos de suas empresas, e isso já alcança o entorno estratégico brasileiro. Nesse sentido, ganha destaque a conclusão do acordo Trans-Pacific Partnership (TPP).

A forma como a demanda crescente por produtos médicos será suprida está diretamente vinculada ao próprio padrão de desenvolvimento e inserção internacional que o Brasil pretende, como potência regional e como membro de uma coligação de potências em nível global (Brics).

A opção do Brasil por uma indústria de saúde (CEIS) robusta e articulada, capaz de atender à sua população em todo o território, de forma autônoma, e impulsionar reformas nas regras e instituições do sistema internacional, colocará o país cada vez mais em conflito com os interesses das grandes empresas transnacionais e das grandes potências, não só no seu próprio mercado, mas também no seu entorno estratégico.

Argumentamos aqui em favor de uma política macroeconômica voltada para o desenvolvimento e o financiamento da área de saúde, nos termos da Constituição Federal, destacando o papel de compra do Estado e as parcerias com o setor privado e empresas estrangeiras. Uma estratégia liderada pelo Estado é condição necessária, mas não suficiente. É preciso que este implemente políticas e arranjos institucionais eficientes e identifique e direcione políticas claras e coesas para os nichos estratégicos de atuação.

A indústria farmacêutica brasileira, baseada na produção de genéricos e similares, percorreu uma trajetória de forte crescimento de 2004 a 2014, associado a um aumento do desequilíbrio e da vulnerabilidade externa brasileira, e se mostra cada vez mais dependente da produção e da tecnologia estrangeiras para atender a suas necessidades. Assim, esse modelo parece esgotado, em razão da crescente importância de medicamentos de maior valor unitário e de maior valor agregado e intensidade tecnológica, bem como da limitação das indústrias do setor no que diz respeito à inovação e ao desenvolvimento de novas moléculas. Esses medicamentos, além de atrair a inserção das grandes empresas globais, têm exercido crescente impacto nas compras do Estado e na balança comercial brasileira. O Brasil faz parte de um grupo de países que conjuga déficit comercial bastante relevante no setor com um volume pouco relevante de exportações.

No Brasil, o significativo déficit comercial no setor Saúde se destaca nos setores de produtos farmoquímicos, medicamentos para uso humano e aparelhos e instrumentos para usos médicos hospitalares. Identifica-se aí uma importante vulnerabilidade comercial e um crescente déficit estrutural, particularmente no setor de farmoquímicos, fármacos e hemoderivados, antibióticos e de insumos farmacêuticos, equipamentos e materiais; neste, inclusive, com risco de extinção de empresas, quadro que se agrava nos produtos com maior intensidade tecnológica.

Aqui identificamos como nichos a biotecnologia e a nanotecnologia, com a produção de insumos, vacinas e antibióticos; o aproveitamento de nossa biodiversidade e o mercado de fitoterápico; a atenção às doenças negligenciadas - não só para o mercado brasileiro; e a produção articulada no setor de máquinas, equipamentos e materiais, no qual as TICs terão papel crescente, e que tem enorme potencial de articulação com a indústria de defesa. 
Sem embargo, a constituição do CEIS com base nos princípios da autonomia estratégica e de segurança em saúde é condição para o Brasil galgar o lugar que lhe cabe no sistema interestatal e atender de forma adequada, invulnerável e soberana, a toda sua população, alcançando os objetivos centrais de segurança e desenvolvimento nacionais. Então, a pergunta central pode ser: que lugar queremos ocupar no mundo cada vez mais competitivo e conflituoso que virá nos próximos anos? No fim, faremos uma escolha: construiremos um modelo capaz de atender a toda a população brasileira ou permitiremos que apenas setores abastados de nossa elite evoluam para o Homo ricus brasiliensis.

\section{Referências}

ACHARYA, S. et al. Brics and global health. Bulletin of the World Health Organization, 92(6): 385-464, 2014. (Special theme: Brics and Global Health)

ADVANCED RESEARCH PROJECTS AGENCY (DARPA). Darpa launches biological technologies office, 1 abr. 2014. Disponível em: <www.darpa.mil/NewsEvents/Releases/2014/04/01.aspx> . Acesso em: 30 jun. 2014.

ALMEIDA, C. Saúde, política externa e cooperação sul-sul em saúde: elementos para reflexão sobre o caso do Brasil. In: GADELHA, P.; CARVALHO, J. N. \& PEREIRA, T. R. (Orgs.). A Saúde no Brasil em 2030: prospeç̧ão estratégica do sistema de saúde brasileiro: desenvolvimento, Estado e políticas de saúde. v. 1. Rio de Janeiro: Fiocruz, Ipea, Ministério da Saúde, Secretaria de Assuntos Estratégicos da Presidência da República, 2013.

ARMITAGE, J. Pfizer drops AstraZeneca takeover BID: American drugs giant admits defeat and scraps offer for British pharmaceutical company. The Independent. London, 26 maio 2014. Disponível em: <www.independent. co.uk/news/business/news/pfizer-admits-defeat-and-drops-astrazeneca-bid-9435767.html>. Acesso em: 26 maio 2014.

ASSOCIAÇÃO BRASILEIRA DA INDÚSTRIA DE ARTIGOS E EQUIPAMENTOS MÉDICOS, ODONTOLÓGICOS, HOSPITALARES E DE LABORATÓRIOS (ABIMO). Dados econômicos. Disponível em <www.abimo.org.br/ modules/content/content.php?page=dados-economicos $>$. Acesso em: 19 set. 2014.

ASSOCIAÇÃO BRASILEIRA DA INDÚSTRIA FARMOQUÍMICA (ABIQUIF). Estatísticas. Disponível em: <www. abiquifi.org.br/mercado_estatisticas.html>. Acesso em: 30 jul. 2014.

BRASIL. Diretrizes de Política Industrial, Tecnológica e de Comércio Exterior, 2003. Disponível em: <www.abdi. com.br/Estudo/Diretrizes_PITCE.pdf>. Acesso em 12 jul. 2014.

BRASIL. Ministério da Defesa. Decreto n. 6.703, de 18 dez. 2008. Aprova a Estratégia Nacional de Defesa, e dá outras providências. Estratégia Nacional de Defesa: paz e segurança para o Brasil. 2. ed. Brasília: Ministério da Defesa, 2008.

BRASIL. Ministério do Desenvolvimento, Indústria e Comércio Exterior. Aliceweb. Disponível em: <http:// aliceweb.mdic.gov.br>. Acesso em: 29 jul. 2014.

BURRILL \& COMPANY. Life Sciences - Capturing Value: healthcare and biogreentech - innovation from discovery. Burrill and Company's 27th Annual Report on the Life Sciences Industry. San Francisco: Burrill Media, 2013.

BUZAN, B. New patterns of global security in the twenty-first century. International Affairs, 67(3): 431-451, 1991.

CHANG, H.-J. Chutando a Escada: a estratégia do desenvolvimento em perspectiva histórica. São Paulo: Editora Unesp, 2002.

CHASE-DUNN, C. Social evolution and the future of world society. Journal of World-System Research, XI: 171192, 2005.

CHASE-DUNN, C.; NIEMEYER, R. \& ALLISON, J. Futures of biotechnology and geopolitics. Irows Working Paper \# 23. Riverside, v. 5-31-06, jun. 2005. 
COPLEY, C. \& SANDLE, P. Novartis and GSK trade assets as pharma industry reshapes. Reuters, 22 abr. 2012. Disponível em: <www.reuters.com/article/2014/04/22/us-novartis-idUSBREA3L07T20140422>. Acesso em: 21 jul. 2014.

DALBY, S. Environmental change. In: WILLIAMS, P. D. (Ed.). Security Studies. London: Routledge, 2008.

DIEGUES, C. Seleção artificial. Piauí. Rio de Janeiro, n. 26, nov. 2008. Disponível em: < http://revistapiaui. estadao.com.br/edicao-26/ficcao/selecao-artificial>. Acesso em: 10 ago. 2014.

ESCOBAR, P. China pivot fuels Eurasian century. On line Asia Times, 19 maio 2014. Disponível em: < http:// atimes.com/atimes/China/CHIN-02-190514.html>. Acesso em: 19 maio 2014.

FIORI, J. L. Ontem, hoje e 2030: tendências do sistema mundial, com ênfase na América do Sul. In: GADELHA, P.; CARVALHO, J. N. \& PEREIRA, T. R. (Orgs.). A Saúde no Brasil em 2030: prospecção estratégica do sistema de saúde brasileiro: desenvolvimento, Estado e políticas de saúde. v. 1. Rio de Janeiro: Fiocruz, Ipea, Ministério da Saúde, Secretaria de Assuntos Estratégicos da Presidência da República, 2013.

FIORI, J. L.; PADULA, R. \& VATER, M. C. A projeção do Brasil na América do Sul e na África Subsaariana e o controle da Bacia do Atlântico Sul. In: CENTRO DE GESTÃO E ESTUDOS ESTRATÉGICOS (CGEE). Dimensões Estratégicas do Desenvolvimento Brasileiro: Brasil, América Latina e África: convergências, geopolítica e estratégias de integração. v. 3. Brasília: CGEE, 2013.

FREEMAN, C. The "National Innovation System" in historical perspective. Cambridge Journal of Economics, 19(1): 5-24, 1995.

FUKUYAMA, F. O Fim da História e o Último Homem. Rio de Janeiro: Rocco, 1992.

GADELHA, C. A. G. \& COSTA, L. S. A saúde na política nacional de desenvolvimento: um novo olhar sobre os desafios da saúde. In: GADELHA, P.; CARVALHO, J. N. \& PEREIRA, T. R. (Orgs.). A Saúde no Brasil em 2030: prospecção estratégica do sistema de saúde brasileiro: desenvolvimento, Estado e políticas de saúde. v. 1. Rio de Janeiro: Fiocruz, Ipea, Ministério da Saúde, Secretaria de Assuntos Estratégicos da Presidência da República, 2013a.

GADELHA, C. A. G. \& COSTA, L. S. A dinâmica de inovação e a perspectiva do CEIS para a sustentabilidade estrutural do sistema de saúde brasileiro. In: GADELHA, P.; CARVALHO, J. N. \& PEREIRA, T. R. (Orgs.). A Saúde no Brasil em 2030: prospecção estratégica do sistema de saúde brasileiro: desenvolvimento, Estado e políticas de saúde. v. 5. Rio de Janeiro: Fiocruz, Ipea, Ministério da Saúde, Secretaria de Assuntos Estratégicos da Presidência da República, 2013b.

GARRET, L. Biology's brave new world: the promise and perils of the synbio revolution. Foreign Affairs, 92(6), 2013. Disponível em: <www.foreignaffairs.com/articles/140156/laurie-garrett/biologys-brave-new-world> . Acesso em: 19 ago. 2014.

GILPIN, R. Global Political Economy: understanding the international economic order. Princeton: Princeton University Press, 2001.

GOMES, R. et al. O novo cenário de concorrência na indústria farmacêutica brasileira. BNDES Setorial, 39: 97-134, 2014.

GUIMARÃES, R. Os dilemas da big pharma. Facto Abifina. Rio de Janeiro, n. 40, abr.-maio-jun. 2014.

GUIMARÃES, S. P. Desafios Brasileiros na Era dos Gigantes. Rio de Janeiro: Contraponto, 2005.

HOMEDICAL. El ganador del Premio Nobel de Medicina Richard J. Roberts denuncia la forma en la que operan las grandes farmacéuticas dentro del sistema capitalista, 13 jun. 2012. Disponível em: <www.homedical.es/ el-ganador-del-premio-nobel-de-medicina-richard-j-roberts-denuncia-la-forma-en-la-que-operan-las-grandesfarmaceuticas-dentro-del-sistema-capitalista>. Acesso em: 2 jul. 2014.

IBAC BRASIL. Brasil fecha parcerias para aumento da produção de biotecnológicos, 25 jun. 2013. Disponível em: <www.ibacbrasil.com/noticias/enfermagem/brasil-fecha-parcerias-para-aumento-da-producao-debiotecnologicos\#sthash.aNJkAuaQ.dpuf>. Acesso em: 23 ago. 2014. 
IMS HEALTH. IMS Health Market Prognosis. Disponível em: <www.imshealth.com:90/files/web/Global/ Market\%20Insights/Market_Prognosis_the_authority_link.pdf>. Acesso em: 20 jun. 2013.

INSTITUTO BRASILEIRO DE GEOGRAFIA E ESTATÍSTICA (IBGE). Conta-Satélite de Saúde Brasil 2007-2009. Contas Nacionais n. 37. Rio de Janeiro: IBGE, Mpog, 2012.

INTERNATIONAL FEDERATION OF PHARMACEUTICAL MANUFACTURERS \& ASSOCIATIONS (IFPMA). The Pharmaceutical Industry and Global Health: facts and figures 2012. Geneva: IFPMA, 2013.

KLARE, M. Rising Powers, Shrinking Planet: how scarce energy is creating a new world order. Oxford: Oneworld Publications, 2008.

KRASNER, S. D. Structural Conflict: the third world against global liberalism. Berkeley and Los Angeles: University of California Press, 1985.

KRASNER, S. D. Power, the State and Sovereignty: essays on international relations. Oxfordshire: Routledge, 2009.

LETTER FROM 10 representatives asking for a meeting to discuss IP policies that could undermine public health and access to medicines, 3 ago. 2011. Disponível em <http://infojustice.org/wp-content/uploads/2011/08/ Ten-Representatives-on-TPP-08022011.pdf> . Acesso em: 20 dez. 2013.

LETTER FROM REPRESENTATIVES Levin, Waxman, McDermott, and Conyers to US Trade Representative Ron Kirk, 19 out. 2011. Disponível em <http://infojustice.org/wp-content/uploads/2011/09/Four-DemocratReps-10192011.pdf>. Acesso em: 10 jan. 2014.

LETTER FROM REPS. Lewis, Stark, Rangel, Blumenauer, and Doggett asking that the May $10^{\text {th }}$ agreement serve as a "non-negotiable starting point" for access to medicines. 8 set. 2011. Disponível em <http://infojustice.org/ wp-content/uploads/2011/09/Five-MOCs-September-8-2011.pdf>. Acesso em: 10 jan. 2014.

LETTER FROM SENATOR Sanders to US Trade Representative Ron Kirk, 1 dec. 2011. Disponível em <http:// keionline.org/sites/default/files/Sen_Sanders_letter_to_USTR_TPP_negotiations_12-1-2011.pdf $>$. Acesso em: 15 abr. 2014.

MAIORES empresas do Brasil em 2013. Exame.com. São Paulo. Disponível em: < http://exame.abril.com.br/ negocios/melhores-e-maiores/empresas/maiores/1/2013/vendas/-/farmaceutico/-/->. Acesso em: 23 jun. 2014.

MCINNES, C. Health. In: WILLIAMS, P. D. (Ed.). Security Studies, an Introduction. London: Routledge, 2008.

MEDEIROS, C. A. O desenvolvimento tecnológico americano no pós-guerra como um empreendimento militar. In: FIORI, J. L. (Org.). O Poder Americano. Petrópolis: Vozes, 2004.

MEDEIROS, C. A. \& TREBAT, N. Military modernization in Chinese technical progress and industrial innovation. In: WORLD KEYNES CONFERENCE, 26-29 jun. 2013, Izmir.

PADULA, R. Integração Regional de Infraestrutura e Comércio na América do Sul nos anos 2000: uma análise político-estratégica, 2010. Tese de Doutorado em Engenharia de Produção, Rio de Janeiro: Instituto Alberto Luiz Coimbra de Pós-Graduação e Pesquisa de Engenharia, Universidade Federal do Rio de Janeiro.

PADULA, R. As visões dominantes sobre a integração regional. In: COSTA, D. (Org.). América do Sul: integração e infraestrutura. Rio de Janeiro: Capax Dei, 2011.

PADULA, R. A geopolítica da Bacia do Pacífico e a integração regional na América do Sul. Revista do Imea-Unila, 1(2): 30-47, 2013.

PADULA, R. A cooperação em saúde no Brics. In: COSTA, D. \& GONÇALVES, W. (Orgs.). O Brasil nos Brics. Rio de Janeiro: Capax Dei, 2015.

PHILLIPS, L. The political economy of ebola. Jacobin. New York, 13 ago. 2014. Disponível em <www.jacobinmag. com/2014/08/the-political-economy-of-ebola/ > . Acesso em: 19 ago. 2014. 
QUENTAL, C. et al. Medicamentos genéricos no Brasil: impactos das políticas públicas sobre a indústria nacional. Ciência \& Saúde Coletiva, 13, supl.: 618-629, 2008. Disponível em: <www.scielo.br/scielo.php?script=sci arttext\&pid=S1413-81232008000700011\&lng=en\&nrm=iso > . Acesso em: 30 ago. 2014 .

QUENTAL, C. et al. Infraestrutura científica e tecnológica para apoio ao CEIS: segmento biofarmacêutico. In: GADELHA, P.; CARVALHO, J. N. \& PEREIRA, T. R. (Orgs.). A Saúde no Brasil em 2030: prospecção estratégica do sistema de saúde brasileiro: desenvolvimento, Estado e políticas de saúde. v. 5. Rio de Janeiro: Fiocruz, Ipea, Ministério da Saúde, Secretaria de Assuntos Estratégicos da Presidência da República, 2013.

REIS, C.; LANDIN, A. \& PIERONI, J. P. Lições da experiência internacional e propostas para incorporação da rota biotecnológica na indústria farmacêutica brasileira. BNDES Setorial, 34: 5-44, 2011.

REIS, R. \& FARIA, J. E. P. Apreensões de medicamentos genéricos e a condenação da UE no Tribunal Permanente dos Povos. Pontes, 6(5), 22 dez. 2010. Disponível em: <www.ictsd.org/bridges-news/pontes/news/apreensõesde-medicamentos-genéricos-e-a-condenação-da-ue-no-tribunal>. Acesso em: 25 jun. 2014.

REIS, R. G. G. Atlântico Sul: um desafio para o século XXI - as velhas ameaças se perpetuam nas novas? In: ACIOLY, L. \& MORAES, R. F. (Orgs.). Prospectiva, Estratégias e Cenários Globais: visões de Atlântico Sul, África Lusófona, América do Sul e Amazônia. Brasília: Ipea, 2011.

RENNSTICH, J. K. The future of great power rivalries. In: DUNAWAY, W. (Ed.). New Theoretical Directions for the $21^{\text {st }}$ Century World-System. New York: Greenwood Press, 2001.

RENNSTICH, J. K. The phoenix cycle: global leadership transition in a long-wave perspective. In: REIFER, T. E. (Ed.). Globalization, Hegemony \& Power: antisystemic movements and the global system. Boulder: Paradigm Publishers, 2004.

SEN, A. Desenvolvimento como Liberdade. São Paulo: Companhia das Letras, 2000.

SILVA, J. B. et al. BRICS cooperation in strategic health projects. Bulletin of the World Health Organization, 92(6): 385-464, 2014. Special theme: BRICS and global health.

SINDICATO DA INDÚSTRIA DE PRODUTOS FARMACÊUTICOS NO ESTADO DE SÃO PAULO (SINDUSFARMA). Gerência de Economia. Indicadores Econômicos. Disponível em: < http://sindusfarma.org.br/cadastro/index. php/site/ap_indicadores>. Acesso em: 25 jul. 2014.

SMITH, M. R. (Ed.). Military Enterprise and Technological Change. Cambridge: MIT Press, 1985.

SPYKMAN, N. Estados Unidos Frente al Mundo. México: Fondo de Cultura, 1942.

THOMAS, C. Poverty. In: WILLIAMS, P. D. (Ed.). Security Studies, an Introduction. London: Routledge, 2008.

UNITED NATIONS CONFERENCE ON TRADE AND DEVELOPMENT (UNCTAD). Trade and Development Report. New York: United Nations, 2007.

UNITED STATES TRADE REPRESENTATIVE (USTR). The United States in the Trans-Pacific partnership, 2011. Disponível em: <www.ustr.gov/about-us/press-office/fact-sheets/2011/november/united-states-trans-pacificpartnership>. Acesso em: 31 jul. 2014.

VARGAS M. A. et al. Indústrias de base química e a biotecnologia voltadas para a saúde no Brasil: panorama atual e perspectivas para 2030. In: GADELHA, P.; CARVALHO, J. N. \& PEREIRA, T. R. (Orgs.). A Saúde no Brasil em 2030: prospecção estratégica do sistema de saúde brasileiro: desenvolvimento, Estado e políticas de saúde. v. 5. Rio de Janeiro: Fiocruz, Ipea, Ministério da Saúde, Secretaria de Assuntos Estratégicos da Presidência da República, 2013.

VEBLEN, T. The Engineers and the Price System. Kitchener: Batoche Books, 2001. Disponível em: <http://socserv2. mcmaster.ca/ econ/ugcm/3ll3/veblen/Engineers.pdf"http://socserv2.mcmaster.ca/ econ/ugcm/3ll3/veblen/ Engineers.pdf > . Acesso em: 31 jul. 2014. 
Formato: 21 x $26 \mathrm{~cm}$

Tipologia: Candara e Charter

Papel: Print Max $90 \mathrm{~g} / \mathrm{m}^{2}$ (miolo)

Cartão supremo $250 \mathrm{~g} / \mathrm{m}^{2}$ (capa)

CTP, Impressão e acabamento: Imos Gráfica e Editora Ltda.

Rio de Janeiro, abril de 2017

Não encontrando nossos títulos em livrarias, contactar a EDITORA Fiocruz:

Av. Brasil, 4036, térreo, sala 112 - Manguinhos

21040-361 - Rio de Janeiro, RJ

Tel.: (21) 3882-9039 e 3882-9041 - Telefax: (21) 3882-9006

www.fiocruz.br/editora

editora@fiocruz.br 
Este livro representa mais um passo importante na formulação de uma política de desenvolvimento do complexo econômicoindustrial da saúde (CEIS), projeto empreendido há mais de uma década pelo Grupo de Pesquisa Inovação em Saúde (GIS) da Fundação Oswaldo Cruz. Os pesquisadores envolvidos neste Brasil Saúde Amanhã: complexo econômico-industrial da saúde almejam subsidiar o planejamento a longo prazo em saúde, considerando a interface entre a construção de um Estado de bem-estar no Brasil e o fortalecimento da base produtiva e da capacidade de inovação.

A ideia mestra é que tal desenvolvimento, a ser concebido de modo integrado, deve, necessariamente, articular a dinâmica econômica com as demandas sociais. Por conseguinte, os desafios para a saúde devem incorporar desde a pressão advinda das novas demandas derivadas da rápida mudança do perfil demográfico de nossa população até a necessidade de avançar significativamente em áreas selecionadas de pesquisa e inovação, passando pelo atendimento universal à saúde (preceito constitucional). A riqueza maior e a oportunidade deste livro estão justamente em sua concepção abrangente do desenvolvimento, que integra, a um só tempo, a dimensão econômica e a social como partes indissociáveis de um projeto nacional de desenvolvimento.

Luciano Coutinho

Economista, presidente do Banco Nacional de Desenvolvimento Econômico e Social (2007-2016)

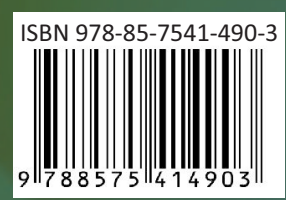

